\title{
Ancient Ways in Current Days: Ethno-cultural Arts and Acculturation
}

\author{
By \\ Stephen H. Fox
}

\begin{abstract}
A thesis
submitted to the Victoria University of Wellington in fulfillment of the requirements for the degree of
\end{abstract}

\section{Doctor of Philosophy} in Psychology

Victoria University of Wellington

2010 


\begin{abstract}
This research investigates the benefits of traditional/ethnic arts participation on wellbeing for immigrant and ethnic minority groups. While arts programs are increasingly seen as beneficial, little empirical evidence exists to support this belief, especially regarding ethnic groups in cross-cultural transition and multicultural environments. Three phases of research were undertaken, the first being qualitative, followed by two quantitative studies. Study 1 was a qualitative research into feelings of migrant and minority artists about how their arts practices affected their lives and acculturation processes. Practitioners from a number of ethno-cultural groups of both traditional and contemporary/Western arts were included to determine whether there were differences in effects of practices between those categories. Several broad themes emerged specific to the traditional/ethnic arts category, providing strong evidence for distinction between ethnic and contemporary/Western arts in effect for ethnic peoples: Cultural knowledge, the learning of cultural history, behaviours, and mores, Connectedness, the feeling of connection to family, peers, and community, as well as to other ethnic communities, Ethnic identity development, the sense of belongingness and meaning arising from ethno-cultural group membership. Study 2 examined data from longitudinal study of New Zealand youth (Youth Connectedness Project), specifically addressing differences based on arts participation for Maori and Pasifika (Polynesian) youth. Results demonstrated that youth who participated in any arts reported greater connectedness and well-being over those who participated in no arts, and that youth who participated in traditional Polynesian cultural arts had the highest ethnic identity scores. The processes involved were modelled and tested with path modelling. Study 3 was designed to investigate components of ethnic arts practices
\end{abstract}


to understand why and how the improvements in ethnic identity, connectedness, and well-being observed in the previous studies come about. Participants were recruited internationally, from a wide range of ethnicities and arts practices. The outcomes of this study include construction of cross-cultural measure of traditional arts participation factors and a structural equation which models the process by which Well-Being is enhanced. Factors arising in exploratory and confirmatory factor analyses of the scale were centrality, pride, belongingness, and cultural knowledge. In the process model tested, level of traditional/ethnic arts participation positively influenced levels of Connectedness and Ethnic Identity, which both served as mediators between level of traditional arts participation and increased Well-Being outcomes. In summary, these studies demonstrate that there are specific individual and group level benefits from participation in traditional arts for members of ethnic cultures and their communities. These benefits operate through enhancement of ethnic identity and connectedness, which in turn positively influence well-being outcomes. The results suggest that public support of such arts and programs which include such arts would lead to better adaptation outcomes for immigrant and ethnic minority groups. 


\section{Preface}

The broad subject of this research regards the benefits of traditional arts participation for those experiencing inter-cultural contact. It is an investigation of processes I have been observing for years in my life as an artist and musician, but which have not been explicated in the world of psychology. I offer, to set the tone for what will follow, a brief view of the experiences and observations that lead me to pursue this particular avenue of inquiry.

I became interested in culture as an adolescent reading about ancient civilizations and, later, listening to the music of other cultures. As an adult, in addition to playing rock, jazz, and reggae as a professional musician and completing a Bachelor's degree in Western music, I have been fortunate enough to collaborate and perform with musicians of several other cultures and to formally study Indonesian gamelan (the classical orchestra of that culture), Japanese taiko (a modern extrapolation of Japanese festival drumming, and Okinawan kotan (their classical court music). Over the past several years I have shared stages with West Africans numerous times, a world renowned taiko master, dear Maori mates, and many others, some of whom have become close friends. As a composer for film, I have brought in players from Korea and Japan, Western classical orchestra, and Hawaiian traditional and contemporary music, to name a few. As a journalist, I interviewed musicians from every continent, including players from Hawaiian, Cuban, Native Americans, Indian, Japanese, Balkan, and African traditions, among others.

In these experiences, these artists and I have normally had a marvellous flow of communication and a deep mutual respect, sharing love of music and a kinship as 
players. I would not say, however, that music is a universal language. I have also been struck by how differently we approach learning and making music, and how different the underlying cognitive structures of musical systems can be. I came to realize that this reflected the world view of their cultures, as well as particulars of social structures, aesthetics, and behavioural norms. At times being thrown suddenly in front of an audience with little or no preparation, I had to learn to quickly and efficiently grasp both the musical elements and the interaction styles of my fellow performers.

When I came to the study of cultural psychology as an older graduate student, I was at times struck by the way the study of culture was approached: things I took for granted were unknown, and practice of scientific research methods in the academic setting comprised a culture foreign to me. In terms of the latter, I have gradually learned the language and customs. Regarding the former, this thesis is a first step toward bringing matters self-evident to many artists into the purview of psychology. Among those are certain benefits of arts participation, which I believe to vary by culture, especially between Western and traditional cultures.

During my adult life, I have lived nearly 25 years in Hawai'i, which has a strong indigenous culture (if a bit commercialized for the tourists) and a host of other ethnic groups, with no majority culture. While the islands are not a utopia without intercultural conflict, particularly those stemming from the overthrow of the Hawaiian monarchy and continued socio-economic domination of the Hawaiian peoples by the United States, they stand as a shining example of multicultural harmony and tolerance. Religions are myriad. Intermarriage raises no eyebrows, and could be considered a norm. Honolulu, particularly, hosts massive festivals of 
Hawaiian music and hula, festivals of Japanese, Okinawan, Korean, and Greek cultures, and Native American powwows, to name a few.

The participants in these cultural activities especially came to mind when I arrived in New Zealand to study and was searching for a topic in the area of acculturation to research. Acculturation is the process experienced in inter-cultural contact, and its study is usually directed toward understanding how to facilitate adaptive outcomes. In Hawai'i's complex cultural mix, the cultural arts participants seem quite well adapted. There are dozens if not hundreds of official and unofficial hula halau for the study and practice of hula, as well as schools and groups dedicated to Chinese lion dance, Japanese taiko drumming or ikebana, Korean dance, etc. in Hawai' $i$. The practitioners of these arts have usually impressed me as the best and the brightest of the multicultural Hawaiian milieu. They know their culture and who they are as members of their culture(s), and they are confident and self-assured in their practice. It seems reasonable that it is their arts participation helps them to adapt and flourish. This research seeks to investigate whether or not this is true: does participating in the arts of one's heritage culture beget certain advantages, are there particular psychological benefits arising in arts processes, and can these benefits be tested and demonstrated? 


\section{Acknowledgements}

Firstly, I must thank my primary advisor, Dr. Colleen Ward, who has guided my acculturative experience as an artist entering the culture of science. Her commentaries later in the process, especially, proved inestimably valuable in making this a coherent psychology thesis. My secondary advisor, Dr. Marc Wilson, has also provided marvellous advice and encouragement, especially when I was floundering in a sea of seemingly incoherent qualitative data. I must thank Dr. Paul Jose, who very kindly provided a beautiful set of longitudinal data, as well as a swift and effective education in the mysterious worlds of advanced analyses such as structural equation modelling. I must also thank Dr. Anthony Marsella, who granted me (a humble musician) initial entre to the gated city of psychology for my Master's matriculation.

I turn now to my family. My departed father dearly wished to see what would come of my $\mathrm{PhD}$, and I hope he would be proud of this research. My mom has always been an unfailing well-spring of supportiveness. To my sister, I give my love: you may not always know what to make of me, but you're always with me. Also a constant presence, though she has been gone for a couple of decades, is my grandmother, Amelia Manning, an amazingly wise woman. Nani and Zoe are the more recent lights in my life. Zoe is a tiny gem of amazing intelligence and coolness, and Nani has unfailingly encouraged me never to give up, painstakingly helping to edit and format this and the Master's thesis. To my older children, Aaron and Amber, now living their adult lives, I hope I provide at least a measure of inspiration that all things are possible and perseverance can pay off. To Uncle Ross and Aunt Cora Evans (rest in peace, Ross), thank you for your help and advice in my returning to university and your continued support along the way. 
To the crew at the Centre for Applied Cross-Cultural Research, you folks have been great friends. Katja and Diana, you have been such great and loving support, and Sammyh Khan, you are a true brother. To my musician friends in Wellington, Joe Standeven and Steve Taylor, you provided marvellous musical experiences to balance the academics and keep me happy, and ushered me into knowledge of the day to day suburban Maori world. Also, I must thank several other Maori friends who prefer not to be named, but who graciously gave me consultation time in development of my final study (I believe they figured that, though they find the academic research paradigm alien if not offensive, if I was dead-set on doing the research it should be done in an informed way). Finally, thanks to Ross Hemera, an Associate Professor in the School of Visual and Material Culture at Massey University and a brilliant Maori artist, who gave a bit of time to provide some eloquent views on how we humans express who we are and how we think through our arts. 
Table of Contents

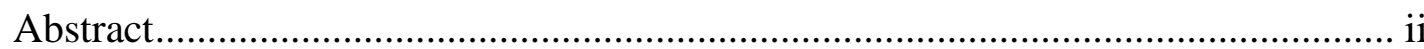

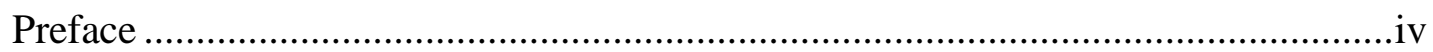

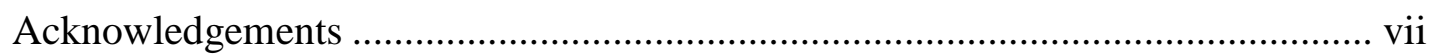

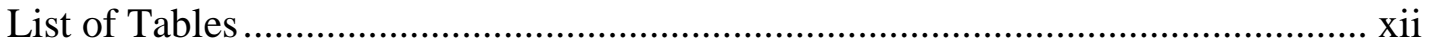

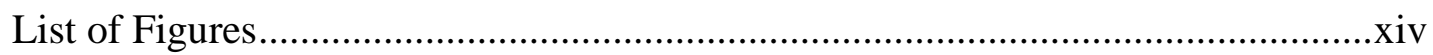

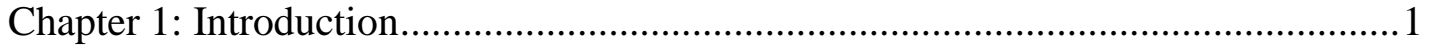

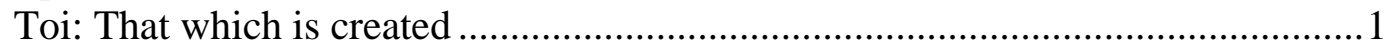

Arts and the sweeping scope of human existence. …....................................... 2

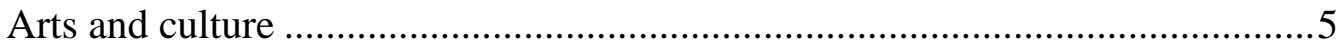

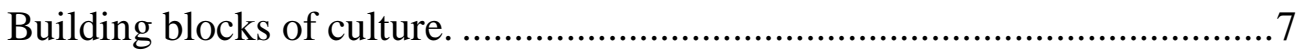

Visual arts and cultural information. ..................................................... 12

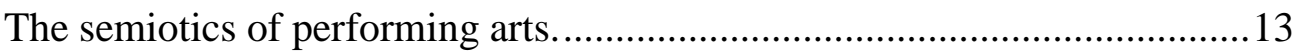

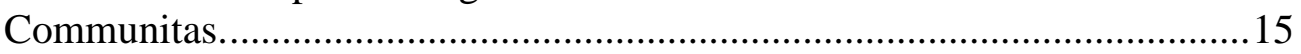

Setting the stage for cultural transmission and maintenance....................... 17

Arts in contemporary and traditional cultures. ............................................ 19

The evolution of arts in Western cultures................................................ 19

Arts in traditional, indigenous, and aboriginal cultures. .............................24

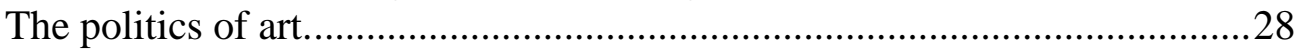

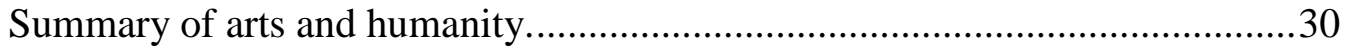

Migration, Globalization, and Inter-cultural Contact .......................................30

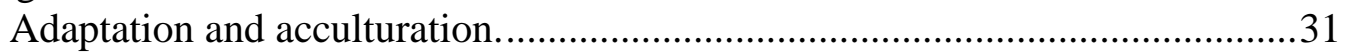

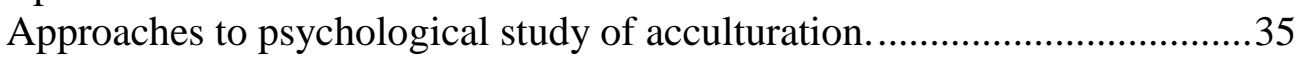

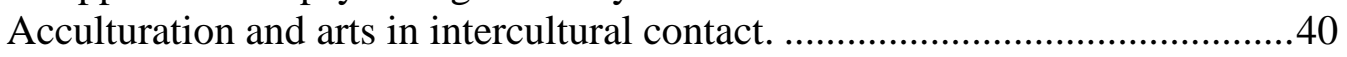

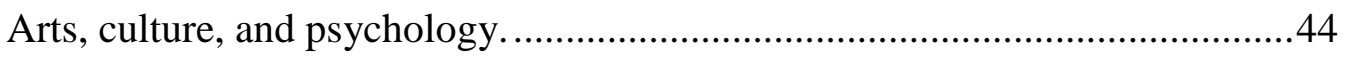

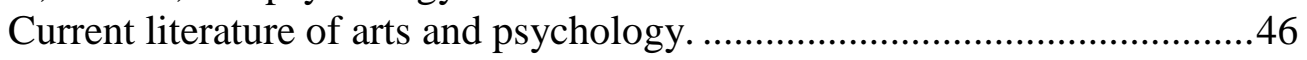

Psychology and music in particular..........................................................4

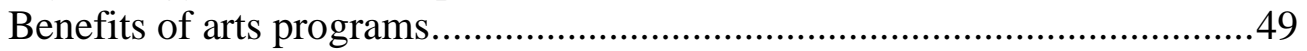

Synthesis of Paradigms and Emerging Questions ............................................5

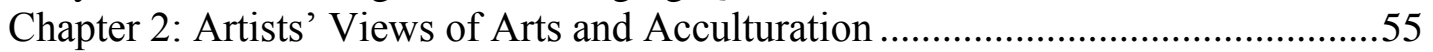

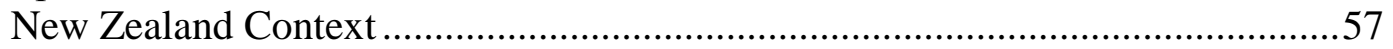

The history of migration to Aotearoa (New Zealand). ....................................58

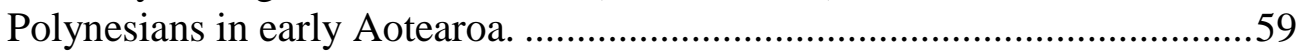

Maori and Europeans in Aotearoa..........................................................6 61

Te Tiriti o Waitangi (The Treaty of Waitangi)...........................................62

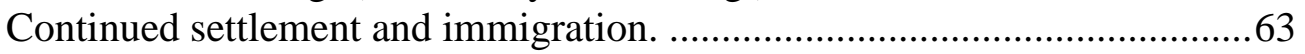

Biculturalism and multiculturalism. ........................................................65

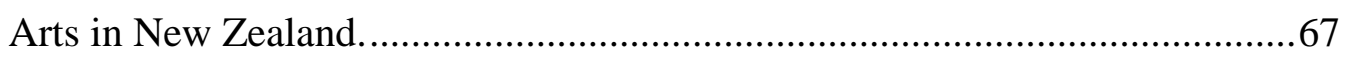

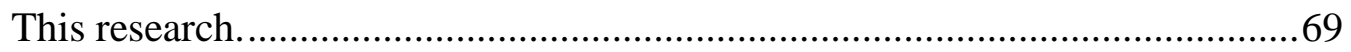

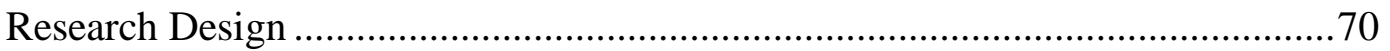

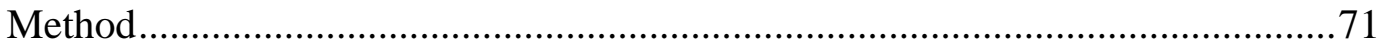

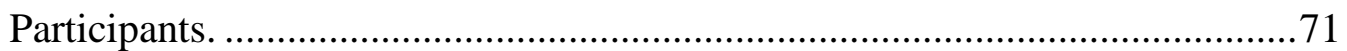

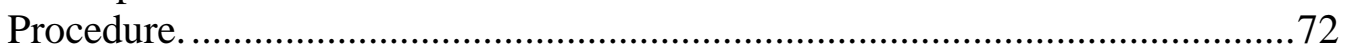

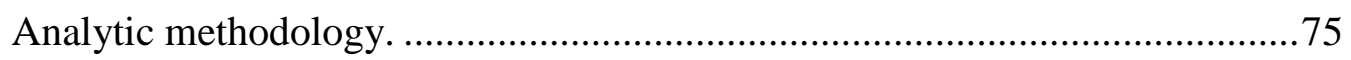

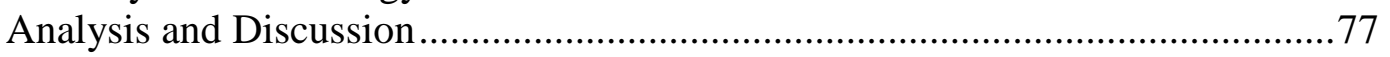

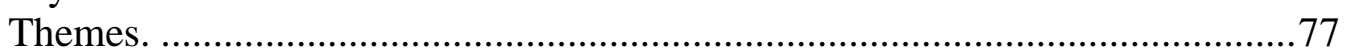

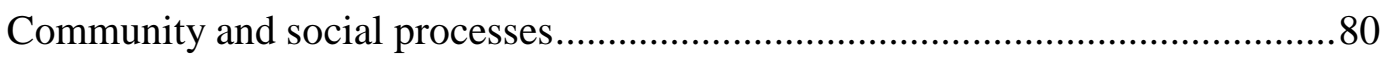

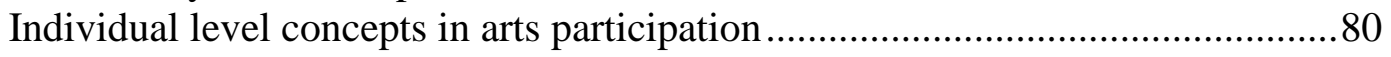

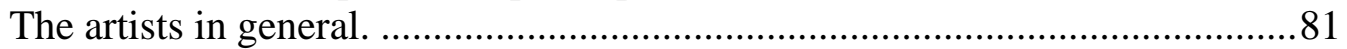




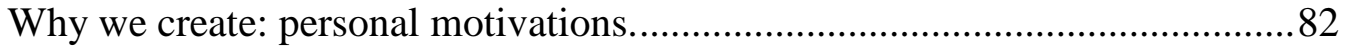

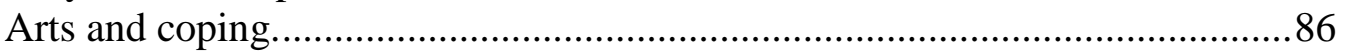

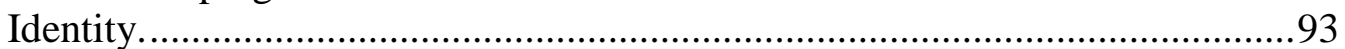

Creating the components of identity through art..................................... 100

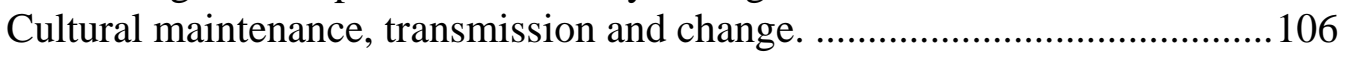

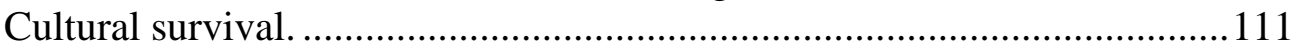

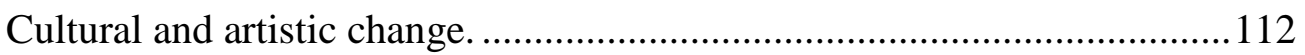

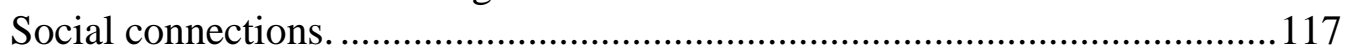

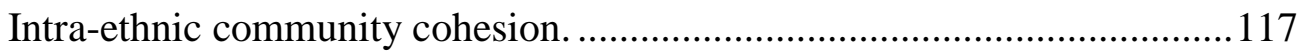

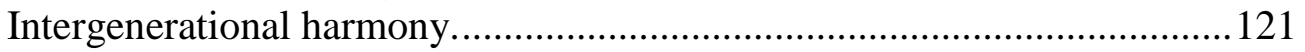

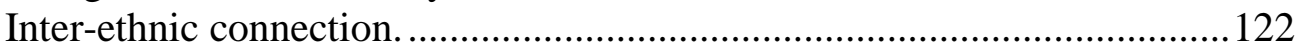

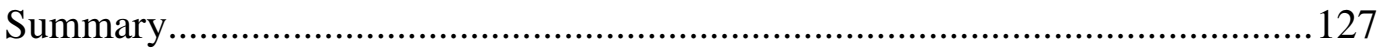

Chapter 3: Implication of TEA participation for ethnic youth .............................. 131

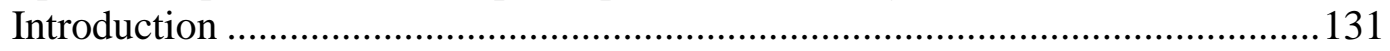

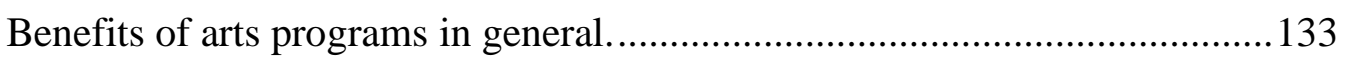

Traditional and Ethnic Arts (TEA) Programs. ......................................... 134

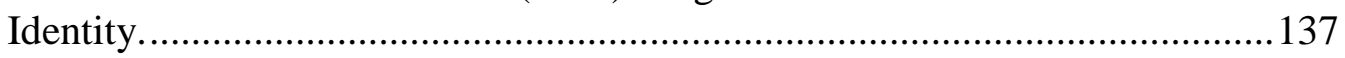

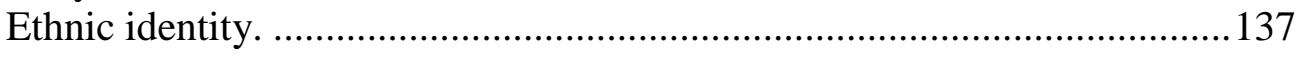

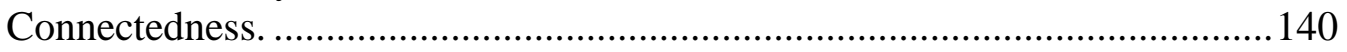

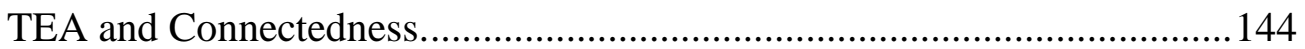

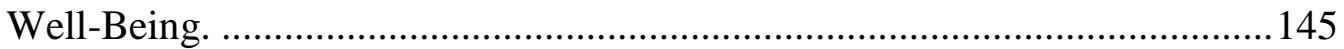

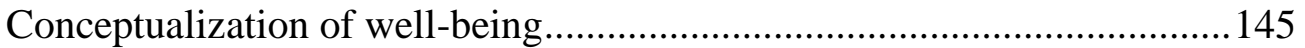

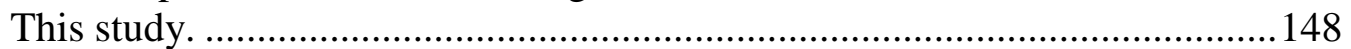

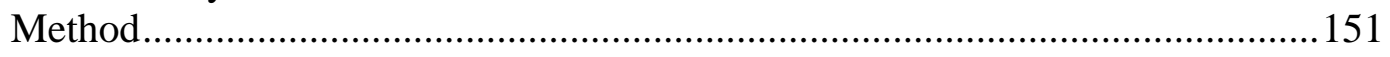

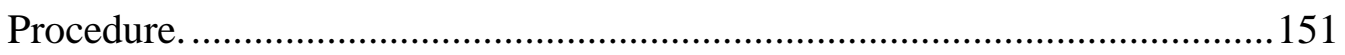

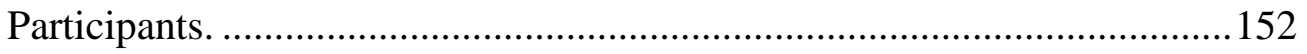

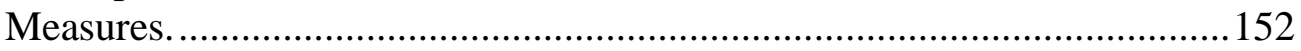

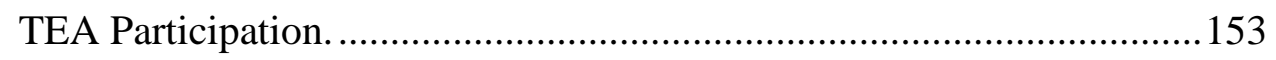

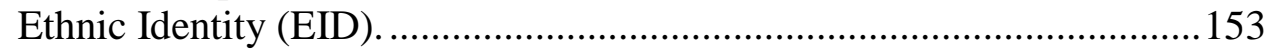

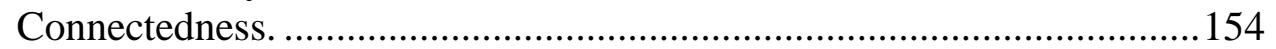

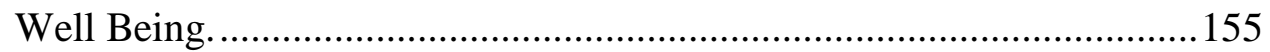

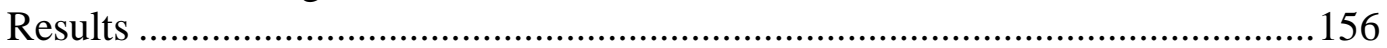

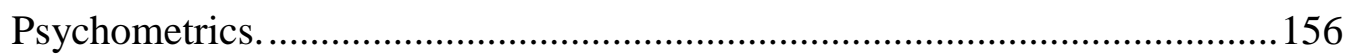

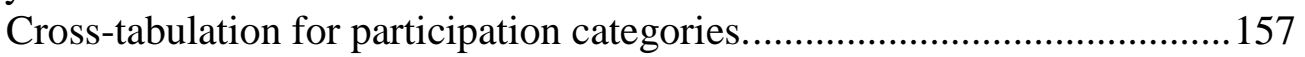

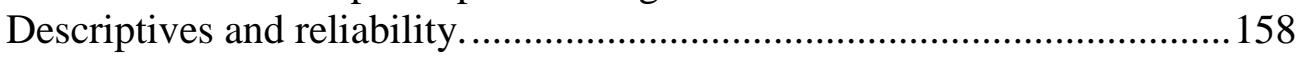

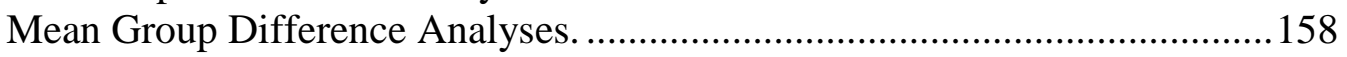

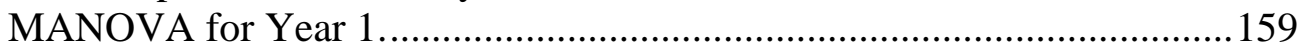

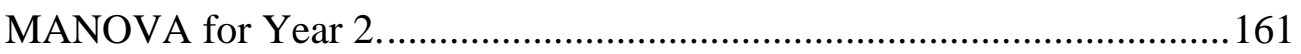

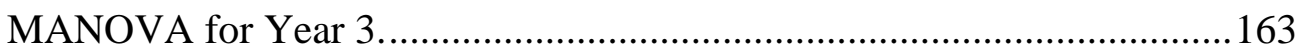

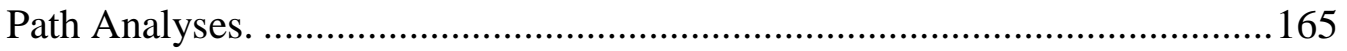

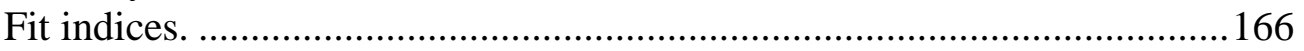

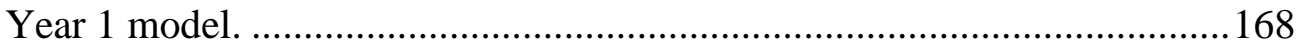

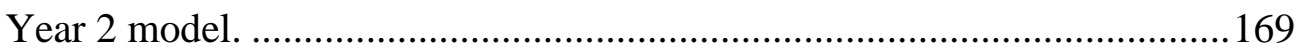

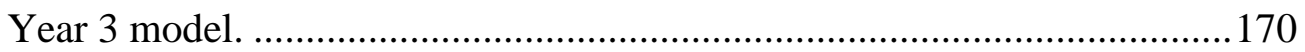

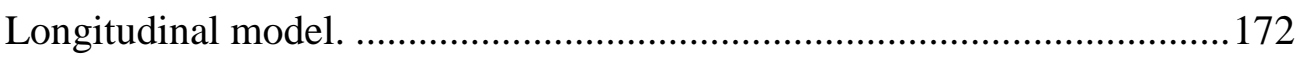

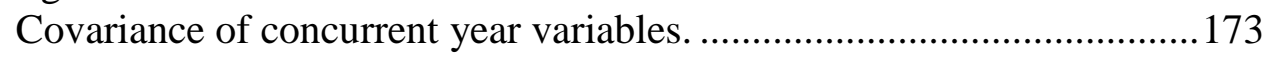

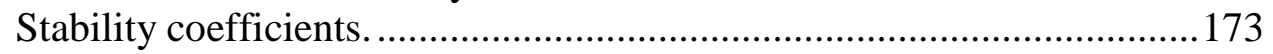

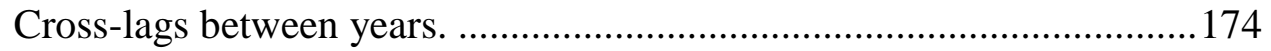

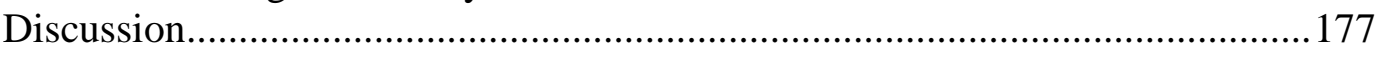

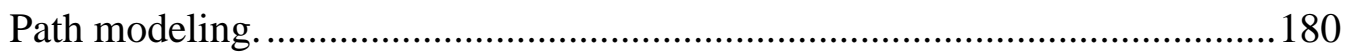




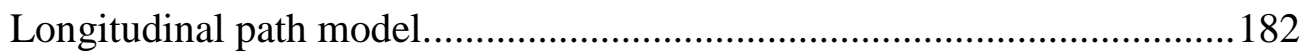

Ethnic identity and traditional ethno-cultural arts....................................185

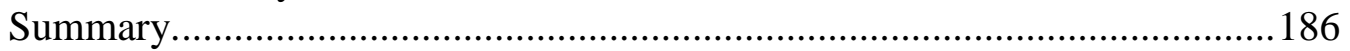

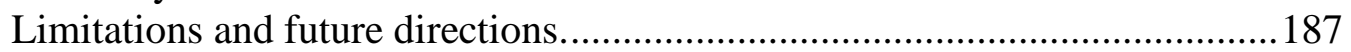

Chapter 4: Refining the measurement of TEA processes..................................... 190

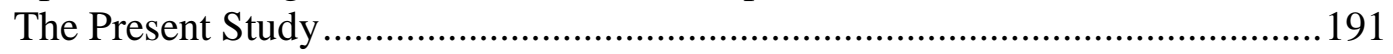

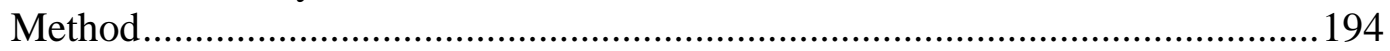

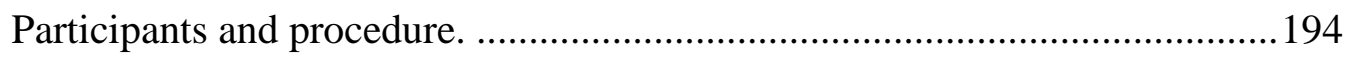

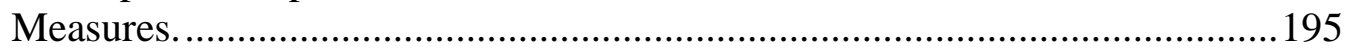

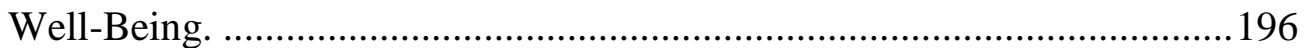

Warwick Edinburgh Mental Well-Being Scale (WEMWBS)................196

The Satisfaction with Life Scale.............................................................. 196

Rosenberg Self-Esteem Scale.............................................................. 197

The Resilience Scale.............................................................................197

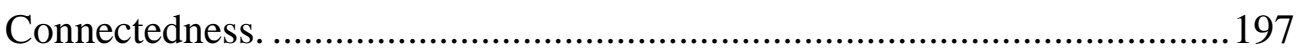

Multigroup Ethnic Identity Measure (MEIM)........................................198

The Traditional and Ethno-cultural Arts Participation Scale (TEAPS). .....199

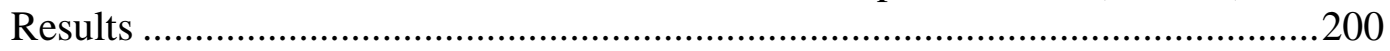

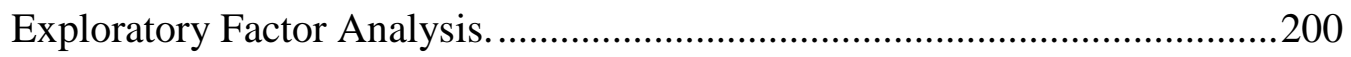

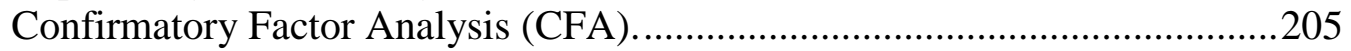

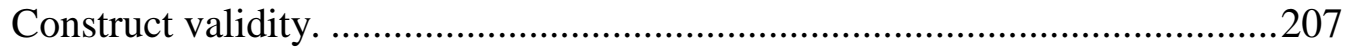

Structural Equation Modelling of TEA participation...................................2208

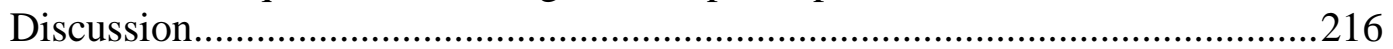

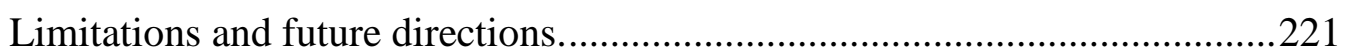

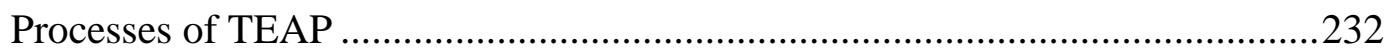

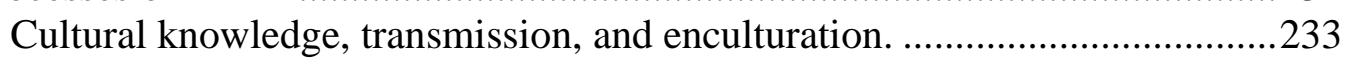

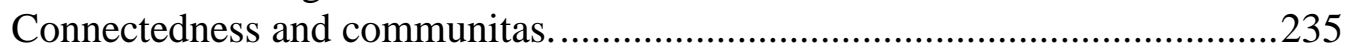

Ethnic Identity. ...............................................................................2236

Interweaving of processes, theoretical structures, and contexts in TEAP......237

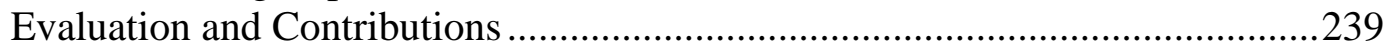

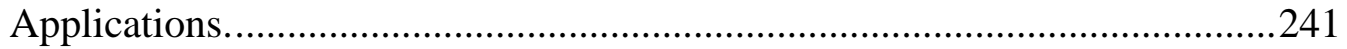

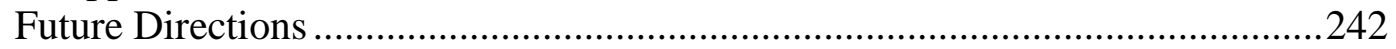

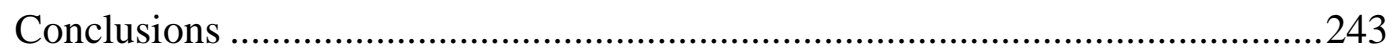

Appendix A: Study 1 information sheet, question schedule, consent form, and

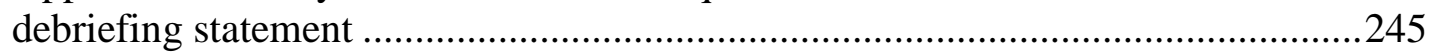

Appendix B: Stury 2 Youth Connectedness Project questions ..............................250

Appendix C: Comparison Models for Study 2 Other Arts and No Arts Groups.....253

Appendix D: Traditional and Ethnic Arts Participation Survey measures ..............2254

Appendix E: Study 3 Information and Consent Form and Debriefing Statement...260

Appendix F: Correlations of TEAPS Items and Factors from EFA .......................263

Appendix G: Correlations of all Study 3 Instruments and Subscales ....................265

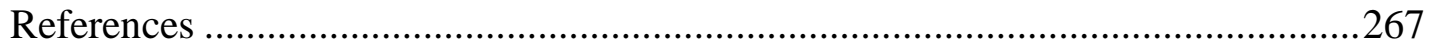




\section{List of Tables}

Table 2.1 Estimated New Zealand population by ethnic group................................64

Table 2.2 Reasons for participation in Maori arts (CNZ, 2000, p. 10) ....................68

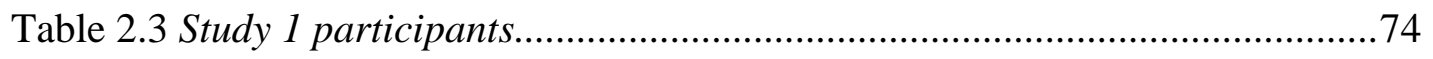

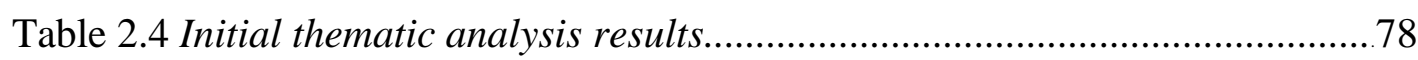

Table 2.5 Second revision of themes and sub-themes of arts participation...............80

Table 2.6 Final themes and sub-themes of arts participation.................................81

Table 3.1 Type of arts participation by year.........................................................156

Table 3.2 Study 2 scale descriptives and reliability............................................158

Table 3.3 Descriptive statistics for TEA, Other Arts, and No Arts participation, Year

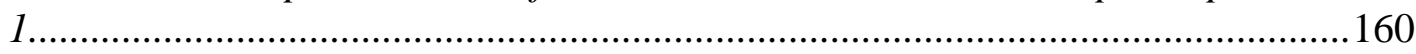

Table 3.4 Tukey HSD post-hoc comparisons by group for Year 1..........................161

Table 3.5 Descriptive statistics for TEA, Other Arts, and No Arts participation Year 2.

Table 3.6 Tukey HSD post -hoc comparisons by group Year 2..............................163

Table 3.7 Descriptive statistics for TEA, Other Arts, and No Arts participation Year

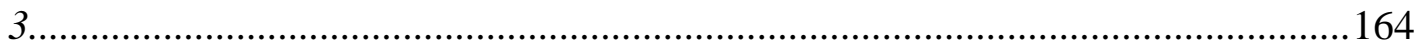

Table 3.8 Tukey HSD post -hoc comparisons by group for Year 3.........................165

Table 3.9 Standardized indirect effects by concurrent year model.........................171

Table 3.10 Covariance of concurrent year error terms (Standardized) in longitudinal model............................................................................................. 173

Table 3.11 Study 2 stability coefficients of variables between years....................... 174

Table 3.12 Correlations between YCP variables for all years...............................175

Table 4.1 Frequency of participation by ethnic art $(N=357)$................................ 195

Table 4.2 Factor structure of the TEAPS instrument (values below .1 deleted)

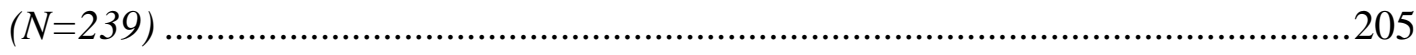

Table 4.3 Correlations of TEAP subscales $(N=357)$............................................207

Table 4.4 Correlations of TEAPS to objective participation responses $(N=357)$ 
Table 4.6 Descriptives and reliability of study instruments $(N=336)$.................212

Table 4.7 Correlations of latent variables of TEAP model $(N=336)$..................215

Table 4.8 Standardized indirect effects of latent variables $(N=336)$...................215 


\section{List of Figures}

Figure 1.1. Neanderthal personal adornments (d'Errico et al., 2003) ......................2

Figure 1.2. Divje Babe flute (d'Errico et al., 2003) ..................................................

Figure 1.3. Aurignacian bone pipe from Isturitz (d'Errico et al., 2003) ....................3

Figure 3.1. Proposed path model of arts participation influences on Well-Being..150

Figure 3.2. Study 2 arts participation levels by year........................................... 157

Figure 3.3. $\beta$ weights, significance, and direct effects in Year 1 Arts Participation

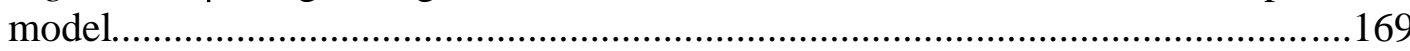

Figure 3.4. $\beta$ weights, significance, and direct effects in Year 2 Arts Participation model.

Figure 3.5. $\beta$ weights, significance, and direct effects in Year 3 Arts Participation model. 171

Figure 3.6. Longitudinal model of YCP variables for all years.............................176

Figure 4.1. Proposed model of influences of TEA Participation on Well-Being...193

Figure 4.2. Scree plot of exploratory factor analysis four factor solution...............203

Figure 4.3. Confirmatory Factor Analysis of the TEAPS scale $(\mathrm{N}=118)$............206

Figure 4.4a. Proposed structural equation Model A of TEAP...............................210

Figure 4.4b. Competing structural equation Model B of TEAP..........................2211

Figure 4.5. Best resulting structural equation model of TEAP $(\mathrm{N}=336) \ldots \ldots \ldots \ldots . .214$ 


\section{Chapter 1: Introduction}

\section{Toi: That which is created}

The Maori term "toi" broadly refers to things created, frequently (but not entirely) referring to products of human endeavour. Toi whakairo are carvings, toi whakaari are performing arts, and mahi toi are generally arts or crafts. Toi-o-ngārangi refers to the uppermost heaven in Maori cosmology, a creation from the divine realm (Moorfield, 2005). Everything we do or make is inherently an act of creation, whether it is making music or making lunch, or deciding how to spend an afternoon (cf. Haley, 2006). Each day, in each moment, we collectively create the stories, props, and soundtrack of our existence. The ways in which we set about these processes and what we produce, of course, have varied by time, technology, environment, and taste, which is why, for instance, an archaeologist can vividly describe aspects of life in a long extinct civilization: the artefacts and even the bones left behind tell stories of the ways people lived and what was important to those people in their lives.

The first portion of this introduction will provide a broad description of the ancient and complicated relations between humans and their arts to build a platform from which to see this intricate landscape as it relates to the human psyche. The purpose is neither to describe the history of arts and humanity in great detail (which would be an encyclopaedic task), nor to present the usual introduction describing previous research in the area (that region being relatively barren), but to provide a contextual and theoretical background by which the subsequent research may be understood. Several threads shall be discussed in terms of social and psychological functions of arts individually and in communities, and of the maintenance and 
transmission of culture. Rather swiftly, the discourse shall race through the rise of Western culture and the changes this has wrought globally for arts and artists, now distinct from non-artists in that broad cultural milieu. In the modern world, arts certainly have continuing functions, though they are frequently different from their ancestral roots. Some of these have been examined by psychology, another human creation springing from the Western mind, and there may be further, crucial functions and effects of arts yet to be explicated. The illumination of these ancient processes and their place in current times, especially in regards to cultural adaptation, is the overarching purpose of this thesis.

\section{Arts and the sweeping scope of human existence.}

Humanity has been creating, sculpting, singing, dancing, and painting, generally being creative, for a very, very long time (e.g., Cross, 2001; d'Errico, Henshilwood, Lawson, et al., 2003; Valladas, Clottes, Geneste, Garcia, et al., 2001). Archaeological evidence shows that the Neanderthal peoples, previous to the rise of homo sapiens sapiens, had already progressed from making simple tools to making bone and shell ornaments of personal adornment (d'Errico et al., 2003 Fig 1.1).

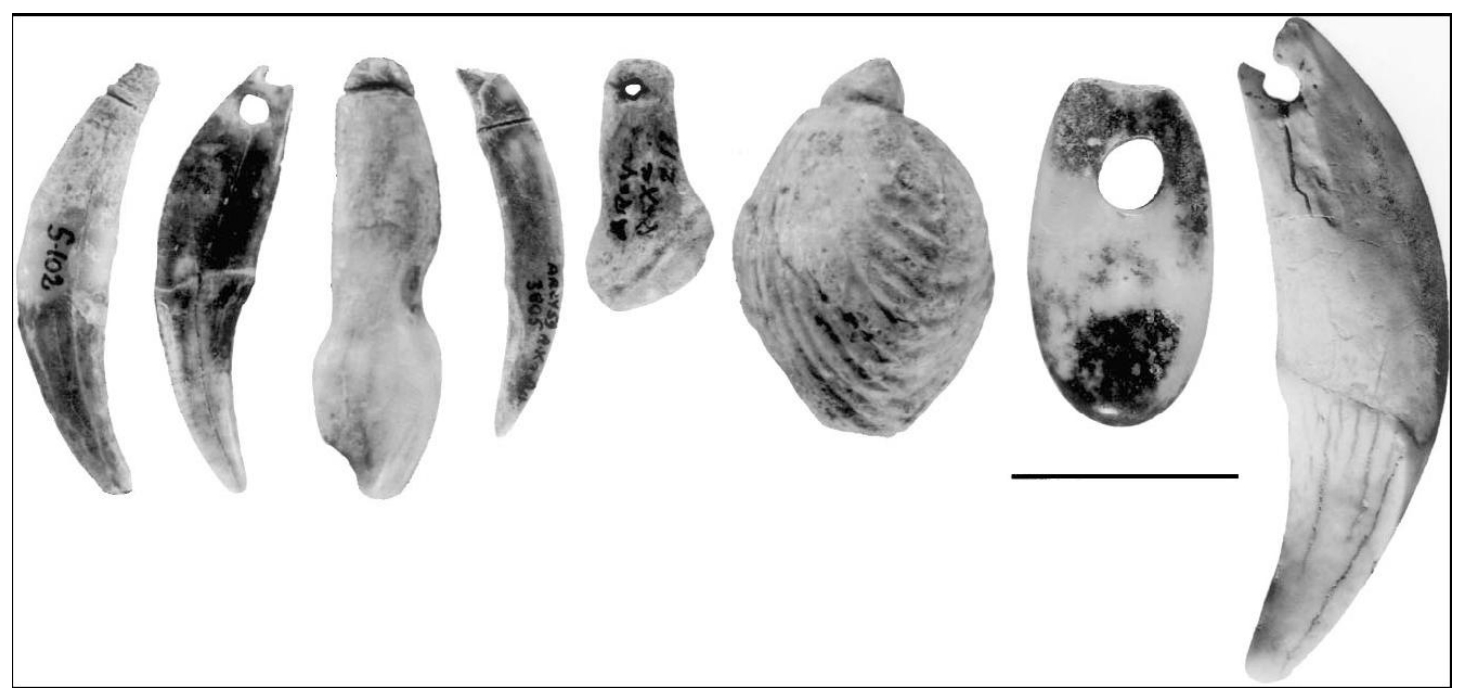

Figure 1.1. Neanderthal personal adornments (d'Errico et al., 2003). 
These artefacts had specific significance to their owners, reflecting aesthetics, values, and beliefs of their cultures. Of music, Cross (2001) explains "it could be that the emergence of proto-musical behaviour and their cultural actualization as music were crucial in precipitating the emergence of the cognitive and social flexibility that marks the appearance of Homo sapiens sapiens" (p.100). Though disputed, an artefact from Divje babe in Slovenia may prove to be a 60,000 year old flute (d'Errico et al., 2003, Fig. 1.2). By about 36,000 years ago, there is no question that flutes were being made and played (Figure 1.3) and musical practices were well established (Hahn \& Münzel, 1995; Richter et al., 2000; Turk \& Kavur, 1997;

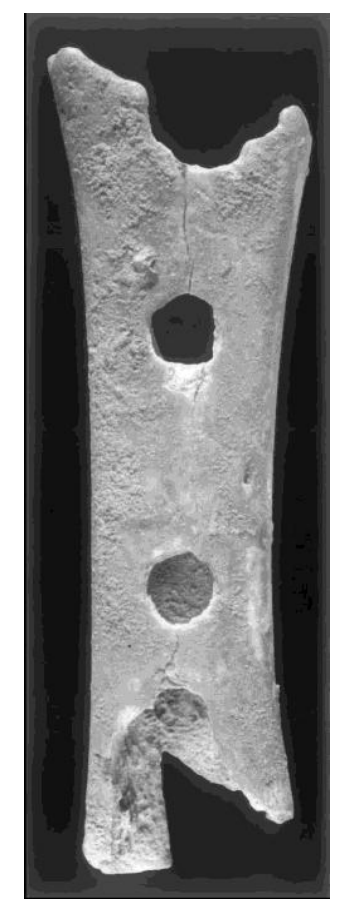

Figure 1.2. Divje Babe flute (d'Errico et al., 2003).

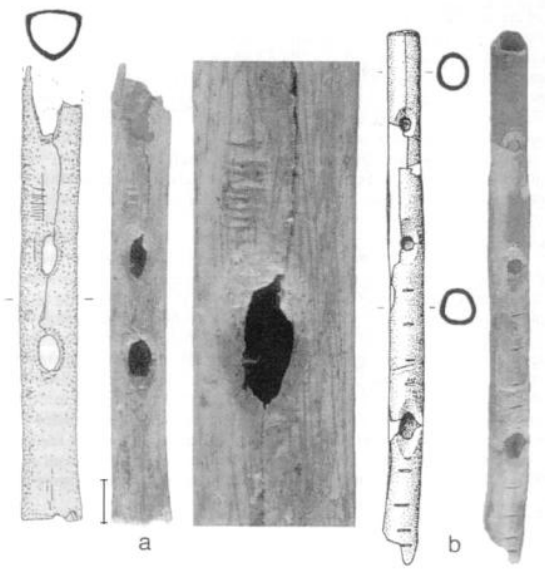

Figure 1.3. Aurignacian bone pipe from Isturitz (d'Errico et al., 2003).
Zhang, Xiao, \& Lee, 2004), including music made with rasps, horns, and bull-roarers (Morley, 2003). Painting was a refined art by 32,000 years ago, with highly realistic illustrations of animals obviously carefully observed and depicted by the inhabitants of caves such as those at Chauvet in Vallon-Pontd'Arc, Ardèche, France (Fishman, 1995; Valladas et al., 2001). A 25,000 year old bas relief, the "Venus of Laussel" ("Dame à la corne") from Laussel, France (Huyge, 1991; Morley, 2003), another complex early artwork in itself, depicts a rotund woman holding a horn with incised grooves similar to musical rasps found in Mexico and Bonaire (Morley, 2003). 
Music, particularly, has a long history of theoretical and practical development stretching far into pre-history. There is evidence of a standardized musical system in China as much as 9,000 years ago, demonstrated by still-playable bone flutes found in excavated burials in Jiahu province, including a tuning reference pipe by which pitch was calibrated in manufacture. The scales resulting from testing of the playable flutes are similar to the scales of later Chinese cultures, are also found westward to Europe, and are still in use, the distance between reference pitches comprising a half-step in Western music (Zhang, Xiao, et al., 2004). The basic elements of music, its instruments, and practice vary in their specifics from culture to culture, but there are commonalities shared across time and across cultures (e.g., Reck, 1977; Titon, 1984; Zhang, Xiao, et al., 2004).

Through these ancient archaeological relics, one finds a rich source of clues about the ways humanity has thought and interacted over vast reaches of time. Ancient people saw the world in particular ways, ascribing unknowable meaning and value to what they saw, but we know some of what they saw and how they chose to represent these things. We know that they played music, for instance, and one can speculate that this happened largely as part of group activities, as it has throughout known history. To place the span of human arts creation and participation in perspective, current archaeological evidence shows that humans began to store food about 11,300 years ago, and domesticated grains about 10,000 years ago (cf. Gilroy, 2009; Kuijt \& Finlayson, 2009); conservatively, humans have had refined arts over three times as long as they have had agriculture. If one places civilization as beginning around the time of ancient Mesopotamia (Eliade, 1978), that span is conservatively no more than one tenth of the time we have participated in organized arts. 


\section{Arts and culture}

An Ifugao child learning his society's dances by imitating his elders is not acquiring $a$ skill in the abstract. He is simultaneously absorbing the ways of his community and the human and social values implicit in them (de Leon, 1990, p. 312).

These arts are components of the cultures in which they were created or enacted (e.g., Campbell, 1973; Turino, 1999; Turner, 1982a). Culture has been described as a pattern of behaviours and beliefs that sets a group apart from others (e.g., Keefe, 1992; Phinney, 1990). The empiricist view from the $19^{\text {th }}$ century was that ideas and culture constituted a type of being-ness quite distinct from material existence (Kashima, 2000). Hofstede (1980) described culture as "the collective programming of the mind which distinguishes the members of one group from another" (p. 21). Anthropology posited a basic tenet that "each human society was governed by its own set of norms, values, and ideas that guided behaviour within it" (Grahame, 1998, p. 157). Kashima (2008) describes culture as "an enduring and shared system of meaning" (p. 107). He continues, "Clearly, people coordinate their activities in their daily living with their shared understandings about institutions, practices, symbols, and concepts" (pp. 107-108). It is this latter view that informs the research trajectory of this thesis, encompassing the material symbols and practices along with the cognitive aspects of culture as essential components and processes of cultural systems.

Culturally organized arts processes and products have played a lasting and meaningful role in the lives and sweeping histories of human beings, serving as repositories and messengers of culture. Turner (1982a), an anthropologist, acknowledged Claude Levi-Strauss as the first to "call our attention to the diverse 'sensory codes' through which information may be transmitted" (p. 9). The arts are, 
by their nature, culturally constructed and encoded systems of transmission. It is through the arts that the myths, history, and identity of a culture are interpreted and expressed, and the process of their creation happens within a set of socio-cultural structures, forms, and circumstances (cf. Hargreave \& North, 1999; Turner, 1982b; Merriam, 1977). Joseph Campbell's seminal work Hero with a Thousand Faces (1949/1973) posits that the stories, myths, and legends of all cultures past and present reiterate a single common thread of narrative, with slight changes in content resulting from adaptation of characters, scenarios, and messages to the particular milieu of a given culture.

On a broad level, all arts, modern or traditional, are symbolic expressions of human experience and thought within a particular context. Burke (1973) comments,

Symbols are strategies for encompassing situations... Critical and imaginative works are answers to questions posed by the situation in which they arose... These strategies size up situations, name their structure and outstanding ingredients, and name them in a way that contains an attitude toward them (in Meyers, 2004, p. 204).

This is a particularly important statement when looking at arts in their broadest purpose: arts are among the receptacles and vehicles of a culture's symbols and a primary means by which the meanings of those symbols are learned, maintained and transmitted. It is via arts that ways of being, thinking and relating have historically been transmitted within cultures, and thus they are ways we learn to answer the questions we face. Each seemingly innocuous legend or fairy tale contains specific instructions for finding solutions in a culturally appropriate way: in European individualistic cultures, for instance, the children establish independence by overcoming the bad elder witch while in collectivist cultures it is more frequent for an errant child to return to acceptance of the elder's wisdom (Taum, 2009). Arts contain all of the coded instructions for life not transmitted by direct biology (cf. 
Turner, 1982a; 1985). Transmission occurs within cultures and also between cultures, such as the wholesale export of Western values via mainstream media.

\section{Building blocks of culture.}

It seems as if tangible objects - whether described as art, culture, or property - retain a power to encapsulate meaning and value, the capacity to 'objectify' such transient notions as identity, ethnicity, and history. Numerous scholars have investigated the ways in which objects are invested with multiple values as they circulate through various social contexts and become means of social agency. (Glass, 2004, p.116).

Cultures comprise systems of beliefs, worldviews symbols, artefacts, languages, and icons shared and recognized among a group or groups of people (Atran, 2001; Blackmoor, 2006; 2000; Heath \& Sternberg, 2001; Kashima, 2008; Turino, 1999). Semiotics, from the Greek for sign (Oxford English Dictionary, 2003), began as a philosophical theory of the ways meanings are ascribed and transmitted symbolically, proposed regarding linguistics under the name semiology by de Saussure (1916, in Elicker, 1999), and in a broader sense (within which linguistics is included) as semiotics by Peirce (1931-1935, in Elicker, 1997). The field of biosemiotics proposes that all living creatures communicate, reproduce, and adapt by methods analogous to and describable as semiotic processes (Sebeok, 1991). The messages transmitted and the means of transmission constitute the lived dynamics of culture, as found in everyday activities and in "the domains of feeling and thinking" (Valsiner, 2009, p. 10) within a culture. The understanding of a culture should include a process of understanding the networks of signs and symbols therein and the methods by which they are transmitted in regular life. Arts have been observed to exemplify the core of these networks within cultures (e.g., Elicker, 1997; Sebeok, 1991) and may provide a means for their evaluation and description. 
Semiotics is generally considered to encompass linguistic and non-verbal communication, including anything created which has symbolic or communicative content (Elicker, 1997; Nattiez, 1991; Sebeok, 1991). This range, as with toi, would therefore include virtually the entirety of human creations, each being describable within a culture and arising in a particular style, usually associated with a particular and identifiable region, aesthetic movement, and historical period. The linguist de Saussure (1920, cited in Nattiez, 1990), explained that "the linguistic sign unites not a thing and a name, but a concept and a sound image" (p. 3). The word provides connection to a concept of a thing in a way that can be interpreted via the verbal sign, in what Peirce theorized was a three stage process, including the word or symbol, that which is represented, and the cognition resulting (Nattiez, 1990). He emphasized that each concept or object signified can, in turn, signify other objects or concepts by inference, potentially adding additional levels of meaning to something signified, and creating complex webs of symbology and multi-layered communication within a given culture. This is especially true of arts, which are composed of aesthetic, symbolic, and/or verbal content laden with meaning(s) specific to a culture (Eco, 1984; Elicker, 1997; Nattiez, 1990; Sebeok, 1991).

Another approach to describing components and transmission of cultural information is found in the concept of the "meme," which was introduced in 1976 by Dawkins. The Oxford English Dictionary (2009) describes a meme as "an element of culture that may be considered to be passed on by non-genetic means, esp. imitation" (Soanes \& Stevens, 2008). Atran (2001) lists “a belief, a melody, a scientific theory, an equation, a philosophical puzzle, a religious ritual, a political ideology, an agricultural practice, a fashion, a dance, a poem, a recipe for a meal, table manners, court etiquette, or plans for cars, computers, and cell phones" (p. 
352) as fitting the definition of meme. Memes have been compared to pathogens, in that they are transmitted from person to person, sometimes spreading throughout a population as in the case of a highly popular hit song or an idiomatic expression (cf. Atran, 2001). The concept has gained certain acceptance, but remains a subject of debate as to exactly what memes are, whether the concept describes what are actually neurological or cognitive processes, and, in the extreme, pondering whether they can exist independently from humanity, such as a programming strategy for robotic intelligence (e.g., Blackmore, 2001; 2006; 2007; Atran, 2001).

Regardless of the debates and divergent streams of thought in the fields of both semiotics and memetics, these concepts have utility in this examination of arts processes and artefacts as elements of cultural learning, identification, transmission, and maintenance (e.g., Atran, 2001; Blackmore, 2001; 2006; 2007; Heath \& Sternberg, 2001). With whatever terminology one uses to describe them, humans receive and transmit bits of information. Theories of semiotics have been used primarily to describe human processes and informational content (e.g., Elicker, 1997; Nattiez, 1991; Sebeok, 1991), while theories of memetics have been used more broadly to describe a range including non-human processes (e.g., Blackmore, 2007; 2006; 2001; Atran, 2001). The terms are used somewhat interchangeably in the following pages, primarily using the more human-oriented semiotic terminology. Both constructs, though arising from different disciplines and philosophical bases, have utility in describing processes investigated in this research; these bits of information, how they are transmitted, and how they function in a given culture, form the webs of tangible and perceivable elements by which understandings are culturally expressed and transmitted (e.g., Elicker, 1997; Fine \& Fields, 2008; Nattiez, 1990; Turino, 1999). 
The transmission and reception of this cultural material is constant as cultures are continually created, maintained, and reshaped by our everyday situated activities (Kashima, 2008). Each process and interaction within a culture is "ritualized in such a way that it becomes predictable, replicable, and part of cultural DNA of society" (Fine \& Fields, 2008, p. 141). Without this constant process, there is no culture. Components include technical knowledge, language, traditions, habits, sentiments and ideas which play out in realms of practical, social, and political life. The ways in which culture is transmitted from one generation to the next also constitute dimensions of culture (Campbell, 1997; Hynie, Lalonde, \& Lee, 2006; Kashima, 2008; Kalesh, Griffiths, \& Lewandowsky, 2007).

In the early $20^{\text {th }}$ Century, the processes by which cultural learning takes place and whereby culture spreads were described under concepts of diffusionism, a school of thought arising from European anthropology and ethnology, which held that humans arrive tabula rasa, all knowledge is transmitted culturally, and all culture arose from a shared, distant source (Kashima, 2008). The concept lost popularity for a time, re-emerging in the 1970's as neo-diffusionism, a meta-theory of culture which holds that:

1. There exists cultural information.

2. Cultural information is instantiated in a material form that can be communicated from a sender to a receiver.

3. The receiver learns (or relearns if the receiver has already learnt it before) cultural information via a communicated form.

4. The distribution of cultural information within a population results in this population's group characteristics. (Kashima, 2008, p. 109)

Kashima (2008) suggests a social psychology dealing with cultural dynamics, which shares features with neo-diffusionism, but would further investigate micro-processes of cultural transmission and specific qualities of retained cultural information, particularly focusing on inter-generational (vertical) and intra-generational 
(horizontal) transmission. Grounding activities, in which information is shared and understanding reached, form the basis for enhancing common ground between the interactants, who experience exchange of content while simultaneously negotiating identity within the context of the exchange.

The arts are arguably codified systems of cultural knowledge, including concepts, symbols, processes, and aesthetics relevant within a culture, which are presented in context and manner acceptable to a culture, and which convey a huge web of semiotic information in particular, replicable processes (Elicker, 1997; Sebeok, 1991; Turino, 1999). Elicker (1997) describes that:

A symbolic form such as a poem, a film, or a piece of music is the result of a complex process of creation (the poietic process) that has to do with both the form and content of the work and is at the same time the point of departure for a complex process of reception (the esthetic process) that reconstructs a 'message' (p. 4).

Explanations of memes and semiotes frequently use various types of artwork as exemplars (Atran, 2001; Elicker, 1999), which may provide common ground for study of culture across the social sciences. Disciplines such as anthropology, cultural studies, musicology, ethnomusicology, art history, and archaeology frequently include the identification and description of artistic elements and practices as primary components in their studies of culture (though this is not widespread in psychology). All deal with memetic/semiotic processes and products. Psychological study of culture depends on the belief that cultures are systems that are describable, maintainable, and transmittable (Kashima, 2008). As described above, primary mechanisms by which this has transpired since distant pre-history are found in artistic practises and products. The arts, as a whole, are literally and factually the inner workings of a culture made manifest, providing observable examples of the informational elements comprising cultures as well as means of 
transmission. More specific explanations drawn from visual and performing arts follow in the next sections.

\section{Visual arts and cultural information.}

Visual arts, as semiotic creations, serve as examples of cultural codification and transmission on a visual level (e.g., Nattiez, 1990; Sebeok, 1991). They depict representations specific to a culture, drawing imagery from the natural world, as they have been since at least the time of the cave paintings mentioned above (Valladas et al., 2001), and from the human world of experience, story, and history. In this way, they carry evidence of the time, place, and cultural context in which they were produced, as well as of how the creator related to the subject. Patterns in every culture carry meanings of kinship, history, cosmology, and aesthetic preferences (Cole, 2003). Visual information may be crucial at times, as in the easily identifiable memes of heraldry or kilts advising of allegiance in battle, information of dire importance at times of conflict (Periera, 1950). Visual images display our ideas of beauty, as in the bas relief "Venus of Laussel" described above (Huyge, 1991; Moreley, 2003), which depicts a woman of opulent girth who might not be considered the most beautiful choice of subject in other times or cultures, but who represented something of great import to those of that time and culture.

As cultures have evolved, visual imagery has been drawn from increasingly more intricate and developed stories of who we are and of how and why we exist. Surviving examples of ancient Indian (Bernier, 1998) and Greek (Becatti, 1968) arts, being primarily sculptures and metal work, are filled with images of gods and heroes, serving as visual cues to bring to mind their stories and the cultural worldview, beliefs, and lessons represented therein. Carravagio's David with the Head of Goliath (circa 1610, in Sgarbi, 2007) relates, in the single image, a whole 
story from the Christian bible, instantly recognizable to people of the artist's time and faith. The stories such images tell are the same ones by which culturally preferred ways of surviving, interacting, and thinking are taught within particular contexts of cultural transmission. In Polynesian cultures, which were previously oral traditions, the sculptures, carvings, and patterns serve as visual references to the underlying memes they depict (cf. Francis, 1997). In fact, the Hawaiian language includes veiled sets of mimetic references, called kauna (Pukui \& Ebert, 1986), by which visual or oral reference to a bird, flower, personage, or location may serve as cues to double or triple layers of cognitive references. Hula is always done with music, and the visual language of the dancer is specifically the manifestation of the linguistic content of the chants or songs, set in gestures that convey recognizable information to those who are enculturated to understand those messages.

\section{The semiotics of musical performing arts.}

Music appears to be a universal of human culture, one of the few things beyond physical necessity shared across humanity (Blacking, 1995), though its forms are incredibly varied across cultures. A growing number of researchers posit that music may have been a crucial component in evolution of the human brain, most specifically in relation to the parallel development of language, which shares regions of function in the brain (Cross, 1999). Concepts of what constitutes music vary across cultures and across academic disciplines (cf. Nattiez, 1990). For this research, music shall be considered generally to be constituted of acoustic vibration woven through time: there must be sound, and there must be some temporal shaping of sound (Sloboda, 2008), though sounds and how they are shaped and combined vary widely (cf. Reck, 1977). Aspects of internal life of the mind shape the music we make and the perceptions generated by what we have shaped, though this is the 
same of all human production. Music, however, moves us to dance and to tears, being loaded with the full range of potential emotion. It is also laden with the culture-specific information of who we are, how we live, and how best to live (Elicker, 1999; Nattiez, 1990; Turino, 1999).

In music, one finds obvious semiotic structures of meaning; the style of music is recognizable, and there are linguistic, harmonic, and/or melodic references which can convey multiple meanings, elicit affective responses, and imply further meanings and interpretations beyond the specific subjects of the work (Elicker, 1999; Nattiez, 1990). Beginning with the songs we hear from infancy (Gregory, 1997), music provides a rich semiotic field (Turino, 1999), reiterating informational elements which shape who we become, unique to one's culture, historic time, and locality (Gaunt, 2006; Gregory, 1997; Hargreaves \& North, 1999). Through music, the myths, history, beliefs, values, and identity of a culture are interpreted and expressed, and the process of its creation happens within a set of culturally specific socio-cultural structures, forms, and circumstances (e.g., Hargreave \& North, 1999; Merriam, 1977; Turino, 1999). Music, especially music with lyrical content, provides particularly salient cultural content and an effective means of transmission in perpetuation of culture (Turino, 1999). Frith (1996) writes, "My point is not that a social group has beliefs which it then articulates in music, but that music, an aesthetic practice, articulates in itself an understanding of both group relations and individuality, on the basis of which ethical codes and social ideologies are understood" (pp 110-11).

Music and dance provide obvious venues for collective community processes (Geurin, Fatuma, \& Guerin, 2006; O’Hagin \& Harnish, 2006). Traditional performing arts have been termed efficacy performance as opposed to entertainment 
performance (Arpin, 2003). The former, in that paradigm, happens within a community and serves particular functions for that community (which would vary by culture), often without distinction between performer and audience. The latter is performance by a highly trained specialist, requiring no direct interaction with the audience and including no implicit or explicit sharing of values, connection, or experience (Arpin, 2003; de Leon, 1990). Efficacy performance forms a continuous, transgenerational activity within a culture, while there is no culturally proscribed commitment to perpetuation of entertainment performance activities over time (Arpin, 2003). On both personal and group levels, the efficacy activities provide means to connect with co-ethnics as individuals and communities, in manners that may remain effective in migration and inter-cultural adaptation (Farrer, 2004; Geurin, Fatuma, \& Guerin, 2006; O’Hagin \& Harnish, 2006; Viladrich, 2005).

\section{Communitas.}

Turner (1986) described ritual in traditional or aboriginal cultures as a primary mechanism of communitas, meaning a sense of unity, equality, and interconnection. The term derives from the Latin for community, and is used by Turner to make a distinction from a physical location of community. In the case of indigenous ritual, which Turner (1985) first observed in Africa, the practices serve, he says, to oppose social hierarchy by inducing unity, but also to preserve social order through communal and transcendental shared experience (see also Alexander, 1998). Ritual, in this sense, is not delineated from life and art as it is in contemporary Western culture (Turner, 1982a) (though Turner observed similarities to the experience of contemporary theatrical production late in his life). The symbols, masks, dances, enacted stories, and music of such events were inextricably interwoven with and derived from elements of life in a given culture (Turner, 1982a; 
1985), serving semiotic purposes of cultural maintenance and transmission, alongside the social cohesion functions. Turner particularly focused on what he describes as the liminal stages of ritual, in which one is essentially between states (during most of one's wedding, one is neither married nor not married), and by which one transitions, for instance, from girlhood to womanhood. In the process, one's place in, and unity with, the community is affirmed and reinforced (we are one, you are us), after which the person enters a new role, distinct from previous roles and potentially from the roles of others, as in becoming a chief (Turner, 1982a; 1982b; 1985). Psychologically, particular states may be induced during and after these rituals. Modern theater, he felt, operated in a similar though secular way, placing actors and audience outside the roles and conventions of daily life for the duration and communications of the performance (Turner, 1982b).

Rituals are enacted in ways derived from stories of myths, legends, and religion. Campbell's Hero with a Thousand Faces (1949/1973) describes a universal process of story which he terms the hero's journey. The story begins in the normal world, which is interrupted or disturbed by a crisis or urgent demand. The hero then undertakes a quest for solution, after which he returns to rejoin the normal world, changed by the experience and possessing new knowledge. In Campbell's view, this core story can be found in the myths and legends of every culture. Ritual enacts the mythic journey in an active and interactive process (Collins, 1985), and the crisis/quest stages are the liminal phase of Turner's (1982a; 1985) description. Campbell (1949/1973) observed this process across what he called "primitive" cultures (such as tribes of the Americas or Africa), though he also observed a parallel in modern culture. Late in his life, he attended a Grateful Dead concert, having been befriended by band members. He described the concert as a 
Dionysian ritual, during which the audience was unified by the process. The transformative phase occurred when all but the two drummers left the stage, removing the relative stability of tonality and lyrics for a period of primal, powerful drumming and frenetic dancing, which was then followed by reunification in ebullient song (Campbell, 1986). Communitas was established in a rock setting.

\section{Setting the stage for cultural transmission and maintenance.}

Whether it is a puberty ritual or a Grateful Dead concert, shared arts experiences occur in particular contextual settings, and include social processes unique to those contexts. There is a body of psychological research investigating individual level innovative creativity as affected by social contexts (e.g., Amabile, 1983; Harrington, 1990; Simonton, 2000), though communal activities such as ritual are outside the purview of this research. On the more generalized level, artistic activities are localized within particular contexts in all cultures, though the contexts are quite different in traditional and non-traditional arts. These contexts have been widely studied in social sciences such as anthropology and sociology, but not in psychology regarding individual and community processes in these settings.

In community psychology, O’Donnell, Tharp, and Wilson (1993) posit a conceptual model they termed activity settings, the important characteristics of which include the people involved, the positions they hold, and the physical environment, as well as elements of time and symbology. All of these are elements of arts practice in varying degrees. In all types of practice, shared cognitions and processes may be featured, even if it is merely in the valuing of the material performed (with or without shared meaning) or in the general ways that one behaves at a performance. In different ways and with different implications, all arts practices provide a setting which perpetuates a shared set of meanings and behaviours as they 
happen. O'Donnell et al. (1993) describe the activity setting as the unitary level at which propagation of community and culture occurs. Microsociology utilizes a similar level of analysis "well positioned to see culture - treated as a domain of content - as it is developed and put into action" (Fine \& Fields, 2008, p. 133).

Traditional performing arts happen in particularly embedded cultural settings and are laden with cultural content. Their re-enactment forms a core arena for community cohesion and cultural transmission for cultures in situ and especially in migration (see below). Music and dance provide the most obvious venues for these processes, but other arts such as Maori weaving (Evans \& Ngarimu, 2005) may provide such a setting when the activity is done as a group. In Arpin's (2003) explication of the differences between efficacy and entertainment performance, he states that in efficacy performance, "participants share a cultural agreement about the meaning of the performance. Such an event becomes a ceremony. It has a conservative function for the community. It is inserted into the community's life and each participant is actor in turn" (Arpin, 2003, p. 308).

In traditional contexts, the processes occurring are explicit and important parts of the culture in which they occur, transmitting and perpetuating cultural symbols and knowledge while simultaneously enhancing group cohesion (cf. Turner, 1982a; 1985). By extension of the activity settings framework, it could be said that human culture has always been perpetuated in such activity settings. In migration also, traditional arts may provide transportable, familiar activity settings in which community and individual processes continue to be enacted in the new locale. Interestingly, the witnessing of ethnic arts performance by dominant and other ethnic communities occurs in another sort of activity setting (concert hall or 
theatre) in which culture may potentially be shared in a known and non-threatening environment (c.f. O’Hagin \& Harnish, 2006).

\section{Arts in contemporary and traditional cultures.}

\section{The evolution of arts in Western cultures.}

The vast body of known musics, both European and non, have persistently worked with generally agreed musical structures whose skeletal frames have remained relatively fixed. The major exception here, not the rule, has been $19^{\text {th }}$ century European classical music (Chambers, 1985, p. 8, in Elicker, 1999).

Arts have continued to move with changes in human existence and conditions, though with substantial alterations in functions and processes as one approaches the present era. Blatt (1985) compared the development of visual arts to cognitive development in children. From Palaeolithic through early Greco-Roman times, he said, forms were presented in isolation and in two dimensions, which Blatt connected to the Sensorimotor and Pre-operational levels. From the early Renaissance through the late 18th Century, Europe developed Concrete Operational Level, in which figures began to appear to be three-dimensional and images were depicted from a particular vantage point of the viewer. From the Impressionists onward, visual arts have entered Formal Operations, becoming increasingly abstracted from form toward representation of pure concept. Blatt's may be a somewhat Eurocentric view, assuming modern European culture to be the most advanced, but the preference for that worldview developed in parallel to those arts.

A major shift throughout Europe began when Catholicism essentially subsumed the role of the controlling force throughout the regions formerly under Roman rule, following the empire's decline (cf. Eliade, 1985). The church 
systematically supplanted the former "pagan" beliefs and rituals, replacing winter solstice practices with Christmas, and spring fertility rituals with Easter, for instance. In this way, the previous mechanisms of communitas and of cultural maintenance and transmission were replaced, methodically and intentionally, by the hegemony of Christian ritual in all aspects of social and cultural interaction, from birth to marriage to annual observances to death (Collins, 1985; Eliade, 1985; Turner, 1985). Outside of the domain of the church, this left only folk musics strictly designed for entertainment value and utilitarian crafts in material culture, at least until the rise of a new ruling class and the later rise of a merchant class who would provide funding via patronage or purchase of arts. A further shift transpired as the Renaissance emerged into the Enlightenment during the $18^{\text {th }}$ century, following Martin Luther's historically revolutionary criticism of the Church and Galileo's heretical revelation that the Sun and not the Earth was the centre of the local heavens. Suddenly, there were demonstrable flaws in Catholic dogma and practice, chipping away at the centrality of Rome as the primary source of social and cultural control (Eliade, 1978), and moving humanity to centre stage.

Increasingly, arts focused on the individual ideas and intentions of artists trained in the relatively isolated and individualistic world of the academe (e.g., Harding, 1979). Between the passing of J. S. Bach (1685-1750) to the life of Beethoven (1770-1827), European music transitioned from a preponderance of religious themes, with the occasional myth or story thrown in, to the favouring of works arising from the mind of the composer, which were to be played exactly per his written instructions (Sadie, 1980). Berlioz' Symphonie Phantastique (cf. Raby, 1982) was an abstract musical description of the composer's imagined, unrequited love affair with a semi-fictionalized woman (considered to be opera singer Harriet 
Smithson Berlioz) and the fictional events leading from the protagonist's infatuation to his suicide. The story was an entirely personal fiction, a psycho-drama, in fact. Berlioz did indeed eventually marry the actual Smithson, an Irish opera star (ending in divorce), but it is the process of composition using personal, individual content that is relevant here: by this time, the artist had been freed from obligation to fit content to the context of the interpersonal community or the sacred in the forms and functions of the arts. Along the way, however, the new arts may have lost much of the embrace of enculturation and communitas found in less "civilized" arts.

Similarly in the visual arts, the stories and symbols have become increasingly secular, subtle, personal, and multi-dimensional as history headed toward contemporary European-derived culture. Caravaggio's David holding the Head of Goliath (1610) tells a second story external to the visual image of Christian reference, somewhat lost to history, in that the artist chose his own face as the model for the head of Goliath (Spike, 2001). It is widely regarded to be his last painting (Sgarbi, 2007), done after he killed a man, fled to Malta, and returned to Italy to seek a papal pardon, only to be murdered himself (Spike, 2001). It is certainly a horrific image, perhaps a symbol of contrition or at least a visual depiction of his psychological turmoil at the end of a tumultuous life (Sgarbi, 2007)

The Avant-Garde movements of Expressionism and Surrealism arose during World War I and its aftermath (Becker, 2000). Surrounded by the overwhelming carnage of the war, that environment became an inexorable part of the thoughts and work of artists of the time. Of the effect of his service in World War I on his art, Andre' Masson (1957) said, "For me, violence is part of existence, and one must express it" (in Becker, 2000, p. 72). The emotional and contextual landscapes had 
changed, and this was happening simultaneously alongside the rise of the concept of the art as a personalized expression of the individual and his personal experience.

Picasso's "Minotaure Caressant une Dormeuse" (Minotaur Caressing a Sleeping Woman) (1933), refers back to Greek mythology, but the story is repurposed by the drawing technique itself. The Minotaur is a mass of harsh ink strokes and squiggles, while the maiden is just a few elegant curves that eloquently express her living form (Myers, H., 2007). One can only speculate, but it may be that the artist was comparing his own turbulent being to the simple grace of his lover at the time. It has been widely accepted that Picasso used the Minotaur, which appeared repeatedly in his work during the 1930's, to represent himself (cf. O'Brien, 1976). Visual imagery had also left the domain of direct or symbolic reiteration or portraiture and become a tool of individual expression.

At present, cultures mix and mesh amidst truly global access to all aspects of culture, now instantly available via internet and digital media, and grow into new forms amongst huge immigrant populations negotiating identity in thriving ethnic sub-cultures. Warhol's 1973 rendering of the image of Mao Zedung made the Communist leader an unintentional icon of Western pop culture.

On Peter Gabriel's 1986 album So, Senegalese singer Youssou N'Dour provided backing vocals late in the song "In Your Eyes," moving "world music" into the mainstream, though the Kingston Trio's rendition of the Rhodesian rebel's rallying song, reworded to "Wimoweh" from "Zimbabwe," had put an African song on the pop charts decades before. The exotic was gradually becoming normative on the global stage. By the 1990's, digital sampling technology facilitated inclusion of ethnic music snippets in the albums of bands like Deep Forest and Enigma, moving into the DJ world around the same time. The Indian Bollywood-based trance and 
house music movement uses this technology to place Bollywood samples in a context of Western dance rhythms on a worldwide basis, featured in nightclubs in New York, Paris, and London. Algerian Rai and pop music in France is another prime example of an immigrant group creating a musical sub-culture. Specific genres have generalized across cultures and continents, such as rap or heavy metal, which are globally ubiquitous, but in which a trans-national, genre-based identity has emerged (Boer, 2009).

In these new combinations, arts certainly stray from old purposes, and perhaps fulfil new ones. We still interconnect and share information via artistic means, though there are unprecedented memes, contexts and technologies involved, and a new order of entirely commercial enterprises distribute the output in massive volume. Also available is a wealth of visual imagery from vast histories of multiple cultures and civilizations, though the ability to receive and interpret the semiotic content as intended has not necessarily been retained. One can potentially experience arts of any living culture, or any for which archaeological or media records remain, though the experience will differ. The recorded music of the Ituri rainforest pygmies (Turnbull, 1992), for instance, is unlikely to convey the sense of communitas felt by those who made the music at that moment in that context. The Western world's shift toward individualism in arts is not surprising: Westerners are the most individualistic (least collective) in Hofstede's (1980) axes of cultural variability. It is unclear, however, whether Europe was as individualism-oriented before the historical processes described above, and whether these developments represent the maturing of society, as Blatt (1986) would say, or a loss of ancient mechanisms of inter-connection. Either way, the shift has coincided with the rise of Western economic and cultural hegemony on a global scale. 


\section{Arts in traditional, indigenous, and aboriginal cultures.}

In sharp contrast to the historical and social processes affecting Western arts and culture, many non-Western cultures, including indigenous cultures within developed countries, retain heritage arts and artistic practices with completely different histories. Though these cultures are now subject to processes of globalization and commodification, some cultures maintain continuing arts practices which have origins hundreds or thousands of years in the past (e.g., Avgorbedor, 2008; Evans \& Ngarimu, 2005; Francis, 1997; Myers, 2004). Among differences between Western and non-Western cultures, many of the latter do not make the distinction between arts practices and other aspects of everyday life (CNZ, 2007), or between artist and audience (Arpin, 2006). Because these arts are the primary subject of this research, a discussion of arts in traditional cultures is warranted.

These terms, traditional, indigenous, and aboriginal, are difficult to define and hotly debated across matters of political and cultural rights, sovereignty, and legitimacy (cf. Barclay, 2005). At some point, every culture has been involved in moving from one place to another, more or less recently (see Global Migration section below), and every culture has some set of traditions. The point here is not to revive the Enlightenment concept of the noble savage, described by Rousseau as living in a utopian state lost to European culture by virtue of their innocence (Cranston, 1991) -- all cultures have issues with which to deal, and a plethora of solutions across cultures which defy sweeping generalizations -- or to argue what constitutes aboriginality. Paradies (2006), an Australian Aboriginal person, points out that by 1986 , legislation in that country included at least 70 definitions of indigineity. The terms indigenous and aboriginal are laden with issues of legality, identity, and politics (Paradies, 2006; Walters, 2007). 
For the purposes of this thesis, "traditional culture" shall be used to describe a super-ordinate level which would include aboriginal cultures, but also long standing societies that were colonized but not overwhelmed by European settlement (Murray, 2004), such as the cultures and sub-cultures of India or China, or relatively un-colonized historic cultures such as those in Greece or Bulgaria. These would be characterized by a long history of shared and socially recognized activities, beliefs, mythologies, world-view and practices. "Indigenous" and "aboriginal" shall be construed as cultures that predated European conquest, colonization and settlement, remaining approximately in situ, usually referring to cultures that were in place centuries or millennia before the European colonial era, though those people were frequently displaced, killed, or overwhelmed by Europeans who settled the region in large numbers. Examples would include the Maori in Aotearoa (New Zealand) or the few surviving tribal groups of the Americas. These groups are typically disadvantaged economically, socially, and politically when compared to the European descendants, who typically continue to wield political and economic control in those areas centuries later (Hoerder, 2002; Walters, 2007).

It may be easier to define traditional arts, at least for this research, by what they are not: modern, potentially commercial products of the post-colonial Western global culture (Sevik, 2001), or in the case of the former Soviet Union or Peoples Republic of China, state approved versions of historic or modern arts stripped of unwanted ideological content and context (e.g., Ahmed, 2006; Gerdes, 2008; Pang, 2005). This is not to say that modern arts are without value, benefit, or purpose, only that they are different.

In the broad categorization of traditional arts, the schism between arts and life is not pronounced in the ways described above for Western cultures (e.g., 
Avgorbedor, 2008; Creative New Zealand-CNZ, 2007; Francis, 1997), and hereditary practices within families may stretch back centuries or millennia, especially among indigenous cultures. Art and life are largely more interwoven with and inextricable from the psyche outside of Western culture (Campbell, 1986; de Leon, 1990). For the purposes of this discourse, traditional arts, including indigenous and aboriginal, would be those which are not stripped of long-standing content, heritage, or process, and would include, for instance, those of cohesive subcultures of Europe, cultures in forced or voluntary migration, and Christianized post-colonial cultures in which a strong sense of identification by and with historic cultural practice remains. Ethno-cultural arts as a whole would further include those such a Bollywood dance, a modern genre popularized in Indian films which retains certain characteristics of traditional and classical Indian dance, but in decontextualized, modernized, and culturally generalized ways (Dawson, 2005; Luck, 2005; Punathambekar, 2005).

The traditional arts among all groups have historically been an important part of maintaining cultural continuity and individual and community well-being (cf. Fortes, 1936; Geertz, 1993). This may be even more true for adapting indigenous and aboriginal groups such as the Maori of Aotearoa, the tribes of Canada (Martel \& Brassard, 2006), the Carib who still minimally maintain their culture in the Caribbean (Palacio, 2006), or the multi-millennial inhabitants of Australia (Blagg, 2008; Paradies, 2006). It could be generalized that most of these groups have suffered heavy mortality since European arrival, have been repressed in expression of their cultures, continue to experience socio-economic and political disadvantage, and are at risk of cultural diffusion or extinction. For these groups, cultural survival has been and is a real and pressing concern. Cultural and physical extinction of 
indigenous groups was a policy and a goal in numerous European origin settler societies (Murray, 2004). Though they are no longer actually physically hunted, the chronic disadvantages indigenous groups face continue the destruction of their cultures at a slower pace (Hoerder, 2002). Ethical and legal issues remain complex, as indigenous groups fight for improved conditions and resources:

...the law of the settler society was used as an instrument of colonization to deny aboriginality and, later, as an instrument of decolonization to recognize aboriginality. Second, they emphasize the paradoxical quality of law in this respect. Through recognizing aboriginality, law denied (and denies) important aspects of aboriginality; in other words, decolonization through law affirms aspects of colonization (Walters, 2007, p. 821).

Indigenous groups must fight for their survival in contexts completely alien to them, within systems originally designed to suborn genocide, now repurposed to maintain social inequity (Murray, 2004; Paradies, 2006).

It should be noted that similar processes continue to occur outside the settler societies, for instance among the tribes of Kalimantan, whose habitat is currently being destroyed by logging and mining. Their artificially created, government-built communities were heavily populated by Madurese who were relocated there by the Indonesian government in Jakarta to establish voting blocks loyal to Java. The situation resulted in heavy ethnic violence against the Madurese from 1996 to 2001, but the ancient Dayak ways of life are already largely destroyed (Anggraeni, 2001).

As discussed earlier, arts are the ancient vehicle for cultural maintenance and transmission, which takes on a new urgency for threatened indigenous cultures. Arts provide the tangible links to continuity of culture, whether in visual records such as sculptures or paintings, or in traditional songs and dances (King, 2001; Turner, 1985). Among many indigenous groups, oral history maintains an ongoing link to histories, myths, legends, and life instructions (Becker, 2004). Participation in 
traditional activities in school is considered to lead to better outcomes such as increased academic participation for indigenous and aboriginal youth (Whitinui, 2008). Traditional arts may form a site of cultural transformation, rejuvenation, or reinterpretation (Davis, 2008), providing familiar elements by which new understandings may be created. In their study employing traditional art to communicate health messages to Mowanjum aboriginal peoples in Western Australia, Davis et al. (2004) found that use of culturally appropriate imagery drawn by local tribal artists provided an excellent platform for transmission of health information (perhaps particularly by inclusion of familiar cultural memetic material), resulting in increased discussion and unprecedented community involvement. As a side note, those authors describe that their own cultural sensitivity to and appreciation of the Mowanjum was greatly increased.

\section{The politics of art.}

Indeed by the 1970s the Inuit had come to believe that a major component of their identity in the world was that of artists, and they built on this new strength to establish new economic, social and political institutions. This case illustrates the complex way in which indigenous art can simultaneously proclaim difference or distinctiveness from the surrounding nation-state and also express that nation's identity within the world of nations (Graburn, 2004, p. 141).

The contexts of arts and arts practices have certainly altered over time, though the transmission of messages and valuing of symbolic content is ongoing (e.g., Barclay, 2005; Graburn, 2004). Cultural symbols, artefacts, and icons form a core of identity for ethnic groups in modern contexts and collisions, both as prototypes of iconic representation and as symbols of legitimacy and empowerment. Repatriation of cultural artefacts and artistic usage of cultural icons is the subject of heated debate and political action by indigenous peoples and formerly colonized countries (Caffaro, 2002; Cameron, 2005; de Vos, 2004; Kramer, 2004). "In this 
way, these artworks, existing in interactive spaces, are sites of action for the creation of empowering social relations" (Kramer, 2004, p. 164). Ownership being a concept alien to many cultures, an international crisis has arisen as cultural icons, artefacts, and ideas have been appropriated, which might more justly receive the same protections given to intellectual property (creations of particular authorship and resulting ownership) in Western law (Barclay, 2005).

In the post-colonial world, arts and the icons and symbols conveyed have become heavily politicized. For the San in Africa, arts are historically considered to be crucial to the health and well-being of their community. Currently, there are serious implications and functions of arts as the San negotiate their place in the modern world. Guenter (2003) describes:

The art is produced in a context of intense identity politics, which in recent years have awakened the San politically and placed this hitherto passive ethnic minority on a course of political action. The art is especially relevant to the issues of identity and selfrepresentation, and holds the potential for exposing and displacing the colonialist, and still cherished, icon of the timeless huntergatherer of the far-away veld (p. 95).

Another sort of conflict surrounds Tibetan Lhamo drama, which is widely practised among dislocated Tibetans as a nexus of sharing culture and of theatrically describing and interpreting their enforced diaspora. A new form of Lhamo has emerged in China, funded and controlled by the State, which turns the medium to support of the political ideologies and goals of the government regarding occupation of Tibet and opposition to the Dalai Lama and the traditional Buddhist monks (Ahmed, 2006). In addition to historic roles in cultural maintenance and transmission, arts have become a front line of intercultural conflict. 


\section{Summary of arts and humanity.}

In the preceding pages, it has been shown that arts are an ancient and universal part of human existence and that they encapsulate and convey cultural information from which understanding and identity are created, maintained, and negotiated. Arts have formed and continue to form a nexus for social and community processes. Arts have changed in recent eras, and reflect, in those changes, changes to human ways of thinking and being. Our cultures and the minds within those cultures are constantly shaped and reshaped by arts practices. Western arts have drifted far from their origins: what psycho-social functions remain, and how do the new and old processes coexist in the modern world? Unprecedented conditions and risks have arisen in the more recent movements of humanity, leading to questions of how arts may factor into these new cultural conditions and conjunctions.

\section{Migration, Globalization, and Inter-cultural Contact}

The majority of instances of local, national, regional, and global problems can be traced to conflicts involving cultural and racial diversity (Marsella, 2009, p. 121).

This section begins discussion of current intercultural contact and its repercussions, leading to a discussion of how arts play into the story. Migration is not new to humanity, stretching back to the first emergence of essentially "modern" humans from Africa beginning some 120 thousand years ago (Hoerder, 2002; King, 2001; Koser, 2009). At present, however, humanity is on the move in ways never seen before, whether for economic, environmental, or political reasons (Marsella \& Ring, 2003). The global population has far exceeded historical levels, and the number of people in transit, whether for economic need or due to natural or man- 
made disaster, is monumental (e.g., Hatton \& Williamson, 2005; Hoerder, 2002; Koser, 2009; Marsella \& Ring, 2003). Since the mid-1980's, numbers of international migrants have more than doubled, with some 25 million migrating between the years 2000 and 2005 alone (Koser, 2009). The cumulative effect of US immigration led Bohlman (2006) to state,

It may or may not be the case in 2006, as I write this review, that everyone in the United States can claim membership in a diaspora, but the very persistence and anxiety of such an argument that diasporas are everywhere bear witness to the degree to which understanding diaspora is crucial to understanding identity on national and global levels (p. 186.)

In this massive shifting of population, cultures are coming into intimate contact as never before. The effects of this include acculturative stresses, and there are resulting needs to investigate effective ways to cope during acculturation (e.g., Hoerder, 2002; Issawasi, 1998; Ward \& Kennedy, 2001). There has never been a greater need for inter-cultural understanding in this regard (Marsella \& Ring, 2003).

\section{Adaptation and acculturation.}

Throughout the increasing colonization and migration processes of the past millennium, intercultural contact has increased, whether for good or ill (Hoerder, 2002). Each contact, whether via conquest, invasion, trade, colonial settlement, or proselytization, exposes societies and the people within them to differing ideas and ways of being. In milder forms, this may provide valuable ideas, technologies, or resources. In more extreme forms, such as forced conversion of indigenous peoples by the Spanish, vast populations have been cut off from traditional structures, supports, and symbols. As a result, changes occur on both societal and individual 
levels, with a range of potential social and psychological outcomes depending on conditions and responses (Ward, 2001).

The term acculturation "refers to changes that occur as a result of continuous first-hand contact between individuals of differing cultural origins" (Ward, 2001, p.412). The process was described by Plato, but first use of the term is credited to Powell in 1880 (Sam, 2006). At that time, it was assumed that acculturation was a process in which "primitive" cultures would willingly adopt the attributes of "superior" (European) cultures. Academic study of acculturation increased in the 1930 's in the fields of anthropology and sociology (e.g., Redfield, Linton, \& Herskovits, 1936). Berry (2006) describes acculturation as a dual process happening during contact between two or more cultural groups and the individual within those groups. Cultural and psychological changes may be experienced more or less by any of the groups and individuals involved, and may happen simultaneously to all. The minority group is considered to be most pressed to adapt, though the dominant culture may take on aspects of the minority, such as the adoption of jazz music and peanut-butter by Euro-Americans (DiMaggio \& Ostrower, 1990; Neto, Barros, \& Schmitz, 2005).

Although acculturation is considered to occur primarily through intercultural contact, there are also cultural changes due to ecological or demographic alterations, or when a population is segmented into traditional and modernized sectors (Social Science Research Council, 1954). It is distinct from enculturation, which refers to the learning of a culture's values, beliefs, norms, etc. during development, and from cultural change, which are changes in a culture at a population level as a result of dynamic events within the culture such as innovation, invention, and discovery (Berry, 1995; Castro, 2003). Graves (1967) called for distinction between 
acculturation at the group level and "psychological acculturation" at the individual level. Further, there is a distinction between "acculturation," as the individual-level changes resulting from intercultural contact, and "psychological adaptation," as the outcomes of the process (Ward, 2001).

Categories of acculturating groups have been proposed, based on whether the contact is voluntary or involuntary and whether the group has migrated or is sedentary, and discussion continues regarding differences in process and outcome for these categories (Berry, 1997; Ward, 2001). The voluntary groups were proposed to include ethnocultural groups in situ (those voluntarily maintaining cultural lifestyles as a minority within a dominant society) and migrants, which include permanent immigrants and temporary sojourners. Involuntary groups include indigenous peoples and refugees or asylum seekers (Berry \& Sam, 1997; Ward, 2001). In all cases, the acculturating group or individual has prior or differing experience of culture which is brought into the contact setting (Nayar, 2009).

Difficulties must be faced by those in all categories. Migrants must find new means of livelihood in situations which are in their nature different from those left behind. These new situations require changes in "identity, values, behaviours, cognition, attitudes and affect" (Bemak, Chung, \& Pederson, 2003, p.31), or the learning of new skills and the acceptance of a new set of social norms, to an extent that varies by context (Nguyen, Messe, \& Stollack, 1999). Minorities and indigenous groups in situ face similar pressures for accommodation whenever dealing with dominant group members, and especially when placed in inequitable social power structures (Berns-McGown, 2007; Hoerder, 2002; Marsella \& Ring, 2003). 
Much of the psychological literature of acculturation focuses on migrant groups. Immigrants face a number of issues and risks in the migration process, partly depending on their reasons for migration. Of the migrating categories, refugees and forced migrants face the worst of these (Bemak et al., 2003; USCR, 2000), but all migrants face some risks. Jablensky, Marsella, Ekblad, Jannsonn, Levi, and Bornemann (1994) state that "There is compelling evidence that specific configurations of migration and displacement have a major impact on both shortterm and long-term mental health and well-being" (p. 329). These authors cited a list of risk factors encountered most dramatically before and during migration, including:

Marginalization and minority status

Socioeconomic disadvantage

Poor physical health

Starvation and malnutrition

Collapse of social supports

Mental trauma

Adaptation to host culture

Though these effects may be considered to be most immediate and pronounced among refugees, the effects upon other migrants are also potentially exceedingly difficult, especially in cases of pushed migration due to environmental or economic hardship, when few resources are likely to be brought on the journey. For many migrants, in fact for many minorities in their land of origin, the life situation includes such factors as very low socio-economic status, dangerous living conditions, language issues, prejudice, political persecution or exclusion, and so on (Arroyo \& Zigler, 1995; Green, 2009; Wilton, 2005). Similar conditions and risks are faced by indigenous groups in areas settled during colonization and ethnic minorities who may have been present for generations, some of these groups having endured such conditions for generations (Hoerder, 2002; Murray, 2004). 
Sojourners, those moving temporarily for work in another country, also face stresses and difficulty in their host cultures in a number of socio-cultural domains (Kuo \& Roysircar, 2009; Ward \& Rana-Deuba, 1999). In other words, basically anyone who is not born a member of the dominant ethnic or national group where they live potentially faces some of these risks and must acculturate in some ways to some degree.

\section{Approaches to psychological study of acculturation.}

Earliest approaches to acculturation assumed that inevitable psychological conflict was involved in the process. The first of these was the marginal man, espoused by Park (1928), which assumed the acculturating individual to be caught between two cultures and accepted by neither, leading to "marginalization" and negative psychosocial outcomes. In a best case scenario, the person might hope for assimilation, or complete adoption of the other culture, for instance acquiring the self-image of an un-hyphenated American (Sam, 2006). Later, the concept of culture shock (Oberg, 1960) was widely embraced and became part of popular culture, also implying only negative emotional experiences and outcomes in the process. Berry (1970) proposed the concept of acculturative stress, related to psychological models of stress and coping (e.g., Lazarus \& Folkman, 1984), in which the acculturating individual is responding to environmental stressors of an intercultural nature. This approach was more balanced, keeping a negative side of the process in the form of stress, but allowing for ways to ameliorate the negative sequelae. Moreover, this model had a parallel theoretical basis from which to draw concepts and methodologies in the stress and coping literature. 
Ward (2001) summarizes acculturation research overall as falling into three theoretical approaches: stress and coping, social identity, and cultural learning. The stress and coping framework focuses on stresses faced in migration and the ways in which the individual copes with these stresses. It has remained an important avenue of acculturation research since Berry's (1970) proposition of the concept of acculturative stress and the subsequent work of Lazarus and Folkman (1984): the acculturating individual encounters stressors in the process of dealing with new environments and world-views, which influence adaptation outcomes. These stressors may constitute $e u$ - or distress on an individual basis, depending upon how they are perceived and appraised by the individual. These cognitive differences may cause wide variation in the type and degree of effect on resulting psychological outcomes (e.g., Berry, 1997; Ward, Bochner, \& Furnham, 2001). Other factors affecting these outcomes include changes over time as the individual adapts to the new environment, demographics of both the individual and new environment, availability of social support, cultural distance between the culture of origin and the alternate environment, discrimination from dominant and other ethnic groups, and knowledge and skills gained (see cultural learning paradigm below), as well as individual factors such as personality characteristics (Berry, 1997; Ward, 2001).

The milieu of acculturation may be a major factor in stressors and adaptive outcomes, primarily in the degree to which the individual is accepted by the dominant or host community: is diversity tolerated, or do attitudes of prejudice and exclusion prevail (Green, 2009; Marsella, 1994; van Oudenhoven, Ward, \& Masgoret, 2006; van Tubergen, 2006)? Strong prejudices from the dominant ethnic group may affect earnings, and thus socio-economic status, potentially leading to a ghettoization and economic disenfranchisement of a group (Green, 2009; Ward \& 
Masgoret, 2006; 2007). The degree of difference between the heritage and host cultures, affecting the amount of accommodation required of immigrants or indigenous groups (Markus \& Kitayama, 1991; Tadmoor, Tetlock, \& Peng, 2009). The presence of co-ethnics in the community (van Tubergen, 2006) may maximize social support, thereby mitigating identity erosion and pathology, as well as providing employment opportunities within the community (Brody, 1994; Liebkind, 1996; van Tubergen, 2006), though others suggest strong co-ethnic presence inhibits the process of acculturation (Brody, 1994; Liebkind, 1996).

The second theoretical approach, social identity, arose from literature regarding social cognition and focuses either on individual aspects of cultural identity or characteristics of the group dynamics involved. Individually, this approach examines the ways in which one identifies with the culture of origin or the dominant culture, including sense of belonging, importance of membership, and evaluation of the group (Ward, Bochner, et al., 2001). The individual may identify with the culture of origin or the dominant culture exclusively, or with both in some combination. Issues relevant to the group level include perceptions of in- and outgroup regarding similarity, status and power, and boundary permeability (Crocker \& Major, 2003; Turner, 1999; Ward, Bochner, et al., 2001).

In terms of the social identity paradigms, much of the research relating specifically to acculturation revolves around either Berry's (1990) acculturation strategies or Phinney's (1990; 1992) more developmental approach to identity acquisition. These paradigms describe processes by which identity is negotiated and the outcomes of strategies of identification. The concepts apply to indigenous and long-term minorities in post-colonial socio-political structures, and to subsequent generations of immigrant populations negotiating sense of identity as minorities 
within an alternate, dominant culture. In other words, social identification has been seen to be most important in opposition to an out-group in a context of inequitable power distribution, making stronger identity formulation most important to those lower in a power hierarchy. Berry's (1990) concept of acculturation strategies includes assimilation, integration (formerly bi-culturality), separation, and marginalization, in which the individual identifies with only the dominant culture, both cultures, only the culture of origin, or neither culture, respectively. Perception of, and identification with, in- and out-groups has been shown to yield various psychological outcomes, primarily with dual identification or solid in-group identification having been demonstrated to lead to better psychological adjustment, and with favourable comparison of in- to out-group also playing a potential role (Berry, 1997; Ward, Bochner, et al., 2001).

The cultural learning paradigm posits that the acculturating individual experiences difficulties arising from lack of knowledge and skills needed in the new cultural context, such as language fluency, communication style, rules, conventions, and norms, necessary for effective interaction, and that acquisition of relevant knowledge and skills are necessary for successful adaptation (Ward, 2001). The effects of the cultural learning paradigm have been shown to follow a learning curve in relation to time spent in contact with the alternate culture. As a person spends more time in the alternate culture of contact, the person learns more about that culture and about appropriate ways of being within that culture, this experiential learning yielding improved adaptation in the new cultural context. A number of researchers have pursued investigations of social learning issues and conditions which focus on potential benefits of pre-departure training, particularly with regards to sojourners travelling for business or education (Cushner \& Brislin, 1996; Ward \& 
Kennedy, 1994). It is understandable that this avenue of inquiry has focused on acquisition of skills of host cultures, those being most important for migrants and sojourners needing to function in a new culture (Ward \& Kennedy, 1994). There may also be merit, however, to further investigation of the acquisition and maintenance of skills necessary to function in the hereditary culture of origin, something which may be particularly important for subsequent generations in indigenous, minority, and migrating groups.

Ward (2001) synthesized these three theoretical approaches to acculturation into what she termed the "A.B.C.'s of crossing cultures" (p. 415), relating to affect, behaviour, and cognition. In this synthesis, the three approaches, though arising from different conceptual bases and bodies of research, are shown to interrelate in complementary paths of influence. The A (affective) component corresponds in this model with the stress and coping literature, and relates to processes of coping with cultural change. The B (behavioural) component relates to cultural learning theories, relating to garnering of skills required in the new environment. The $\mathrm{C}$ (cognitive) component relates to the social identification approaches, relating to how one conceives of identity in the intercultural context. The synthesis suggests that these approaches all have merit and may be applicable in certain aspects of acculturation, though bringing together such divergent streams of research, she cautions, must be handled with great care.

Research using multiple acculturation paradigms is relatively recent (Ward, 2001). Further, within identity research, there has been very little information concerning the specific processes or components of identity which are most adaptive. Phinney (1992) found a factor of "identity search" in development of the Multigroup Ethnic Identity Measure (MEIM), but the questions are general in nature 
and do not identify specifically those aspects which would be most important to "find." Which behaviours or activities are most important or how they actually affect the individual psyche are not well described, especially in terms of skills and strategies related to culture of origin. Are there particular activities that develop a stronger sense of identity or serve as coping strategies that protect the individual from negative sequelae in acculturation? If one is best served by the integrated strategy of acculturation, can one fully embrace two distinct cultures, or does one embrace varying portions of identity depending upon context? As Kashima (2008) suggests, culture may have to be viewed in terms of both content and process if psychological implications are to be fully grasped, and acculturation may be a highly complex set of interwoven processes, acquisitions, and retentions which vary over time, age, and context. An avenue toward this sort of understanding may be available amidst the historical and essential aspects of culture included in arts and artistic processes.

\section{Acculturation and arts in intercultural contact.}

Arts have forever travelled with humanity, serving continuing and adapted functions along the way as different cultures have interacted, and maintaining or spreading cultural information and practices as they went. Musical instruments and styles, for instance, have been transported and shared through migration, trade, warfare, and religious proselytization (Montague, 2007; Reck, 1977), spreading specific cultural practices such as ancestral veneration rituals in the process (Provine, 1992; Provine, Tokumaru, \& Witzleben, 2001). For cultures in migration or occupation, arts have served as continuing means of cultural transmission and preservation (e.g., Farr, 1997; Gaunt, 2006; de Silva Jayasuriya, 2006). Examples 
herein shall be limited (for the sake of brevity) to music, which is one of the most transportable of art forms, though discussions in literature addressing other aspects of migration and acculturation have extended across arts including, for instance visual arts and literature (Stern, 2004; Sussman, 2010).

In inter-cultural contact, music has become an important part of negotiating social processes and transitions, whether in diaspora or in indigenous situations of colonial or domestic inter-ethnic contact, (Graburn, 2004; James, 1999; de Silva Jayasuriya, 2006; Kramer, 2004). For example, the female Kiba performers across southern Africa have established a new, more vigorous version of a style associated with the Lebowa region, and in doing so have created a unified identity for women across tribes, challenged male hegemony, and gained political voice. Kiba performance was prominently featured at the Mandela presidential inauguration to symbolize a national unity transcending the previous divisions of race and gender (James, 1999). Music and poetry provide rallying points and symbols which have helped to unify the Berbers of Algeria, both in their native regions and in France, in their struggle for political acknowledgement and autonomy (Goodman, 2005).

In terms of cultural maintenance, Gaunt (2006), in her study of jumping rope and hand clap games among African American girls, illustrates how the seemingly simple games are a means of transmitting cultural knowledge of musical practice along with values and beliefs illustrated by the lyrics. The forms of, and the content conveyed in, these games extend in unbroken continuity to pre-slavery roots in Africa. The process occurs in a fun and comfortable way, and those conveying or receiving this knowledge would rarely be aware of the importance or antiquity of the process. 
As mentioned above, arts, music, and dance played major roles in the lives of indigenous peoples. In Africa, music and dance were particularly salient factors in maintaining social cohesion and negotiating transitions (rites of passage). According to Farr (1997), "it also provided a mechanism for communal coping- an expressive outlet with restorative benefits to ensure healthy adaptive functioning, particularly under difficult circumstances" (p. 184). The music, the dances, and their functions travelled from Africa with the slaves brought to other countries, providing the same psychosocial benefits in new lands. This extends not only to Europe and the Americas, but also across the Indian Ocean (notably to Sri Lanka, which retains a surviving African sub-culture) during Portuguese (1505-1658), Dutch (1658-1796), and British (1796-1948) colonial eras (de Silva Jayasuriya, 2006; Farr, 1997). In the United States, rap music (an extension of African musical tradition) provides a contemporary outlet for expression of rebellion against continued prejudice and suppression (Kopano, 2002), continuing to serve functions similar to those served before Africans were enslaved and exported, but having been filtered through church music, blues, jazz, soul, and funk along the way. It is for this reason, Farr (1997) explains, that hip-hop dance therapy is effective in treatment of at-risk African American adolescents. In Hamilton, New Zealand, Guerin, Fatuma, and Guerin (2006) observed Somali refugee women's groups. The women's participation in parties and celebrations involving music and dance, "was easily seen as contributing positively to their mental health and well-being, and their feelings of belonging in their new country, as they changed with the better position of the community over time" (p. 4).

Among Chinese immigrants in Japan, their "dance parties," utilizing particular musical content, provide affirmation of identity and sense of belonging 
while also providing a venue in which to garner social capital and support, and to further various individual purposes (Farrer, 2004). Similarly, the tango subculture in New York City is a means of accessing social networks and resources among Argentineans in the city (Viladrich, 2005). These activities, in cultural contexts far removed from their origins, serve functions for these subcultures which ameliorate issues common in migration (e.g., Jablensky et al., 1994; Marsella \& Ring, 2003).

Music provides a means of increasing social cohesion among Latinos in Toledo, Ohio, helping to unify a population that is actually diverse in countries and cultures of origin (O’Hagin \& Harnish, 2006). It has also been observed to provide a means of connecting to other ethnic groups (including the dominant group) in communities. The researchers were told that experience of Latino musical festivities was perceived, by their respondents, to help overcome the "Taco Bell" image of Latinos. Inclusion of Latino music elements in school curriculum was seen by them to help to increase intercultural understanding. Similarly, inclusion of Cape Verde music in Portuguese curriculum reduced skin colour based prejudice among children less than ten years of age (Sousa, Neto, \& Mullet, 2005). In these ways, the musical events described served adaptive functions both inter- and intra-culturally.

The lists of issues and risks in migration mentioned in the preceding section are remarkably opposite to the potential beneficial effects of traditional and ethnic arts. These arts happen in particularly embedded cultural setting and are laden with cultural content (e.g., de Silva Jayasuriya, 2006; Geurin et al., 2006; Obeng, 1997). Their re-enactment forms a core arena of community cohesion and cultural transmission for cultures in situ (Hurley-Glowa, 1977) and especially in migration (Goodman, 2005; Geurin, Fatuma, \& Guerin, 2006; James, 1999; de Silva Jayasuriya, 2006). In migration, traditional musical and artistic practices both 
continue (Gaunt, 2006; Obeng, 1997; Waseda, 2005) and change to reflect the migration experience (de Silva Jayasuriya, 2006; Valdez \& Halley, 1996).

Despite the obviously large quantity of cultural information within music and the implications of cultural performance participation, very little psychological research has been conducted regarding the role of arts in acculturation. Study of cultural products and producers has been the academic domain of anthropology, ethnomusicology, and various culture-specific studies (Hargreave \& North, 1999), and these disciplines are not geared to investigate individual and group level psychological processes. From the scattered bits of psychological inquiry that have transpired, traditional or ethnic music and dance, particularly, have been shown to strengthen or maintain ethnic identity (Waseda, 2005), alleviate anxiety and homesickness (Son \& Kim, 2006), increase social bonds, and facilitate transmission of cultural values (Hargreave \& North, 1999). The present research explores the potential for a range of new theoretical implications in psychology by investigating arts practices and experiences, especially in regards to the reshaping of identity and social structure in intercultural contact and resulting acculturative processes.

\section{Arts, culture, and psychology.}

Culture is a traveller, still negotiating its entrance into the walled city of psychology (Valsiner, 2009, p. 5).

The previous sections set out ways in which arts have historically (and prehistorically) served as primary sources of the information from which culture is made, the means by which culture is maintained and transmitted, and contexts within which cultural activities take place. These are areas of import to the 
individual psyche within culture. How, then, can these arts and activities be related to the discipline of psychology and psychological discourse of acculturation?

Though culture in general was suggested as an area worthy of psychological research as early as 1904 (Jilek, 1995; Marsella, 1994), it has been addressed primarily in more recent decades. Entry of non-Europeans into the discipline, as well as inter-cultural experiences of certain American and European psychologists, has gradually increased attention on culture (Kashima, 2000; Marsella, 1999; Marsella \& Pedersen, 2004). The discipline, however, has not yet widely examined those elements which are most commonly perceived as "cultural," such as art, music, ritual, customs, and food (Matsumoto, Weissman, Preston, Brown, \& Kuppersbusch, 1997). Arts are, after all, considered to be an affective rather than a cognitive set of processes and products which seem to be perceived as somewhat unscientific and unobjective (Bresler, 2006), and artists deal in intangibles which are not easily quantified. New methods of research are needed to reach more deeply into the hearts and minds of the remaining range of some 5,000 unique cultures (Marsella \& Pedersen, 2004), but cultures are constructed of shifting constellations of beliefs, behaviours, values, and world-view. Those nebulous regions may actually be most clearly explicated in the domains of arts and artists. In these particularly cultural processes, one may find, as neatly arrayed as possible, the systems of meaning, concepts, and shared understandings of a culture, packaged within the actual institutions, practices, and symbols of a given culture as they are habitually shared and transmitted (Frith, 1996; Hargreave \& North, 1999; Kashima 2000; 2008; Turino, 1999). 


\section{Current literature of arts and psychology.}

There is a curious relationship between arts and psychology as represented in the literature. On one hand, the discipline is happy to use artistic images and music as stimuli in experiments, but frequently with an alarming lack of definition. In neuropsychology, for instance, Lundqvist, Carlsson, Hilmersson, and Juslin (2009) undertook a Functional Magnetic Resonance Imaging (fMRI) study mapping brain activation in emotional reactions to "happy" or "sad" music without defining any parameters by which happiness or sadness were determined, and without specifying the culture or genre from which the music was drawn beyond the description "singer-songwriter." Gypsies in Transylvania play the same songs at weddings and funerals, leading to some difficulty in creating an operational definition of "happy" or "sad" music within that culture (Baraldi, 2009), and they certainly would have members who write and sing songs. According to Juslin and Västfjäll (2008) "researchers have studied musical emotions without regard to how they were evoked, or have assumed that the emotions must be based on the 'default' mechanism for emotion induction, a cognitive appraisal" (p. 559). Their research revealed a complex process involving six additional mechanisms: brain stem reflexes, evaluative conditioning, emotional contagion, visual imagery, episodic memory, and musical expectancy. Cognitive psychology and neuropsychology have contributed significant research into perception of arts and neurological processes therein, though virtually all of this work involves only arts of the Western world (Hallam, Cross, \& Thaut, 2009). The remaining available literature in psychology focuses primarily on therapeutic uses of arts and music with growing evidentiary bases (cf. Silverman, 2010). There is also a lesser body of research on characteristics of individual artists and on personal preferences in music (Boer, 
2009; Elicker, 1999). Inter- and intrapersonal functions of arts remain largely the domain of anthropology or sociology.

Within the domain of therapies and treatments, there is a body of evidence of benefits of arts participation developing, from which examples are presented below. Direct participation in dance has been shown to improve neurotransmitter balance (Jeong et al., 2005). Koch, Morlingaus, and Fuchs (2007) used dance to reduce depression in psychiatric patients. Choi and Lee (2007) utilized folk songs and other cultural components to create a more comfortable therapeutic environment for treatment of Korean women with Hwa-Byung, a very difficult culture-bound illness usually translated as anger syndrome. Creative arts provide a method of expression in therapeutic situations, such as Kagan's (2004) use of creative arts, drawing, storytelling, and music with high-risk children who had suffered abuse or neglect. Catherine Phillips (2007) used an arts-based approach in her qualitative cultural analysis of pain experiences and daily in her social work practice. Puig, Sang, Goodwin and Sherrard (2006) found creative arts therapies efficacious in treatment of psychological implications of breast cancer. Kobin and Tyson (2006) found hiphop an effective means to facilitate empathy between client and patient in their work with inner-city clients. The mechanisms by which these effects were created, whether they are interpersonal or some direct result of the arts themselves, were not explicitly set forth in these articles.

\section{Psychology and music in particular.}

Of all the arts, psychology seems to take an unusual interest in music over other arts $(12,581$ journal articles in a search of PsycInfo using the term "music" on May 20, 2009), and perhaps rightly so, since music is (at a minimum) one of few trans-cultural universals (Boer, 2009; Zentner, Grandjean, \& Scherer, 2008). Boer 
(2009) describes two broad domains of music psychology: “a) research on musical performance (i.e., music making), and b) research on musical reception (i.e., music listening)" (p. 3). Hargreaves and North (1999) place psychological functions of music as falling into domains of cognitive, emotional, and social functions. The cognitive domain examines perception and memorization of music, as well as the triggering of memory by listening to music. The emotional domain regards the expression and induction of emotions through music. In social functions, music has been observed to foster the construction and expression of identity and values and the support of interpersonal relationships. There is very little research addressing the social functions and virtually no research which addresses issues or variables of music on a cross-cultural basis (Boer, 2009).

Much of previous research involving music has been a search for particular benefits of listening to music. The "Mozart Effect" has received wide popular attention, primarily in terms of supposed benefits of listening to the music of Mozart. Public perceptions of effects far exceed any demonstrable evidence. Actual evidence primarily supports improvement of task efficacy due to increased arousal, or indicates a temporary improvement in spatial relations testing response (Jones, West, \& Estell, 2006).

Certain neuro- or physiological effects have indeed been observed in responses to musical stimuli, one effect being the differentiation of brain areas activated between professional musicians and non-musicians (e.g., Sacks, 2008), though variability across non-Western musics and musicians has not been specifically measured. Murrock (2005) postulates that musical vibrations cause the release of hormones and neurotransmitters, and that these releases produce physiological effects, yet there is no hard data offered in the article, and little of the 
published research goes beyond supposition of belief. Medical research has, however, shown a strongly significant effect of music on induction time of sedation, intra-operative levels of propofol and satisfaction with peri-operative care among women having hysterectomies (Zhang, Fan, Manyande, Tian, \& Yin, 2005). In her study of nostalgia, Batcho (2007) elaborates extensively on the psychological meaning and importance of nostalgia and uses songs as the stimuli in her experiments, yet she makes no suggestions as to why she chose music as the stimulus, or as to the relations of music to the other inter- and intrapersonal functions of nostalgia. Maher (1976) observed differences between Indians (from the Indian subcontinent) and Canadians in their responses to musical intervals, exploring potential cultural mechanisms and calling for further research, but subsequent credible intercultural research has been rare. As described above, features have certainly begun to be charted on the topography of psychological and physiological effects of arts practices and experiences, but vast regions remain unexplored.

\section{Benefits of arts programs.}

A related area in which a body of research has begun to slowly manifest regards arts-based school and community programs, which have begun to appear with increasing frequency over the past few decades, rooted in the belief that they provide multiple benefits to participants (e.g., Clawson \& Coolbaugh, 2001; Stickley, 2007; Mason \& Chuang, 2001). A number of governments have begun overarching programs to foster such activities, including the Arts and Health Agenda in Great Britain (Stickley, 2007) and the YouthARTS development project in the United States (Clawson \& Coolbaugh, 2001). Thorough research of high quality that actually measures effects and outcomes is surprisingly rare, much of the 
evidence presented being anecdotal (Rapp-Paglicci, Rowe, \& Ersing, 2006). Stickley (2007) comments, "until the right kind of evidence is produced, the evidence remains marginalized and will continue to be subject to criticism” (p. 336). The subject draws strong (if uninformed) feelings from both supporters and detractors, insisting that arts participation is either crucial to well-being or a complete waste of time and money respectively (Heath, 2001; 2004).

The current body of research does indicate positive possibilities, though much of the evidence remains more anecdotal or (at best) qualitative, with quantitative studies being few and frequently having methodological flaws such as lack of randomization or controls (Clawson \& Coolbaugh, 2001; Mason \& Chuang, 2001). Fauth, Roth, and Brooks-Gunn, (2007) found that participation in the arts was associated with lower average substance abuse and attenuated increases in usage over time, but that study looked very broadly at general participation in a variety of arts activities without specification as to quality or type of programs or degree of participation. Mason and Chuang (2001) studied African American youth participation in an African arts program and found significant differences in selfesteem, social skills, and in leadership competencies in a post-test. The sample size, however, included only 25 each for participation and control groups.

Heath and Roach (1998) found that students who participate in arts programs are more likely to participate in science and math fairs, to win awards for attendance, and to win academic achievement awards than those who do not participate in arts, though Heath $(2001 ; 2004)$ remains particularly vocal about the need for more specific investigation. A national evaluation of the YouthARTS Development Project (Clawson \& Coolbaugh, 2001), across several U. S. metropolitan areas, found that the program had the following effects: 
The programs achieved the desired immediate effects on participants (e.g., increased art knowledge and improved program-related skills such as communication and cooperation).

The programs had the desired intermediate effects on the attitudes and behaviors that affect delinquency and academic performance (e.g., healthier attitudes about drug use, increased positive peer and adult associations, improved self-esteem).

The programs had the desired long-term impacts on juvenile delinquency and academic performance (i.e., decreased court referrals and increased academic achievement). (online)

As with many programs, attrition rates are high and data is difficult to collect. Other program evaluations mentioned increased self-esteem, math and reading skills, conflict resolution skills, and more positive relationships (RappPaglicci et al., 2006). As with therapeutic and other benefits of arts, the mechanisms by which these benefits occur have not been specified: are they based on social networks, on intrinsic value of arts practice, or some combination of these and other factors?

\section{Synthesis of Paradigms and Emerging Questions}

Arts have played major roles in shaping and defining human lives and lifestyles throughout human existence, providing the information by which worldview and identity are shaped as well as contexts for social interaction and resulting cohesion. Despite the obvious possibilities of how and why artistic processes and products influence psychological conditions within cultures, arts remain a largely unexplored area in psychology. Study of cultural products and producers has been and remains the academic domain of anthropology, ethnomusicology, and various culture-specific studies (Hargreave \& North, 1999), and these disciplines are not geared to investigate individual or group level psychological processes. 
Study of acculturation in psychology has established that there are potential risks and various potential outcomes of the process, and it is widely agreed that a strategy including elements of both cultural maintenance and dominant culture accommodation seems the preferable course (e.g., Berry, 2007; Ward, 2001). Psychology has also discussed ways in which context affects the process and outcome in terms of family, community, and larger social environment, including aspects of support for identity and potential reduction of stress (see Ward, Fox, et al., 2010 for a review of acculturation context research). The discipline has not, however, addressed the dynamics of cultural transmission in contextualized social activities, or examined the dynamics of cultural formation, maintenance, and transformation (Kashima, 2008), processes which may be important in understanding the heritage culture maintenance aspects of acculturation.

From the scattered bits of inquiry that have transpired related to arts and acculturation, music and dance have been shown particularly to lead to positive psychological consequences including the maintenance and strengthening of ethnic identity (Waseda, 2005), alleviation of anxiety and homesickness (Son \& Kim, 2006), increased social bonds, and facilitated transmission of cultural values (Hargreave \& North, 1999). Visual and literary arts are also laden with cultural content. There may be a range of new theoretical implications from research into arts and psychology, especially in regards to the reshaping of identity and social structure in intercultural contact. As central elements of culture, study of arts practices in acculturation may explicate aspects of cultural and inter-cultural processes as yet unaddressed in psychological literature.

In the shifts of human existence of recent years, importance of arts for creation and maintenance of well-being has been increasingly demonstrated. One 
can certainly conjecture that trends in research will continue to find general benefits arising from the practices of arts of all sorts. Are there particular psychological benefits from arts practices within traditional and acculturating ethnic groups? As described in the earlier section dealing with arts and psychology, non-Western cultures play a small role in arts-related research and discussion of the psychological effects of arts in cultural adaptation is virtually absent. As described, acculturating minority and immigrant groups face the greatest challenges in the context of globalization and migration. It may be that arts practices provide particular resources for the formulation of healthy sense of identity, understanding of roles and behavioural norms, and maintenance of sense of communitas within a given cultural milieu, and potentially in milieus of acculturation. It must be established whether there are differences between artistic media or cultural groups in these processes. It may be that artistic practices have implications for well-being in migration and acculturation, but this is an area largely absent in psychological research.

Three studies were planned for this research. The first is qualitative, inquiring into the perceptions of arts practitioners from various cultures regarding the effects and implications of their practices in their experiences of migration or minority adaptation. This study is intended to discern how artists practicing traditional or non-traditional arts perceive and express the personal, interpersonal, and cultural effects of arts practices in acculturative settings. That study is followed by two quantitative studies. The first of those examines arts practices within Polynesian cultures in New Zealand to determine whether there are differences between those youths who practice traditional arts, Western arts, or no arts. The data from that study was also used to test a model of the processes by which traditional arts practices may influence well-being. The final study expands upon 
the observations from the previous two studies to examine components of traditional arts participation. A scale by which to measure factors of arts participation across cultures was created and tested for construct validity. This third study also crossculturally tested the model of patterns of benefits for well-being established in the second study. In addition to confirming certain paths in the model, the crosscultural sample provides some evidence of generalizability of the concepts and benefits of traditional arts participation. 


\section{Chapter 2: Artists' Views of Arts and Acculturation}

In this section, the questions to be answered focus upon arts in the lives of artists who are experiencing acculturation: how do artists perceive themselves to be psychologically affected by their practices during this process: do their practices affect their acculturation process and adaptation outcomes, and what are the effects of their practices on the quality of their relationships with those around them?

The previous section established the long importance of arts in human existence and illustrated a number of ways that arts remain important in the current world situation. It is known that humans have engaged in arts practices for millennia, music probably evolving in tandem with speech, and visual arts appearing tens of millennia before agriculture. Disciplines such as anthropology have demonstrated that ancient cultures may be understood to some degree through the visual content of the objects they left behind, these forming a record of the semiotes by which those ancients conveyed their experiences, histories, and beliefs. Culture is still maintained and conveyed via memetic or semiotic signs and symbols that form the content of arts in all cultures, though the content and relevance to cultural systems have changed with modernization and globalization, with traditional arts widely being replaced by commoditised Western arts. In the massive cultural flux of migration and inter-cultural contact, do traditional or ethno-cultural arts continue to play their historical roles of cultural maintenance and transmission, and can they continue to help shape the ways people understand and experience their cultures during acculturation processes?

The introduction also presented the social level functions of arts experience or participation, with more traditional cultures having been observed to utilize 
symbols, music, and dance to reinforce social cohesion and continuity. These functions have been observed to be especially strong in ritual activities and contexts. In Westernized cultures, these functions continue to some degree, though in altered form, partly due to the decontextualization and secularization of the activities. Changes in social networks are among the risks in migration and acculturation. Does participation in traditional or ethno-cultural arts during these transitions provide or enhance social resources and connections?

Arts participation in general has been shown to provide a range of benefits to participants individually. There is growing evidence for benefits in both clinical and public program settings. In clinical settings, these would include a range of cognitive benefits and reduction in symptoms of psychopathology (e.g. Belgrave, 2009; McFerran, Roberts, \& O'Grady, 2010), though clear evidence of effects is rare (Silverman, 2010). The therapeutic benefits may occur in non-clinical situations, but associated literature is largely limited to diagnosable cases, thereby, perhaps, omitting potential prophylactic benefits. The small literature regarding public arts programs suggests that they may provide benefits including increases in social skills and self-esteem, but that body of research is too small for firm conclusions to be drawn even for majority groups. There may be particular individual level benefits from participation in the arts of one's own culture, and these may be particularly beneficial in acculturation, but this remains untested.

In general, the subject of arts in acculturation has not yet been widely examined in psychology, though the fields of anthropology, ethnic studies, and sociology have examined the subject within their paradigms. Questions remain as to whether there would be any psychologically relevant difference between art forms or if any arts practice would be equally beneficial. Also, the matter of cultural 
relevance of the art form is unknown: does it matter if the art is of one's own culture, or are all arts equally beneficial? In other social sciences which have some literature regarding arts practices in acculturation, the issue of cultural relevance of arts is assumed: of course O’Hagin and Harnish's (2006) Latino communities played Latino music: no other music would be relevant to the enculturative or connective ways those festivals affected the communities. There is no literature, however, of cultural consonance of arts leading to better psychological outcomes, or whether participation in Western arts, for instance, would serve the same purposes.

For these reasons, Study 1 was undertaken to investigate potential differences between practices of traditional or ethno-cultural arts and of contemporary, Western, or culturally neutral arts by ethnic and/or immigrant artists in situations of acculturation. This was intended to identify aspects of arts practice considered by the artists to be most salient and relevant to themselves and their communities in acculturation, and to determine whether possible beneficial functions of arts participation would be specific to a culture or a medium, or would be generalizable across cultures and arts.

\section{New Zealand Context}

This research was conducted in New Zealand, which is a particularly rich environment for study of the processes of adaptation and acculturation. The ethnic landscape of the country has changed dramatically since the alteration of immigration policy in the late 1980's (Liu, McCreanor, McIntosh, \& Teaiwa, 2005). New Zealand's immigration process is not unlike those of other developed countries (e.g., Hoerder, 2006; Westin, 2006), though in New Zealand they are occurring in a particularly constrained time period and, therefore, have a unique intensity. The shift from a largely European population with an indigenous Maori minority to a 
$20 \%$ ethnic immigrant presence has occurred in only 20 years (Liu et al., 2005; Statistics, New Zealand, 2006), while similar processes have been ongoing for centuries in other countries such as the United States (Hoerder, 2006).

\section{The history of migration to Aotearoa (New Zealand).}

The great migrations of Pacific peoples began in the south of China in an ancient period spanning from 50,000 to 25,000 BCE. During this period, they spread throughout the larger islands of Southeast Asia (Irwin, 2008). The more specific migration from whence the Polynesian peoples descended is thought to have begun from the South China Sea and Southeast Asia about four to five thousand years ago, eventually extending from Madagascar in the west to Rapa Nui in the east, Hawai ' $i$ in the north, and Aotearoa in the south (the Maori language name for New Zealand). Somewhere in that process, Polynesian voyagers also went to and came back from South America, bringing the kumura, or sweet potato, which was present in the Cook Islands by $1000 \mathrm{CE}$ and is shared throughout the Polynesian region. Also common throughout these regions are the names for sail, mast, outrigger float, and outrigger boom, which are the technologies that facilitated these sea voyages (Irwin, 2008; King, 2001).

Aotearoa represents the southern extreme of the Polynesian Triangle, an area of some ten million square miles comprising the range of historic Polynesian migration (Kanuha, 2004). According to oral history, the Polynesian peoples have surviving transmitted memory going back at least 800 generations, or 16,000 to 20,000 years (Kame'eleihiwa, 2009). By 1200 BCE, populations had been established in Fiji, in Tonga by 1100 BCE, and in Hawai'i by about 900 CE (King, 2001). These peoples share elements of history, culture, linguistic origins, practices, 
and social processes (Finney, 1994; Kyselka, 1987), though over time the resulting cultures evolved variations in language and unique elements of specific aesthetic styles by island group (King, 2001).

\section{Polynesians in early Aotearoa.}

Most recent archaeological evidence indicates that the Maori began settlement of New Zealand in about 1250 CE (Hogg et al., 2003), though this date is disputed. Earliest estimated dates range from 0 CE to 500 CE (Anderson, 1991; Irwin \& Waldron, 2008; Kirch, 1986). The earlier dates are based on changes to vegetation which may be attributable to human activity, though they may alternately have been the result of natural events (Anderson, 1991; Sutton, 1987). Oral tradition holds that migration was achieved in several waves, travelling by waka, or canoe, in those cases the large, double hulled, ocean-going variety (King, 2001; Taonui, 2008; Walker, 2004). Their descendants are now known as the Maori, describing themselves as Tangata Whenua, or "People of the Land," due to their long presence and deep ties to the environment (Bedford, Ho, \& Lidgard, 2000; Walker, 2004). The term Maori (normal, usual) was not used to describe the ethno-cultural group until the 1840's when they began to use the term to distinguish themselves from the Europeans as Tangata Maori, "normal people" (King, 2001).

As the Maori settled Aotearoa, they diverged culturally to some extent from other Polynesians, primarily due to differences of climate and available organic and mineral resources. This required different methodologies of food and material culture production. Further variations within the broader culture emerged in the varying climates of the 1500 kilometre expanse of the land mass from north to

south. For all groups, cultural life centred on iwi (tribe) and hapu (sub-tribe), connected by ancestral lineage and waka origins. These groups cooperated to 
varying degrees in trade and resource gathering, as well as in military alliance against other groups. Inter-group fighting over land, resources, and social infractions continued well into the $19^{\text {th }}$ century. Social hierarchies were relatively level, with distinction by ruling or commoner class. Distinction by merit was primarily achieved by prowess in battle, though artistic talent was highly valued in areas including visual arts of carving (wood, bone, shell, and stone), weaving, and singing (waiata) (King, 2001).

The Maori pre-contact cultures and sub-cultures were highly complex, including well developed systems of agriculture and astronomy as well as elaborate material culture. The former were taught primarily to the young men in a formalized educational context of whare wānanga (White, 2001), school-like settings which oral tradition holds have existed continuously back to legendary origins on the fabled island of Hawaiki, the ancestral home of the Maori before migration (Royal, 2008). The material culture of the Maori was extremely sophisticated, especially regarding components of buildings, which are ornately carved to convey visual memes of complex stories and lineages (White, 2001). These are still represented in Marae (Māori sacred meeting and ceremonial houses) in the present day.

By 1887, when White (2001), who lived from 1826 to 1891, published his The ancient history of the Maori, his mythology and traditions, the Maori had begun to realize that substantial parts of their oral histories and detailed legends were being lost to the influence of Christianity (White, 2001) and attrition by mortality (Barclay, 2005). Undoubtedly, this formed part of White's inspiration to chronicle the knowledge he retained. A vast number of stories remain, from primordial creation, to the creation of humanity, to the waka migrations, and onward to the 
present. Their recitation, along with the singing of waiata (chants and songs), continues to convey not only the oral history and mythology of the culture, but also its values and behavioural norms (cf. Walker, 2004; White, 2001).

\section{Maori and Europeans in Aotearoa.}

The first European encounters with the archipelago were led by Able Tasman, a navigator for the Dutch East India Company, in 1642 (Keightley, 2005; Slot, 1992), and by Englishman James Cook in 1769 (Beaglehole, 1961). Tasman's ship had a brief, lethal encounter with Maori warriors and declined to land. Cook sharply limited his contact with the land and people, experiencing hostility which he found less troubling than Tasman, but definitely not welcoming. His more measured response, however, began a process in which trade between Maori and Europeans gradually became common (White, 2001).

By 1792, whalers had begun to stop in harbours to re-supply, and sealers were spending months at a time "harvesting" oil and fur. The first missionary arrived in 1814. Increasing numbers came to trade in flax and timber (J. Phillips, 2008). Permanent settlement gradually began between 1800 and 1840 , primarily by English speaking whalers, traders and missionaries from the British Isles. By 1839, their numbers were estimated to be less than five percent of the population, Maori comprising 85,000 at a minimum, with Europeans at only 2,000 (Davidson, 1984; Liu, Wilson, McClure, \& Higgins, 1999; Phillips, 2008). In 1840, the first shiploads of colonists sent by The New Zealand Company arrived, marking the beginning of intensive British settlement and intensive acculturative experiences between Maori and Europeans. 


\section{Te Tiriti o Waitangi (The Treaty of Waitangi).}

Unlike other British colonial conquests, the eventual process of permanent European settlement in New Zealand was established by a series of treaties with the indigenous Maori population rather than overt military action, probably because the Europeans were so drastically outnumbered at that time. The process eventually did include considerable use of military force, questionable and overtly illegal seizures of lands, and subsequent generations of social and economic repression of the Maori (Walker, 2004). In 1840, a treaty was proposed by the new British inhabitants, under Consul William Hobson. It was one of several of that time, but one which is considered a landmark because it granted sovereignty to the Crown. It was signed by a number of iwi leaders (though not all by any means), who were assured the document was a protection, granting them perpetual control over their physical and cultural assets, as well as full rights as citizens of the British Empire. The English and Te Reo Maori (Maori language) versions contain significant and probably intentional discrepancies, principally around uses of the Maori words tino rangatiratanga (sovereignty, self-management, self-determination) and kawanatanga which comes from the Maori adaptation of the term governor. In the Maori version, the Crown was granted kawanatanga, with Maori retaining tino rangatiratanga. The English version ceded political dominion over the land and people to the Crown. The Maori culture had no equivalent concepts of ownership by which to evaluate the document, or overarching political structure by which to enforce adherence by the British (Barclay, 2005; Liu et al., 1999; Walker, 2004; White, 2001). The treaty was broken by Crown subjects within 72 hours, but the document currently provides a legal basis for claims for redress in modern courts (Barclay, 2005; Walker, 2004; White, 2001). 


\section{Continued settlement and immigration.}

Following the signing of Te Tiriti o Waitangi, a growing stream of immigrants began to arrive, primarily from the British Isles. The New Zealand Company began offering free fare to necessary labour and trades-people, though many fare paying passengers also came. These were a mixture of people seeking land ownership and greater status than was possible in the rigid British system, mixed with the black-sheep of aristocratic families sent to make something of themselves in a place where previous acts were less relevant. In the years from 1840 to 1870 , the European population swelled to 250,000 (Phillips, 2008). Continued disagreements over land rights and British abuses of the Maori led to wars from 1860 to 1872 (Dyson, 2005; Nayar, 2009; Statistics NZ, 2006).

Discovery of gold in 1861 led to a new, slightly different wave of migration, that of miners, who were mostly unmarried males from the British Isles, though small numbers came from other European countries. Also included in this wave were Chinese, primarily from Guangdong province, 2,641 appearing in the census of 1871 (O’Connor, 1990; J. Phillips, 2008). Other ethnicities were added as a small percentage of Indian and other Chinese inhabitants began to arrive in the latter $19^{\text {th }}$ century (cf. Liu et al., 2005; Nayar, 2009; O’Connor, 1990). Attempts were made to restrict Asian immigration, primarily from China and India by legislation in 1881 and 1896, though as citizens of the Empire, Indians could not be excluded. Despite restriction by language requirements in 1899, a stream of Indians continued to immigrate (McKinnon, 1996; Nayar, 2009).

Following World War II, Europeans from non-British countries immigrated in larger numbers, with skilled Europeans receiving government assistance for resettlement during the 1950's (Ip, 2003), but including a larger numbers of Asian 
immigrants than entered before the war (Nayar, 2009). The Dutch, including Dutch Indonesians, became a significant percentage of the population, with over 20,000 present by 1971 (Phillips, 2008). A growing number of Pasifika peoples began to be admitted, primarily to address labour shortages (Loomis, 1990), with 65,000 reported in the 1976 census (Pearson, 1990).

In 1986, immigration laws began to be changed from a preference for Europeans to a system based on points for skills and education, regardless of ethnic or national origin. This resulted in a large influx of immigrants, primarily from various parts of Asia, but sill including Pacific Islanders (Bartley, 2004; Liu et al., 2005; Macpherson, 2004; Trlin \& Watts, 2004). Augmented by emigration of New Zealand born residents to other countries, a dramatic transition has occurred in just over two decades, wherein nearly $22.9 \%$ of current residents were born elsewhere (Ministry of Social Development, 2008) making the country a unique and dynamic locale for acculturative processes.

The largest ethnic groups currently residing in New Zealand (4,027,947 total population in the 2006 Census Night Count) are New Zealand European (NZE); Maori (565,329); Asian (358,521), predominantly Chinese $(147,594)$; and Pacific Islander $(265,974)$ according to the 2006 Census Night Count (Statistics New Zealand, 2006). Estimated total population by ethnicity is presented in Table 2.1.

Table 2.1

Estimated New Zealand population by ethnic group

\begin{tabular}{lc}
\hline Ethnic group & 2006 estimate \\
\hline NZ European \& other Europeans & $3,213,300$ \\
Maori & 624,300 \\
Asian & 404,400 \\
Pacific Islander & 301,600 \\
Middle Eastern, African, Latin American & 38,600
\end{tabular}




\section{Biculturalism and multiculturalism.}

Throughout the history of New Zealand as a colony and a country, an official system known as "biculturalism" developed, in which virtually all inhabitants were presumed to be of Maori or British descent. The two groups are legally bound to cooperation by Te Tiriti o Waitangi, though inequities, disparities, and contested issues between Maori and Pakeha (British Europeans) have continued from signing into the present (Dyson, 2005; Walker, 2004). While advances have been made to address socio-economic inequities and to preserve Maori language and culture, the situation remains tense (Walker, 2004). A 2004 legislative act overturned jurisdiction of the Maori Land Court in matters pertaining to the seabed and foreshore (extending from high tide mark to limits of territorial waters) and placing ownership and jurisdiction with the Crown (Kirkwood, Liu, \& Weatherall, 2005). In 2007, government raids took place in which 17 members of the Tuhoe $i w i$ were arrested as suspected terrorists, setting relations back 100 years to the days of the violent raid on the religious community at Parihaka according to Maori Party leader Pita Sharples (NZ Herald staff, 2007; see also Walker, 2004 regarding Parihaka).

The ongoing post-colonial governmental inequities and disagreements are reflected in the country's demographics. The 2006 median annual income for Maori adults remained nearly $20 \%$ below the national average of $\mathrm{NZ} \$ 24,400$ for the entire population at NZ\$20,900 (Statistics New Zealand, 2008). They are also underrepresented in educational achievement, with only six percent of Maori students continuing to university education, compared to $12 \%$ in the general population (Hui Tamata, 2005).

With a lack of resolution and continuing issues in the bicultural paradigm, the growing populations of other ethnic groups and resulting multicultural situations 
present additional challenges. Despite having settled in New Zealand for well over a hundred years, Chinese migrants have constantly faced strong discrimination the entire time, and the Maori population is particularly concerned about the impact of the so-called new, especially Chinese, migrants to New Zealand (Ip, 2003; Ward \& Masgoret, 2006), given no achievement of equity in their own situation. The same issues apply to the Indian population, despite a similar period of immigration and generations born and raised in the country (Nayar, 2009). Lacking status as signatory groups to Te Tiriti o Waitangi, immigrant groups face issues of cultural, social, and legal legitimacy, with prejudice from all sides (e. g. Liu et al., 2005; Nayar, 2009). In this milieu, all groups face issues of acculturation and psychosocial adaptation to differing peoples around them (Liu et al., 2005).

In the past two centuries, New Zealand has gone from indigenous culture to a supposedly bicultural colonial setting, followed by the sudden massive immigrant influx. From barely one out of a hundred people being neither Maori nor European, the number has now rocketed to one out of five in only 20 years. The lack of resolution to Maori-Pakeha relations and the rapid shift to what is actually a multicultural nation, whether or not this is desired by all who live there, make New Zealand a unique and dynamic setting for acculturation. There are centuries old processes ongoing between Maori and European cultures, long-term but virtually invisible Indian and Chinese minority enclaves, a few decades of non-Maori Polynesian immigrants who form one of the poorest social strata, and the abrupt arrival of dozens more cultures who are economically crucial but culturally discomfiting as accommodation of their presence is navigated. Long- and shortterm acculturative processes are happening in context of both very great and lesser cultural distance, the latter being the case in contact between Maori and other Pacific 
Islanders and between groups from regions of Asia. A number of public and private initiatives have been set in motion, including the national Ministry of Maori Affairs, the Ministry of Pacific Island Affairs and the Office of Ethnic Affairs. Private initiatives include the Federation of Multicultural Councils, which has regional councils in many areas of the country. Altogether, New Zealand is a unique and dynamic place for the study of acculturation, ongoing between Maori and Pakeha, and increasing between those groups and more recent arrivals.

\section{Arts in New Zealand.}

There is widespread involvement with arts in New Zealand, both as audience and participants. Creative New Zealand (2008), the government agency responsible for matters related to arts programs and funding, reported that $65 \%$ of their national survey respondents $(\mathrm{N}=2099)$ considered that "the arts are "part of their everyday life" and 79\% stated that arts "help define who we are" (p. 20). For the general adult population, $83 \%$ attended at least one arts event in the preceding twelve months and half actively participate in some art. The range of arts activities included:

- Visual arts: painting; photography; sculpture; web-based/digital art; ceramic-making; filmmaking

- Performing arts (theatre, dance, music): ballet or contemporary dance performances; theatre; concerts; singing or musical performances or events; circuses

- Literature: writers' workshops or literary events; writing poetry, fiction or non-fiction

- Māori arts: art or craft; workshops including carving, weaving or singing; kapa haka or other Māori dance or music activities

- Pacific arts: weaving and other Pacific handicrafts; workshops; carving; traditional dance; choir or other musical activities. (CNZ, 2008, p.17) 
The participation and attendance numbers are slightly higher for Maori and Pasifika peoples when viewed separately, with $88 \%$ of Maori and $86 \%$ of Pasifika having attended an event with the year, and $68 \%$ and $54 \%$ respectively actively participating in some art. For young people aged 10 to 14 years $(\mathrm{N}=1015), 99 \%$ had actively participated in some arts within the past year, with $84 \%$ doing an art outside of school, and $68 \%$ attending an arts event. Most Maori participation takes place in the home $(47 \%)$, and $43 \%$ take part on a Marae (CNZ, 2008). The top five Maori arts activities are waiata (song), karakia (prayer), te reo (language and oratory), kapa haka (music and dance) and poi (balls on rope which are swung during dance or music performance) (CNZ, 2000). Reasons for Maori arts participation appear in Table 2.2. Similar figures are not available for Pasifika arts.

Table 2.2

Reasons for participation in Maori arts (CNZ, 2000, p. 10)

\begin{tabular}{ll}
\hline Reason & \% \\
\hline To pass on skill or tradition & 71 \\
For satisfaction/enjoyment/entertainment & 69 \\
To participate in community activities & 28 \\
As a means of expression & 28 \\
To learn a skill & 13 \\
To meet new people & 12 \\
To overcome stress/anxiety/depression & 5 \\
To help make activities happen & 4 \\
To earn an income & 3 \\
To pass the time & 3 \\
For therapy/rehabilitation & 2 \\
\hline
\end{tabular}

Asian communities (not delineated by country, ethnicity, or region in available studies) generally attend or participate least according to that study (CNZ, 2008), with $77 \%$ attending events and $44 \%$ participating in an art. If they do attend, a CNZ study of Asian arts in the Auckland region found that there are four motivating factors: maintenance of tradition and culture, outward expression and communication, stimulation, and fun family involvement (CNZ, 2007). In actuality, 
certain Asian arts are highly visible and widely attended. The Diwali "Festival of Lights" from India has become a huge event in Auckland and Wellington, with over 200,000 people attending in 2008 (Asia New Zealand Foundation, 2009). Arts in which the interviewees in the Auckland study participated included church choirs, piano, violin, drumming, drawing, ikebana, eggshell carving, calligraphy, animation, musicals, and origami (CNZ, 2007).

In comparison, only $35 \%$ of those surveyed in the US attended a museum or art event within the previous twelve months. Percentages who participate across arts are not available, but the highest rate of participation for a single artistic practice is photography at 14\% (NEA, 2009). Given these figures, the New Zealand population widely and enthusiastically embraces arts by comparison. It appears that New Zealand is uniquely suited for a study of arts practices.

\section{This research.}

With its unique history of intercultural contact and recent dramatic increase in immigration, New Zealand forms an ideal locale for this research. The country has an ethnically diverse population with a variety of community contexts and intercultural situations. As suggested in the preceding section, intercultural issues are salient in daily life. The country also has a great deal of artistic activity, both in ethnic and contemporary/Western domains.

As discussed in the introduction, benefits of arts participation have been studied only to a limited extent and ethno-cultural arts in specific virtually not at all. The questions include whether there are differing psycho-social and cultural implications between different types of arts practice, and whether certain arts may lead to better adaptive outcomes. It is possible that acculturating artists across type 
of arts will believe there are benefits from their practices, but that artists' views may reflect differences in benefits between traditional and contemporary/Western arts, with the traditional category potentially being most effective for achieving adaptive outcomes in acculturation.

\section{Research Design}

The scarcity of previous research on functions of ethnic arts in psychology suggested that an initial inquiry should be qualitative in nature, utilizing the strengths of qualitative methodology to draw out relevant themes and concepts where none have been previously identified (e.g., Patton, 2002). Certainly, there has been inquiry into ethnic arts in other social sciences (see introduction), but whether these arts have implications for acculturation, are associated with psychological processes, or apply to the New Zealand context remains unidentified. This necessitates an initial approach which is creative and exploratory.

While qualitative research should ideally be done in a way that maximizes opportunity for unique and unexpected results to emerge, a complete absence of constraints may yield an overwhelming and incoherent data set (Patton, 2002). Drawing from a number of qualitative streams, two limitations were set: the interviews would target "experts," as described below, and follow a loose set of topical questions (Appendix A).

The present study was limited to professional artists or those recognised within their community as doing a practice with excellence. These artists, it was felt, would provide a more equivalent set of data than if interviews included participants with a range of skill development and experience: inclusion of novices alongside experts could result in misleading differences simply from variation in training and experience. It was expected that experts would have more 
encompassing artistic or cultural knowledge, a basis from which to describe the characteristics of their identity as an artist and as a member of their cultural group, and an informed perspective on their own processes of acculturating in New Zealand. Such experts form a class also most likely to be consciously familiar with the processes of their arts, something which would require time, training, and experience (Ericsson \& Charness, 1994; Machida, 2002; Zimmerman, 1997). There were no limits placed upon the range of ethnicities and art forms of those invited to participate. This was done so that results could be examined for evidence of generalizability across artistic media and across ethnic groups.

The interview guide (Appendix A) was employed to keep the resulting, somewhat conversational interviews, to a similar range of topics, while allowing for some divergence (Braun \& Clarke, 2006; Ryan \& Bernard, 2003; Patton, 2002). The interviews were done in a conversational style for the comfort of participants.

\section{Method}

\section{Participants.}

This phase of research involved 28 interviews with professional artists who were immigrants or ethnic minority members in New Zealand, recruited through government and public organizations. Creative New Zealand (the national arts agency) posted packets with information and consent forms (Appendix A) to relevant artists. From the community directory website of the Office of Ethnic Affairs (the national agency charged with administration of the affairs of nonEuropean, non-Maori, and non-Pacific Islander affairs), all relevant ethnic organizations with email addresses were sent a description of the research and asked if they would provide contact with any ethnic artists in their community. Those 
contacts were then sent the information and consent materials and asked if they had other contacts (snowballing). The result was a concentration of artists in Wellington, Auckland, and Christchurch. Interviews were scheduled at a place of the artist's choice during a limited time period in each city to restrict travel expenses.

The artists who were able to participate are listed below (Table 2.3). Ages are approximate. Participation was voluntary, and participants could withdraw at any time. No compensation was provided for participation. Participants were from China, Korea, Taiwan, India, Fiji, New Zealand, Samoa, Solomon Islands, Kenya, England, Papua New Guinea, Viet Nam, and South Africa. Ethnicities included national identities listed plus Maori and New Zealand Chinese. Art forms included visual arts, writing and acting, film production, weaving, traditional dance, and music (both traditional and modern). To preserve anonymity, names and exact place or institutional designations are replaced with pseudonyms or omitted, respectively.

\section{Procedure.}

The interviews were semi-structured, loosely following the schedule in Appendix A, including questions such as "What do you perceive to be your ethnic identity," "Why is it important to you to practice your art," "What about your art do you consider to be unique to your ethnic group," and "Are your children or young people of your community learning or practicing your art, and if so, how does it affect them?" These formed a set of topics to be raised, and the exact wording and order of queries were not set to allow a natural flow of discourse from participants. Participants were also free to digress to other topics at will. The interview schedule was modified slightly in its order during the interview process. The re-structuring 
principally involved ordering questions differently to facilitate more coherent responses as participants became familiar and comfortable with the type of questions asked (Stewart \& Shemdasani, 1990), and primarily comprised moving questions regarding the term "ethnic identity," which proved to be politically laden for some, to points later in the interview (see Appendix A).

Interviews ranged from approximately 18 to 62 minutes, depending on the amount of information provided, proficiency in the English language, and frequency of digressions. Each was recorded using an audio and/or video device. The resulting 21 hours (approximate) of interviews were transcribed by the author. 
Table 2.3

Study 1 participants

\begin{tabular}{|c|c|c|c|c|}
\hline Pseudonym & Age group & Art form & Origin & Ethnicity \\
\hline Amy & $20-30$ & Traditional dance & China-mainland & Chinese \\
\hline Chris & $30-45$ & Visual art & England & English \\
\hline Sue & $30-45$ & Visual art & China-HK & Chinese \\
\hline Mina & $60-75$ & Traditional dance & Philippines & Filipina \\
\hline Emmie & $30-45$ & Visual art & Fiji & Fijian \\
\hline Timo & $45-60$ & Music/dance & Samoa & Samoan \\
\hline Jim & $75+$ & Visual art & China & Chinese \\
\hline Maxine & $60-75$ & Writer/actor/film & $\mathrm{NZ}$ & Chinese \\
\hline Harvey & $60-75$ & Visual art & South Africa & White African \\
\hline Jean & $45-60$ & Weaving & NZ & Maori \\
\hline Joey & $60-75$ & Sculpture & Samoa & Samoan \\
\hline Jane & $45-60$ & $\begin{array}{l}\text { Weaving/Music- } \\
\text { traditional }\end{array}$ & Solomon Isl & Melanesian \\
\hline Albert & $60-75$ & Director/ Actor & $\mathrm{NZ}$ & Pakeha \\
\hline $\operatorname{Max}$ & $20-30$ & Kapa haka & $\mathrm{NZ}$ & Maori \\
\hline Miko & $20-30$ & Kapa haka & $\mathrm{NZ}$ & Maori \\
\hline Yin & $30-45$ & Film/dance & Korea & Korean \\
\hline Wendy & $30-45$ & Fashion design & Korea & Korean \\
\hline Palani & $30-45$ & Traditional dance & Niue & Niuean \\
\hline Renee & $30-45$ & Writer/actor/film & NZ & Chinese \\
\hline Sana & $30-45$ & Writer/actor/film/radio & India & Indian \\
\hline Sabri & $30-45$ & Actor & England & Indian \\
\hline Ram & $20-30$ & Music-Bollywood & India & Indian \\
\hline Lynn & $45-60$ & Visual art & Papua New Guinea & European \\
\hline Tame & $30-45$ & Kapa haka & $\mathrm{NZ}$ & Maori \\
\hline Devraj & $30-45$ & Indian dance & India & Indian \\
\hline Kioni & $60-75$ & Actor & Kenya & Kikuyu \\
\hline Wallace & $20-30$ & Music-modern & China-Taiwan & Chinese \\
\hline Anna & $30-45$ & Film & Viet Nam & Vietnamese \\
\hline
\end{tabular}




\section{Analytic methodology.}

Broadly, these analyses were approached as a phenomenology in which the artists' views were used to ascertain the ways in which their arts are "experienced, conceptualised, understood, perceived and apprehended" (Marton, 1994, p. 424). Bresler (2006) likens qualitative research to the aesthetic process, as a dialogical process in which one connects to the phenomena (or artwork), makes meaning via dialogical connection within the self, and communicates this meaning to the audience (e.g., academia). As with viewing a painting, proximity is required to appreciate detail. The proper distance, Bresler (2006) posits, is midfield: too far and there is no connection, too close and the object no longer functions as a symbol but rather as a reality. From an aesthetic distance, the observed has the power to evoke ideas and imaginings which, of necessity, arise from the individual viewpoint of the researcher (Bresler, 2006; Geertz, 1988).

Data were analyzed using Thematic Analysis methodology, which is a method by which patterns or themes can be identified, analyzed, and reported (Braun \& Clarke, 2006). The appeal of Thematic Analysis for this project was that its methods and techniques are flexible enough to accommodate the constraints of locating and arranging interviews with the artists, and the diversity of views recorded. Other methodologies such as Grounded Theory, which have very specific rules for analysis, may require repeated interviews as themes and theories develop (e.g., Attride-Sterling, 2001; Braun \& Clarke, 2006; Glaser, 1992; Locke, 2002; Patton, 2002; Schilling, 2006), something which was not practical with these participants due to scheduling and budget constraints in the research. In this data set, all 28 participants were unique: in national origin, ethnicity, gender, art form, age group, and language skills; there were no participants who shared more than two 
categorical designations in common. This, combined with the sheer volume of data collected in many hours of interviews, necessitated great breadth and flexibility to find common themes and sub-themes.

Attride-Sterling (2001) describes the stages of Thematic Analysis as (a) the reduction or breakdown of the text, (b) the exploration of the text, and (c) the integration of the exploration (p. 390). Ryan and Bernard (2003) describe the stages slightly differently as follows: “(1) discovering themes and subthemes, (2) winnowing themes to a manageable few (i.e., deciding which themes are important in any project), (3) building hierarchies of themes or code books, and (4) linking themes into theoretical models" (p. 85). In whatever way the process is broken down, the intent is to allow the researcher to make replicable and valid inferences from the data collected (Krippendorf, 1980).

The data were first analyzed using notes in tape-based method (Stewart \& Shemdason, 1990) to determine overarching themes. The recorded interviews were then transcribed. The transcriptions are verbatim regarding verbal content, though the level of transcription does not include pauses or non-linguistic utterances. For participants who are not native speakers of English, these occurrences tend to obscure rather than enhance readability and meaning, since they are often a product of difficulties of on-the-spot translation thought processes or corrections, rather than being affective expressions (cf. Flick, 2002; Reicher \& Sani, 1998). Transcriptions of the data were loaded into QSR NVivo, version 7.0.247.0 (QSR International, 2006) to organize and categorize data by thematic nodes, which is the term for categorical elements employed in the program.

The process of analysis eventually allowed reduction of data from several hundred pages to the few quotes which are contained in the following results and 
discussion. In the first stage of analysis, all statements were examined without consideration of the expected domains and placed into topical categories with related data. In subsequent stages, these elements were sifted to include only categories related to arts and acculturation and further examined to identify relevance to concepts within psychology. In the final phase of analysis, individual statements were regrouped into themes with correspondence to psychological structures and theories subsequently identified in the general introduction.

\section{Analysis and Discussion}

This section presents the qualitative data results from this study, discussing them simultaneously as they are presented. Not surprisingly, given the broad range of participants and questions, the topics of the total resulting data were diverse, from specific aspects of a particular artistic practice to experiences that could be common to any immigrant or ethnic minority. Also, thematic elements tended to overlap, with statements sometimes falling into more than one thematic element, and with particular processes having multiple implications on multiple levels. As expected, there were a variety of salient differences between traditional/ethnic arts and the other, more modern arts.

\section{Themes.}

The following (Table 2.4) is a complete list of themes and sub-themes extracted from the initial analysis of data: 
Table 2.4

Initial thematic analysis results

\begin{tabular}{|c|c|c|c|}
\hline Theme & Sub-themes & Theme & Sub-themes \\
\hline $\begin{array}{l}\text { Audience } \\
\text { experience } \\
\text { Colonization }\end{array}$ & & Community & $\begin{array}{l}\text { Ethnic community } \\
\text { NZ community }\end{array}$ \\
\hline Economics & & & Global \\
\hline $\begin{array}{l}\text { Effects of doing } \\
\text { art } \\
\text { Nature }\end{array}$ & & Ethnicity & Commonalities \\
\hline Viewpoint & & & History and tradition \\
\hline What is art & & & Cultural maintenance \\
\hline Youth & & & Language \\
\hline Adaptation & Internal conflict & & Values \\
\hline \multirow[t]{8}{*}{ Arts practice } & $\begin{array}{l}\text { Accreditation } \\
\text { Professional status }\end{array}$ & Ethnic identity (EID) & $\begin{array}{l}\text { Effects of arts on } \\
\text { identity } \\
\text { EID concept contested }\end{array}$ \\
\hline & Economics and art & & Identity conflicts \\
\hline & Advantages of ethnicity & & Integrated ID \\
\hline & Changes in technique & & Pakeha identity \\
\hline & Colour & & Assimilation \\
\hline & Responsibility & Generations & Family \\
\hline & Politics and art & & Offspring \\
\hline & Subject matter & & Perceptions \\
\hline \multirow[t]{4}{*}{ Transmission } & Learning the art & & $\begin{array}{l}\text { Intergenerational } \\
\text { relations }\end{array}$ \\
\hline & Family & $\begin{array}{l}\text { Motivations/reasons to } \\
\text { do art }\end{array}$ & Accolades \\
\hline & Teachers & & Communication \\
\hline & Teaching & & $\begin{array}{l}\text { Convey culture and } \\
\text { history }\end{array}$ \\
\hline \multirow[t]{3}{*}{ Styles } & Learning the art & & Politics \\
\hline & $\begin{array}{l}\text { Family } \\
\text { Teachers }\end{array}$ & $\begin{array}{l}\text { New Zealand } \\
\text { experience }\end{array}$ & $\begin{array}{l}\text { Changes in ethnic } \\
\text { landscape } \\
\text { Economics in NZ }\end{array}$ \\
\hline & Teaching & & Prejudice \\
\hline
\end{tabular}


Ultimately, the data were reduced on strict criteria of relevance to arts and acculturation, with attention to potential psychological effects around the topic. Comments about Economics (in general) and Viewpoint (artistic) were not germane to arts as related to acculturation, ethnicity, or psychology. Comments regarding Colonization did not contain reference to arts. Nature, while fascinating, included only two statements, also not germane to acculturation or psychology. Colour was also a fascinating subject in visual arts, but with only two remarks, both regarding aesthetic rather than acculturative topics, could not be considered relevant for inclusion. Prejudice was a concern for many participants, but was a general phenomenon not specific to arts, though a reverse effect of prejudice (Advantages of ethnicity) was mentioned by two participants in terms of attention for their work and access to funding. Language was of concern to many participants in the sense that they wished their progeny to know their heritage language, but the subject was unrelated to art and generally vague in expression. Several participants discussed the nature of art in general (What is art), but this would be a subject more suited for an investigation of aesthetics. Responsibility of the artist was seldom mentioned, and then mostly philosophically, except in matters of cultural preservation and maintenance. Accreditation was mentioned only in regards to New Zealand bureaucratic processes, excepting once in terms of exclusion prior to garnering New Zealand based credentials. The theme of Styles was not related to matters of acculturation or ethnicity for non-traditional artists or was subsumed within themes of ethnic identity for traditional artists.

The remaining themes were winnowed again into other, more elegant categories. The Economics of performance and sales in New Zealand was pared down to statements related only to inter-ethnic relations, given that all artists face 
issues of compensation and survival. Comments related to Youth primarily fit well into Cultural Maintenance and Inter-generational categories. Some comments from Adaptation and Internal conflict are included, along with statements from Effects of doing art. Remaining topics were categorized within Community and social processes and Individual level concepts in arts participation.

Table 2.5

Second revision of themes and sub-themes of arts participation

\begin{tabular}{l|c}
\hline Community and social processes & $\begin{array}{l}\text { Individual level concepts in arts } \\
\text { participation }\end{array}$ \\
\hline $\begin{array}{c}\text { Cultural maintenance and transmission } \\
\text { Cultural evolution and change }\end{array}$ & $\begin{array}{c}\text { Ethnic identity } \\
\text { Informing identity }\end{array}$ \\
Social networks & Well Being related concepts \\
Intergenerational harmony & Self-efficacy \\
Intra-ethnic community cohesion & Resilience \\
Inter-ethnic connection & Self-esteem \\
& Collective self-esteem (CSE) \\
\hline
\end{tabular}

This resulted in a somewhat theory-led presentation which did not match the flow of the data. A further winnowing and reorganization followed, still focusing on topics specifically related to arts and psychology in acculturation context. The resulting themes and sub-themes are listed in Table 2.6. The ordering of the thematic material as presented below progresses roughly from the very personal to the broadly societal. 
Table 2.6

Final themes and sub-themes of arts participation

\begin{tabular}{ll}
\hline Theme & Sub-themes \\
\hline Why we create: personal motivations & \\
Arts and coping & \\
Identity & Creating identity through art \\
$\begin{array}{l}\text { Cultural maintenance, transmission and } \\
\text { change }\end{array}$ & Cultural survival \\
& Cultural and artistic change \\
Social connections & Intra-ethnic community cohesion \\
& $\begin{array}{l}\text { Intergenerational harmony } \\
\text { Inter-ethnic connection }\end{array}$ \\
\hline
\end{tabular}

\section{The artists in general.}

As one might expect, given the broad history of arts and humanity, there are commonalities across the artists who participated, despite their cultural and artistic diversity. At a minimum, each participant spent time learning a particular art, has emotional and experiential link to that art, and conveys messages of some sort through their artistic expression. In this sample, they have all also done the art in some situation of ethno-cultural adaptation. They all have specifically had some sort of acculturation experience in New Zealand, whether as an indigenous minority, an immigrant, or a member of an ethnic minority group born in the country. Their views about art and about their adaptation experiences in New Zealand are presented in concert, grouped by topic rather than art. Some views are shared across arts, and others are specific to a genre or practice. Quotes are numbered in the order they appear. 


\section{Why we create: personal motivations.}

As was presented in the introduction, the purposes and rationales of artistic production have changed in recent history, and have always been multifaceted. The reasons people create are at the core of this entire study: what motivates these people, in the midst of cultural transition, to spend enormous amounts of time to learn, refine, and practice an art?

1. Joey (Samoan modern arts sculptor): That rock [a sculpture] didn't take me 3 days, it took me thirty years to do that.-- It took me 30 years to learn to make that rock.

The investment of time and energy to develop as an artist is often monumental. For whom is it done? What does one give and get out of the process? These are the issues of the place of the artist in the world and the ways arts affect the artist and surrounding community, which the artist must now find in a modernized setting. Reasons and rationales will appear throughout the following pages, with this section providing a glimpse of the most direct, individual responses.

From the outset, it should be noted that any discussion of motivations for "doing art" may contain an inherent Western bias:

2. Sue (Maori weaver): In Maori, there's a word toi. Toi for us kind of can mean art, but it also means, broadly put, creativity, so I use Maori toi more easily than I use Maori art. And I validate that, I suppose, by saying there is no word in Maori language for art. And so anything you create is toi, from child rearing- child birthing- to painting a picture, so in that way we're all artists, all creators.

There is no separate artist or art, so the discussion is moot. In that view, our entire existence is spent as an inseparable part of the huge, interwoven whole of creation we are all constantly and simultaneously constructing and experiencing. Even in the traditional world, though, it is only a limited few choosing or chosen to make the investment and commitment to become highly skilled at a specific art. 
3. Harvey (South African modern visual artist): As a "maker," what are your responsibilities, if any? Do we live in an age where we still consider things like that? That you need to contribute to your culture in a particular way? Or are there expectations? Do you trade off the money and time that is spent in educating and training you? I think those are interesting questions, particularly when you set more traditional cultures against our expectations and the way that we operate [in Western art].

Whatever art one pursues, the process does not occur in a vacuum. There are teachers or exemplars, and there are those who listen, look, and encourage, he explains. There is the community (or individuals, depending on situation) providing the resources for the art and the space in which the art is experienced, whether it is a gallery in Soho or a bonfire in a jungle clearing. Resources and time are invested by the artist, but also by the community. It is for this reason, according to Emmie, that very few members of the Pasifika communities of suburban Auckland are doing arts professionally:

4. Emmie (Fijian painter): There's also a lot of stigma that art is not a viable career option. It doesn't generate income that can support a large family, for example, so it's not seen as a serious thing for kids to use their time on.

Their time and resources must be used for issues of survival, and arts are seen to be a frivolity, despite the many millennia spent by those cultures doing arts and surviving well. Emmie wants the community to know that art is of value and people do make a living from it. Chris is a professional whose art provides livelihood:

5. Chris (British visual artist): Well, I tend to think of it as a bit of a private addiction, really. One that I'm fortunate enough to get paid for-- To be perfectly honest, I'm quite impressively unemployable. So it's a good job really. It's something that-I can't help it. I'm always just looking at things and thinking what can we do with this?

Chris paints, he believes, because it is in his nature, in the way his mind works and there is nothing at which his particular way of being would be better put to service. When he is going about his business, at the same time he is constantly looking for inspiration and material. He is concerned with two things here, his enjoyment of the 
process, and the livelihood he makes from it. To be fair, he does consider his role in the wider world:

6. Chris: I really, really like to make beautiful images. There's so much disgusting stuff in the world- and I don't mean art. It's nice to make something that can be a little bit uplifting for the soul.

Beauty provides a resource as a refuge against the negatives around him, and his patrons take home a little something to provide relief from adversity and brighten their mood when needed. He is very much a product of the Western paradigm described in the introduction: art is made by individuals, largely for personally relevant purposes, and only loosely connected to abstract others for whom the work provides an entertaining and/or aesthetic service.

For Ram, a Bollywood singer from India, his motivation derives from the direct contact with his audience:

7. Ram (Indian singer): For a musician, there's nothing like applause and recognition. At the end of the day they don't want monetary benefits as much as they want the applause. So once you know 3000 people liked what you did on stage it works really well for you.

While he may sound very focused on himself, it really is a two-way exchange. The musician gets his rewards because he has provided something valuable and enjoyable for the audience. Because he sings music of an Indian genre in Hindi, his audience is almost entirely Indian and events also serve community functions, something of which he is conscious (see quote \#63 in the Intra-ethnic section below). He is receiving his accolades, which he likes very much, in a context with elements of community sharing made possible by his performance.

Though Joey's work is decidedly contemporary in style, he does come from a family of Samoan carvers and he incorporates Samoan visual elements in work he hopes will serve the community: 
8. Joey (Samoan modern sculptor): I sit there and think somebody in end of this new millennium will ask the same question I'm asking now- "where was the art [of Samoans]? Where was the art a thousand years ago?" When I look back in my own people there is nothing. Because they is coming from somewhere, how many years we been ... 400, 500 years? Surely there is still some art happen, something?(See also Joey, quote 54)

He has chosen stone as his medium because it will last and answer that question for future generations. His art, in his view, will provide a lasting record which will provide his descendants with a sense of cultural continuity and connection to their progenitors.

Another strand of motivation is more personally psychological and internal:

9. Maxine (NZ Chinese actress/writer): It seems to me that art is a way of working out the problems and questions around identity. Among other things, I view the practice of one's art as the process of problem-solving - or, more specifically in this case, the process of "re-solving" how one feels about one's identity. It is a quest to arrive at a place of clarity and acceptance and thus resolution.

To her, writing provides a personal tool of self examination by which she can come to greater understanding of who she is as an acculturating person and how she feels about that process. The resolution and clarification motivation was reiterated, interestingly, primarily by contemporary-style artists, perhaps because this motivation is inherently internal and individual. These artists work in solitude, untangling personal issues through an art drawn from and presented in the Western contemporary milieu, as opposed to more collective, traditional activities.

The motives described above range from an indigenous view in which creativity is an inextricable part of the fabric of existence toward contemporary arts that become more individual in nature as they move away from traditional collective or cultural bases. In the following pages, the question of motivation underlies all other themes, though not explicitly stated as it was the preceding quotes. The 
discussion following shall continue to proceed from the individual level to the more collective, and finally to the broad level of intercultural contact.

\section{Arts and coping.}

The artists all spoke to varying degrees about the issues they faced, the stresses and tensions of their lives, and in several cases, about how their artwork directly helped them to cope. Some methods were very specific to the individual artist. For June, her arts are simply a break from problems:

10. Jane (Solomon Islander weaver/singer): Those are things with no stress. When I do composing songs, singing, and weaving, you have no problems. Just no problem. Your mind is clear, life is beautiful, and life is so easy.

Focusing on the task of the art stills her mind and allows her to forget her worries for a time. These are arts she learned from early childhood in the Solomon Islands, which was a very low technology, relaxed lifestyle. Harvey, in contrast, faced great cultural contrasts and conflicts in Apartheid South Africa, and his process has been directed toward navigating the differences of languages and cultures surrounding him. As a child on the edge of the Kalahari, the people around him were indigenous tribes and Afrikaans, while his own family maintained the language and traditions of their English origins. Walking out the door, he was faced with other languages and behaviours to negotiate. Learning and practicing his art in Europe, the US, and NZ, he was faced with additional entirely different worlds to navigate.

11. Harvey (SA visual artist): Because I lived on the edges of the Kalahari desert, because it was out in the middle of nowhere, because most of my acquaintances, playmates and so on, were of a different race, colour, ethnicity, culture from myself-- my lived experience in my formative years, and into my thirties, was African. That's how I moved through the world, and that is the context that shaped me. However, my learned experience was European-- I see most of my work as a dialogue between those two things, as a kind of interrogation, can you use the one to explain the other? And what happens in that process, the shifts, the translations that take place. 
By blending and reinterpreting imagery from multiple cultures he has experienced, he expresses outwardly the processes he experiences internally. His life has been a mix of conflicting experiences, ranging from the primitive wildness of the Kalahari to the tamed environments of art schools, galleries, and museums. On the way, his art was filled with anti-Apartheid messages couched in starkly contrasting images. Now, living in New Zealand, he chooses more peaceful images, but they are still composed by combining images that are not necessarily congruent, yet coexist on his canvas. In the process, he can see and experience this dialogic process of imposing congruence, of taking an image from one culture and representing it visually translated into another cultural idiom. It is a very personal mental process done while creating, and one which is not necessarily visually apparent in viewing his work. Some degree of explanation is required to understand the abstractions and transformations of images. One series of images, on the wall behind him as he spoke, included three panels drawn from decorative motifs. Imagery transitioned between two outer fabric designs, the final piece being a very traditional European paisley wallpaper design imported from India during the Raj. The "destabilizing element" was taken from a tablecloth he had purchased in a dusty outdoor African market, covered with pictures of European fruits he said the sellers would probably never see or taste. The fruit tablecloth, by its very existence, implies the injustice that survival requires those African merchants to sell cheap plastic items depicting images of things unattainable in their world, within a context of post-colonial history that simultaneously placed them in economic distress and brought such items into their world. All three panels were idioms of décor, and all hang together harmoniously on his wall, but beneath is a complex negotiation of clashing realities. 
Similarly, Yin draws her artistic themes from her position as an outsider bridging two worlds, in this case New Zealand and Korea.

12. Yin (Korean dancer/film maker): My work is always... my conception of reality. I always sit at the border, I sit at the wall-- I'm sitting on it. You can see on this side and you can see on this side. You're sitting at the border where you have more perspective. Outside perception of what it feels to be inside the society.

During the interview, she shows a very abstract film she has made with no dialogue, only images of herself wandering and dancing through a deserted city at night (evidently Auckland), eventually ending up outside a house in an embrace with a man. She does not offer any explanation: that would be up to the viewer to decide. There is a definite and obvious sense, though, of loneliness and isolation which is finally remedied by connection. heritages.

For Emmie, the issues are related to her mixed Fijian and European

13. Emmie (Fijian painter): It's important to practice my art because as a mixed race person there's a lot of internal conflict, and I think art is a way that helps me understand who I am and why I am the way I am. So I have to practice it, otherwise I'll go crazy.

Her art, and the other works in the gallery she operates, are Pasifika in their core imagery, but generally entirely modern in manner of expression. She uses her practice as a way to explore and express elements of identity. Unlike Harvey and Yin, who claim to express themselves primarily as outsiders, Emmie feels she is an insider in two camps. She grew up and has lived partly in Fiji, partly as a diplomat's daughter in Europe, and now in European dominated New Zealand. To her, the European culture lifestyles are so different from Fiji that it takes something therapeutic to resolve the disjunctions, though she does not explain exactly how that works. From her work, it would appear that her primary interest (at least at that 
time) was in exploring herself as Fijian and resolving her place as an internally Fijian woman in the European world.

Rose uses her arts in two ways, one by which she maintains a sense of stability, the other by which she re-evaluates stressful situations. Prior to immigration, life in Hong Kong was tumultuous for her and her family. The house to which her family moved upon arrival in New Zealand formed a haven of peace and security. She returns to the house for literal visits, but more importantly, she returns in her artwork:

14. Rose (Chinese visual artist): it comes back over and over again. It's a physical house. It still exists in a suburb of Wellington. All I have to do is just see it and I do have a yearning to be a part of that house... but the yearning isn't a physical yearning-it's a touchy-feely yearning and I want to-- And I think I try to recreate that peace in subsequent houses that I've lived since that time.

Migration has been thought to bring a loss of "symbolic resources" of familiar culture and environment (Markovitsky \& Mosek, 2005). In this case, it would seem to have brought a symbolic resource of stability which she has literally transformed into visual symbols in her art. Rose relates that it appears in every piece of artwork she creates, though it would take an explanation to understand the way she abstracts it into different pieces. The house has provided an icon of safety and stability in her life, and, in a very real sense, it gives continuity and stability to her body of work.

The second way she uses the process of creating her art is to resolve residual issues, metaphorically reworking her history and environment by creating pieces that represent an idealized world, the way she would prefer things to be or have been.

15. Rose: I've come to realize you can have your future influencing your past. Interesting-- it's like a rewriting of an event in your past in terms that you would like to see. I had a very turbulent departure from Hong Kong, and I rewrote that part- the present influencing the past. And I've taken that 
theme to rewrite the city of Auckland. Actually the globe. This is my globe [points]. And this is a plan view of [local subdivision] [points to an artwork] just made into a 3 dimensional form. I'm actually taking it from myself as a singular person to my community, to the global community. I'm changing the world.

She appears quite clear in her process: her turbulent experience leaving Hong Kong and issues in her current life have been re-imagined from the safety of the symbolic house/haven, alleviating negative feelings and memories. The subdivision map is a re-envisioned version of the actual place in which disharmonious elements are resolved. There are no neighbourhood disputes or grumpy neighbours.

This method is congruent with the aspect of the stress and coping paradigm regarding perception of stressors (e.g., Berry, 1997; Lazarus \& Folkman, 1984; Ward, Bochner, et al., 2001). While she may not literally change her past, the neighbourhood, or the world, she has changed her perception of the stressful aspects of her own world, and thereby gained a measure of control (Li \& Yang, 2009). It is also similar to the cognitive reframing technique associated with Cognitive Behavioural Therapy (CBT) (e.g., Dobson, 2001; Rush, Khatami, \& Beck, 1975) in which self-perceptions or evaluations of experiences are reinterpreted in a more positive light. The conceptual or emotional content or the point of view are altered such that they still explain the same situation, but do so changed to a more positive or acceptable meaning. The reframing reduces the adverse psychological effects of negative events on the individual. The ability to naturally do this has been associated with highly successful people, allowing them to more efficiently and effectively overcome adversity (Gomez et al., 2001).

Kioni has a light-hearted approach to dealing with her stresses:

16. Kioni (African actress): There's another poem about the questions that you get when you look like me. Where you from, how long have you been here, what brought you here? So that poem-- it's a cheeky poem, but it's a 
poem that a lot of people, even Africans cheer me up because they've been asked the same question. So I give my background in a cheeky way.

Kioni's professional work has been in theatre and film, but she started in more traditional performance settings as she entered the nascent 1960's Kenyan theatrical scene. She draws on the traditions of story-telling and oratory to communicate where she is from and the cultural insensitivity she has experienced in New Zealand. There is a substantial body of literature regarding use of humour as a coping strategy (e.g., Herzog \& Strevey, 2008; Martin, 2001; Wanzer, Sparks, \& Frymier, 2009). The technique works as a coping resource for her personally and vicariously for other Africans who have had similar experiences, while simultaneously providing education for the New Zealand Europeans present who may have been unintentionally offensive in the ways about which she jokes.

Max has a different way of coping with prejudice through his art:

17. Max (Maori kapa haka): It builds up a resilience, it makes young people so confident.-- what you can do is you can build yourself up to be so grounded and so confident that when those things come flying at you they just bounce off.

His conceptualization of how kapa haka participation builds resilience takes advantage of several aspects of traditional arts practice: enhanced ethnic identity, social networks, self awareness, and self-efficacy (see following sections). Resilience, the ability to persevere or rebound from adversity, has been viewed as either a state or a trait in previous literature (e.g., Block \& Kremen, 1996; Niell \& Dias, 2001). This statement would tend toward the view that it is a state that can be learned through the traditional arts practice. Social networks and self-efficacy have been shown to interlink with state resilience and self esteem in previous research, leading to enhanced coping abilities (Li \& Yang, 2009). In this quote (see also \#29 
and \#40), he suggests that developing a solid sense of identity through kapa haka provides protective factors to cope with or deflect threats to self-esteem.

18. Amy (Chinese dancer): I think it's a good thing to learn dance, even though you're not going to become a professional dancer. It really helps in your life, like the way how you walk and the way how you think, the perceptions you receive from others.

As with Max above, Amy perceives benefits from her practice spilling into other domains. By learning to be excellent at dance, she gains a confidence in herself and her abilities in general. Self-efficacy is the belief that one is competent and capable, which, in coping terms, means that one can handle difficult situations (Cheng \& Cheung, 2005; Li \& Yang, 2009). To her, one can move more confidently through life as a result of learning to do the art, whether or not one goes on to achieve professional status. This is then confirmed by feedback from others, these "perceptions you receive," or at least how one evaluates these perceptions.

19. Ram (Indian singer): I wanted to sing to other people and see what they thought. Luckily, most of the time when people heard me they like it.

Singing is central to how he evaluates himself and constructs his self-image, and the positive reinforcement he gets from the audience by performing is a large part of his motivation for singing (see \#7). He is aware that it is an exchange in which he provides a context for community cohesion (see quote \#67), and his personal reward is a boost to his self-esteem and confidence.

20. Tame (Maori kapa haka): You felt like you belonged, so immediately your self esteem boosts, your confidence boosts... Kapa haka built my self esteem, it got my confidence up, got me out of my shell, cracked the egg as they say.

These results reflect several very different uses of arts practices in coping with acculturation and acculturative stress, in a range from deeply personal and internal to more interpersonal and outward. Tame emphasises belongingness as an important component for him. Interestingly, the more internal methods are 
described by the Western/contemporary artists. This may be a result of the evolution of the concept of artist as individual discussed in the introduction. Kioni, active in the contemporary form of ancient theatrics and from a traditional culture, described an actively interpersonal coping in this section, actually reaching across cultures along the way. Max and Tame speak of a complex web of coping tools, including social networks and sense of self comfortably identified as part of the arts group and community.

\section{Identity.}

The artists were asked their feelings about their identities culturally and artistically. The responses were diverse.

21. Maxine (NZ Chinese writer/actress): Because of my background and the length of time that I've been here, I don't really see myself as an ethnic-because I can't see myself-- in my terms, my ethnic identity would be a New Zealander of Chinese descent or a New Zealander of Chinese ancestry. So that's the cultural, and the racial kind of afterthought.

Maxine was born in New Zealand, growing up in the 1950's and 60's. She relates that the extreme prejudice of earlier history had died down after World War II, from when China and New Zealand were allied against Japan. It was, however, still a time of assimilationist attitudes toward immigrants, if less authoritarian ones, with few co-ethnics. She entered her adult sphere without a sense of what it would mean to be Chinese, and though she has explored that aspect of herself to some degree, still places that label second.

22. Maxine: I've come to a position of comfort now that I do see myself as a New Zealander first, and that's partly as a result of the fact that I didn't have access to the culture, and I was often the only Chinese person in the circles that I moved in. which was school, which was theatre, which was film and television, which was public service. So I was kind of like a pioneer, if you like, and it wasn't because I sought that situation- it was just what happened. 
Maxine was of the generation that bridged into mainstream New Zealand society, and she did it partly by not thinking of herself as different. That process began for her during the 1960's and 70's, in the context of anti-war protests, civil rights, and counter-culture trickling in from other parts of the world. She was in a particularly progressive, artistic milieu, which probably facilitated her acceptance. From a generation before hers, Jim's attitude against identification as "ethnic" is stronger:

23. Jim (Chinese modern visual artist): What do I care about ethnicity? It has nothing to do with my art. That comes from living in London next door to [famous artist] and knowing [another famous artist].

He identifies himself as an artist only, and his art is a product of his own life and experiences, not of anything, he feels, to do with his ancestry. He began his profession in England after World War II, in an artistic milieu that included some of the most prominent artists of the $20^{\text {th }}$ century, and it is to this that he credits his style, development, and success as an artist. It is notable that this attitude is very much a product of the modern Western world, seeing the individual as solely responsible for his output and solely due the credit. As discussed in the introduction, the art and music industries of the present era are definitely the domain of the auteur musician and the self-expressive artist. He described growing up in the strongly assimilationist environment of New Zealand before World War II, mentioning a number of situations of unjust prejudice continuing after his return in the 1960's. He rails against these by strongly declaring himself a human being who cannot be reduced by categorization into some minority.

Several of the contemporary artists shared this concern that they and other non-European artists should be accepted and admired as humans first without the filter of ethnicity. Otherwise, even if they are successful, there is the potential that 
they are being patronized, in the negative sense, by people who are interested in their work only due to the ethnicity of the artist.

24. Renee (NZ Chinese writer/actress): You tend in the western media world to get ghettoized into certain ethnic ways of expression, and that's something I'm extremely wary of- I don't want to be "the Chinese woman filmmaker." I've actually rallied against that. My first films pretty much had just white people in them. And I realize that was kind of a backlash against feeling like people think of me as I'm 'just the female Chinese filmmaker.'

The non-traditional artists resisted being labelled and hence evaluated based on ethnicity rather than on the merits of their work. Though several chuckled that their ethnicity gave them increased access to public funds due to national mandates, it was important to them that they be perceived as equal by objective merit to artists of the dominant culture.

In practice, though, the media artists actually did have to confront and create representations of their ethnic groups as roles or in stories. Sana described the process by which she would create an Indian character:

25. Sana (Indian Writer/actress/radio): It's behaviour rather than clothes that would indicate where these people came from. So when I say Indian-ness, it doesn't mean wearing the Indian clothes or having the embellishments or the symbols that indicate this person is from India, but rather how the character behaves and the character's points of reference? Interaction with, say for instance the family, or other friends, or doing certain things in the story which indicate what the Indian-ness is. And of course if it's an Indian from India and they're going to hum a song, it's not going to sing Brian Adams, are they? It's those little things that really matter-- not the exoticism.

What creates identity for her comes primarily from within, made manifest in behaviours of daily life. What she and others in New Zealand media constantly face, however, are base and entirely predictable stereotypes. She ruefully describes that every time an Indian woman appears on a particular popular New Zealand show, the woman always wears a sari (unusual in daily life) and there is an 
inevitable night club scene in which the woman does a Bollywood style dance. While many Indians are wealthy, perhaps owners of multiple properties, she relates, in the stories that make it onto television, the Indians must be struggling owners of a small convenience store (a "dairy," as they are called in New Zealand). Similar experiences were described by actors and writers of other ethnicities.

It was a much darker, violent form of prejudice driving Harvey's resistance to racial or ethnic identifications, though he was of the dominant group.

26. Harvey (SA visual artist): Race is highly contested for me, to the extent that in South Africa there wasn't a form you could fill in where you didn't have to say race, and one got to the point where one simply wrote human as a way to protest at every level.

His introduction to concepts of race or ethnicity happened in a context of gross socio-political inequity. His early adult life was spent protesting the Apartheid system through his art, and to think even now of ethnic categorization is morally discomfiting. In that time, there was no middle ground. As shall be discussed further (p. 113), he explained that artists in that milieu, if they were against Apartheid, were expected to make political statements with each piece. Even to omit message was to tacitly condone Apartheid. The content inescapably defined the artist's political and social identity. Though he understands the need for Maori to push for distinct treatment in certain political and educational processes, he finds the dialogue disturbing close to the rhetoric of Apartheid, though in New Zealand, it is the Maori promoting the idea of separate systems and identity for themselves.

While the New Zealand situation is not as grim as Apartheid South Africa, there are serious issues related to ethnicity, as described in the chapter introduction.

27. Sue (Maori weaver): I think in this country it's really important to focus on identity, and in some places, in some contexts, the purpose, you have to make a decision and you have to foster that decision as the right one. 
She is a Maori living in a highly politicized milieu, in which a struggle for equity and social justice has gone on for nearly two centuries between the dominant Europeans and her people (McIntosh, 2005; Walker, 2004; Wilson \& Parker, 2007; Zodgekar, 2005). In this charged atmosphere, in which cultural survival is at stake, to identify and live visibly as Maori is to make statements of pride or protest, depending upon context. As with the negative views of ethnic categorization earlier, the categorization is happening as part of socio-political inequities, but in her case, rather than minimize ethnic difference, the response is to identify strongly and visibly. Identification begets cultural continuity.

This raises interesting questions around motivation for choosing an art specific to one's culture; is it that identity and cultural participation are most pronounced when one is involved in some struggle as an ethnic group and therefore one has impetus to choose and support arts associated with one's group? As part of a group that is deeply involved in a struggle for political and social equity and for cultural survival, gaining political voice requires a demonstrable unity and recognizable identity. The development of a group identity and a widely shared sense of unity necessitate a body of symbolic content around which to rally and by which to increase public visibility (e.g., de Vos, 2004; Graburn, 2004; Guenther, 2003; Kramer, 2004). In the case of Maori traditional arts, they provide a rich body of iconic symbols, but also a core set of information including geographic and familial origins (see Creating Identity below), expressed visually. These give the cultural insider a literally grounded sense of who and what they are (cf. Durie, 1995). Tangible results of Maori political assertion in the creative arena include Maori representation in Creative New Zealand and mandates for inclusion of Maori content in broadcast schedules (New Zealand Legislation, 2003). 
The struggle with prejudice and inequity continues in daily life, however, and forms a topic addressed in kapa haka youth groups.

28. Max (Maori Kapa Haka): We often tell our young people that we work with that if someone's going to bully you because you're Maori, you can't change that. There's nothing you can do to change that. They think that way because that's obviously the way they've been influenced to think.

The method by which to build one's identity is, in this case, kapa haka (see \#17). These feelings were reiterated regarding Samoan dance/music, suggesting that this is a shared Polynesian process. They will experience prejudice, but through their arts, they learn how to be unshakably and unequivocally identified in a positive sense. This calls to mind that the literature related to construction of group identity, both in Collective Self-Esteem and Social Identity Theory, often deals with identity in contrast to an opposing group (e.g., Crocker \& Major, 2003; Drury \& Reicher, 1999; 2000). While Drury \& Reicher (1999; 2000) focus on polarizing crowd behaviour at isolated social protest events, the Maori identity movement is considered by the Maori themselves to be an ongoing, continuous protest in which the polarization is centuries old (Walker, 2004). Traditional arts provide a forum for Maori unity, community, and strength even though many Maori are dispersed into urban, completely non-traditional environments.

29. Max (Maori kapa haka): These kids have grown in a world that is completely Pakeha [European origin], it's completely outside of the tribal area. So they aren't exposed all the time to their culture and the ways of their people. And what haka does for them is it enables them to reconnect, and that's what it does in a big way-it reconnects them with their culture, they wouldn't get that from an orchestra.

The comparison of kapa haka to the Western orchestra (see also \#47) applies to its relevance for Maori youth he encounters who are otherwise disconnected from their hereditary and cultural origins. Their participation in the traditional art allows them 
to create a sense of identity in ways otherwise unavailable in their environment, and unavailable in other arts practices.

30. Timo (Samoan dance/music): I notice that with Samoan youngsters. They love the dance and they love the song, and the movement as well. I think partly because of their own-it's like a confirmation of who they are?

By participating in an art that is specific to their culture, their identity as members of that group is confirmed and is simultaneously being reinforced by culture-specific movements, singing style, and informational lyrical content.

There is a general division in the comments around identity, with the Western/contemporary artists speaking more often of preferring to be perceived and treated the same as others, while the traditional practitioners speak of their arts as a way to feel, strengthen, and celebrate their differences from other cultures. In a sense this is not surprising: one cannot equate something like kapa haka with opera, for instance, because the motivations and content are entirely different. A Maori opera star such as Kiri Te Kanawa may be proudly identified as having Maori heritage, but it is her excellence as a performer that dominates her promotional literature (IMG, 2009). With kapa haka, as these artists say, the entire experience is about being Maori. This is not to say that the Western/contemporary artists have no concerns of identity in their arts: the media artists certainly do. The primacy of identity, however, is reversed. One is a person doing art who happens also to be Chinese, while the other is a Samoan doing a Samoan art specifically to reinforce his Samoan identity, for instance. In addition, what is being transmitted and received becomes ethno-culturally relevant in different ways, with the Western/contemporary arts related to more general, decontextualized culture, while traditional arts convey content specific to one culture. 


\section{Creating the components of identity through art.}

Max (\#29) suggests in the previous section that kapa haka provides a way for young people to reconnect to their culture and the ways of their people, and hence to have confidence in their identities. Indeed, a theoretical structure for establishment of identity was proposed by Marcia (1966), in which exploration of identity is crucial to reaching the final stage of identity achievement, in which the person understands and has committed to the identity (Marcia, 1966; Rowe \& Marcia, 1980). In the literature of ethnic identity, aspects of identity which one would gain on the journey to identity achievement include language, attitudes, behaviour, values, and group historical knowledge (Phinney, 1990). This section discusses the ways in which arts practices inform the artist of these aspects of identity. The Western and contemporary artists largely mentioned only language and certain values such as respect for elders as culturally important to them, but these were not discussed as relevant to their arts processes.

Traditional arts provide specific information upon which to build understanding of and identity within a culture. Mina (Filipina dancer) spent several minutes, too much for a concise quote, describing the history of the Philippines and how it is expressed locally and nationally through dance. To summarize, the entire history, even the prehistory of the Philippines, is contained in and expressed by the repertoire of traditional dance she performs and teaches. The movements, costumes, stories, and music are drawn from and tangibly describe the historical time, the influences of other cultures (whether colonial, trading, or religious groups), and the feelings of the people about events and conditions in those times.

31. Mina (Filipina dancer): It's something that-- ok, you study a culture without reading a book and that's in a dance presentation. Don't have to turn a page! 
Of course, this is not surprising when one considers that only in recent millennia has humanity had means of transmitting history other than oral recitation and performance (e.g., Campbell, 1949/1973; Turner, 1982a). Artefacts and traditional arts practices in Solomon Island cultures provide both historical knowledge and continuity:

32. Jane (Solomons weaver/musician): I really want to know headhunting times, what they did, and these were real people I was asking. That's how I know all about those times that passed... was it Solomon Islanders who weave themselves? Who taught them, you know, the roots? Actually, headhunting times, the men weave the shield, you know, when fighting? That's their job but it's totally different materials from the basket. It's like cane, very solid, very strong. And we used to get those when they were fought in many years ago. We still keep those because they are materials that they don't rot.

Her community retained many items from their days before Westernization, the collection comprising those creations of less destructible materials. To these, one could point and say it was made by a certain ancestor and used in a certain way, tying the individual to familial history and to ways of being in those times. The bulk of her learning process would have transpired as oral history recitation, frequently as stories told in a context of basket weaving (see Intergenerational Harmony). The artefacts provide an additional, lasting, tangible link to their past. The people with whom she wove and from whom she heard stories were the elders, many of whom lived during those historic times. The stories and artefacts link her to aspects of an identity about which she became passionate and proud.

Traditional arts include information on less direct levels as well, sometimes in the semiotic cues of particular visual, auditory, and kinaesthetic information.

33. Amy (Chinese dancer): If you do Chinese traditional dance, it's completely different from ballet or Vietnamese dance. You can tell from the gesture, the positions, all these things. And the costumes as well, the music. 
Dance requires the performer to learn particular ways of moving in certain rhythmic and emotional contexts. Traditional dance, she implies, literally embodies the culture in ways completely unique to that culture. For a cultural insider, these informational cues are perceived and understood. The processes of learning and practicing these codes occur in activity settings (O’Donnell et al., 1993) which have evolved as part of the particular culture and are designed for the specific process of transmitting that particular set of instructions and information (Turino, 1999). In Amy's case, she was formally trained at a national school of dance in Beijing, which became somewhat different from historic dance schools following the advent of the Communist system, but which is still unique to China. It was a harshly rigorous course of study she says has been too tough to be popular with New Zealand European students, but which must be endured if one is accurately to convey those gestures and movements.

The cultural dynamics of transmission may happen intentionally or incidentally (Kashima, 2008; Sperber \& Wilson, 1995), but in the case of traditional arts, both levels can simultaneously occur. The art may not be learned in a formal process, such as the informal, conversational setting in which the Solomon Islands weaver learned her art (\#32). In that case, the informal setting is itself the culture's transmission method, the context of weaving being where, when, and how transmission occurs, with that style of teaching and learning forming an important component of the culture (cf. Ng'andu, Anri, \& Herbst, 2004; also see the Cultural Transmission and Maintenance section below). The implicit systems of transmission through arts are also potentially accessible to cultural outsiders. 
34. Miko (Maori/ Japanese kapa haka): I always think about our friend from Germany-it made her part of us. She knew protocol after like a week, she knew what was appropriate.

Miko marvels at how effectively the information is transmitted, that in a very short time someone from a completely different culture could not only be participating, but already have a working knowledge of the intricate norms for ceremonial behaviour and interaction. Primarily, though, the processes are designed for transmission of culture-specific information to members of the culture.

35. Timo (Samoan dance/music): The cultural aspect of it comes into it when you say do we all understand what the song is about, what we're singing? In the show we've got on Saturday coming up, some young kid gets up and recites like an introduction-you're about to witness what goes on when mom and dad don't get on so well, acting out family life that's not going so well... So you learn all the stuff that you need to do, the rhythm, going together, but we're also trying to make sure the young ones understand what the song is about, the message in the song.

There are a number of processes occurring simultaneously: they are singing and dancing as a unit, they are learning their language, they have learned songs and stories about adaptive domestic life, they are sharing this information with the community, and they receive applause as an extra reinforcement for doing all of this. These complex webs of multiple functions may be a reason these arts are effective at informing and consolidating identity and shall be discussed further.

In performance arts, lyrical content provides an overt means of transmission of information (cf. al-Deen, 2005), but the participant does not immediately need to be aware of the process by which cultural knowledge has been gained or the layers of meaning conveyed, and may only understand the importance of the information much later.

36. Miko (Maori/ Japanese kapa haka): So even now, I think I know that song. I knew that when I was seven but I don't know why. And they say, 'well that song was written by bla and it's got this and this, and now I know why I was taught that song, because it's got this in it and it's teaching me how to do this. 
The type of information may vary, and may in fact be concealed within cultural idioms and symbols.

37. Miko (Maori/ Japanese kapa haka): It could be something as basic as growing a tree, and that could be symbolic of a family. Or it could be 'your skin is as smooth as a carved tuatara plane,' and it's like why would you say that to a woman? It's not soft, it's like tautara's rough, it's not very nice at all.' But then you think there's not a lot of soft smooth things back in those times for our ancestors, they would consider that beautiful. So they would liken that to a woman's skin. That's all they had, that's what they thought, that was symbolic of a woman's face.

This sort of information is essential to world-view within Maori culture, to ways of perceiving and embracing life and the natural world in the systemic modality of the culture. One is learning multiple levels of semiotic information in this way, including how the culture historically described, analogized, and anthropomorphized the world around them. In this case, the signifier is tuatara, which refers to a roughgrained wood, but within the cultural context has traditionally carried a meaning of feminine beauty. Also conveyed in the learning she experienced is how the semiote should be appropriately placed into the artistic product. In other words, what do these images mean inferentially and how is that image properly presented? To be relevant to the community, the collective group experience must be salient in the art, and both participants and audience (if there is a division) must be learning or have already learnt the meanings of multi-layered symbolic content to receive the semiotic information.

38. Emmie (Fijian visual artist): The artwork I really enjoy and like to promote, and like to work with artists who make work like this... is art that talks about... like the kind of... the processes of tapa making and mat making. I like contemporary work that sort of speaks to those... you know, you're making work about who we are, and it's Pacific art that acknowledges the collective. 
Emmie operates a small gallery in a desperately poor area of Auckland, inhabited almost entirely by Pasifika and Maori people. The gallery is not geared for making money but rather to provide a venue for artists in the community who have no outlet for their work, and to bring art experiences into the lives of the other non-artists in the community. The shop has become a hub for community members who would otherwise probably have no access to arts (when she arrived, as she related in \#4, arts were devalued because they were seen to have no expediency for feeding a family), and area children have begun to "hang out" discussing meanings and qualities of works presented.

39. Emmie (Fijian visual artist): I love contemporary Pacific artists who can really walk that talk, but also... I mean it's their work that can translate to an area like this, to an audience like this? It's when old people can come in and they can understand it, because it's similar to what they know as visual expression.

Several children knocked on the door and peered through the glass during the interview, hoping to be allowed inside though the store was closed. In this way, modern visual arts, specifically of Pacific design and creation, carry, transmit, and expand meaning for the group. She has created, quite consciously, a completely untraditional venue in which Pasifika cultural information, meaning, and experience is shared, discussed, and enjoyed.

It is the lived experience of the culture that may be the most important aspect and the common thread for identity across these arts and artists.

40. Max (Maori kapa haka): When they leave haka every day, they don't leave it behind. It's something that they are every single moment of the day. Haka is an embodiment of them. So the connection is a real one and it's a living one, so the performance in turn becomes a very authentic one. It becomes less and less of a rehearsed performance and one that's triggered by real experiences when they can think back and they were at school a week ago and somebody bullied them because they were Maori. I think that reconnection is becoming grounded in your own identity. 
Kapa haka, he says, is particularly a discipline in which one is supposed to be aware of and internalize the feelings and experiences related to a given haka as it would have been performed and understood cognitively, emotionally, and viscerally in historical context (see also quote \#47). In this way, the cultural knowledge, as well as other aspects of identity, becomes an integrated and inseparable part of the artist, providing a lived sense of being and knowing that is protective in situations of threat and stress. The same would be true to varying degrees of all of the ways in which arts support or reinforce aspects of identity, including the visitors to Ema's Pasifika arts gallery. Though the style is modern, they are actively discussing and evaluating the content and execution of works by Pasifika artists composed of Pasifika related imagery, and hence making the culture relevant to their lives.

Culture related arts provide an interwoven set of direct experiences whereby cultural knowledge becomes vividly tangible, identity is discussed and rehearsed, and the sense of identity as a member of the group becomes a real part of participants' lives. It is by practice that one learns an art, and the learning here is an inverse corollary to the cultural learning theory in acculturation research (cf. Ward, 2001). In these situations, rather than learning the ways of the contact culture, one learns the ways of the heritage culture.

\section{Cultural maintenance, transmission and change.}

41. Miko (Maori/ Japanese kapa haka): [quoting, in translation, a song that the youth group she leads had performed] We are youth; we are here today representing our ancestors to display these treasures. Our singing comes from the ancestor who takes charge of music and we acknowledge her.

42. Sana (Indian writer/actress): The loss of local cultures because of globalization-- what I have seen is that it's rejuvenating local cultures. In India with the proliferation of television channels, cable TV and Bollywood becoming international, you would think that's it, these guys are telling 
western stories, it's homogenising the whole thing, but actually local, regional language television and film have really gone up, and websites in local languages have really gone up. Suddenly people have realized this need for preservation and maintenance.

As discussed in the introduction, traditional arts practices have served as central mechanisms in the iterative ways by which culture is maintained and transmitted for great spans of time (Kalish, Griffiths, \& Lewandowsky, 2007). Miko quotes a song from the beginning of a performance which dedicates it to their ancestors and ties them back to the distant ancestress who invented singing. Nontraditional artists in this sample are involved in communicating culture that is sometimes either ethnically non-specific or is more closely associated with the dominant culture, though Sana suggests that broadcast and internet have become means for cultural maintenance in India. In the actual data of this set, however, the non-traditional artists express few opinions on issues of cultural maintenance beyond perhaps having their children learn the language or eat the cuisine. For traditional artists, conversely, maintenance and transmission of their specific culture is a core part of their motivation.

43. Mina (Philippine dance): Dance would remind us where we come from, where we are now, and where we are heading tomorrow. It's always there.

As mentioned in the previous section, Mina feels that everything one could need to know about her culture is in the dances. She has taught her children and grandchildren to dance, her elders taught her, and the process extends back through time. In this way, her family learns and re-enacts their culture, keeping it alive and passing it on.

History transmits specific, relevant information for any culture. As a culture long preserved its history by oral recitation, kapa haka provides additional meaning 
for Maori by tying the learner bodily into a continuous, historical chain that extends, as mentioned earlier, some 800 generations (Kame'eleihiwa, 2009).

44. Max (Maori kapa haka): The songs are definitely a way that we've used to pass stories down, and stories of history, of mythology, of cosmology, genealogy.

Similarly, genealogies serve an informational function, but also connective and ceremonial functions. Any time two or more Maori meet for the first time, as well as when engaging in any formal function, enough genealogy is provided to establish the speaker's place in families and tribes at least back to arrival in New Zealand (Walker, 2004; Maori.org.nz, 2009). For instance, in the Pōwhiri, or formal welcoming, the Whaikörero would be a formal oratory in which the Mihi ki te whare tupuna section would describe origins from a central ancestor to present (Tauroa \& Tauroa, 1990; see also Miko, quote 36). Kapa haka serves as an instrument by which this information is learned and passed on, and this is well known to practitioners. It provides them with a complete set of cultural information, the knowledge of how they fit into that culture, codes and protocols of behaviour, and a context for the process. In short, it is a complete system for cultural maintenance and transmission.

45. Miko (Maori/Japanese kapa haka): From a basic level it's to do with learning your genealogy, most of it is through our singing, chanting. At an early age children are taught these songs as a sources of vocab. Vocabulary, places, names - they're not necessarily taught why but they're-it's exposure to the songs, names, places, so when they get older they're already installed here [points to her head].

She adds information about the process here. Again, genealogy is a component, but the process of language learning is concurrent. As in Gaunt's (2006) observations of learning by African American girls, the process is accessible to children at an early age, and happens in such a way that the children do not feel oppressed or put-upon in the memorization process. In fact, music has unique qualities for recall, both in 
terms of cognitive process, such as nostalgic immediacy, and neurologically, as when Alzheimer's patients who otherwise do not speak or interact will be able to sing songs they learned in younger days (Witzke, Rhone, Backhaus, \& Shaver 2008). It is also an excellent way to reinforce language learning, as Miko says. Max shares a similar view.

46. Max (Maori kapa haka): This has probably proven to be one of the most successful mediums to carry the language through and as soon as we take that away [language] then we've almost lost the essence of what it is.

As with Gaunt's (2006) observations, kapa haka combines information is presented in the mnemonic form of song, conjoined with ritualized movement, in a focused and supportive cultural setting. One is reminded of Gardner's $(1993 ; 2006)$ Theory of Multiple Intelligences (Nolen, 2003; Maasjo, 2002), which are linguistic, logical-mathematical, musical, bodily-kinaesthetic, spatial, interpersonal, and intrapersonal intelligence (Gardner, 1993; 2006). From Gardner's work, a philosophy of teaching has developed to better fit the various learning style(s) of students, touching on each of these ways of learning in the course of study (Douglas, Burton, \& Reese-Durham, 2008; Nolen, 2003; Maasjo, 2002). It is notable that all of these modalities are present in performing arts (for logical-mathematical, consider the metered aspects of music and dance). Whatever the learning style, the message is delivered and reinforced.

Kapa haka and similar arts add yet another dimension to learning, perhaps of active imagination, but it is more an experiential, direct linkage to the times and people gone before (see also Max, quote \#40).

47. Max (Maori kapa haka): When they stand up and they perform a haka and they know the story behind that haka, they can think back to their ancestors performing this haka in war and in those circumstances. It gives them something real to connect to, whereas it's very hard to sit in an orchestra and connect to Mozart and the time when Mozart wrote his 
wonderful symphony. It's somewhat disconnected from them. But this is a very real thing that they are living and breathing every day.

He mentioned this as he discussed the additional benefits that such practices have for ethnic groups over arts unrelated to the group. The songs become a powerful, experiential source of embodied knowledge: the youths are actually making the same motions, singing the same melodies, and voicing the same words as their ancestors perhaps centuries before. It is notable that this participant also sings barbershop quartets and was trained in Western classical music, in fact having won international competitions. He has experienced both types of practices, and both types of practice maintain culture, but only the traditional has that relevance and immediacy for him in terms of identity.

The need for a sense of place and continuity in time and history drove Joey's choice of stone as a medium:

48. Joey (Samoan modern sculptor): Where was the art a thousand years ago? When I look back in my own people there is nothing.-- Surely there is still some art happen, something? And there is no steel now can guarantee a thousand years. And who is going to ask this question in a thousand years I am asking now? And I believe there is only one medium can last this millennium: the owner of this planet. They were here before us and they will still be here when we die. Rocks. And I say any of my mokopuna in a thousand years down, they will ask how did our grandfathers do this rock? (See also Joey, quote 8)

There was nothing in Samoa, he believes, older than decades or perhaps a couple of centuries due to the impermanence of the materials from which they were made. Though the forms and images of items made by his grandfather were ancient, the actual items were not. He has an apparent sense of loss in the lack of material culture from his ancestors, which he feels would have provided a tangible link to the past, to what they made, to what was important to them, and by extrapolation, to how they saw the world. Mokopuna is the Maori word for grandchildren or 
descendants, which he may have used out of deference for the Maori weaver sitting with us. He has chosen stone so that remote descendants have a link to him, a tangible anchoring of inherited identity.

\section{Cultural survival.}

Cultural maintenance has a deeper level of meaning for some of the traditional artists, in that the Maori and other Polynesians confront the prospect of extinction of their cultures on a daily basis, directly and tangibly.

49. Mina (Maori/Japanese kapa haka): Amongst my generation, in the number of dots who speak Maori, that sing Maori, there's this huge drop between my parent's generation and mine. Going to my generation where there's maybe $10 \%$ ?

50. Palani (Niuean dancer): with our Niuean dance, we're losing that part of it as well, so I'm trying to research the old way of dancing, the cultural and the heritage side of that dance. So that way people will know.

By "that part of it," he refers to the elements that make the dances uniquely Niuean, authentically reflect the ways the dances were done before migration, and directly transmit the cultural content. Niuean culture in particular has a very real risk of being lost: the 2006 census counted a population of only 1625, while the New Zealand census for that year counted 22,473 Niueans (Statistics NZ, 2006; Government of Niue, 2006) living there. He feels a deep obligation to see that his culture survives, despite migration and rising seas. It is not enough for him simply to do some sort of dance, even some generic Polynesian dance: it needs to be authentic Niuean dance to achieve his goals with his ensemble and thereby his ethnic group. The threat of extinction is a tangible concern for several cultures in the sample.

51. Max (Maori kapa haka): I guess the ways of our old people are starting to become less and less practiced. And I'm sure this has to be across the 
board. It's definitely evident in my father's Cook Island side and in my Maori side as well.

His lineage includes both New Zealand Maori and Cook Island Maori, which are not as closely related as their names imply. Cook Island Maori come from a group of 15 islands scattered across an area the size of Mexico some $3000 \mathrm{~km}$ north of New Zealand, and began migrating to New Zealand after World War I (Walrond, 2009). The common threat of slipping into cultural oblivion was mentioned by all of the Polynesian participants, and in Max's case, he sees two cultures disappearing in his own ancestral lines. This threat of extinction motivates the artists to practice and to spread their arts: the traditional arts define their groups (symbolically and literally) and stimulate a cohesive social identity in defiance of opposing cultural forces (e.g., Crocker \& Major, 2003; Drury \& Reicher, 1999; 2000; Tajfel \& Turner, 1979).

\section{Cultural and artistic change.}

All situations of cultural adaptation inherently involve some degrees of change. In these data, change may be internal to the artist, as in acquiring differing perceptions, purposes, or techniques, or change may be more external, as in accommodation of new audiences or opportunities. The previous section dealt with cultural maintenance. The following statements by traditional practitioners address the antitheses, cultural alteration into new forms, as they are adapted to new settings and situations. In some cases the changes were simply the result of availability of the materials needed.

52. Jane (Solomons weaver/singer): The basket, that's Melanesian to me, but I call it a fusion because it's New Zealand materials with a Solomon Islands style of weaving. So I call it a fusion. And because the weaving in NZ was different from ours, it's Melanesian. 
She retains the techniques of Solomon Islands weaving, including the patterns and forms, but without access to the traditional raw materials, she has had to adapt to accommodate the materials available. For Harvey, his transitions were a matter of content, in terms of visual imagery, and in the meanings attached to imagery:

53. Harvey (SA visual artist): Because I'd grown up in the countryside, and because the landscape in South Africa is extraordinarily dramatic, and I think I had a very close connection to it, a lot of my work referenced the landscape in some form... I see it as a way of identifying and claiming a space. I can think of, in 14 years in New Zealand, four small sketches of landscape that I've made. Landscape here is so politicized, land is so politicized. And I see myself as standing outside of that debate; I'm a latecomer to it. It's complex, it's thorny, it's very, very difficult, and I'm not part of it. I don't believe I have anything to say. I can make no claims on it; I don't have any observations to make around it.

In South Africa, Harvey's work was, of necessity, constantly politicized in the extremity of the Apartheid debate. Artists were considered to always be making a statement for or against Apartheid, the latter being committed simply by omission of a message of protest. He expressed that he found life in New Zealand wonderfully peaceful after a long life of struggle: his ancestors were not the offenders or the offended, and he feels others can state the issues of Aotearoa much more eloquently. The situation does necessitate a change in his subject matter, but frees him of the burden of being required to convey a political message in the semiotics of imagery, explicating hard meaning by the ways in which images are combined and expressed in each work. He is relieved of the psychological stresses and pressures of that imperative and milieu. For Joey, freedom of imagery and technique was also a primary impetus for his migration, but in a different way.

54. Joey (Samoan modern sculptor): If I was still in Samoa, I would keep repeating myself, what my grandfather is doing. It's a golden opportunity to grow myself up to what I believe is me. There would be a lot of repeating of myself in the cultural ways of doing things. Instead of, not only to go over the boundary, but to explore myself. 
His work refers visually to his native culture in subtle ways, containing certain elements of shape and sign that are vaguely Samoan, but his is very definitely modern art. He chuckles as he speaks about the new opportunities he found by virtue of migration, and the new ways in which he might communicate visually. Had he remained in Samoa, he would not have been exposed to modern art images or techniques, and feels he would have remained within the materials and images of his traditional culture. These influences have allowed a greater depth of selfexploration in addition to opening a wider realm of visual expression.

For traditional performing artists, there are deeper, more existential issues of cultural authenticity and survival. How this is expressed varies, to some extent, by perception of threat to survival and of political marginalization.

55. Max (Maori kapa haka): There is a lot of discussion going on right now about the traditional elements of kapa haka. Particularly the way that we express this culture, our physical expression of our culture through our dance and through our song, there is an ever growing want or need to move it into a contemporary style, in a fashion that becomes more attractive for young people to want to be a part of.

Pasifika and Maori participants expressed particular concern that traditional ways are at risk of being forgotten or diluted as successive generations acculturate and adopt preferences for popular culture. This also is happening frequently in the form of hybridized practices. Palani (Niuean dancer) feels that some of the other Pacific Islands performing groups he has encountered have followed a dangerous pathway which cuts the core from their culture. He feels that by mixing in popular culture elements, the arts are diluting their identity related content and losing authenticity. In such a situation, the dances no longer serve the functions they did in the home environment, and their value as mechanisms of cultural maintenance is reduced or lost. He and other traditional arts participants admit, however, to having made 
accommodations in style for two reasons: to retain the interest of young people in participation, and to make their performances more appealing to diverse audiences.

56. Max (Maori kapa haka): To an extent it's sad that we have to compete, but that's the reality of it. And I-- I don't think it's a matter young people or the culture bowing down to the Westernized pressures if you'd like to call it that, but it's more being pragmatic- taking a pragmatic approach and making it more relevant to the time. But, I completely understand the danger we run into in that.

A popular program in New Zealand is called Stage Challenge, a series of performance contests presented annually by a non-profit organization which is part of the international Global Rock Challenge organization. It is enormously popular, with 17,000 participants in New Zealand alone each year (Stage Challenge, 2009). Max states categorically that without some alteration, such as adding hip-hop dance elements, his students would not choose kapa haka. The dilution and alteration of pristine authenticity is necessitated if the art is to survive.

The corollary issue of change for audience satisfaction is aesthetically and somewhat economically driven, and applies to groups who perform publicly for other ethnicities. The artists who addressed this issue do feel, though, that these performances are necessary to help them fit into New Zealand society, and the income helps assure survival of their ensembles.

57. Mina (Filipina dancer): You cannot really show the traditional, traditional old dances because it will be boring according to the audience, the standard of the audience. You have to do a little bit of improvement in the movement, a little bit of improvement in the-- put some glittering or some bright colours, and the movement itself and the stage presentation will be different.

She does not convey the same depth of existential concern as the Maori and Pasifika participants above. Filipino cultures have survived centuries of colonization and occupation, though the arts have constantly added trans-cultural elements throughout that history. 
These contradictory statements regarding preservation and necessary change hint at underlying ideological and cognitive dissonances for the artists. On the one hand, they are jealously guarding the traditional forms within their cultures, and on the other, they are acting as agents of change to the tradition. They resolve dissonance (cf. Adams, 1961; Festinger \& Carlson, 1959; Triandis \& Triandis, 1960) about these alterations by considering the beneficial effects they perceive as resulting from presentation of their culture to the New Zealand Europeans and to the other ethnic groups around them (see Inter-ethnic section), and by the needed financial support they receive though performances. They also identify and retain core elements by which they identify the arts as uniquely belonging to their culture.

58. Palani (Niuean dancer): What I've done with our dance-- it's not traditional-- I pretty much kept it there, the actions are all the same-- all I've done is make the actions bigger and the beat faster. So when you're on stage, it's all about growing and performing and actually seeing what looks nice, and without going too far off the essence of Niuean dance. You just watch, and then you learn if you're on stage and [if] you do little actions it just doesn't look good at all. So that's what I've done, and it's quite hectic-fast paced.

In this case, he expresses that the core elements are the types of motions, which are the physical expression of the cognitive historical, mythological, and symbolic content, and the musical content, which he implies is not impacted by tempo increase. The movements evolved in the intimate setting of tribal ritual in which there were no limina between performer and audience, and hence there was no need for further entertainment value. All present were deeply aware of how the physical content related to cultural content and purpose of the ritual. When the setting is changed to one of entertainment performance (Arpin, 2003), however, in which the audience may have no prior knowledge of the cultural information being expressed, the artists acknowledge that the form must necessarily change in some way to provide aspects of common understanding between performer and audience, in this 
case entertaining stage performance. He identifies parameters which, he feels, can be altered, and limits beyond which cognitive and cultural disjunction would be too great. In this case, the movements have been amplified to appear more dramatic in a large theatre, and the tempo has increased to a pace that provides an element of excitement without the need for cognitive comprehension of the semiotic content to support that excitement.

\section{Social connections.}

Social interconnection has been demonstrated to be important for psychological health and well-being (e.g., House, Umberson, \& Landis, 1988; Turner \& Marino, 1994). Arts activities in general may provide features beneficial to the strengthening of social networks. In traditional arts, this is an age old process (e.g., Campbell, 1973; Turner, 1985). In non-traditional arts, this principally occurs in group performances or in classroom settings, but often extends to networks of friends who have artistic practices in common. This section discusses the ways in which the artists perceive their practices to provide opportunities for social support and increased social networks, both intra- and inter-ethnically.

\section{Intra-ethnic community cohesion.}

Several traditional artists discussed particular ways in which their arts provided opportunities for connection with co-ethnics:

59. Amy (Chinese dancer): It's a good thing to provide an opportunity to get those young kids to get involved into their cultural group, so they have same identity, same ethnic students, like friends, which they might not have in their schools. They can make more friends with their own cultural group.

House et al. (1988) identified quantity, structure, sustenance provision, conflict level, and regulating quality as elements and processes of social networks in support. 
Traditional arts differ markedly in this data set from non-traditional arts in ways these elements appear. The data above suggest that traditional arts environments are particularly supportive of identity formulation, and here Amy describes ways her students are provided with social supports for identity. Across the traditional arts, the forms of interaction and types of relationships are culturally defined and regulated. Typically, these groups function in harmonious (low conflict) ways, and may be a source of sustenance in response to out-group prejudice. For young people who are studying abroad, increased social networks and identity reinforcement are even more crucial, given their separation from familial support (Ward, Okura, Kennedy, \& Kojima, 1998). Amy's students have come as sojourners for education, and have no family and few friends in New Zealand. The dance classes provide a social network and a Chinese cultural setting for frequent and regular interaction.

Traditional arts can provide a group context in which learning of the culture is shared and reinforced, as is the case with kapa haka:

60. Miko (Maori/Japanese kapa haka): Even in kohanga reo, which is preschool, you learn how to sing within a group of people, and you sort of play with the fact that you're learning it and they're learning it and you've got that part and so we'll remember those, and you just sort of toy with this thing that we're learning until you've all got it. And that starts at a really early age, so you don't even realize you're doing it.

One is learning literally how to be a harmonious part of the collective, while simultaneously learning one's origins in the physical landscape, one's place in a web of heredity and interrelationships, and the ways of behaving and interacting within that culture. The Samoan singer/dancer expresses a specific sense of communality coming from the practice, especially for the youths in his groups.

61. Timo (Samoan dance/music): They all get stuck into it-lose themselves in it, but also they learn the skills of dancing in a line, being together, moving together, singing in rhythm... you're trying to get them to stand still 
to show discipline, to show everybody's ready as a team, as one when you move.

His students are learning how to be a solid part of the group in a manner and context that is particularly Samoan. Being a collectivist culture (M. Mead, 1961), Samoan youth would need to learn to function as part of a group. The more individualistic orientation of the dominant culture and arts does not provide any help in this sort of learning, in fact rewarding more often individual goals and motives. In these dances, they synchronize rhythm and movement, and thereby literally are moving and breathing as one. This art acts as a training program for youth in how Samoans work together in a Samoan way. He also told a story from his church choir about how the group corrects members gently and supportively:

62. Timo (Samoan dance/music): One of our bass singers, the choir master stopped it and said 'could you get your voice back here? It's on holiday.' That was one of the best ways to tell someone they're singing out of tune.

The singer is not told directly that he is singing badly, he experiences no serious embarrassment, but is none the less brought in line. This would seem a very collectively supportive, embracing approach. Western music is not always so kind. Eminent conductor Sir Thomas Beecham was quoted saying to a lady cellist "Madam, you have between your legs an instrument capable of giving pleasure to thousands and all you can do is scratch it" (Langston, 1998, online).

Participants also discussed community level social functions of renewing and maintaining connection with the culture of origin in a context including with less closely related co-ethnics.

63. Ram (Indian Bollywood singer): It strengthens the community. When you do concerts, people gather together and they come for one common goal which is music. It gives them a platform to be united? I think? In a faraway place... so many miles from India, you kind of miss India. Me and the other people who are culturally active, they are quite responsible for, well, you can take us out of India, but you can't take India out of us. So you have to be responsible for that. 
He self-identifies his art as Bollywood singing, a form that grew out of the Indian film industry in the latter twentieth century (Dawson, 2005). The style has become associated with the Indian diaspora, and has been studied in anthropology as a means of creating or negotiating identity in immigration (Luck, 2005; Punathambekar, 2005). Migration has brought together Indians of very different linguistic and cultural origins from across the sub-continent. A pan-Indian style has emerged through the films and the music. This allows a common ground for gatherings of Indians of diverse cultures in diaspora and has resulted in a pan-Indian identity in migration (Dawson, 2005). On the most ancient, basic level, traditional arts happened as an integral part of life in small, closely connected communities, serving functions of increasing cohesion and group harmony (e.g., Donahue, 2005; Fortes, 1970; Sieber \& Walker, 1987). This type of process was described rather fondly by participants, and data reflect continuation of those ancient processes in new contexts, but also of evolution of ways to connect larger, more diverse groups.

A more serious type of support was described by the Niuean dancer, who specifically seeks to bring young Niuean males into his group who would otherwise be at risk of criminal behaviour. He actually goes so far as to consult with police to identify at-risk Niuean youths and attempt to pull them into his ensemble. Though he says there are no actual data to show benefits, he feels that once they are in the group, they are much less likely to find themselves in trouble. His intent is to provide a setting in which pro-social behaviour, enhanced ethnic identity, and enhanced self-esteem are supported by peers and by the community, with the group acting as a vehicle for that support. 


\section{Intergenerational harmony.}

The preceding section dealt with social support networks on a peer-to-peer and community level. This section regards family.

64. Mina (Filipina dancer): When we get together, we sing and dance, and so perhaps I would see-- and I admired my elders who were able to dance, and despite their age, they were able to move their hands and turn and twirl. So perhaps I have also inherited it from them, and I'm glad that the environment encouraged me to develop that liking.

Music and dance were a way for Mina to connect with her elders and to appreciate their tenacity and skill. Social cohesion faces particular challenges in migration and acculturation at a familial level, with tensions between generations having been seen to be a major source of issues and conflicts in that domain (Miller \& Rasco, 2004; Nguyen et al., 1999). As the children adopt Western normative patterns, the result is often an increase in dissonance in their homes (Liebkind, 1996). The continuity of traditional arts practice, transmitted across generations and frequently enacted collectively, creates a linkage between previous and subsequent generations. In the more traditional world, "arts" were woven throughout the fabric of life, connecting generations in continuity of thought, values, behaviours and practices (e.g., M. Mead, 1961). Unlike modern Western culture in which a youth may not want to be seen dancing with elders, she was inspired by the elders to take up dance. While she did say that her family was very arts-oriented, these traditions are a widespread part of Filipino life, even in migration (Andaya, 1996; Machida, 2002).

As the arts pass from generation to generation, elders and students are linked in an ongoing web of reciprocity.

65. Jane (Solomons weaver/musician): That's the tradition way, when you first weave you have to give it to the old people. Everything you learn from the old people. The best friends that I had in Solomons, my favourite friends, are the old people, not young people, but old people. 
O'Donnell et al. (1993) emphasize the importance of reciprocity in activity settings, to which they refer as joint productive activity. This sort of activity particularly meets their stipulation that an activity setting "facilitates learning, relationships, and individual, family, and community development" (p. 506). These traditional activities take place in settings which have evolved to engender particular competencies on both individual and group levels which are specific to the culture and to the knowledge transmitted. In migration, these provide particularly authentic experiential opportunities for successive generations to learn symbols, cognitive content, and behaviours in a culturally accurate manner and context. Jane, the Solomon Islands weaver/musician, is passing her cultural skills to her daughters in New Zealand. Though they seldom go to the Solomon Islands, and they are half New Zealand European, they are learning in an approximation of the activity setting in which they would have learned in the Solomons.

66. Jane (Solomons weaver/musician): we choose weaving and Roviana first at the moment, because I want to have them speak fluent Roviana, then go into weaving and any languages they want to know about Solomons. That's very important to [daughters' names] and I, is communication, to share things, to share about weaving, about music.

As the learning process goes on, the daughters are also learning the languages of the Solomons and, undoubtedly hearing stories, songs, and legends of their mother's people in much the same activity context and manner that their mother and all of their ancestors did. This process provides the information and experiences needed to facilitate their construction of Solomons identity and links them to their ancestors in a continuously shared historical process.

\section{Inter-ethnic connection.}

Inter-ethnic connections were discussed to some degree by all of the participants, with varying implications depending upon the art involved. The 
presentation of arts by minority groups occurs in activity settings in which culture can be shared in a known and non-threatening environment. By exposing their groups to the public in performance or exposition, ethnic artists play a role as representatives of their groups. These usually happen in the settings of theatre, concert hall or gallery, all widely familiar venues.

67. Albert (NZE director/actor): I think there's genuine things-- educational value, appreciation of the richness of cultures... I think any sizeable group can tend to become ghettoized. This sort of cultural activity is one way to-- a very positive way because it has its own enjoyments, enrichments-a way to avoid that happening.

The exposure and accolades of public performance may act in two ways, one within and one between cultures. Within cultures, the favourable perception of the artist by the audience and resulting positive input may bring an increase in collective selfesteem (cf. Crocker \& Luhtanen, 1990) by providing evidence that there are ways in which the ethnic group culture is appreciated and valued by other groups:

68. Amy (Chinese dancer): You express your ethnicity to Auckland, so you kind of like representing your ethnic group, and also you have better networks and more frequent contacts with government, because you are artist, because we performed in quite many functions or performing activities for people in the large area of Auckland.

As an inter-group process, it is reminiscent of the reduction of prejudice observed in relation to Allport's Contact Theory (cf. Pettigrew \& Tropp, 2006; Wright, Aron, McLaughlin-Volpe, \& Ropp, 1997). Allport and those who followed primarily described situations of direct, personal contact, though in recent years the theory has been expanded to include indirect influences of having friends with out-group relations (Wright, Aron, McLaughlin-Volpe, \& Ropp, 1997) and imagined interactions (Crisp \& Turner, 2009). Arts may provide an expansion of the theory to less direct exposure, providing opportunities to learn about the culture, which has been identified as a component in the contact process (Pettigrew, 1998; 2008). 
69. Miko (Maori/Japanese kapa haka): We're always welcoming people from wherever they come from, because we perform at [a large museum]. Whoever walks in from wherever because they see the signs-then we get people tapping on the shoulder going hey, do you mind if I come and listen to you guys sing? Or hey, we want to come and see what you guys do after this.

When exposed to arts of other ethnicities, previous research has demonstrated that the resulting familiarity increases inter-cultural understanding (Sousa, Neto, \& Mullet, 2005). This has been described as happening both because of the pleasant contact with the other and because of the information transmitted and received in the process.

70. Harvey (SA visual artist): At [name deleted] college, which has quite a large proportion of international students, many of them from Asia and Southeast Asia, those students have proved to be really an important part of my ongoing education in terms of the way that they, without even realizing it, challenge certain First World, Western assumptions around culture and artmaking and how you think about it, how you talk about it and so on.

In this case, there is a two-way transmission of information: the students are learning Western arts, and Harvey is learning how they perceive and express within their cultures. In his teaching of students from other cultures, he has been exposed to other ways of thinking and perceiving, the teacher himself learning from his exposure to the students.

There is also a sense of intercultural tolerance mentioned as a direct result of immersion in the arts practices of one's own culture.

71. Max (Maori kapa haka): It makes you more aware, it highlights the differences in society. You become more appreciative, more understanding. I think when you go and practice your own traditional dance and haka, I think you definitely stop and take a look every time you think of difference or you think of cultural division. You can definitely relate more easily to other cultures. It's not the same, but you can more easily put yourself in their shoes and understand that they see the world through completely different eyes as well, and that their world view may not be the same as yours, but on the same token it's not wrong to view the world differently and it's not wrong to want different things from the world. 
He expresses that by coming to a greater understanding of his own culture and his own origins in that world view, he has come to a greater sensitivity toward other cultures and ways of being. While one could become more isolated and intolerant of other views which are not in accord with one's own, his experience has been the opposite. He is well educated and said elsewhere in his interview that university level educational processes were important in formulating his present ways of understanding culture and identity. He remains also, however, part of an ethnic minority struggling for cultural survival, and he sees this struggle as being not unlike the struggles of other minorities and their alternative ways of perceiving and understanding the world as no less valid than his own.

There is potential that by becoming involved in the arts of a different culture one can learn that culture in a very intimate way (see also Miko, \#34). This is a process that Miko sees as unique to this artistic context of inter-cultural interaction.

72. Miko (Maori/Japanese kapa haka): We've had a girl from Germany who was with us for like two years-she mastered the poi, she was amazing! Never seen or heard, sung Maori in her life, and she was part of us, and when she left there were tears. I always think to myself, would there even be any other way to include yourself in a group and be part of that group.

This young woman from a completely different culture came to be a functional part of the group, both practically and emotionally. She learned cognitive and physical aspects of the culture and connected deeply with other group members in the process. Miko sees this as particularly being facilitated by kapa haka practice.

The various arts activities of these non-European artists are seen as having practical implications in New Zealand society.

73. Maxine (Chinese writer/actress): What's happened now because of the new migrants, and a certain amount of whinging on the part of people like me, but also I think, a new generation of writers coming in who write for television and film, but particularly, the real thrust has been in television, and the need to have culturally diverse casts like for Shortland Street, is that 
people are starting to realize that they can write roles for Chinese, and they should be writing roles for Chinese. What some of them still have to get over is getting beyond the stereotype that they're writing for. But it means now that I'm getting called to auditions. To play Chinese roles which are becoming less stereotyped.

In her life as a minority actor and writer in New Zealand, she has seen a gradual transition from very limited inclusion of her culture in public life to a paradigm in which diverse cultures can appear in popular media without controversy. This is a very different milieu from her childhood, when Chinese people were only recently beginning to be accepted in New Zealand society (previously having been shunned and isolated), and she sees this change as coming at least partly through the efforts and contributions of non-European artists throughout her life. Media arts provide particular advantages in communicating inter-culturally on a large scale.

74. Renee (Chinese writer/actress): The next film is about my experiences as an actor in New Zealand, and Asian female stereotypes, the sexual objectification of particularly Asian women-I know it happens to all women but particularly Asian women with the "me so horny" and "me love you long time," and the inscrutable doctor stereotypes as well.

The film will allow some therapeutic release and perhaps a bit of revenge as well. She will convey not only aspects of her personal experiences as an Asian woman frequently faced with stereotypic prejudices, but also the more general inequity of prejudicial treatment of minorities in New Zealand, and this will be broadcast to a national audience on her terms and in her words.

Overall, these artists are playing serious roles in the larger context of sweeping acculturation between ethnic groups of New Zealand. Within their cultures, they provide a means of maintaining and transmitting cultural knowledge and venues for enhancement of interpersonal cohesion. Inter-ethnically, and one might say this especially about the ethnic arts practitioners, they put a face on and provide information about the unfamiliar cultures now interacting in the society. 


\section{Summary}

The psychologically relevant topics discussed by the artists who participated in this study included their motivations, coping strategies, and identity on a personal level, and the cultural and interpersonal dynamics they experience on community and societal levels. To use Hofstede's (1980) conceptualization of culture as "the collective programming of the mind" (p. 21) the artists were well aware of both the content and the process of programming. For instance, when the Samoan youths learn to move together, they are simultaneously learning part of the art, but also part of the behavioural norms for interaction in Samoan culture, and a values structure that says the group is the primary seat of agency. As Maori youth learn kapa haka, they are learning the language, the genealogies teach them their place in the culture, and the stories within the songs teach them the cultural belief system.

There is programming involved in Western arts as well; Harvey started his career studying and expressing himself in the European tradition of painting. He used particular content to express political protest because that was what was appropriate for a person with his beliefs in that time and place. He happily shifted to another visual idiom because it was not his place to access the references encoded in images of the land in New Zealand, and he has learned new ways of perceiving and expressing from his students. He has not, however, learned how to feel and move as part of a collective group from his art. If he learned his ancestry, it probably was not reinforced using mnemonics of song, and would be unique if he has gained a conscious, visceral awareness of his place within the entirety of his cultural history from his practice, though it is possible.

Individually, all participants perceived some personal benefits for their acculturation process from their practice. This is in accord with previous research 
demonstrating that there are benefits for coping with issues and maintenance of selfesteem from participation across arts (e.g., Appalachia Educational Laboratory, 1999; Emerson \& Shelton, 2001; Jones, 1986; Michalos, 2005; Michalos \& Kahlke, 2008). Jim started out in very problematic social conditions of prejudice and exclusion, but went on to construct his identity as a highly successful and respected human artist. He coped with his low social status by redefining himself in such a way that, if there must be social hierarchy, he placed himself at the top, at least in his chosen field. Sue cognitively reframed by creating works that depicted her world being the way she wanted it. Several of the Western genre artists discussed how they resolved their personal issues through their practice.

The traditional artists described more group level concerns and solutions. The arts group provides a network of social support on several levels. There are improved connections to peers and families, as well as within and between ethnic communities. This forms a platform for their sense of security and resilience as part of a tightly woven web of factors contributing to their well-being. As one learns the art, one becomes more self-confident, the process happening in the context of improved social networks. The cosmology in the myths and legends, forming, for example, the lyrical content in kapa haka or the underlying stories in Indian dance, say that the universe is a particular sort of place, one's people came from a certain region in this world, making a particular journey to where and how they live now. The genealogies of Polynesian arts define one's place in the culture, and shared practice in any art teaches that one is tangibly and viscerally part of the group. This is where one belongs and how one fits as a member of the culture. This is your identity and what you need to know to understand that identity, and these are your social resources. Secure in this knowledge and this net of support, say the 
traditional artists, one has the resilience and fortitude to cope with whatever comes and be well. The exact details, of course, vary to some degree by culture and by art. The Bollywood singer is the star of his own show instead of one element in a collective creation, but he is also firmly embedded in the Indian community, and the stories of Bollywood films are frequently drawn from the ancient Hindu texts that continue to inform Indian world view.

These interpersonal and identity influences were uniquely the domain of the traditional artists. Identity, when mentioned by contemporary artists, was individual, and ethnic identity was a concept that caused discomfort. Social network was not mentioned by them. It is therefore proposed that there is a class of arts with unique benefits in acculturation. As mentioned above, there are a range of arts associated with ethno-cultural groups, some of which are more or less traditional than others. Bollywood being a recent development, for instance, does not have a long historical tradition, though the style and content of the songs and dances are uniquely Indian, and it may provide a measure of resources similar to more traditional arts. The class of arts proposed would comprise arts specifically associated with and recognized by an ethnic group as being a product of their cultural and aesthetic system. Western classical music would not qualify, for example, because it has been developed over several centuries by several cultures, including German (Bach), Italian (Vivaldi), and Russian (Tchaikovsky) which have completely different languages and histories. No one culture could claim the art. Bollywood, to be fair, comes from a sub-continent with numerous linguistic and cultural groups, but they have shared political and artistic history to varying degrees for centuries, and they themselves claim Bollywood in diaspora as an over-arching 
means to collective Indian identity and community. Maori kapa haka fits the categorization as an art clearly identified with a particular culture.

The name Traditional and Ethno-cultural Arts (TEA) is proposed for this category of arts to accommodate the range of potential traditions and innovations. The results of this study substantiate that the category may be valid and important, but several serious questions remain: are there measurable psychological implications of TEA participation, does it lead to substantially different outcomes, and are they transferable broadly across ethno-cultural arts and groups? Finally, is it possible to theoretically model the process? The following studies address these questions.

This study is obviously not all encompassing; no study could include an entire world of arts and artists. In fact, there is some weakness in the diversity of the sample, because there is no way to know if the data were complete for any one culture. There is also no way to know the potential input of myriad other cultures. The data contain, however, some commonalities that may form the groundwork for future research which would investigate these processes within specific cultures and across traditional cultures in general. The following studies are intended to begin that work. 


\section{Chapter 3: Implication of TEA participation for ethnic youth}

\section{Introduction}

The preceding study established that practitioners described both commonalities and differences between contemporary/Western arts and traditional/ethno-cultural arts (TEA) in a number of areas. Artists in general believe their arts are good for them and define who they are to some degree, but there are differences in the artists' motivations and, more importantly, in ways the TEA participants learn to relate to their cultures and life situations. Broadly, these ways include themes of coping and identity, the participants developing particular resources in these domains. This second study is intended firstly to clarify whether contemporary/Western arts and TEA participation lead to measurably different outcomes, especially when compared to those who do not participate in arts. The second purpose is to test a model of the process of TEA participation both concurrently and longitudinally. Participants are drawn from a single set of cultures and ages, that being youth of Polynesian ancestry, as described in the Method section below. The acculturation process in this case is primarily between Maori/Pasifika and the dominant European culture. While much acculturation literature regards immigrant/host adaptation, indigenous groups also face serious issues and sequelae of intercultural contact (Berry, 1970; 1995; Walters, 2007).

Study 1 indicated that, consistent with previous literature, arts in general were associated with certain coping resources including increased senses of selfesteem and self-efficacy (e.g., Emerson \& Shelton, 2001; Jones, 1986; Michalos, 2005; Michalos \& Kahlke, 2008) and with improved inter-ethnic social connections. If they spoke of coping-related aspects of their practices, contemporary/Western 
artists primarily used their practice to therapeutically evaluate and re-frame life events and conditions, as well as their sense of identity. TEA participation was associated more frequently with enhanced sense of identity, specifically ethnic identity (EID), and with a wider set of social resources, described as aiding increased resilience. TEA participation particularly provided cultural information and sense of belonging to sense of EID.

In the conclusion of the preceding study, it was demonstrated that these various resources are interwoven in TEA participation to yield advantageous circumstances for participants. Study 1 participants indicated that identity is inculcated in a supportive social environment, in ways that reinforce memory and make the experiences and information relevant. Social networks are established and enhanced across peer, familial, community, and inter-ethnic levels. The result, according to those participants, is a more resilient, aware, and identified person able to resist or bear more comfortably the negative aspects of acculturation. Altogether, identity and connectedness aspects of TEA participation, along with other resulting aspects of enhanced coping, may result in more adaptive outcomes for ethnic groups at risk in acculturation settings. These resource topics are discussed at greater length, in terms of previous research and potential utility for use in the study to follow. The various types of social resources mentioned in the previous study fall within the content of connectedness literature, which is described below. Also described in detail are definitions and concepts of well-being, improvements in which are the anticipated outcome of arts and TEA participation. 


\section{Benefits of arts programs in general.}

As mentioned in the introduction, arts-based social and community programs have begun to appear with increasing frequency over the past few decades, based on a belief that they provide multiple benefits to participants (Bucknavage \& Worrell, 2005; Johnson \& Stanley, 2007; Stickley, 2007). Several governments have begun overarching programs such as the Arts and Health Agenda in Great Britain (Stickley, 2007) and the Community Arts Development Scheme in Australia (Johnson \& Stanley, 2007) to foster such activities. Research into the relative value, merits, and effects of extra-curricular activities in general has yielded a mix of results from very beneficial to damaging (Bucknavage \& Worrell, 2005). Thorough research of high quality that actually measures effects and outcomes is surprisingly rare, much of the "evidence" being anecdotal (Rapp-Paglicci et al., 2006; Stickley, 2007). Stickley (2007) comments, "until the right kind of evidence is produced, the evidence remains marginalized and will continue to be subject to criticism” (p. 336).

The current body of research does indicate positive possibilities, particularly in youth groups. For instance, participation in the arts was associated with lower average substance abuse and attenuated increases in usage over time (Fauth, Roth, \& Brooks-Gunn, 2007). In the Youth Arts Public Art program in Oregon, participants improved their cooperation skills, attitudes toward school, and resistance to peer pressure and decreased their delinquent activities. The evidence is not overwhelmingly strong, however, since complete data were available for only 21 participants. As with many programs, attrition rates are high and data are difficult to collect. Other program evaluations mentioned increased self-esteem, math and reading skills, conflict resolution skills, and more positive relationships (RappPaglicci et al., 2006). 
A number of arts programs have specifically targeted at-risk or minority populations. John, Wright, Duku, and Willms (2008) assessed the effectiveness of a Canadian multi-site controlled arts program targeting low income youth from multicultural communities by comparing participants with scores from the National Longitudinal Survey of Children and Youth. They found a significant decrease in emotional problems, though they suggest that this may have been an effect of afterschool supervision, as was observed by Richardson, Radziszewska, Dent, and Flay (1993), rather than any inherent benefit of arts. In Orange County, California, an experimental group of at-risk students were sent to a program called 'Summer at the Center.' It was observed that their GPA increased significantly compared to the control group, and future arts participation also increased, implying potential for cumulative effects (Coronado, 2000). Research that is more sensitive to the type of student, ethnicity, and activity have more frequently demonstrated value of prosocial arts activities (e.g., Eccles, \& Barber, 1999; Fredricks \& Eccles, 2008; Marsh \& Roche, 1996), though ethnic program outcomes are even more rarely assessed due to cultural differences and logistical difficulties (Coppens, Page, \& Thou, 2006).

\section{Traditional and Ethnic Arts (TEA) Programs.}

The implications of participation in ethnic arts activities for communities and individuals have been discussed for many years in the fields of anthropology, sociology, and cultural studies. As observed in those disciplines, such arts affect connectedness factors including cohesion and reduced conflict on community and family levels, and support ethnic identity (EID) and belongingness on an individual level. Indigenous arts, for instance, have been observed to be a specific method to increase levels of connection to the individual's ethnic group and community (Dole \& Csordas, 2003; Hill, 2004). These observations are most frequently the result of 
qualitative studies and do not address psychological constructs or measure specific outcomes (Stickley, 2007).

Study 1 participants particularly emphasized the importance of these arts for youth. In situations of minority or immigration status, TEA groups may form a particular subset of arts programs with unique potential for benefit to participants who are growing up in a national cultural milieu not related to their own historical culture. Coppens et al. (2006) observed a program of instruction in Cambodian dance for young Cambodians living in a large Cambodian American community in the north-eastern US. The stated goals of the program were to "increase awareness and pride in Cambodian culture, promote healthy behaviors, and create linkages within the community (p. 321)." The outcomes of that program demonstrated positive influences. In one interview excerpt, for instance, a young woman related that before the program, she and her mother had no common ground for communication, a condition which was remedied by her participation. This strongly reflects the findings of Study 1, and supports the possibility that TEA programs may have significant and transportable benefits in multiple cultures.

Hugget (1992) documented the efforts of Ana Tia, who taught Maori culture to inmates in the Auckland area of New Zealand for some 25 years. Her students spoke of lasting improvement in attitude and a new-found sense of direction. In 2002, kapa haka became an academic part of New Zealand curriculum, counting toward graduation from secondary schools. The action drew protests, primarily from right-wing politicians (Niesche, 2002). Whitinui (2008) used qualitative methods to assess the effectiveness of the program, which is believed to lead to greater participation and retention in education for Maori, who are consistently lower-performing scholastically, in no small part because schools fail to address 
unique cultural and learning-style differences. Findings from the students were that kapa haka participation:

- reaffirms who they are (essence and identity) as Māori and therefore provides a collective purpose to want to learn;

- develops a sense of learning success by performing what they know through the art of movement;

- enhances and enriches the learning experience- singing, dancing and performing actions simultaneously were considered a very dynamic, powerful and creative way of learning;

- constructs learning responsibilities that are shared (i.e., experience of whole-group or team learning) reducing individual learning anxiety, stress and isolation;

- elicits positive emotions including joy, fun and an overall sense of happiness about attending school and in some ways increases their desire to succeed at school;

- improves individual confidence, self-esteem/self-worth and commitment to participate in the learning environment. (p.9)

The teachers indicated that the activity:

- improves individual confidence, self-esteem and their understanding of a Māori identity;

- helps teachers to identify some of the specific learning talents, strengths and aspirations Mãori students possess and in which may well be extended on in the classroom;

- enhances Mãori students' sense of pride in their culture, school and relationships with others;

- improves levels of attendance, engagement and a stronger desire for Māori students to want to succeed in their education;

- supports Māori students to use and strengthen various cognitive processes including memory, problem-solving and imaging as well as their ability to think more conceptually;

- supports Māori students to make healthier decisions/choices and enables them to contribute more positively to life at school and within the community. (p.9)

The present study examines the differential outcomes of TEA and Western arts participation for a group of Maori and Pasifika youth in New Zealand. The sample is divided between those who participate in an art associated with their ethnic group, in this case Maori and Pasifika music/dance, other arts not associated with the group, primarily Western classical or modern arts, or no arts. From the results of Study 1, it is anticipated that the TEA practices will favourably influence 
the participants' sense of identity, as well as the quality and quantity of their social networks, and thereby lead to better well-being outcomes. To test group differences as well as the process model, several measures are employed. These measure sense of identification with the ethno-cultural group (ethnic identity or EID), strength and quality of interpersonal sense of connectedness, and well-being in a number of domains. These concepts are described in more detail below.

\section{Identity.}

Identity would seem to be a basic assumption of human existence, that "set of ideas about who they are and with whom they belong by which humans define themselves" (Grahame, 1998, p. 156). To enter in discussion of acculturation, one must first address identity, and more specifically, ethnic or cultural identity, which Grahame (1998) argues is an inevitable part of being human. At the core of any discussion of the psyche are questions of identity: who are we, how did we get to be that, why do we choose to stay that way, and how do we interact with others around us as that entity we have identified as self? Historically, identity has been conceptualized to some degree in contrast to "the other" not-self (Laurence, 1998; Marshall, 1998). In acculturation, identity is seen as being negotiated primarily by minority group members in relation to a dominant group, including adaptation of indigenous groups to colonial groups (e.g., Berry, 2006), as is the case with the Maori having to accommodate the presence of New Zealand Europeans.

\section{Ethnic identity.}

Cultural, racial, or ethnic identity (EID) has become an increasingly important consideration in the study of minority and non-Western groups (e.g., Hill, 
2006; Jones, Cross, \& deFour, 2007; Saylor \& Aries, 1999; Umaña-Taylor, 2004). Phinney (1996) defines it as "an enduring, fundamental aspect of the self that includes a sense of membership in an ethnic group and the attitudes and feelings associated with that membership" (p. 922). Social Identity Theory (Tajfel, 1981) refers to a person's sense of membership in a social group or groups and the emotional and evaluative significance of the membership(s). Gone (2006) refers to cultural identities, which are intentionally constructed to render life comprehensible to the individual within a culture or community, balancing convention and structure with agency and individual intention. Participants in the previous study specifically identified ways in which arts in general rendered their identities more comprehensible, the TEA participants most specifically discussing their sense of identity as positively tied to ethnic group membership.

The key aspects of EID described in the literature have included a dimension of attitudes and feelings, such as belongingness and commitment, values and attitudes, attitudes toward one's group, or contrasting, more practically oriented dimensions including language, behaviour, values, and cultural knowledge (Phinney, 1990). Ward (2001) lists belongingness (the degree to which one feels group membership), centrality (the degree to which one bases identity on group membership), evaluation (perceptions of the group), and tradition (participation in and practice of cultural activities, and acceptance of values and norms). In presentation of her Multigroup Ethnic Identity Measure (MEIM), Phinney's (1992) list of components included self identification and ethnicity, ethnic behaviours and practices, affirmation and commitment, and ethnic identity achievement (a developmental process by which one comes to a secure sense of self as a member of the group). 
A body of literature positively connects level of EID with a variety of improved outcomes and indices. Stronger EID has been increasingly associated with aspects of more positive well-being in a number of studies (e.g., Gray-Little \& Hafdahl, 2000; Ryff \& Keyes, 1995; Tsai, Ying, \& Lee, 2001; Umaña-Taylor, 2004; Umaña-Taylor, Diversi, \& Fine, 2002). Higher levels of ethnic identity and higher regard for one's ethnic group have also been associated with higher Quality of Life, another concept or indicator of well-being (Kiang, Yip, et al., 2006; Utsey, Chae, Brown, \& Kelly, 2002) and increased self-esteem (Rowley, Sellers, Chavous, \& Smith, 1998). Noh et al. (1999) found that stronger EID allowed their participants to utilize better forbearance as an effective coping mechanism against the effects of prejudice.

EID is particularly regarded as important for youth who are not members of the dominant ethnic group. Higher (stronger) EID as measured by the Multigroup Ethnic Identity Measure (MEIM) (Phinney, 1992) has been correlated with positive self-affirmation and improved psychosocial adjustment among Navajo youth (Jones \& Galliher, 2007). Other associations with higher EID among youth include better school adjustment (Oetting \& Beauvais, 1990), higher academic achievement (Spencer, Noll, Stoltzfus, \& Harplani, 2001), and adherence to anti-drug norms (Kulis, Napoli, \& Marsiglia, 2002). Further, EID has been linked to higher selfesteem, self-confidence, and life purpose (Jones \& Galliher, 2007; Martinez \& Dukes, 1997). Jones and Galliher (2007) observed clear associations between positive psychosocial development, ethnic identity commitment, and belonging. They recommend the fostering and encouragement of identity by the Navajo community as an instrumental way to improve the lives of Navajo adolescents. 


\section{Connectedness.}

The results of Study 1 suggest that ethnic identity is supported in TEA participation by the presence of and interaction with the co-ethnics doing the art together. John Donne's famous quote which posits that no one can exist as an island (1624/1987) reflects the endurance of this truth. Maslow (1943) placed love and belongingness needs midway in his hierarchy of needs, above basic survival and safety needs, but prerequisite for higher order fulfilments. The characteristics of these necessary inter-relationships with others have begun to be researched and described as connectedness (Barber \& Schluterman, 2008; Baumeister \& Leary, 1995; Townsend \& McWirter, 2005). The concept bears some explanation at this time, since it formed an increasingly central focus of this research.

Connectedness as a concept in psychology has been discussed in terms of senses of belonging, inclusion, caring, interdependence, or emotional closeness (Flanagan, Cumsille, Gill, \& Gallay, 2007; Hardaway, \& Fulghini, 2006; Hynie, Lalonde, \& Lee 2006). Shannon (2002) posits that it is via relationships and interconnections, whether on physical, mental, emotional, social, or spiritual levels, that a person is defined. To Baumeister and Leary (1995), connectedness is a "pervasive drive to form and maintain at least a minimum quantity of lasting, positive and significant interpersonal relationships"' (p. 497). Belongingness is a related concept included within connectedness (Hill, 2006), but the concepts differ in that connectedness can be more encompassing, as in a feeling of connectedness to nature (Hill, 2006; Mayer \& Frantz, 2004). Another similar term is social relatedness, which overlaps conceptually with social support (Gest, Welsh, \& Domitrovich, 2005). Connectedness has received increasing attention in recent years, but the concept has been difficult to specify, perhaps due to an evolution of 
definition, as well as the variety of concepts related to or subsumed in connectedness research (see Townsend \& McWirter, 2005 for a comprehensive review of connectedness literature). Though diverse, comments from a number of participants in Study 1 fall within these domains of connectedness literature.

The increased investigation of connectedness in psychology reverses previous trends in which the discipline has viewed individuality and autonomy as normative (Townsend \& McWirter, 2005) and devalued intimacy or relatedness (Rude \& Burnham, 1993). There is, conversely, a literature that began in anthropology and sociology regarding collectivism, the importance of and connection to family and/or community groups (e.g., Kluckholn \& Strodbeck, 1961; G. Mead, 1967). The contrast of individualism and collectivism has been found to be an important dimension of intercultural differences (Hofstede, 1980) in domains of variation of including communality of social processes, resource allocation, and motivations (e.g., cf. Kluckhohn \& Strodtbeck 1961; G. Mead, 1967; Triandis, McCusker, \& Hui, 1990). In individualist cultures, the individual places importance on personal goals over those of a group (Wagner, 1995) and is perceived to be a separate and distinguishable entity. In collectivist cultures, self and goals are construed to be inseparably linked to family, tribal group, or some other definably collective set (Hill, 2006; Markus \& Kitayama, 1991; Petrova, Cialdini, \& Sills, 2007). In the literature of I-C, non-Western societies are consistently found to be higher in Collectivism and lower in Individualism. This places the level of being at which goals are defined and decisions are made, also called level of entitativity, at more of a group than individual level (Kashima, Kashima et al., 2005; Yamaguchi, 1994). Thus, appropriate function in non-Western contexts may require a greater degree of connectedness, though this may vary across social contexts. Connection 
within the ethno-cultural group was a frequent topic for TEA practitioners in Study 1 and has been shown in other research to be particularly important for the wellbeing of indigenous peoples (Dole \& Csordas, 2003; Hill, 2006; Thomas \& Bellefeuille, 2006) and acculturating minorities (Saylor \& Aries, 1999).

Recent research has actually indicated that diminished levels of connectedness may have psychopathological consequences in any culture (Baumeister \& Leary, 1995; Katz, 1985; Townsend \& McWirter, 2005). Increasingly, lack of connectedness is seen to put one at risk of alienation, loneliness, and lack of purpose or motivation (Bellingham, Cohen, Jones, \& Spaniol, 1989; Cordingly \& Webb, 1997). Further, recent research has linked lack of Connectedness to a number of physical impacts, including increased stress hormones, decreased immune function, and impaired cardiovascular function, along with disruptions of cellular regulation processes, bringing predisposition to premature aging (Cacioppo \& Patrick, 2008). From more of a positive psychology perspective, Connectedness has been linked to reduction of aggression (Twenge, Zhang, et al., 2007) and improved mood (Twenge, Baumeister, Tice, \& Stuke, 2001; Twenge, Catanese, \& Baumeister, 2003), both of which have correlation with improved well-being. A sense of Connectedness appears to be crucial, regardless of the types of social domains in which one is embedded (Kohut, 1984; McGraw, Moore, Fuller, \& Bates, 2008).

Connectedness, as described in the literature, happens within a number of domains, most notably those of family, peer, school (for youth), and community. Perception of what constitutes a healthy level of family connectedness varies across ethnicity, though endorsement of family as a primary source of self-concept seems to be a cross-cultural constant (Hardaway \& Fulghini, 2006). Community or 
neighbourhood connectedness also appears to cross ethnic boundaries, with a number of researchers finding relations between well-being and these realms of connectedness (e.g., Chavis, Hogge, McMillan, \& Wandersman, 1986; Chipuer \& Pretty, 1999). Peer and school Connectedness are closely related for adolescents, and are associated with improved well-being, better school performance, reduced negative affect, and reduced delinquency (McGraw et al. 2008).

Migration increases the difficulty of maintaining connectedness and the associated risks through loss of social networks and changes in social contexts (Jablensky et al., 1994). Frequently, there are changes in availability of friends, family, and other co-ethnics, though peers of similar cultural background and history of migration with similar attitudes and experiences with out-group members may ameliorate these losses, when available. For immigrants, indigenous groups and ethnic minorities, the degree of difference between the host culture and the heritage culture may also affect sense of connectedness, with greater differences bringing more sense of anomie (Hoerder, 2002; Issawi, 1998). The valuing of connectedness to family has been observed to remain salient in acculturation and across acculturating generations (Naidoo \& Mahabeer, 2006; Phalet \& Schönpflug, 2001), though, in practice, difficulties arise. Younger generations are socialized more directly by peers and schools, creating a generational rift regarding values and behaviours, especially around obedience and respect, increasing discord and decreasing family cohesion (Liebkind, 1996; Miller \& Rasco, 2004; Nguyen et al., 1999) Connectedness to family has been shown to be highly important to psychological health and well-being (Wilkinson, 2004) and to sense of identity (Hall \& Brassard, 2008), making this a particularly important issue in acculturation. 


\section{TEA and Connectedness.}

A fundamental component of life and world view of many indigenous and non-Western cultures is that our lives and world are intricately and inextricably interconnected, leading to a particular emphasis on the necessity of strong and harmonious connections for well being (c.f. France, 1997; O’Donnell, 1999; Durie, 1995; Pradittatsanee, 2000;). As discussed in the introduction, facilitation of sense of connectedness through traditional arts practices such as music and dance has been researched in other social sciences. Turner $(1985 ; 1986)$ described the processes whereby ritual performance brings sense of communitas, for instance. Dole and Csordas (2003) observed that Navajo youth developed their sense of connectedness through their participation in traditional ceremonies. O'Hagin and Harnish (2006) observed improved community and inter-ethnic connectedness through performance of Latino music. Similar observations were made for musical gathering of Chinese and Argentinean migrants (Farrer, 2004; Viladrich, 2005, respectively), and for the many Indian communities of their diaspora in which Bollywood functions are sites of community and peer connection (Penethumberkar, 2005).

The activities of ethnic arts, as described in the preceding sections, all engender and encourage connectedness on familial, peer, and community levels. In this way, these arts can serve as prophylaxis against the isolation that can occur in migration through loss of social networks (Jablensky et al., 1994). As discussed above, connectedness has been linked to both identity and well-being in other research (Hall \& Brassard, 2008; Wilkinson, 2004). Also discussed above are ways in which other disciplines have observed facilitation of connectedness across peer, family, and community levels. Connectedness may be a critical element in the 
phenomena of TEA participation, potentially forming a central link in possible influences of TEA on well-being outcomes.

\section{Well-Being.}

UN Declaration of Human Rights (1948), Article 25. (1) stipulates:

Everyone has the right to a standard of living adequate for the health and well-being of himself and of his family, including food, clothing, housing and medical care and necessary social services, and the right to security in the event of unemployment, sickness, disability, widowhood, old age or other lack of livelihood in circumstances beyond his control.

"Well being is also viewed as a process, something we do together, and as sense-making, rather than just a state of being” Haworth \& Hart, 2007 p.I

Since the adoption of the UN Declaration of Human Rights (1948), the subject of well-being has been increasingly debated and researched (Haworth \& Hart, 2006). The constitution of the World Health Organization (WHO, 1946/2006) states that "Health is a state of complete physical, mental and social well-being and not merely the absence of disease or infirmity" (p.1). Greve (2008) laments, however, that well-being is a transitory state, difficult to define, and worse yet, comprising more of an evaluation of a state depending on surrounding systems and standards rather than being an objective state itself. Haworth and Hart (2007) summarize that well-being "has been viewed as happiness, satisfaction, enjoyment, contentment, and engagement and fulfilment, or a combination of these and other hedonic and eudaimonic factors" (p. 1). There is no absolute consensus or definition, except that it is something desirable that everyone should possess.

\section{Conceptualization of well-being}

"What would happen if we studied what is right with people?" Former Gallup CEO Donald Clifton (Snyder \& Lopez, 2007, p. 53). 
Kammann and Flett (1986) proposed two definitions for well-being, emerging from literature and prior research: “(a) a complete and lasting satisfaction with life as a whole; (b) a preponderance of good or pleasurable feelings and a scarcity of unpleasant feelings (p.3)." In psychology, well-being is generally conceived to consist of several factors, hopefully measurable, which vary from study to study. McKennell (1978) found that the indicators of perceived well-being used in scales at that time were a conceptual mix of both affect and cognition. Diener (1984) discusses literature regarding subjective well-being which includes happiness, life satisfaction, and positive affect. In development of the Satisfaction with Life Scale the following year, Diener et al. (1985) identified three distinct components of subjective well-being relevant to its measurement: positive affect, negative affect, and life satisfaction, the latter concerning the cognitive-judgemental aspect of well-being. Among strong predictors suggested by Diener most relevant to this research are social contact, activities, and self-esteem. For their WHO health paper on well-being, Nacpal and Sell (1985) identified eight areas they perceived to be related to and indicative of well-being in an effort to encompass all of these various components or indices. These areas were:

Subjective well-being -- positive affect

Subjective well-being -- negative affect

Mental mastery over self

Rootedness, belongingness

Structural and cohesive aspects of family life

Density of social network

Security in crisis (socio-economic and related to health)

Expectation-achievement harmony (p.13)

These areas, excepting negative affect, are indicators of good things in a person's life, an approach associated with the growing positive psychology movement (Seligman \& Csikszentmihalyi, 2000). Diener (1984) discussed the paradox that, while philosophers have eternally considered happiness to be the 
ultimate human goal and state, psychology has largely only focused on extensive exploration of human unhappiness. Seligman and Csikszentmihalyi (2000), in the introduction to a special issue of American Psychologist on positive psychology, expound that, rather than conceptualising health as an absence of disease, true health includes a constellation of positive traits, characteristics, and evaluations. Wellbeing can be conceptualized as a collection of positives rather than an absence of negatives. The positive attributes may potentially be nurtured, supported, and facilitated (Haworth \& Lewis, 2005) or protected using resources such as anticipation, altruism, humour, sublimation, and suppression (Vaillant, 2000). In other words, well-being can be created and maintained (Haley, 2007; Haworth \& Hart, 2007).

The creation and maintenance of well-being was discussed by the traditional artists in Study 1. Max (Maori kapa haka, quote \#17) opined, “you can build yourself up to be so grounded and so confident that when those things come flying at you they just bounce off." The arts practice leads one to become more stalwart and secure, and thereby able to avoid ill effects in the potential risks of acculturation (c.f. Jablensky et al., 1994). Those with higher resilience thrive when others do not (Anthony \& Cohler, 1987; Cicchetti \& Garmezy, 1993; Hurtes \& Allen, 2001). This resilience and self-efficacy, learned and supported in the TEA participation process, may form an important part of participants' ongoing well-being.

Contextual factors also play a role in well-being, including economic and demographic factors influencing the status of families, organizations, and communities, which in turn impinge upon or support individual well-being (Haworth \& Hart, 2006; Kagan \& Kilroy, 2007; Prilleltensky \& Prilleltensky, 2007). Little, in his 1961 article "The Social Architect," suggests that people may be 
assisted "to lead more satisfying lives through their spontaneous association with other people, that is, in the context of their natural groupings in ordinary community life" (p. 603). The influence of sense of community on individual well-being has been discussed for some time, pivotally by Sarason (1974), and continuing, especially in the field of Community Psychology (Bishop, Colquhoun, \& Johnson, 2005; Christakopoulou, Dawson, \& Gari, 2001; Davidson \& Cotter, 1991; Kagan \& Kilroy, 2007; Sarason, 1974). Individual well-being happens with and is influenced by social support and social context (Albrecht \& Adelman, 1984; Pahl, 2006; Prilleltensky \& Prilleltensky, 2006).

As discussed above, traditional arts provide a socially supportive context, both within and between communities (Dole \& Csordas, 2003; O’Hagin \& Harnish, 2006), providing resources for the social support of well-being on individual and community levels. The traditional artists in Study 1 also discussed ways in which their practices provided specific social supports, as has been observed in other disciplines. Given the previous research linking connectedness, identity, and wellbeing (Hall \& Brassard, 2008; Wilkinson, 2004), it may be that TEA participation provides particular resources enhancing well-being in acculturation, in this study concerning contact between the Polynesians and Europeans of New Zealand.

\section{This study.}

This study is intended to test empirically whether arts participation yields measurable differences in outcome for youth, and whether there are measurable differences by type of art (traditional or Western/contemporary). The variables employed were suggested by Study 1 data, exploring EID, connectedness, and wellbeing, and testing whether these components can be modelled as a process both 
concurrently and longitudinally. Literature and the previous study suggest that arts participation will be beneficial for participants' EID, connectedness, and well-being (e.g., Clawson \& Coolbaugh, 2001; Heath, 2001). Though the mechanisms by which these benefits come about remain poorly defined (Stickley, 2007), there is growing evidence that arts participation does somehow promote well-being (Stickley, 2007; Rapp-Paglicci et al., 2006), and that traditional arts specifically bring about increased sense of connectedness and cultural identity (Dole \& Csordas, 2003). Thus, there is reason to expect that arts participation in general will positively influence outcomes and that, as the results of Study 1 suggest, these improvements will be most pronounced for TEA participants.

$\mathrm{H}_{1}$ : TEA participants will exhibit greater levels of EID than both of the other groups. $\mathrm{H}_{2}$ : TEA group will exhibit significantly greater Connectedness than Other Arts, which will in turn exhibit stronger Connectedness responses than the no-arts group.

$\mathrm{H}_{3}$ : TEA group will exhibit significantly greater Well-Being than Other Arts, which will in turn exhibit stronger Well-Being responses than the no-arts group.

Previous research has demonstrated links between enhanced EID and improved well-being (e.g., Jones \& Galliher, 2007; Martinez \& Dukes, 1997; Phinney, 1992), as well as between connectedness and well-being (e.g., Flanagan et al., 2007; Hardaway \& Fulghini, 2006; Hynie, Lalonde, \& Lee 2006). Based on Study 1 results and the literature of EID, connectedness, and well-being discussed above, a model of the influences of TEA participation on well-being is hypothesized as diagrammed in Fig. 3.1. The diagram shows direct influence of TEA participation on ethnic identity and sense of connectedness. The influence on connectedness comes through the social networks with peers and community that are enhanced by TEA participation, as well as the increased intergenerational connection with family. The influence on identity would operate primarily through 
the learning of cultural information and rehearsal of behaviours. A direct influence also flows from EID to connectedness, EID having been observed to support connectedness in previous research regarding participation in traditional arts (e.g., Dole \& Csordas; 2003; Saylor \& Aries, 1999), and fitting well with views expressed in Study 1. Enhancement of both EID and connectedness would influence the wellbeing of the TEA participants.

These paths shall be tested with both cross-sectional and longitudinal data. Longitudinal testing using a cross-lagged panel analysis approach permits the identification of possible bidirectional associations between variables over time, more accurately investigating the directionality of influences between variables. There are limitations to this approach, however, since the assumption of stationarity, that the causal structure remains stable over time, can rarely be proven (Kline, 2005). This is also true of the requirement that there are no correlated causes omitted from the model (Kline, 2005; Maruyama, 1998). Still, the analysis provides some additional insight into relations between the variables that cannot be gleaned from concurrent models.

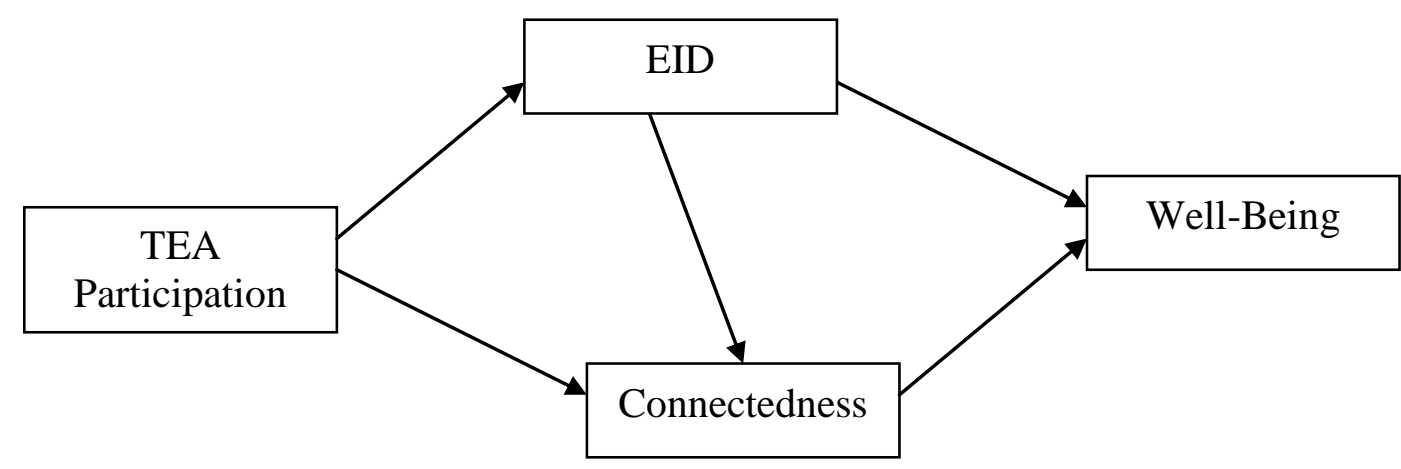

Figure 3.1. Proposed path model of arts participation influences on Well-Being 


\section{Method}

\section{Procedure.}

Data for this study were drawn from the Youth Connectedness Project, a study of New Zealand adolescent youth administered by the Roy McKenzie Centre for the Study of Families under the direction of Drs. Paul Jose and Jan Prior, during 2006 for the first wave and through 2008 for the third wave. The project was funded by a grant from the New Zealand government (the Foundation for Research, Science, and Technology, or FRST). The project investigated youth well-being, focusing on the connectedness of youths to their peers, families, schools, and communities, and including identity and well being measures. The study had been previously designed and implemented when Fox became involved, his role being data management and certain analyses. His contributions included annual bivariate coding and reconciliation of extra-curricular activities and ethnic identities, along with mean score calculations for scales and subscales of a wide range of measures. These were used in the analyses which follow and form data resources made available to other researchers.

Participants were recruited from 78 schools on Te Ika a Maui, the north island of Aotearoa (New Zealand) based on a stratified random sampling approach, which provided participants from diverse socioeconomic and regional conditions. After obtaining the consent of at least one parent and the adolescent prospective participant, the participants completed a survey in the presence of research assistants, administered on laptop computers provided for the study. Upon completion, they were given a token of appreciation, consisting of a chocolate bar or movie voucher, depending on availability. 


\section{Participants.}

The entire sample in the first year included 2,184 youths of various ethnicities. Their ages in the first year ranged from nine to fifteen. By Year 3, attrition reduced this number to 1,729 . Of these, there were 675 participants of Maori and/or Pasifika origin who comprised the set that was used for all analyses ${ }^{1}$. Other ethnicities were not included in these analyses because it was not clear whether there would be equivalence in terms of importance of ethnic identity (EID), relations of arts activities to culture of origin, or issues of acculturation. The sample included 306 males (45.3\%) and 369 females (54.7\%). The mean age for the sample was 11.94 in the first year $(\mathrm{SD}=1.67)$.

\section{Measures.}

Several scales are used in these analyses (see Appendix B for questions), plus categorical responses for participation in activities including Western and traditional/ethnic arts. The instruments were selected and/or created by the staff of the McKenzie Centre under the direction of Drs. Jan Pryor and Paul Jose with the assistance of a Maori advisory committee. The scales used in these analyses measured the constructs of Connectedness, EID, and Well-being. Higher scores on all scales indicate more positive responses, i.e. greater Connectedness, stronger EID, and greater Well-Being. In cases where scales were "adapted" (see below), this was done by project staff to make items comprehensible to nine year olds, and to keep the overall length of the survey reasonable for youth.

\footnotetext{
${ }^{1}$ Data were checked for outlying participants using Mahalanobis $\mathrm{D}^{2}$ and stem-and-leaf plots (Pallant, 2007). Violations were noted for 17 participants who were removed, yielding the final sample size of 675.
} 


\section{TEA Participation.}

The TEA activities included in this study were kapa haka (a traditional set of Maori musical and dance forms) and Pacific Islands "cultural groups" (which also practice traditional Polynesian dance and music). TEA participation was determined by coding of responses from a list of activities both in and out of school with an additional category of "Other," in which the participant could type their own responses. Coding categories of Western arts choices included Drama, Music, Marching band, Dance, Ballet, Classical music, and Visual arts. TEA participation categories were kapa haka, Pacific Islands Dance, and Cultural Groups, which include cultural music and dance components. All categories were then recoded to reflect participation in Traditional and Ethnic Arts (TEA), participation in "Other Arts" activities, or No Arts participation. The No Arts category comprised those who indicated no activity and those who indicated categories including Student Council, Sports, Special interest (e.g. computers or debate), Library assistant, Peer mediation, and Patrols. Total numbers for arts participation are reflected in Table 3.1 and Fig 3.2. The No Arts group is largest in all years, and becomes fully $72.7 \%$ of the sample in Year 2. This represents a 2/3 drop in arts participation, which was only partly reversed in Year 3 (see Psychometrics section below for further information).

\section{Ethnic Identity (EID).}

EID items (six) were adapted from the Multigroup Ethnic Identity Measure (MEIM) (Phinney, 1992), including "I am happy to be a member of this ethnic group." These were rated on a five-point scale from (one) "Strongly disagree" to (five) "Strongly agree." 


\section{Connectedness.}

Connectedness was measured with a 35 item scale including sections to assess connectedness to family, peers, and school, as well as a general social support scale. The ten family connectedness items related to cohesion, identity, and mutual activities, and was generated for the study by the McKenzie Centre staff, with cohesion and mutual activities items being influenced by FACES II items (Olson, Portner, \& Bell, 1982). The items included, for example, "My family/whanau asks each other for help" and "We are proud to be members of our family/whanau." These items were rated on a five-point scale from (one) "Never/Almost never" to (five) "Always/Almost always."

The ten school connectedness items included three regarding teacher relationships, five regarding school community, and two regarding relationships with class- and schoolmates. Teacher and School Connectedness items are loosely adapted from the Psychological Sense of School Membership Scale (Goodenow, 1993) and the School Connectedness Scale (Blum, McNeely, \& Rinehart, 2002), and the school peer connectedness items were generated for the study. Items included "I always get an opportunity to talk to my teacher," and "I like going to my school/kura." These items were rated on a five-point scale from (one) "Strongly disagree," to (five) "Strongly agree." School peer items included "How well do you get on with your classmates?" rated on a five-point scale from (one) "not at all well" to (five) "really well."

Connectedness to peers outside school were measured by three items generated for the study and included "I can trust my friends with my personal problems," rated on a five-point scale from (one) "Strongly disagree" to (five) "Strongly agree." General social support items (12) were adapted from the Social 
Provisions Scale (Cutrona \& Russell, 1987), including "There is someone in my life who tells me I am special," rated on a five-point scale from (one) "Strongly disagree" to (five) "Strongly agree." A composite mean was created for Connectedness from the items listed above.

\section{Well Being.}

The 24 item Well-Being scale included items designed to measure general well-being (11 items), life satisfaction (three items), resilience (four items), positive affect (three items), and self-efficacy (three items). The general well-being items were adapted from the Ryff Wellbeing Scales (Ryff \& Keyes, 1995), including "I work hard now to create a good future for myself" and "Most people think I am a nice person," and the Rosenberg Self-Esteem scale (Rosenberg, 1965) including "I feel confident and positive about myself." All were rated on a five-point scale from (one) "Strongly disagree," to (five) "Strongly agree."

The positive affect items were adapted from the Center for Epidemiologic Studies Depression Scale (CES-D Scale) (Radloff, 1977), including "I enjoyed life” rated for the previous week on a five-point scale from (one) "Less than 1 day" to (five) "5-7 days." Life satisfaction items were adapted from the Diener scale (Diener, Emmmons, Larsen, \& Griffin, 1985), including “I am happy with my life," rated from "Strongly disagree," to "Strongly agree." Self efficacy was rated by three items following the question, "How well do you think you are doing" in these areas? Areas were classes, clubs, and sports, rated on a five-point scale from (one) "Very poorly" to (five) "Excellent." State resilience was adapted from the Resilience Scale (Niell \& Dias, 2001), including "I can find a way to solve my problems," rated from "Strongly disagree," to "Strongly agree. 


\section{Results}

The following results are divided into three sections, the first being the psychometrics of the study. The second includes analyses of differences in outcome measures between TEA participants, participants in "Other" arts, and those who participate in No Arts activities. The third section presents results of path analyses of the concurrent and longitudinal relationships between and among Arts Participation and the EID, Connectedness, and Well-Being variables.

\section{Psychometrics.}

Participation in arts by category is presented below in Table 3.1. There was a significant change of status each year (see Cross-tabulations section below), indicating arts participation was highly unstable across years. This change is illustrated in Fig. 3.2, showing the contrast between arts participation of both types and the numbers who do not participate in arts in Year 2.

Table 3.1

Type of arts participation by year

\begin{tabular}{llcc}
\hline & $\mathbf{n}$ & $\mathbf{\%}$ \\
\hline Year 1 & No arts & 309 & 45.8 \\
& Other arts participation & 150 & 22.2 \\
& TEA participation & 216 & 32.0 \\
\hline Year 2 & No arts & 491 & 72.7 \\
& Other arts participation & 55 & 8.1 \\
& TEA participation & 129 & 19.1 \\
\hline Year 3 & No arts & 385 & 57.0 \\
& Other arts participation & 106 & 16.7 \\
& TEA participation & 184 & 27.3 \\
& Total & 675 & \\
\hline
\end{tabular}




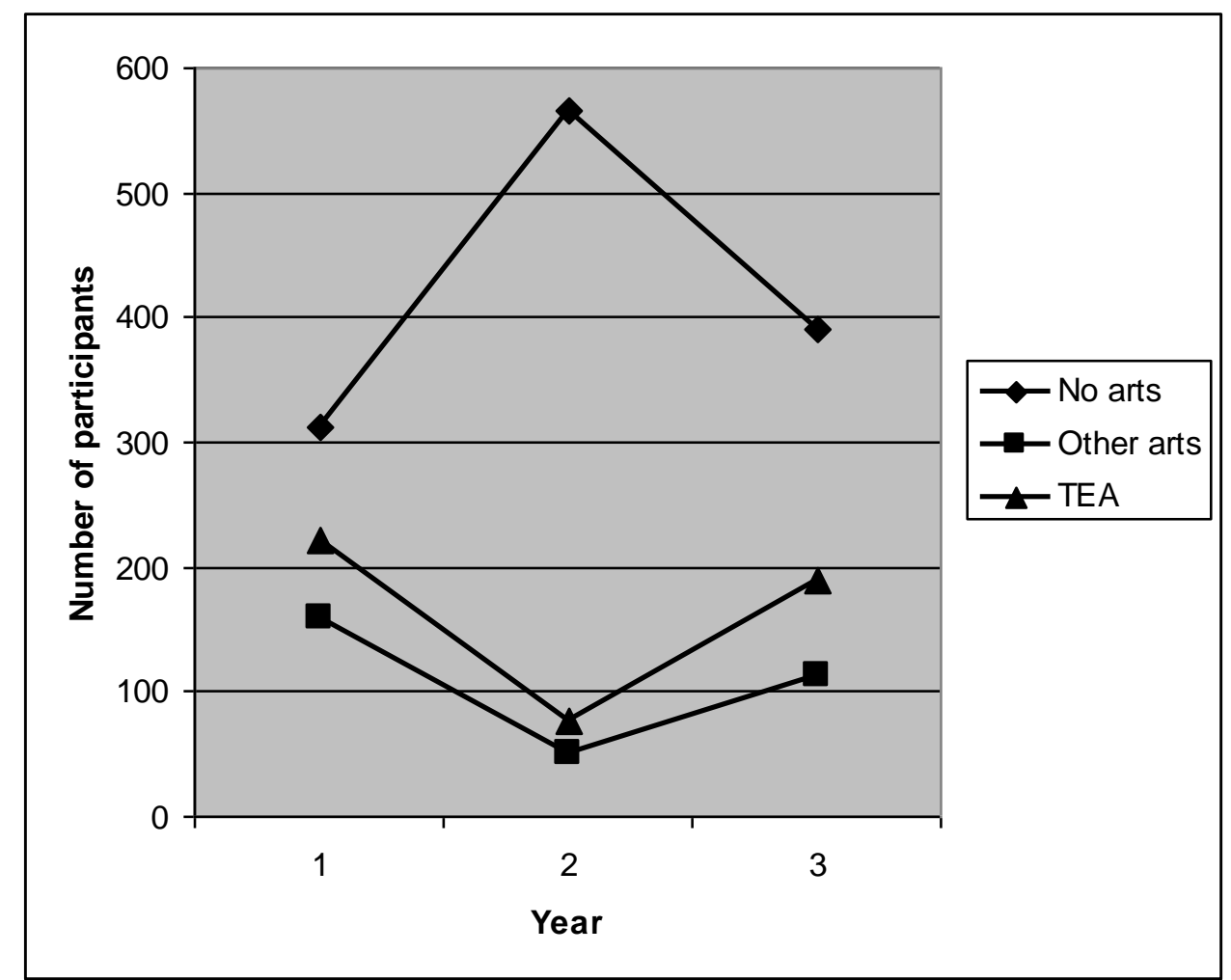

Figure 3.2. Study 2 arts participation levels by year

\section{Cross-tabulation for participation categories.}

Chi-square significance was calculated for consistency of arts participation over the three years. All chi-square tests for contiguous years were significantly different at $p<.01$. From Year 1 to Year 2 and from Year 1 to Year 3, 52\% of participants remained in the same category of participation. From Year 2 to Year 3, stability was slightly greater at $62 \%$. These results indicate that participation varies significantly across years. 


\section{Descriptives and reliability.}

Means and other descriptive statistics for each scale in each year are presented below in Table 3.2. Cronbach's alphas for reliability of the subscales fell within an acceptable range, ranging from .83 to .94 (Briggs \& Cheek, 1986).

Table 3.2

Study 2 scale descriptives and reliability

\begin{tabular}{lccccccc}
\hline Scale & Year & $\begin{array}{c}\text { \# of } \\
\text { items }\end{array}$ & Mean & SD & Skewness & Kurtosis & $\begin{array}{c}\text { Cronbach's } \\
\text { alpha }\end{array}$ \\
\hline Well Being & 1 & 23 & 3.77 & 0.66 & -0.35 & 0.97 & .87 \\
& 2 & & 3.72 & 0.73 & -0.52 & 1.12 & .85 \\
& 3 & & 3.74 & 0.71 & -0.31 & 0.54 & .91 \\
$\begin{array}{l}\text { Connected- } \\
\text { ness }\end{array}$ & 1 & 40 & 4.10 & 0.46 & -0.47 & -0.08 & .94 \\
& 2 & & 3.80 & 0.53 & -0.61 & 0.51 & .93 \\
& 3 & & 4.05 & 0.50 & -0.38 & -0.10 & .92 \\
EID & 1 & 6 & 3.83 & 0.49 & -0.49 & 0.31 & .84 \\
& 2 & & 4.04 & 0.49 & -0.36 & -0.16 & .83 \\
& 3 & & 3.79 & 0.55 & -0.53 & 0.18 & .87 \\
& & & & & & & \\
\hline
\end{tabular}

Mean Group Difference Analyses.

To determine differences by arts participation for each dependent variable in each year, a MANOVA was performed with the arts participation variable for the year as the fixed factor and the EID, Connectedness, and Well-Being measures for the year as dependent variables. A mean score of each construct was calculated for each participant. For cases which had missing data after creation of means, group means were inserted.

Preliminary assumption testing was conducted for the entire data set with checks for normal distribution (skewness and kurtosis, Table 3.2), univariate and 
multivariate outliers, homogeneity of variance-covariance matrices, and multicollinearity.

\section{MANOVA for Year 1.}

A Multivariate Analysis of Variance (MANOVA) was conducted to determine differences between TEA participants, Other Arts participants, and No Arts participants on responses for overall outcome measures of Well Being, Connectedness, and Ethnic Identity, as averaged for each participant from all items within each construct. Variable means are displayed in Table 3.3.

A significant difference across groups was found in the omnibus test: $F(6,1340)=13.84, p<.01 ;$ Wilks' Lambda $=.89 ;$ partial eta squared $=.06$. All dependent measures yielded significant differences between arts participation categories: $F(2,672)=37.40, p<.01$, partial eta squared $=.10$ for EID; $F(2,672)=14.38, p<.01$, partial eta squared $=.04$ for Connectedness; and $F(2,672)=9.84, p<.01$, partial eta squared $=.03$ for Well Being. Observed power of .98 to 1.0 for each DV makes Type II errors unlikely. 
Table 3.3

Descriptive statistics for TEA, Other Arts, and No Arts participation, Year 1

\begin{tabular}{llccc}
\hline Variable & Participation group & Mean & Std. deviation & N \\
\hline EID & No Arts & 3.61 & 0.61 & 309 \\
& Other Arts & 3.66 & 0.63 & 150 \\
& TEA participation & 4.07 & 0.66 & 216 \\
Connectedness & No Arts & 4.00 & 0.47 & 309 \\
& Other Arts & 4.12 & 0.48 & 150 \\
Well Being & TEA participation & 4.21 & 0.40 & 216 \\
& No Arts & 3.74 & 0.49 & 309 \\
& Other Arts & 3.85 & 0.51 & 150 \\
& TEA participation & 3.93 & 0.47 & 216
\end{tabular}

These results confirm the hypothesis that there would be differences between groups based on participation. Based on the significant F-ratio levels, a post-hoc pair-wise Tukey HSD comparison of groups was performed (Table 3.4). For group comparisons in the EID variable, the TEA group differed significantly from both the Other Arts and the No Arts group without significant differences between the Other Arts and the No Arts groups, supporting $\mathrm{H}_{1}$. In Connectedness, the No Arts group had the lowest scores and differed significantly from both the Other Arts and the TEA groups, but there was no significant difference between the TEA and Other Arts groups. This partly confirms $\mathrm{H}_{2}$. In Well-Being, the only significant difference was between the No Arts and TEA groups, only partly confirming $\mathrm{H}_{3}$. 
Table 3.4

Tukey HSD post-hoc comparisons by group for Year 1

\begin{tabular}{|c|c|c|c|c|c|}
\hline \multirow{2}{*}{$\frac{\text { Variable }}{\text { EID }}$} & \multicolumn{2}{|c|}{$\begin{array}{c}\text { Groups } \\
\text { compared }\end{array}$} & \multirow{2}{*}{$\begin{array}{c}\begin{array}{c}\text { Mean } \\
\text { Difference }\end{array} \\
-.04\end{array}$} & \multirow{2}{*}{$\begin{array}{c}\begin{array}{c}\text { Std. } \\
\text { Error }\end{array} \\
.06\end{array}$} & \multirow{2}{*}{$\frac{\text { Sig. }}{0.76}$} \\
\hline & No Arts & Other Arts & & & \\
\hline & & TEA participation & $-.46^{*}$ & .06 & $<0.01$ \\
\hline & Other Arts & TEA participation & $-0.42 *$ & 0.07 & $<0.01$ \\
\hline \multirow[t]{3}{*}{ Connectedness } & No Arts & Other Arts & $-.12 *$ & .04 & 0.03 \\
\hline & & TEA participation & $-.21 *$ & .04 & $<0.01$ \\
\hline & Other Arts & TEA participation & -0.09 & 0.05 & 0.12 \\
\hline \multirow[t]{3}{*}{ Well Being } & No Arts & Other Arts & -.11 & .05 & 0.09 \\
\hline & & TEA participation & $-.19 *$ & .04 & $<0.01$ \\
\hline & Other Arts & TEA participation & -.08 & .05 & 0.24 \\
\hline
\end{tabular}

* Mean difference is significant at $p<.05$

\section{MANOVA for Year 2.}

A Multivariate Analysis of Variance (MANOVA) was conducted to determine differences between TEA participants, Other Arts participants, and nonarts participants on responses for overall outcome measures of Well-Being, Connectedness, and Ethnic Identity in Year 2 to determine generalizability of Year 1 scores. Variable means are displayed in Table 3.5.

A significant difference across groups was found in the omnibus test: $F(6,1340)=10.61, p<.01 ;$ Wilks' lambda $=.91 ;$ partial eta squared $=.05$. All measures yielded significant differences between arts participation categories: $\mathrm{F}(2,672)=29.63, p<.01$, partial eta squared $=.05$ for $\mathrm{EID} ; \mathrm{F}(2,672)=8.09$, $p<.01$, partial eta squared $=.03$ for Connectedness; and $\mathrm{F}(2,672)=4.16, p<.01$, partial eta squared $=.02$ for Well Being. These results confirm that there are significant differences between groups in all dependant variable measure scores. 
Table 3.5

Descriptive statistics for TEA, Other Arts, and No Arts participation Year 2

\begin{tabular}{llccc}
\hline Variable & Participation group & Mean & Std. deviation & N \\
\hline EID & No Arts & 3.60 & 0.71 & 491 \\
& Other Arts & 3.83 & 0.63 & 55 \\
& TEA participation & 4.12 & 0.69 & 129 \\
Connectedness & No Arts & 4.00 & 0.50 & 491 \\
& Other Arts & 4.18 & 0.40 & 55 \\
Well Being & TEA participation & 4.16 & 0.43 & 129 \\
& No Arts & 3.76 & 0.54 & 491 \\
& Other Arts & 3.89 & 0.49 & 55 \\
& TEA participation & 3.89 & 0.52 & 129
\end{tabular}

These results also confirm the hypothesis that there would be differences between groups based on participation. Based on the significant F-ratio levels, a post-hoc pair-wise Tukey HSD comparison of groups was performed (Table 3.6). For group comparisons in the EID variable, the TEA group differed significantly from both the Other Arts and the No Arts group without significant differences between the Other Arts and the No Arts groups, again supporting $\mathrm{H}_{1}$. In Connectedness, the No Arts group had the lowest scores and again differed significantly from both the Other Arts and the TEA groups, but there was no significant difference between the TEA and Other Arts groups. This again partly supports $\mathrm{H}_{2}$. In Well-Being, the only significant difference was again between the No Arts and TEA groups, only partly supporting $\mathrm{H}_{3}$. These results are congruent with Year 1 analyses. 
Table 3.6

Tukey HSD post -hoc comparisons by group Year 2

\begin{tabular}{lllccc}
\hline $\begin{array}{l}\text { Dependent } \\
\text { Variable }\end{array}$ & \multicolumn{2}{c}{ Groups compared } & $\begin{array}{c}\text { Mean } \\
\text { Difference }\end{array}$ & $\begin{array}{c}\text { Std. } \\
\text { Error }\end{array}$ & Sig. \\
\hline EID & No Arts & Other Arts & -0.23 & 0.10 & 0.05 \\
& & TEA participation & $-0.52^{*}$ & 0.07 & $<0.01$ \\
& \multirow{2}{*}{ Other Arts } & TEA participation & $-0.29^{*}$ & 0.11 & 0.03 \\
\hline Connectedness & \multirow{2}{*}{ No Arts } & Other Arts & $-0.18^{*}$ & 0.07 & 0.02 \\
& & TEA participation & $-0.16^{*}$ & 0.05 & $<0.01$ \\
& \multirow{2}{*}{ Other Arts } & TEA participation & 0.02 & 0.08 & 0.95 \\
\hline Well Being & No Arts & Other Arts & -0.13 & 0.08 & 0.18 \\
& & TEA participation & $-0.13^{*}$ & 0.05 & 0.03 \\
& \multirow{2}{*}{ Other Arts } & TEA participation & $<0.01$ & 0.09 & 1.00 \\
\hline
\end{tabular}

* Mean difference is significant at $p<.05$

\section{MANOVA for Year 3.}

A Multivariate Analysis of Variance (MANOVA) was conducted to determine differences between TEA participants, Other Arts participants, and nonarts participants on responses for overall outcome measures of Well-Being, Connectedness, and Ethnic Identity in Year 3 to determine whether results were generalizable across the three years. Variable means are displayed in Table 3.7.

A significant difference across groups was again found in the omnibus test: $\mathrm{F}(6,1340)=6.42, p<.01 ;$ Wilks' Lambda $=.95 ;$ partial eta squared $=.028$. All measures yielded significant differences between arts participation categories: $\mathrm{F}(2,672)=17.32, p<.01$, partial eta squared $=.05$ for $\mathrm{EID} ; \mathrm{F}(2,672)=5.17$, $p<.01$, partial eta squared $=.02$ for Connectedness; and $\mathrm{F}(2,672)=6.25, p<.01$, partial eta squared $=.02$ for Well Being. These results confirm that there are significant differences between groups in all dependent variable measure scores. 
Table 3.7

Descriptive statistics for TEA, Other Arts, and No Arts participation Year 3

\begin{tabular}{llccc}
\hline Variable & Participation group & Mean & Std. deviation & N \\
\hline EID & No Arts & 3.64 & 0.71 & 385 \\
& Other Arts & 3.66 & 0.58 & 106 \\
& TEA participation & 4.00 & 0.70 & 184 \\
Connectedness & No Arts & 4.00 & 0.50 & 385 \\
& Other Arts & 4.08 & 0.57 & 106 \\
Well Being & TEA participation & 4.15 & 0.45 & 184 \\
& No Arts & 3.73 & 0.57 & 385 \\
& Other Arts & 3.79 & 0.59 & 106 \\
& TEA participation & 3.91 & 0.48 & 184 \\
\hline
\end{tabular}

These results confirm the hypothesis that there would be differences between groups based on participation. Based on the significant F-ratio levels, a post-hoc pair-wise Tukey HSD comparison of groups was performed (Table 3.8). As in the group comparisons of the EID variable in Years 1 and 2, the TEA group differed significantly from both the Other Arts and the No Arts group without significant differences between the Other Arts and the No Arts groups, again supporting $\mathrm{H}_{1}$. In Connectedness, the No Arts group had the lowest scores and again differed significantly from the TEA group but not the Other Arts group, and again there was no significant difference between the TEA and Other Arts groups. This less strongly supports $\mathrm{H}_{2}$, given the lack of difference between the Other Arts group and either other group. In Well-Being, the only significant difference was again between the No Arts and TEA groups, only partly supporting $\mathrm{H}_{3}$. The results are relatively stable across years, with congruence in EID and Well-Being differences, but not in Connectedness. 
Table 3.8

Tukey HSD post -hoc comparisons by group for Year 3

\begin{tabular}{lllccc}
\hline Variable & & $\begin{array}{c}\text { Groups } \\
\text { compared }\end{array}$ & Mean Difference & $\begin{array}{c}\text { Std. } \\
\text { Error }\end{array}$ & Sig. \\
\hline EID & No Arts & Other Arts & -0.02 & 0.08 & 0.96 \\
& & TEA participation & $-0.35^{*}$ & 0.06 & $<0.01$ \\
& \multirow{2}{*}{ Other Arts } & TEA participation & $-0.33^{*}$ & 0.08 & $<0.01$ \\
\hline Connectedness & No Arts & Other Arts & -0.08 & 0.05 & 0.36 \\
& & TEA participation & $-0.14^{*}$ & 0.04 & $<0.01$ \\
& \multirow{2}{*}{ Other Arts } & TEA participation & -0.06 & 0.06 & 0.52 \\
\hline Well Being & \multirow{2}{*}{ No Arts } & Other Arts & -0.05 & 0.06 & 0.64 \\
& & TEA participation & $-0.17^{*}$ & 0.05 & $<0.01$ \\
& \multirow{2}{*}{ Other Arts } & TEA participation & -0.12 & 0.07 & 0.18 \\
\hline
\end{tabular}

* Mean difference is significant at $p<.05$

In summary, the three groups differed significantly in EID as predicted in each year, strongly supporting $\mathrm{H}_{1}$. In Connectedness, results were not consistent, with differences between the No Arts and TEA groups in all years, but with differences between No Arts and Other Arts only in Years 1 and 2, and with no differences between the TEA and Other Arts group in any year. This partly fails to confirm $\mathrm{H}_{2}$, though results suggest that participation type is to some degree affecting Connectedness. In Well-Being, there were differences only between the No Arts and TEA groups in any year, minimally supporting $\mathrm{H}_{3}$.

\section{Path Analyses.}

Path modelling was chosen as the method to explore the relations between variables (Kline, 2005). Path modelling also has the ability to test effectively hypothetical models for accuracy (Buhi, Goodson, \& Neilands, 2007; McCoach, Black, \& O'Connell, 2007), and its use throughout concurrent and longitudinal 
analyses maintains consistency in presentation of results. The models were specified (Bentler, 1980) and tested using AMOS software, version 17.0.0 (Arbuckle, 2008). Tests for significance of indirect effects were performed in LISREL 8 (SSI, 2008). For these analyses, the arts variable included only categories for TEA participation and no TEA participation (TEAP), given that the three categories utilized in group comparisons above do not meet strict criteria for ordinal data. For comparison, Other Arts was modelled against No Arts (Appendix C) to determine whether the same paths would result. The resulting models differed from the TEA/No TEA models in significance of paths, model fit, path loadings, and variance explained, justifying use of the TEA/No TEA categories as representative of a unique process differing from effects of Other Arts participation.

The observed variables were constructed as in the MANOVA section, using means for Connectedness, Well-Being, and EID to approximate normal distribution for the items (Hancock \& Mueller, 2006). Correlations of the scales which comprise the observed variables for the analyses are presented below in Table 3.12.

Based on the theoretical background presented in the introduction and the resulting hypotheses, the model in Figure 3.1 was proposed for concurrent year data, with Arts Participation exerting influence on both EID and Connectedness, EID also directly influencing Connectedness, and EID and Connectedness influencing WellBeing.

\section{Fit indices.}

Several fit indices are presented for each model and sample, as is recommended practice, due to the varying strengths and sensitivities of different tests (Byrne, 2006; Buhi, Goodson, \& Neilands, 2007; Hu \& Bentler, 1999; Joreskog \& Sorbom, 1996). Chi-square should ideally be non-significant, indicating 
no significant difference between the sample data and the model as specified, though this statistic has been observed to be affected by sample size. The chi-square divided by degrees of freedom $\left(\chi^{2} / \mathrm{DF}\right)$ is a common indicator used to compensate for sample size ramifications and should be as low as possible, with five being a recommended high cut-off (Kline, 2005).

The Goodness-of-Fit Index (GFI) has been found to perform well as an absolute fit index, estimating how well the sample data are represented by the model (Hu \& Bentler, 1999; Marsh, Balla, \& McDonald, 1988). It measures the absolute amount of variance and covariance explained by the model (Hu \& Bentler, 1999; Joreskog \& Sorbom, 1986). A perfect fit would have a GFI value of one, and values greater than .90 are considered to be acceptable (Meyers, Gasmst, \& Guarino, 2006).

The Comparative Fit Index (CFI) has long been a recommended fit index (Bentler, 1980; Byrne, 2006). The test judges fit by comparison to a hypothetical unparameterized model (Hu \& Bentler, 1999) and remains stable in conditions of small sample size or violated assumptions ( $\mathrm{Hu} \&$ Bentler, 1995; Hu \& Bentler, 1999). The CFI value approaches a maximum of one as fit improves, with values from .90 to .95 considered acceptable (Bentler, 1980; Byrne, 2006; Meyers, Gasmst, \& Guarino, 2006).

Root Mean Square Residual (RMR) also compares the proposed model to a hypothetical null model, in this case using the average residual value resulting from fitting of the proposed model to the null model (Byrne, 2006). In a well-fitting model, the value should be .05 or less (Byrne, 2006; Hu \& Bentler, 1999).

Root Mean Square Error of Approximation (RMSEA) is considered to be one of the most sensitive absolute indices due to its sensitivity to model complexity (Byrne, 2006). Improvements in fit result in smaller RMSEA values, with values 
below .05 considered optimum, though values less than .08 have been deemed acceptable (Meyers, Gasmst, \& Guarino, 2006) and MacCallum, Browne, and Sugawara (1996) argued for acceptance of values up to .1.

\section{Year 1 model.}

For the theoretical model as proposed (Fig. 3.1), the resulting $\chi 2(1, \mathrm{~N}=675)=.265, p=.68$, the GFI and CFI were 1.00 , the $\chi^{2 / \mathrm{DF}}$ (chi-squared value divided by the degrees of freedom) was .265 , the RMR was $<.01$, and the RMSEA (root mean square error of approximation) was $<.01$, suggesting that the model yielded exceptionally good fit (e.g., Byrne, 2006). However, the path from EID to Well-Being proved not to be significant $(\beta=.03, p=.25)$, and the path from Arts to Connectedness was also non-significant $(\beta=.07, p=.07)$, contrary to key predictions of this model. The $\chi^{2}$ and fit indices are well within recommendations, with the GFI actually indicating a perfect fit, possibly due to the small degrees of freedom. The non-significant paths were trimmed from the model (e.g. Kline, 2005), creating a more parsimonious model and adding degrees of freedom potentially to reduce overfit. Removal of these paths provided somewhat less model overfit (Fig. 3.3), $\chi 2(3, \mathrm{~N}=675)=4.81, \quad p=.19, \chi^{2 / \mathrm{DF}}=1.60, \mathrm{GFI}=1.00$, $\mathrm{RMSEA}=.03, \mathrm{RMR}<.01, \mathrm{CFI}=1.00$, and all $\beta$ values were significant at $p<.01$. The analysis substantiated only three of the proposed paths of influence, but yielded an interpretable model with no non-significant paths. Paths from TEAP to EID, EID to Connectedness, and from Connectedness to Well-Being were confirmed. The influence of TEAP on Connectedness is mediated by EID, and those influences on Well-being are in turn mediated by Connectedness (see Table 3.9 for indirect effects). 


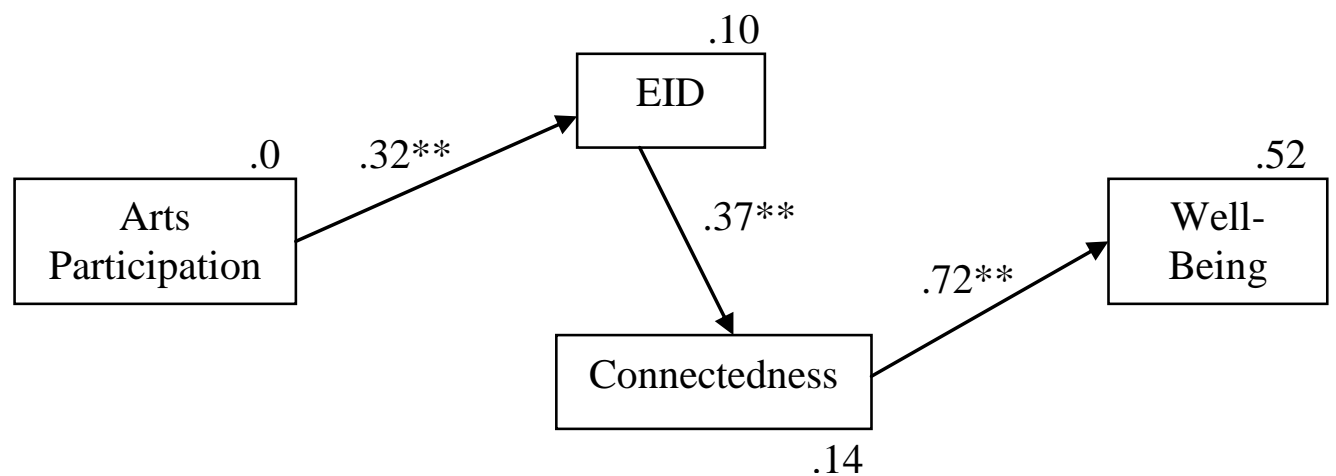

** significant at $p<.01$

Figure 3.3. $\beta$ weights, significance, and direct effects in Year 1 Arts Participation model (Note: indirect effects are found in Table 3.9)

\section{Year 2 model.}

Upon completion of Year 2 data collection, the resulting Year 1 model (Fig. 3.3) was again tested using a confirmatory or cross-validation strategy of model testing (Cudek \& Brown, 1983). The resulting model provided excellent fit, $\chi^{2}(3, \mathrm{~N}=675)=2.70, p=.44, \chi 2 / \mathrm{DF}=.90, \mathrm{GFI}=1.00, \mathrm{RMR}<.01, \mathrm{CFI}=1.00$, RMSEA $<.01$, and all $\beta$ values were significant at $p<.01$ (Fig. 3.4). Given the exploratory nature of this research, modification indices were consulted to determine whether inclusion of additional paths would improve the model (cf. Schumacker \& Lomax, 1996). The modification indices indicated no significant improvements would be found by including additional paths. Again, the influence of TEAP on Connectedness is mediated by EID, and those influences on Well-being are in turn mediated by Connectedness (see Table 3.9 for indirect effects). 


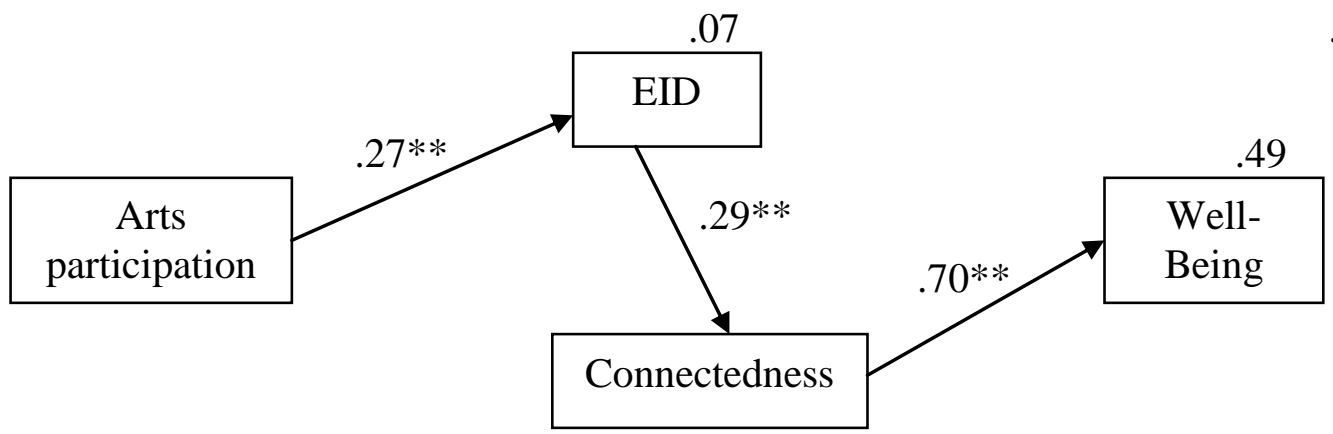

.08

** significant at $p<.01$

Figure 3.4. $\beta$ weights, significance, and direct effects in Year 2 Arts Participation model (Note: indirect effects are found in Table 3.9)

\section{Year 3 model.}

Data collection for the YCP project was completed during the writing of this thesis. Due to the ad-hoc nature by which the theoretical model was altered, the altered model (Fig. 3.3) was re-specified and retested using Year 3 data. This allowed further confirmation of the model, and potentially the amelioration of effects of inconsistent TEA participation across years. In this model, the $\left.\chi^{2(3, N}=675\right)=13.76, p<.01$ indicated that the model differed significantly from the sample data. While this may be an artefact of large sample size (e.g. Kline, 2005), it may also indicate a mis-specified model. This provides another reason to retest the original theoretical model. In this case, the $\chi 2(3, \mathrm{~N}=675)=1.52, p=.22$ was non-significant, indicating no significant difference between the model and the sample data. Examining the model, the path from EID to Well-Being was significant, though with a low $\beta$ weight $(\beta=.09, p<.01)$. The direct path from TEAP to Connectedness was again not significant $(\beta=.03, p=.40)$. After removal of the TEAP to Connectedness path, the resulting model provided acceptable fit, with a non-significant $\chi^{2}(2, \mathrm{~N}=675)=2.45, p=.29$. Indices were: $\chi^{2 / \mathrm{DF}}=1.22$, $\mathrm{GFI}=1.00, \mathrm{RMSEA}=.02, \mathrm{RMR}<.01, \mathrm{CFI}=1.00$, and all $\beta$ values were 
significant at $p<.01$ (Figure 3.5). In this model, the influences of TEAP on Connectedness were mediated by EID, and the influences of EID and Connectedness on Well-Being were both direct, with additional partial mediation of associations of EID with Well-Being via Connectedness. This model confirmed significance of four path relations between variables in the original hypothetical model, though the path from TEAP to Connectedness was still eliminated. In this case, EID again mediates the influences of Arts participation on Connectedness and Well-Being (see Table 3.9 for indirect effects). Once again, the original hypothetical model failed to be substantiated in its entirety but the resulting model is interpretable.

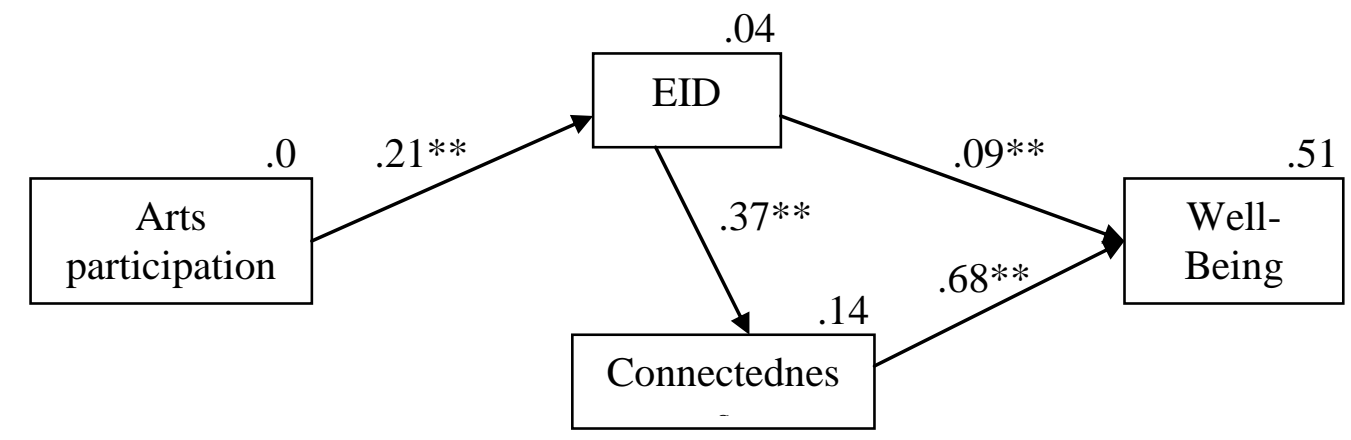

** significant at $p<.01$

Figure 3.5. $\beta$ weights, significance, and direct effects in Year 3 Arts Participation model (Note: indirect effects are found in Table 3.9)

Table 3.9

Standardized indirect effects by concurrent year model

\begin{tabular}{lcc}
\hline Variable & $\begin{array}{c}\text { Arts } \\
\text { Participation }\end{array}$ & EID \\
\hline Y1 Connectedness & .12 & - \\
Y1 Well-Being & .08 & .27 \\
\hline Y2 Connectedness & .08 & - \\
Y2 Well-Being & .06 & .20 \\
\hline Y3 Connectedness & .08 & - \\
Y3 Well-Being & .08 & .25 \\
\hline All
\end{tabular}

All effects are significant at $p<.01$ 


\section{Longitudinal model.}

At the conclusion of data collection, a longitudinal model was specified using the three years of data in order to explore the structure and directionality of links between variables using a cross-lagged panel analysis and to assess longerterm influences of TEA participation over time, and potentially to clarify discrepancies between years of data. Examination of the significance of crosslagged paths between variables across time in a longitudinal model has been suggested as a way empirically to establish directionality of causal links more definitively than can be done in concurrent models (Hunter \& Gerbing, 1982; Kim, Kim, \& Kim, 2009). In this case, longitudinal testing also allowed an additional avenue to investigate discrepancies between theoretical and measurement models, and between differing years. Correlations of variables are presented in Table 3.12.

A model was constructed including cross-lag paths between variables over time. Covariances were included between residual error terms of variables within a given year to control for the possibility of bi-directional influences in concurrent years. This model was then pruned by eliminating non-significant paths one by one, beginning with the least significant while also checking modification indices, resulting in the model in Figure 3.6. The resulting model provided acceptable fit: $\chi^{2}(32, \mathrm{~N}=675)=49.73, p=.03, \chi^{2 / \mathrm{DF}}=1.55, \mathrm{GFI}=1.00, \mathrm{RMSEA}=.03$, $\mathrm{RMR}=.01, \mathrm{CFI}=1.00$. While the $\chi^{2}$ value is below $p=.05$, the number of analyses would suggest the more conservative level of $p<.01$ to indicate a significant difference between model and data. For clarity of presentation, covariance paths between error terms of concurrent year variables are not shown in the figure (Table 3.10), nor are stability coefficients between years (Table 3.11). 
Covariance of concurrent year variables.

It was expected that there would be significant positive covariance between all concurrent year error terms in the longitudinal model, which would reflect the relationships obtained in the concurrent year models above. All variables covaried significantly in Year 1. All covaried in Year 2 except TEAP, which covaried only with EID. The Year 3 variables covaried similarly to Year 2, except that the TEAPEID covariance became weaker (see Table 3.10).

Table 3.10

Covariance of concurrent year error terms (Standardized) in longitudinal model

\begin{tabular}{|c|c|c|c|c|c|c|}
\hline \multirow{3}{*}{$\begin{array}{l}\text { Origin } \\
\text { Year } 1\end{array}$} & \multicolumn{6}{|c|}{ Covariants } \\
\hline & \multicolumn{2}{|c|}{ EID } & \multicolumn{2}{|c|}{ Connectedness } & \multicolumn{2}{|c|}{ Well-being } \\
\hline & $\beta$ & Sig. & $\beta$ & Sig. & $\beta$ & Sig. \\
\hline Arts partic. & .32 & $<.01$ & .18 & $<.01$ & .15 & $<.01$ \\
\hline EID & & & .37 & $<.01$ & .30 & $<.01$ \\
\hline Connectedness & & & & & .72 & $<.01$ \\
\hline \multicolumn{7}{|l|}{ Year 2} \\
\hline Arts partic. & .19 & $<.01$ & N.S. & & N.S. & \\
\hline EID & & & .17 & $<.01$ & .14 & $<.01$ \\
\hline Connectedness & & & & & .59 & $<.01$ \\
\hline \multicolumn{7}{|l|}{ Year 3} \\
\hline Arts partic. & .08 & .03 & N.S. & & N.S. & \\
\hline EID & & & .22 & $<.01$ & .25 & $<.01$ \\
\hline Connectedness & & & & & .59 & $<.01$ \\
\hline
\end{tabular}

Stability coefficients.

In longitudinal modelling, it was expected that each variable (Arts Participation, EID, Connectedness, and Well-being) would have significant, positive paths of stability between years, Arts Participation in Year 1 influencing Arts Participation in Year 2, for instance. This was indeed demonstrated in the model, though $\beta$ weights and effect sizes were relatively small, especially for Arts Participation and EID, reflecting the changes in participation and identity over the years. Weights were greater for contiguous years than from Year 1 to Year 3 in all cases. All are significant at $p<.01$ (Table 3.11). 
Table 3.11

Study 2 stability coefficients of variables between years

\begin{tabular}{llll}
\hline Variable & Year 1 to Year 2 & Year 2 to Year3 & Year 1 to Year 3 \\
\hline Arts Participation & .24 & .26 & .19 \\
EID & .30 & .34 & .13 \\
Connectedness & .57 & .49 & .26 \\
Well-Being & .41 & .40 & .13
\end{tabular}

All paths are significant at $p<.01$

Cross-lags between years.

As expected, there were cross-lags from Connectedness to Well-being across contiguous years $(\beta=.18, p<.001$ and $\beta=.20, p<.001$ respectively). There was not a continuing path of influence, however, from Year 1 to Year 3. There was also an unexpected cross-lag from Year 1 Well-being to Year 2 Connectedness $(\beta=.11$, $p<.01)$. There were no cross-lags from EID to Connectedness or Well-Being across any years, though the variables displayed significant covariance within years. There were, also unexpectedly, cross-lags from Year 1 Connectedness to both Year 2 and $3 \operatorname{EID}(\beta=.08, p<.05$ for Year 2 EID and $\beta=.12, p<.001$ for Year 3 EID), though not from Year 2 Connectedness. This is surprising because subsequent retesting of concurrent year models with revised directionality failed to produce acceptable models in any year. Also as expected, there were cross-lags from Arts Participation to EID. Year 1 Arts Participation influenced both Year 2 and Year 3 EID $(\beta=.12, p<.001$ and $\beta=.10, p<.001$ respectively). Year 2 Arts Participation, however, had no influence on Year 3 EID $(\beta=.05, \quad p=.17)$. 
Table 3.12

Correlations between YCP variables for all years

\begin{tabular}{|c|c|c|c|c|c|c|c|c|c|c|c|}
\hline & $\begin{array}{l}\text { Y1 arts } \\
\text { Partic. }\end{array}$ & $\begin{array}{l}\text { Y2 arts } \\
\text { Partic. }\end{array}$ & $\begin{array}{l}\text { Y3 arts } \\
\text { Partic. }\end{array}$ & Y1 EID & Y2 EID & Y3 EID & Y1 Connect & Y2 Connect & Y3 Connect & $\begin{array}{c}\text { Y1 Well } \\
\text { being }\end{array}$ & $\begin{array}{c}\text { Y2 Well } \\
\text { being }\end{array}$ \\
\hline Y2 arts participation & $0.28 * *$ & - & & & & & & & & & \\
\hline Y3 arts participation & $0.25^{* *}$ & $0.31 * *$ & - & & & & & & & & \\
\hline Y1 EID & $0.32 * *$ & $0.19^{* *}$ & $0.20 * *$ & - & & & & & & & \\
\hline Y2 EID & $0.24 * *$ & $0.27 * *$ & $0.19 * *$ & $0.37 * *$ & - & & & & & & \\
\hline Y3 EID & $0.27 * *$ & $0.22 * *$ & $0.22 * *$ & $0.35 * *$ & $0.47 * *$ & - & & & & & \\
\hline Y1 Connect & $0.18^{* *}$ & $0.09 * *$ & $0.11 * *$ & $0.37 * *$ & $0.22 * *$ & $0.28 * *$ & - & & & & \\
\hline Y2 Connect & $0.16^{* *}$ & $0.12 * *$ & $0.13^{* *}$ & $0.28 * *$ & $0.29 * *$ & $0.29 * *$ & $0.65^{* *}$ & - & & & \\
\hline Y3 Connect & $0.14 * *$ & $0.13 * *$ & $0.11^{* *}$ & $0.25 * *$ & $0.25^{* *}$ & $0.37 * *$ & $0.58 * *$ & $0.66^{* *}$ & - & & \\
\hline Y1 Well being & $0.15^{* *}$ & 0.07 & $0.10^{*}$ & $0.30 * *$ & $0.18 * *$ & $0.18^{* *}$ & $0.72 * *$ & $0.52 * *$ & $0.46^{* *}$ & - & \\
\hline Y2 Well being & $0.11 * *$ & $0.08 *$ & $0.12 * *$ & $0.22 * *$ & $0.24 * *$ & $0.23 * *$ & $0.48 * *$ & $0.70 * *$ & $0.48 * *$ & $0.54 * *$ & - \\
\hline Y3 Well being & $0.09 * *$ & $0.10^{* *}$ & $0.13^{* *}$ & $0.19^{* *}$ & $0.21 * *$ & $0.36^{* *}$ & $0.42 * *$ & $0.55 * *$ & $0.71 * *$ & $0.45^{* *}$ & $0.62 * *$ \\
\hline
\end{tabular}

$* p<.05, * * p<.01$ 


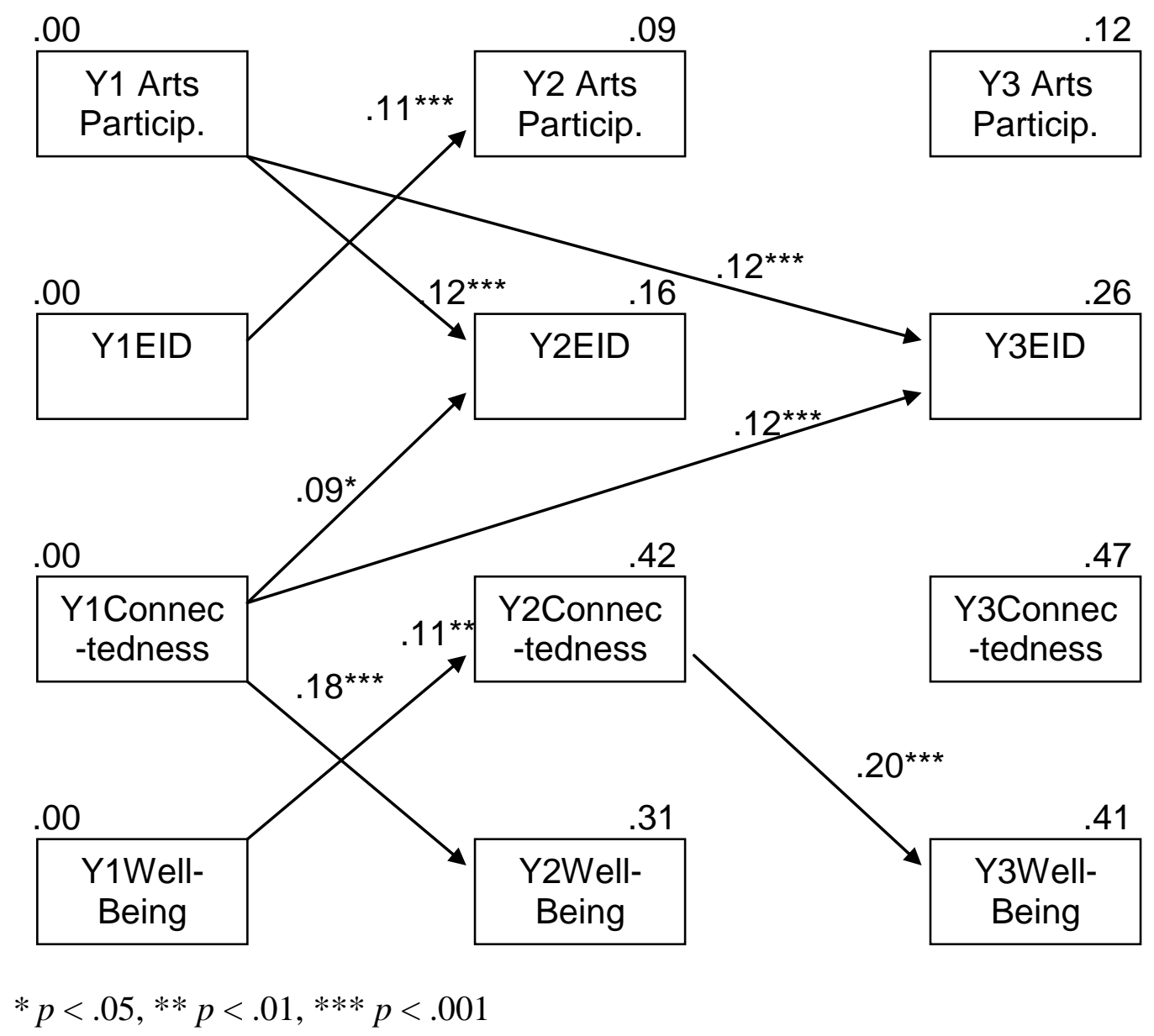

Figure 3.6. Longitudinal model of YCP variables for all years

Some writers have noted that the maximum likelihood algorithm in path modelling produces biased estimates for categorical variables (Arbuckle \& Wothke, 1999; Joreskog \& Sornbom, 1986). In the present analyses, the first variable is categorical, and thus the process of analysis represented in Figure 3.6 may be distorted by this variable. In order to verify that the obtained model was unbiased, a Bayesian analysis was performed on the model (Lee \& Song, 2004; Lee \& Tang, 2006). The results of this analysis verified that maximum likelihood estimates were virtually identical for both models. 


\section{Discussion}

This study formed an inquiry into the distinctive consequences of the TEA category of arts, and the potential benefits and processes involved. Hypotheses were tested for group differences in each year, and the process was modelled and tested. The study was intended to differentiate quantifiably between implications of arts practice versus none, and between TEA and Western arts, thereby objectively testing the qualitative results of Study 1. The proposed model tested the processes implied in Study 1 and related literature.

There were clearly differences between groups in the analyses of mean differences, but these were not entirely consistent with hypotheses or stable across years. To a large extent, however, this study was successful in its purpose of demonstrating that there are differences arising from particular types of arts participation. With only the exception of Year 2 Connectedness scores, the TEA participants had the highest score for each measure and the No Arts group had the lowest. In each measure and each year, the differences between the No Arts and the TEA group were significant, and, excepting Year 2 Connectedness, very highly significant at $p<.01$. Differences regarding the Other Arts group were not as clear.

As expected, TEA participants differed from both No Arts and Other Arts in EID each year, with no significant differences between No Arts and Other Arts. This result supports the idea that there are important functions in traditional practices for development and maintenance of individual EID (Coppens et al., 2006; Hugget, 1992), and that these functions are not provided to the same degree by other arts. If the processes by which this happens is indeed as described by the Study 1 artists, the youths are simultaneously receiving focussed cultural information and social support in a culturally specific setting in an environment designed to establish 
and maintain identity (e.g., quote \# 41 Timo). The setting provides role and behavioural models (e.g., \#20 Tame), and a source of co-ethnic peers to share and support the process (e.g., \#65 Amy). As discussed earlier this should allow them to learn the components of identity and to practice ethnically specific behaviours and interactions, which would not be the case with Western or contemporary arts training (e.g., \#53 Max). These results also support the findings of Whitinui's (2008) qualitative research into kapa haka practice in schools, which found that kapa haka reaffirmed identity, as well as establishing a sense of collective purpose in wanting to learn.

Regarding differences between groups for the Connectedness variable, results were mixed in support of hypotheses. A number of previous studies have suggested that arts in general can increase feelings of connectedness (e.g., Carson, Chappell, \& Knight, 2007; Reynolds, Prior, \& Lim, 2008; Pascual i Ruiz, 2002), especially in situations of identity search (Batcho et al., 2008). Drawing on this literature of general arts programs, $\mathrm{H}_{2}$ predicted that the social support and network implications of participation in arts programs in general would lead participants in Other Arts to exhibit stronger Connectedness responses than the no-arts group. This was confirmed in Years 1 and 2 but not in Year 3. Regarding the literature suggesting particular implications of traditional arts for connectedness (Dole \& Csordas, 2003; O’Hagin \& Harnish, 2006), the TEA group was significantly higher in Connectedness than the No Arts group but not the Other Arts group, leading to the conclusion that TEA may provide no particular facilitation of connectedness beyond other artistic practices, though the categorical nature of the Arts Participation variable is not a sensitive measure of participants' motivations or level of involvement in their practices, potentially clouding results. It may also be the 
case that TEAP affects different aspects of connectedness than those affected by other arts, though this is not specifically explicated in these measures or analyses. Even if the results are somewhat unclear it is an important finding that TEA participation is associated with increases in connectedness, in that anomie is a key risk in acculturation (Hoerder; 2002; Marsella \& Ring, 2003), with particular problems arising as youth acculturate away from their elders, leaving an intergenerational rift (Liebkind, 1996).

The Well-Being variables also yielded mixed results. Drawing on the literature of the favourable influence of general arts programs on Well-Being (e.g., Rapp-Paglicci et al., 2006; Stickley, 2007), $\mathrm{H}_{3}$ predicted that Well-Being scores would be higher for all arts participants than for the No Arts group. Drawing on the literatures associating traditional arts with well-being (e.g., Chipuer \& Pretty, 1999; Jones \& Galliher, 2007), it was anticipated that TEA participants would have the greatest Well-Being scores. In actuality, the only consistent result across years was that TEA participants scored significantly higher in Well-Being than the No Arts group in every year. The Other Arts scored significantly higher in Well-Being than the No Arts group in Years 1 and 2, but was different from the TEA group at no time. These Well-Being scores provide supporting evidence for benefits of arts programs in general, though not especially so for TEA in particular. These results clearly support that TEA participants are better off than the No Arts participants, but the exceptional protective benefits of TEA participation discussed by participants in Study 1 beyond Other Arts participation was not clearly demonstrated.

As with the Connectedness results, this lack of distinct differences may be explainable in other ways, such as the crudeness of measurement of Arts Participation. On a practical level, it may take a certain amount of time spent in 
practice doing TEA to affect well-being, information that is not clearly measured in these data. Also unavailable is information about participants' investment in or internalization of their art. Especially with TEA arts, the meaning and importance of the practice may be crucial to the implications of participation. The same may be true of other arts as well: the enjoyment of the experience and involvement with cohorts may vary widely, affecting outcomes as a result.

\section{Path modeling.}

The complexity of the processes involved in the influence of TEA participation is revealed and clarified to some degree in the path analyses. In modelling of the concurrent year samples, a consistency across the three years is that the strongest paths form a series from Arts Participation to EID, EID to Connectedness, and finally Connectedness to Well-Being. In this way, TEA practices seemed to begin the process of enhancing identity which supported connectedness and led to better well-being. The $\beta$ weights in these models are highly significant $(p<.01)$, though the variance explained in EID and Connectedness is relatively small, the highest being $14 \%$ of the Connectedness variable in Years 1 and 3. On the other hand, the variance in Well-Being explained by the model overall in Year 1 is .52. This level of explanatory power is consistent over time, with values of .49 for Year 2 and .51 for Year 3. The effect is primarily driven by Connectedness, which has indeed been shown to be a predictor of wellbeing (e.g., Chavis, Hogge, McMillan, \& Wandersman, 1986; Chipuer \& Pretty, 1999). There are also indirect effects of the other variables on Well-Being in each year, those of EID being the larger (Table 3.9) This is in keeping with previous research regarding relations between EID and well-being (e.g., Gray-Little \& 
Hafdahl, 2000; Ryff et al., 2003; Tsai et al., 2001; Umaña-Taylor, 2004). In this way, TEAP is demonstrably, if slightly, supporting both EID and Connectedness, and leading to better outcomes for TEA participants as predicted. Though the categorical nature of the Arts Participation variable may not accurately portray the nature and magnitude of this construct in the path analyses, the study provides some support for previous research indicating benefits of TEA-type arts (Farrer, 2004; Geurin, Fatuma, \& Guerin, 2006; O’Hagin \& Harnish, 2006), with EID and Connectedness serving as mediators of the process.

The concurrent models did not match precisely the proposed model from Study 1. Notable inconsistency between proposed and resulting models across the three years concerned two potential paths, namely those between TEAP and Connectedness, and between EID and Well-Being. Both were anticipated to be significant, based on Study 1 and relevant literature, and the variation between years may arise from the complexity of the relations between identity and other variables (e.g., Tadmore, Tetlock, \& Peng, 2009), or it may simply be the result of other factors such as the large change in TEAP between years. This change of category could lead to very different processes as more or less experienced and involved students came and went from their groups, which could change both the individual experiences and dynamics of the TEA groups in which they were involved.

Connectedness, measured in greater detail, was more stable across years and was the main factor explaining variance in Well-Being within and across years. This is consistent with the literature regarding benefits of connectedness in general (e.g., Chavis, Hogge, McMillan, \& Wandersman, 1986; Chipuer \& Pretty, 1999) and from TEA-related activities, specifically, by promoting connectedness in acculturation situations (e.g., Dole \& Csordas, 2003; Farrer, 2004; O’Hagin \& 
Harnish, 2006; Viladrich, 2005). These results are incongruent, however, with other research which would suggest a more robust path to Connectedness arising from traditional arts practices (e.g., Aguilar, 2007; Dole \& Csordas, 2003; Navarro, Wilson, Berger, \& Taylor, 1997). The resulting models also differ from paths suggested by the literature of EID, in which the positive relations between EID and well-being are time-honoured and widely (if not entirely) supported by numerous studies (cf. Rudmin, 2006). Given that literature, it was expected that there would be significant pathways between EID and Well-Being, but in Years 1 and 2 this was not the case.

Overall, the concurrent models provide evidence that they reflect a process occurring in this sample. The good fit indices and the high explanatory power for the Well-Being outcome variable show that strong influences are being modelled. The effects of TEA participation category on Well-Being are indirect, with EID and Connectedness mediating these effects. The weak $\beta$ weights and low explanatory power in the upper model paths may be a function of the very simplistic dichotomous TEAP variable and the reduced EID scale, which uses only six items. Connectedness and Well-Being, on the other hand, are robust measures with numerous items measuring variance, and their psychometric strength may be disproportionate to the other two measures.

\section{Longitudinal path model.}

Questions remained as to whether directionality of paths has been accurately specified, as well as whether there may be continuing influences of TEAP over time. To attempt to answer these questions arising from the concurrent year path analyses, a longitudinal model was specified and tested, beginning with a cross-lagged panel model in which all possible cross-lags between variables were represented, and 
including covariance between variables within concurrent years. The result was an "ad hoc" model, derived by pruning paths as suggested by the data rather than according to any proposed theoretical constructs, which is one way to test directionality empirically (Hunter \& Gerbing, 1982).

The strongest and most consistent paths in the model were those from Connectedness to Well-Being in the subsequent year, though the effect faded from Year 1 to Year 3. This is consistent with the literature regarding support of wellbeing through aspects of connectedness (e.g., Chavis, Hogge, McMillan, \& Wandersman, 1986; Chipuer \& Pretty, 1999). The significant bi-directional paths between Connectedness and Well-Being between Years 1 and 2 suggest that wellbeing also influences future connectedness, though this is not a matter addressed by the connectedness literature. Certainly, the two concepts are closely inter-related.

Across years, participants' choice of TEAP or No Arts continues to influence EID from Year 1 to Years 2 and 3. As shown in the MANOVA and post-hoc tests above, the TEA group has the highest EID score, and this score is influenced by Year 1 TEA participation throughout the three years. In other words, if the youth participated in TEA during Year 1, her/his EID remained higher over time. The $\beta$ weights and effect sizes in this portion of the model are relatively small, but the influences from Year 1 TEAP are highly significant and carry through to successive years' level of EID.

An interesting cross-lag is that found between Year 1 EID and Year 2 TEAP. This would suggest that at least to some degree, identity influences TEA participation, which is a reasonable supposition. The comments in Study 1 around identity, particularly \#27 from Sue, highlight that these youths are from cultures in peril, and that they face daily prejudices and inequities. It may be that TEA 
participation is a natural choice they make themselves, or that there are environmental influences from family and community that have already helped to reinforce their identities (Ward, Fox, et al., 2009) that also impel them to the art.

In the longitudinal model, EID had no influence on Connectedness over time. This result gives rise for concern about both concurrent and longitudinal models, given the strong influences of EID on Connectedness identified in the concurrent year models. The models were retested with the reversed directional path, though this failed to yield a supportable model. These discrepancies may be a result of allowing variables within years to co-vary in the longitudinal model, which may have yielded residuals that were different from those in the concurrent models, and thereby changing predictive power. Alternately, results may reflect the large changes in arts participation. Those who maintained an arts practice may experience the continued influences of EID upon Connectedness, whereas those who changed, discontinued, or began arts practices may have different modes of identification and differing sorts of social connections or support across years. The changes in arts participation may violate the assumption of stationarity, namely that the causal structure remains stable over time (Kline, 2005), meaning that these results may not be a definitive indication of the directionality of influences between these variables. Participants would most likely experience different support of identity and different aspects of connectedness to the changing people in their lives. With the low correlations of arts practices between years, even those who continued their arts practice experienced shifts in their arts cohort. These changes may have implications throughout the model.

Within concurrent year samples, EID more strongly influences Connectedness than the reverse. Between years, however, Connectedness in Year 1 
influences the variance in EID in years two and three, though not between Year 2 and Year 3, while maintaining covariance within concurrent years. While violations of stationarity may render these results inconclusive, the results also reflect conflicting reports found in the literature connecting EID and connectedness, in which some researchers have found EID to predict connectedness (e.g., Dole \& Csordas; 2003; Saylor \& Aries, 1999), while others have found the reverse (e.g., Juang, Nguyen, \& Lin, 2009; Prelow, Bowman, \& Weaver, 2007). Those studies, along with the present study, underscore the complexity of the relations between these variables. Factors of social ecology may be important in the construction of identity and identity may simultaneously be important to sense of connectedness (e.g., Rivas-Drake, Hughes, \& Way, 2009; Sabatier, 2008).

\section{Ethnic identity and traditional ethno-cultural arts.}

Development of a strong and coherent cultural identity is particularly important for youth in acculturation (Oetting \& Beauvais, 1990; Spencer, Noll, Stoltzfus, \& Harplani, 2001), providing one mechanism by which to render life comprehensible to the individual (Gone, 2006). The present study has demonstrated that TEA participation acts powerfully on EID development, differing significantly from the practices of other arts (as expected) in this regard. The psychological literature of acculturation addresses contextual influences on ethnic identity, primarily familial (e.g., Hall \& Brassard, 2008; Su \& Costigan, 2009; Yip, 2009) and peer group (e.g., Hall \& Brassard, 2008; Kiang \& Fulgini, 2009). Presence of co-ethnics in community has also been addressed in terms of influences and outcomes (Frisbie, Cho, \& Hummer, 2001; Salant \& Lauderdale, 2003). The literature addresses influence of the larger community on identity in terms of multiculturalism (Le, Lai, \& Wallen, 2009) and host community context, but mostly 
in regards to acculturative consequences (e.g., Ajrouch \& Kuslow, 2007; Ward, 2001). The mechanisms by which these influences manifest, however, are largely not explicated in the literature (or this study), particularly in regards to manner of strengthening ethnic identity. It is certain that traditional arts provide information and explanation regarding heritage values and behaviours (Dole \& Csordas, 2003; Belcourt-Dittloff, 2006), and that they provide a supportive environment in which identity can be affirmed (Jones \& Galliher, 2007). Traditional artists in Study 1 spoke of construction of identity by connecting with the culture, learning about the culture and culturally preferred ways of being, and bonding with the group. More detailed investigation of TEA participation may provide insight into the underlying processes by which identity, especially EID, is formulated and maintained.

\section{Summary.}

Despite the complexity and inconsistency of results, there are interesting and meaningful findings arising from this study. Overall, this study demonstrates that arts participation leads to better outcomes for participants than no arts participation, and that TEA participation particularly affects sense of ethnic identity. Benefits of arts programs have been widely touted but seldom empirically tested (e.g., Clawson \& Coolbaugh, 2001; Stickley, 2007; Mason \& Chuang, 2001), and benefits of traditional arts participation has not been addressed in the literature of psychology (Hacking et al., 2006). Differences between those who do or do not participate in arts have been described qualitatively but tested in only a small but growing body of research. This study adds to the body of research quantitatively supporting the concept, something which is necessary for informed public policy debate over funding of arts programs (Stickley, 2007). 
Though the results are not as strong or consistent as would be anticipated from the strong opinions of Study 1 participants, the data do show distinctly differing results for the three groups. These results may suggest benefits of TEA participation in acculturation, driven primarily by its significant influence on EID. If, as the literature suggests, traditional arts enhance ethno-cultural identity and there are well-being benefits of strong ethnic identity, then a more nuanced measure of intensity of and investment in the arts participation may more clearly demonstrate this. Also, a more robust measure of EID than the abbreviated one employed in this study is advisable, though the age of YCP participants necessitated the abbreviation of survey elements.

A unique contribution of this study is the specification and testing of models relating to arts participation. This is an apparently heretofore untried approach in an under-researched field. The mechanism(s) may be protective, informational, supportive, or otherwise, though this cannot be deduced from simplistic categorical designation of arts participation herein. Still in all, the data support that a beneficial process is at work for these cultural activities. It is a complex process, but one worth investigating more thoroughly, given the differences in outcomes across groups. Further investigation may explicate specific, meaningful benefits of TEA participation.

\section{Limitations and future directions.}

A primary limitation of this study is that data were drawn from a more general investigation of connectedness not specifically designed to explicate consequences of TEA participation. For this reason, the participation measure only reflects categories of extra-curricular activities and gives no indication of the 
reasons for participation, what the participation means to the participants, how often or long they have participated, what level of advancement they have reached, or whether it is an activity shared amongst family or friends. A person who has been a TEA participant for only a short time, participating only because they are required to do so, and who really does not enjoy the experience, would potentially have very different scores from someone who has participated since early childhood as a much-loved part of family and community life. Measurement via the categorical variable can in no way reflect these nuances of motivation or experience, and differing motivations have been demonstrated to lead to variation of involvement and outcome in certain activities (Azman, 2005). A measure is needed that reflects qualities of participation such as motivation emotional investment, commitment, and centrality, in order to apprehend what and how much the arts activity means to the participant.

Another major limitation is the inconsistency of participation across years, with no correlations above .32 between years. Year 2 is particularly problematic in that participation in TEA dropped by $40 \%$ and Other Arts participation by $73 \%$ between Year 1 and Year 2. The change overall is 48\% from Year 1 to Year 2, and $38 \%$ from Year 2 to Year 3. Without consideration of any other potential changes in causal structure over time, this violates the assumption of stationarity and casts doubt on results in longitudinal modelling. If TEA participation indeed contributes to sustained well-being via enhancement of EID and connectedness, this may happen gradually over time, and inconsistency of participation in these data may obscure effects. The reasons for these changes are unknown, but could relate to changes in funding availability in particular communities, loss of instructors, or simply normal transfers between schools or between grade levels. A study in which 
this factor is more carefully controlled would be informative as to directionality of processes.

A third limitation is in the ethnic composition of participants. The results may or may not be generalizable across Polynesian groups, which are historically, linguistically, and culturally closely related, sharing practices and social processes as well as basic stories of creation and migration which form important content for these arts (Finney, 1994; Kame'eleihiwa, 2009; Kanuha, 2004; King, 2001; Kyselka, 1987). This possibility needs to be tested with larger samples from various Polynesian groups in various locales and from other ethnic groups. The YCP sample is definitely too limited in ethnic composition to suppose any results can be generalized to other less closely related groups.

Research must be done which views arts practices in greater detail to discover whether there are important factors within arts processes that must be present to yield better outcomes. These could also comprise areas that are important in identity construction and maintenance, and which could potentially inform measures of identity. Studies should be conducted with more robust samples from numerous traditional cultures for comparisons between cultures and to establish whether results are generalizable across cultures. These studies could also be limited to particular media to investigate differences by art, such as dance which does or does not include verbal information, or entirely different media such as poetry in the Middle East or mask-making in Africa. The following study will address some of these limitations by establishing a continuous scale of the factors of participation and testing hypotheses across a number of cultures. 


\section{Chapter 4: Refining the measurement of TEA processes}

In the previous two studies, evidence was introduced that there is a distinct class of traditional and ethno-cultural arts participation (TEAP), and this proposed category was tested using data from the Youth Connectedness Project. In Study 1, the primary differences between TEA and other types of artists were found to be in regard to their motivations for doing their arts, ways of coping, concepts of identity, attitudes about cultural maintenance, transmission and change, and ways in which their arts connected them to those around them. In Study 2, significant differences were observed in measures of EID, connectedness, and well-being in a sample of Maori and Pasifika youths in New Zealand. The differences were highly significant between the TEA and No Arts conditions in every measure and every year, and between TEA and Other (Western) Arts in EID. Also in Study 2, a model of the process by which differing arts participation influenced the well-being outcomes of participants through mediation of the EID and Connectedness variables was proposed and tested as a path model. A major weakness of the second study was that arts participation was measured categorically, lacking indicators of more nuanced information such as commitment, personal investment, or experience, which could potentially affect results.

There are a growing number of studies measuring outcomes of arts "participation," though there are two divergent streams using that term. One theme regards attendance at arts events, the audience being termed participants (e.g., CNZ, 2007). These studies look at economic or social benefits to communities, but not at psychological aspects. The other theme looks at individual psycho-social outcomes of doing the art (e.g., Hacking et al., 2008; Stickley, 2007), such as improved selfesteem, improved quality of life, personal growth in the sense of identity 
transformation, and increased artistic skill (Hacking et al., 2006). Neither stream has identified the active psychological mechanisms or components of the arts themselves or attempted to model how the dynamics of the art-form itself may affect the practitioner.

\section{The Present Study}

The purpose of this study was to re-examine the issues and models from Study 2 with more sophisticated measures and analytical techniques. The primary concern about Study 2 was the categorical nature of the measure of arts participation. For this reason, results are presented in two sections here, the first regarding measure construction, and the second utilizing an improved measure to retest the TEA model. This study begins with initial construction and validation of an instrument to measure components of TEA participation on a continuous scale.

Participants in Study 1 who practiced a traditional art discussed a number of themes which may be important components or processes of their practices, and from which items were generated. These included:

- Connecting (or reconnecting) with the culture: quote 41 Miko (Maori/ Japanese kapa haka); 44 Max (Maori kapa haka); 29 Max (Maori kapa haka)

- Transmission of cultural knowledge: 31 Mina (Filipina dancer); 32 Jane (Solomons weaver/musician); 37 Miko (Maori/ Japanese kapa haka)

- Learning culturally preferred ways of being: 33 Amy (Chinese dancer); 35. Timo (Samoan dance/music)

- Construction of identity: 30 Timo (Samoan dance/music); 40. Max (Maori kapa haka); 59 Amy (Chinese dancer)

- Building arts-based efficacy and capacity: 17 Max (Maori kapa haka); 18 Amy (Chinese dancer)

- Bonding with the group: 59 Amy (Chinese dancer); 60 Miko (Maori/Japanese kapa haka); 61 Timo (Samoan dance/music)

This study was designed under the assumption that these components or factors would measurably increase with time and intensity of participation, as would the centrality and salience of the practice. These themes arose in analyses of data from a 
diverse set of cultures, formed a set of commonalities across traditional practices, and therefore had the potential to be applicable to diverse ethno-cultural arts practices. Informed by research related to social or cultural group membership, the components above were used to generate a set of items that may be important in TEA participation (Appendix D), specific to an arts practice and the group with which one practices. Items related to arts-related efficacy, connectedness, and cultural information were based on themes drawn from Study 1 data. Items addressing commitment, centrality, and collective self-esteem were based on the literatures of ethnic identity and group membership (e.g., Crocker \& Luhtanen, 1992; Phinney, 1990).

Items were generated to represent potential components of participation, with theoretical subscales for commitment to practice, efficacy of performance, centrality and salience of practice, group-esteem related to the art, arts group belonging, and cultural information learned from the practice, with an additional component regarding attitudes toward and motivations for ethno-cultural arts participation. The resulting data were factor analyzed and the number of items was reduced to form a concise scale. Construct validation was then undertaken by tests of convergent validity and known group comparison. Examination of the data was expected to reveal significant positive correlations between the TEAP instrument scores with frequency and years of participation as well as with self-reported level of achievement. Examination was also expected to reveal that the groups of more and less experienced participants would differ significantly in their TEAP scores.

After validation, a structural model was constructed to test the hypothesized model examined in Study 2 with these data (using parcelled factors of the TEA participation (TEAP) scale). In that model, TEAP was expected to influence both 
EID and Connectedness directly. These would in turn both influence Well-Being outcomes, with an additional path connecting EID to Connectedness. The directionality of this influence is a point of contention in the literature, with some researchers positing EID as the precursor, leading to greater feelings of connectedness (e.g., Dole \& Csordas; 2003; Saylor \& Aries, 1999), while others argue that feeling connected increases identification (e.g., Juang, Nguyen, \& Lin, 2009; Prelow, Bowman, \& Weaver, 2007). The research cited that endorses the EID to Connectedness direction (e.g., Dole \& Csordas; 2003; Saylor \& Aries, 1999) was related to ethnic arts practices, and appeared to fit well with views described in Study 1. Results from Study 2 were inconclusive on the subject, with the better fitting, more logical concurrent models revealing EID to Connectedness directionality, but no support for this was obtained in the longitudinal model. The failure of the longitudinal model to support the concurrent models cannot be taken as conclusive due to violations of assumptions of stationarity of conditions and inclusivity of all correlated components. To address this gap, the model was tested separately with the original directionality as well as the competing reversed path model (Fig 4.1).

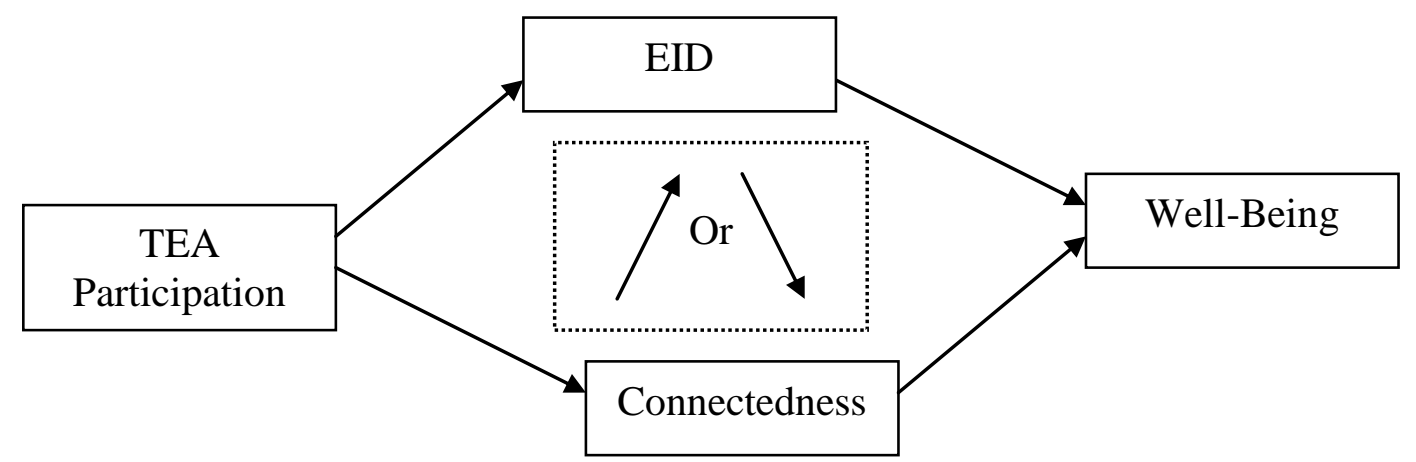

Figure 4.1. Proposed model of influences of TEA Participation on Well-Being 


\section{Method}

\section{Participants and procedure.}

Participants were recruited in several ways: via internet arts interest groups, through the New Zealand Federation of Multicultural Councils, and through performing groups including the Maori and Pasifika group at Whitireia Polytechnic and the Halla Huhm school of Korean dance. A large sample $(\mathrm{N}=448)$ began the survey. After removal of those who did not complete at least the TEAPS section of the survey (73), and those who participated but whose ethnicity did not match their art participation (18), the resulting sample comprised 357, with 235 females (66\%), 120 males (34\%), and two omitting gender. Mahalanobis distances revealed no outliers in this reduced sample. Ages ranged from 16 to 81, with a mean age of 29.9 $(\mathrm{SD}=13.48)$. There were 336 participants who completed the survey beyond the TEAPS measure (some failing to go further in the online version), of whom 219 were female and 115 were male (65\% and $34 \%$ respectively). This group formed the sample for SEM analysis. The sample included individuals hailing from or living on continents including North, Central, and South America, Europe, regions of Asia, and Africa, as well as New Zealand and Hawai'i. Arts included dance, music, and visual arts (such as Chinese calligraphy). Arts represented by more than one participant are listed Table 4.1. Cultures included Maori, Native American, Indian, Chinese, Filipino, Korean, Japanese, Hawaiian, African, and several Pasifika types, along with a few European cultures such as Hungarian and Scottish. Arts included the following: kapa haka, hula, and Pasifika music/dance; Native American music, dance, and sand painting (Navajo); Japanese taiko drumming and ikebana 
(flower arrangement); Hungarian, Filipino, Korean, and Scottish dance; Indian music and dance; and Chinese music, dance, and calligraphy.

Table 4.1

Frequency of participation by ethnic art $(N=357)$

\begin{tabular}{lcc}
\hline Art & Frequency & Percent \\
\hline Polynesian dance/music & 99 & 25 \\
Indian dance/music & 68 & 16 \\
Chinese music/dance & 11 & 2.7 \\
Philippine dance & 15 & 3.7 \\
Korean dance & 9 & 2.2 \\
Euro-ethnic dance/music & 14 & 3.5 \\
Japanese/Okinawan & 21 & 5.2 \\
music/dance & & \\
Native Am dance/music & 12 & 3.0 \\
Other Asian music/dance & 4 & 1.0 \\
Chinese visual & 4 & 1.0 \\
Native Am visual & 4 & 1.0 \\
\hline
\end{tabular}

Participants were provided either with paper copies of the survey to complete or sent a link to an electronic version of the survey on the internet. Participants were offered the opportunity to enter a drawing for an Apple iPod music player. Information and consent materials are found in Appendix E.

\section{Measures.}

Instruments included measures of well-being, connectedness, ethnic identity, and arts participation, as well as demographic information and specific information on type, duration, and frequency of arts practice. Statistics for scales in this study can be found in the Structural Equation Modelling portion of the Results section. Well-being was measured with scales of well-being, life satisfaction, self-esteem, and resilience as described below. Connectedness and Ethnic Identity scales are also described, along with the initial TEAP measure. All scales are presented in Appendix D. 


\section{Well-Being.}

Warwick Edinburgh Mental Well-Being Scale (WEMWBS).

General well being was measured with the positively-worded 14 item Warwick-Edinburgh Mental Well-Being Scale (WEMWBS) (Tennant et al. 2007), developed as a measure of hedonic and eudaimonic positive mental health. The hedonic approach focuses on happiness, defining well-being in terms of pleasure and absence of pain, while the eudaimonic approach emphasizes meaning and selfrealization, defining well-being as being fully functional (Ryan \& Deci, 2001). The scale includes questions such as "I've been feeling relaxed" and "I've been feeling interested in other people," rated on a five-point Likert scale from one, "none of the time," to five, "all of the time." It was chosen because all items are positively worded, which Maori consulted in study development found much more culturally acceptable than measures including negative items. Test-retest reliability at one week was high at .83 . Cronbach's alphas during scale development were found to range from .89 (student sample) to .91 (general population) (Tennant et al., 2007). The Cronbach's alpha for this sample was .92.

\section{The Satisfaction with Life Scale.}

Life satisfaction was measured using the five-item The Satisfaction with Life Scale (Diener, Emmons, Larsen, \& Griffin, 1985), including questions such as "I am satisfied with life" and "So far I have gotten the important things I want in life". Respondents gave their answers on a five-point Likert scale from one, "strongly disagree," to five, "strongly agree." The scale has seen widespread use in numerous countries and cultures (e.g., Gouveia et al., 2009; Neto, 1993; Sachs, 2004). Diener et al. (1985) reported test-retest reliability of .82 , and a meta-analysis found a mean 
Cronbach's alpha across 196 articles of .78 (Vassar, 2008). The Cronbach's alpha for this sample was .85 .

\section{Rosenberg Self-Esteem Scale.}

Self-esteem was measured using eight items of the Rosenberg Self-Esteem Scale (1965), which has been used for over 40 years and has proven reliable and valid cross-culturally. Two negatively worded items were omitted on the advice of Maori consultants who felt the items were inappropriate and could be hurtful, "I certainly feel useless at times," and "At times I think I am no good at all." Remaining items included "I am able to do things as well as most other people" and "I take a positive attitude toward myself," rated for this study on a five-point Likert scale from one, "strongly disagree," to five, "strongly agree." The scale has been very widely used, and has been translated into several languages (e.g., Mimura \& Griffiths, 2007; Shin, 1992). Rosenberg (1965) reported internal alpha coefficients of .85 to .88 for college samples. The Cronbach's alpha for this sample was .82 .

\section{The Resilience Scale.}

Resilience was measured using 16 questions adapted from The Resilience Scale (Wagnild \& Young, 1993) and from the Youth Connectedness Project (YCP), including "I feel that I can handle many things at a time" and "I am determined," rated on a five point Likert scale from one, "strongly disagree," to five, "strongly agree." The Cronbach's alpha for the shorter scale used in the YCP study was .70. The Cronbach's alpha for this sample was .91.

\section{Connectedness.}

Connectedness contained 22 questions pertaining to the domains of family, peers, ethnic community, and other groups, which were scored separately to create 
observed variables. The family ( 8 items) and peer (5 items) questions were drawn from the YCP and included questions such as "My whanau/family likes to spend free time together" and "I get along well with my friends." Ethnic community (5 items) and other group (4 items) questions were inspired by items in the YCP and from the Neighborhood Youth Inventory (Chipuer, Pretty, Delorey et al., 1999), including items such as "I frequently attend gatherings of people in my ethnic community" and "I am involved in activities with people of other ethnic groups," rated on a five point Likert scale from one, "strongly disagree," to five, "strongly agree." The Cronbach's alphas for those subscales were .77 for Own Community, .86 for Other Communities, and .93 for Family. For the four peer items, reliability was very low at .53. Deletion of one item, "My friends are who I go to when I have problems," brought the alpha level to .70 .

\section{Multigroup Ethnic Identity Measure (MEIM).}

Ethnic Identity was measured using the twelve-item Multigroup Ethnic Identity Measure (MEIM) (Phinney, 1992), which contains two factors regarding ethnic identity search and affirmation/commitment. Questions include "I have spent time trying to find out more about my ethnic group, such as its history, traditions, and customs" and "I am active in organizations or social groups that include mostly members of my own ethnic group." The Cronbach's alpha for the entire scale in this study was .92. This is at the high end of the range found by Pontrero, Gretchen et al. (2003), who found alphas ranging from a low of .81 (Goodstein \& Ponterotto, 1997; Phinney, 1992) to a high of .92 (Taub, 1995), with a mean of .86.

The scale has two factors, Ethnic Identity Search (five items) and Affirmation and Commitment (seven items) (Phinney, 1992). These factors were split into three parcels to create a latent variable for SEM analysis, one for Phinney's 
(1992) five-item Ethnic Identity Search factor and two for the seven-item Affirmation and Commitment factor. The use of at least three parcelled indicators per latent variable, made by grouping individual scale items, has been recommended as being more reliable than creating a latent construct from all of the individual items, and more balanced than combining all items additively to form an observed variable (Bollen, 1989; Little, Cunningham, Shahar, \& Widamen, 2002).

\section{The Traditional and Ethno-cultural Arts Participation Scale (TEAPS).}

The TEAPS measure was designed by drawing on themes from Study 1 as described above. Seven theoretical subscales were proposed: commitment to practice (three items), efficacy in the art (four items), centrality and salience of practice (six items, partly modelled on the Multidimensional Inventory of Black Identity by Sellers, Rowley, Chavous, Shelton, and Smith, 1997), arts group esteem (four items, modelled partly on Luhtanen and Crocker, 1992), arts group belonging (seven items), and cultural information learned from the practice (11 items), along with general attitudes toward the arts practice (9 items). The version administered contained 44 items, including (commitment) "I am very committed to the practice of my art," (arts efficacy) "I do my art very well," (arts related esteem) "I feel proud to be a member of my arts group," (centrality and salience) "My arts practice forms a big part of how I feel about myself," (belonging) "I never socialize with the people in my arts group" (reverse coded), (attitudes) "Ethnic arts help people to see what the important things are about their ethnic group," and (cultural information) "By learning this art, I learn the values of my people." All items were rated on a five point Likert scale from one, "strongly disagree," to five, "strongly agree." Additionally, the objective measure of TEA participation for validation purposes included three items: "How long have you practiced your art," "How often do you 
practice or perform each week," and "What level of qualification have you reached in your art?" The full scale can be found in Appendix D.

\section{Results}

There were three phases of analysis: data reduction, construct validation, and hypothesis testing. Relationships among items were examined by exploratory and confirmatory factor analysis. To allow confirmatory analysis using a separate sample, data were randomly split at approximately $2 / 3(\mathrm{~N}=239)$ for the exploratory analysis and $1 / 3(\mathrm{~N}=118)$ for the confirmatory analysis. This division allowed slightly more than the frequently recommended minimum of five participants per item (Gorsuch, 1983; MacCallum, Widaman, Zhang, \& Hong, 1999) for the EFA of the full set of questions and for the CFA of a reduced scale including up to 23 items. Construct validation was then undertaken by performing correlations between reduced scale TEAPS scores, frequency of practice, years of practice, and level of achievement, and conducting known group comparison of groups based on selfreported high or low levels of advancement. The resulting trimmed scale was then used as a continuous measure in a structural equation model to retest and expand upon results of Study 2.

\section{Exploratory Factor Analysis.}

The 44 items of the TEAPS scale were subjected to principal component analysis (PCA) using SPSS Version 17. Suitability of the data for factor analysis was determined by inspection of the correlation matrix, Kaiser-Meyer-Olkin value, and Bartlett's test of sphericity. The correlation matrix revealed the presence of a large number of coefficients above .3 , the Kaiser-Meyer-Olkin value was .95 , well 
above the recommended value of .6 , and Bartlett's test of sphericity was significant at $\mathrm{p}<.01$, all within suitable range for the analyses (Pallant, 2007; Kaiser, 1974).

Because it was likely that derived factors would be related, oblimin rotation was chosen to aid in the interpretation of these components. The rotated solution revealed the presence of a simple structure (Thurstone, 1947), with all items showing a number of strong loadings. The principal component analysis revealed seven factors with eigenvalues over one, explaining 42.25, 7.50, 5.74, 4.14, 3.25, 2.79 , and 2.42 percent of variance respectively for a total of $68 \%$. Inspection of the scree plot revealed that by the fifth point plotted, the resulting line was nearly horizontal, suggesting that by Cattell's test criterion perhaps no more than five factors should be retained for further investigation. When this analysis was compared using Parallel Analysis (Cota, Longman, Holden, \& Fekken, 1993), it was found that only four factors exceeded the corresponding criterion values for a randomly generated data matrix of the same size (44 variables x 239 participants), which was the number of factors eventually retained.

Items were deleted based on several methods, including inspection of itemtotal correlations, high or low correlations with theoretical subscale, cross-loading on multiple factors, and redundancy within subscale. Five negatively worded items had very low item-total correlations and they were drawn from different theoretical subscales, so they were removed. After gradually removing other items using similar criteria, the eventual optimal solution contained 18 items in four factors, explaining a total of $73.84 \%$ of the variance. The size of the eigenvalue of the fourth factor (1.14) fell slightly below the Parallel Analysis estimate of 1.2. The scree plot (Fig. 4.2), however, revealed that the resulting line does not become horizontal until the fifth factor, and further, the items included in this factor form a 
clear construct. The resulting four factors were named Centrality, Cultural Transmission, Belongingness, and Pride. The Centrality factor is composed of items of the commitment theoretical subscale along with items from centrality and salience. The Pride factor is drawn from the efficacy and group-esteem theoretical subscales. Belongingness and Cultural Transmission factors retained their theoretical structures, with cultural knowledge being renamed to better capture the dynamic nature of the process represented. The items related to attitudes toward one's art were not retained in analysis. The reduced final scale is presented in Table 4.2. The fourth factor (Centrality) contains negative loadings, although all items are positively correlated with each other (Appendix F), as are the factors (Table 4.3), suggesting that the negative loadings are an artefact of the oblimin rotation process. Cronbach's $\alpha$ for this entire set of items was .94. 


\section{Scree Plot}

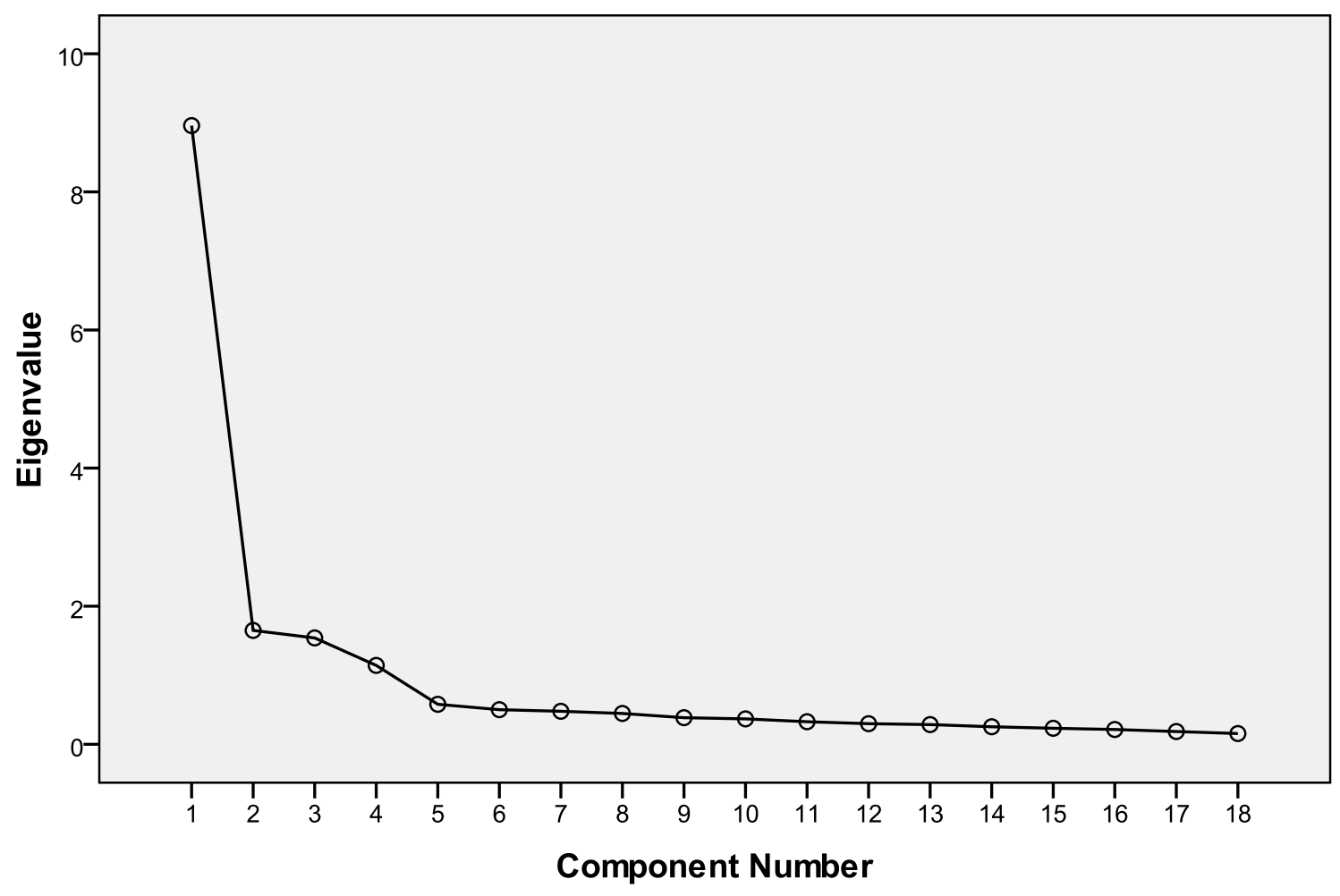

Figure 4.2. Scree plot of exploratory factor analysis four factor solution 
Table 4.2

Factor structure of the TEAPS instrument (values below 30 deleted) $(N=239)$

Factor

Scale item

Cultural

Pride Transmission Belongingness Centrality

I am a capable member of my arts $\quad \mathbf{8 3}$

group

I do my art very well

.82

My arts group is very good at

.75

what we do

My arts group is considered by

others to be very good

I feel confident when performing $\quad \mathbf{6 6}$

or showing my art

I am proud of my arts group when

.64

we perform or do a show

Practicing this art helps me learn

the stories of my people

Doing this art connects me to the

history of my ethnic group

By learning this art, I learn the

values of my people

By learning this art, I understand

the meanings of our myths and

legends

My arts group friends are who I

.85

talk to when I have troubles

My arts group friends provide me

with support in my life

I feel a strong sense of attachment

to the members of my arts group

My arts practice forms a big part

of how I feel about myself

My arts practice forms a central

part of my self-image

I am very committed to the

practice of my art

I plan to continue to practice my

art

cultural art group is a very

important part of my life 


\section{Confirmatory Factor Analysis (CFA).}

This analysis attempted to replicate the factor structure identified in the exploratory factor analyses. The remaining sample of 118 participants is above the recommended five participants per items to analyze the 18 remaining items (Gorsuch, 1983; MacCallum et al., 1999). The hypothesized model from the EFA above was assessed using AMOS version 17 (Arbuckle, 2008). The model was evaluated by the five fit indices discussed previously in the path analyses of Study 2: GFI, CMIN/DF, RMR, RMSEA, and CFI. Results of the indices largely supported the model fit, though the GFI value was low at .85 . One item which loaded the weakest for its factor of Pride was removed ("My arts group is considered by others to be very good"), bringing the GFI to .87 (see Fig. 4.2). Although this fit index value is slightly below acceptable levels, all other indices fell within the acceptable range. The chi-square yielded a value of $155.8(107, N=118), p<.01$, with values of 1.36 for CMIN/DF, .06 for RMR, .06 for RMSEA, and .97 for CFI. The Cronbach's alpha for the 17 item final scale in this study was .94. In the CFA model, all paths between first order factors and the second order TEAP construct were significant at $p<.01$. The strongest relationship was from the Centrality factor $(\beta=.99)$, followed by the Pride factor $(\beta=.85)$, the Belongingness factor $(\beta=.78)$, and the Cultural Transmission factor $(\beta=.70)$. 


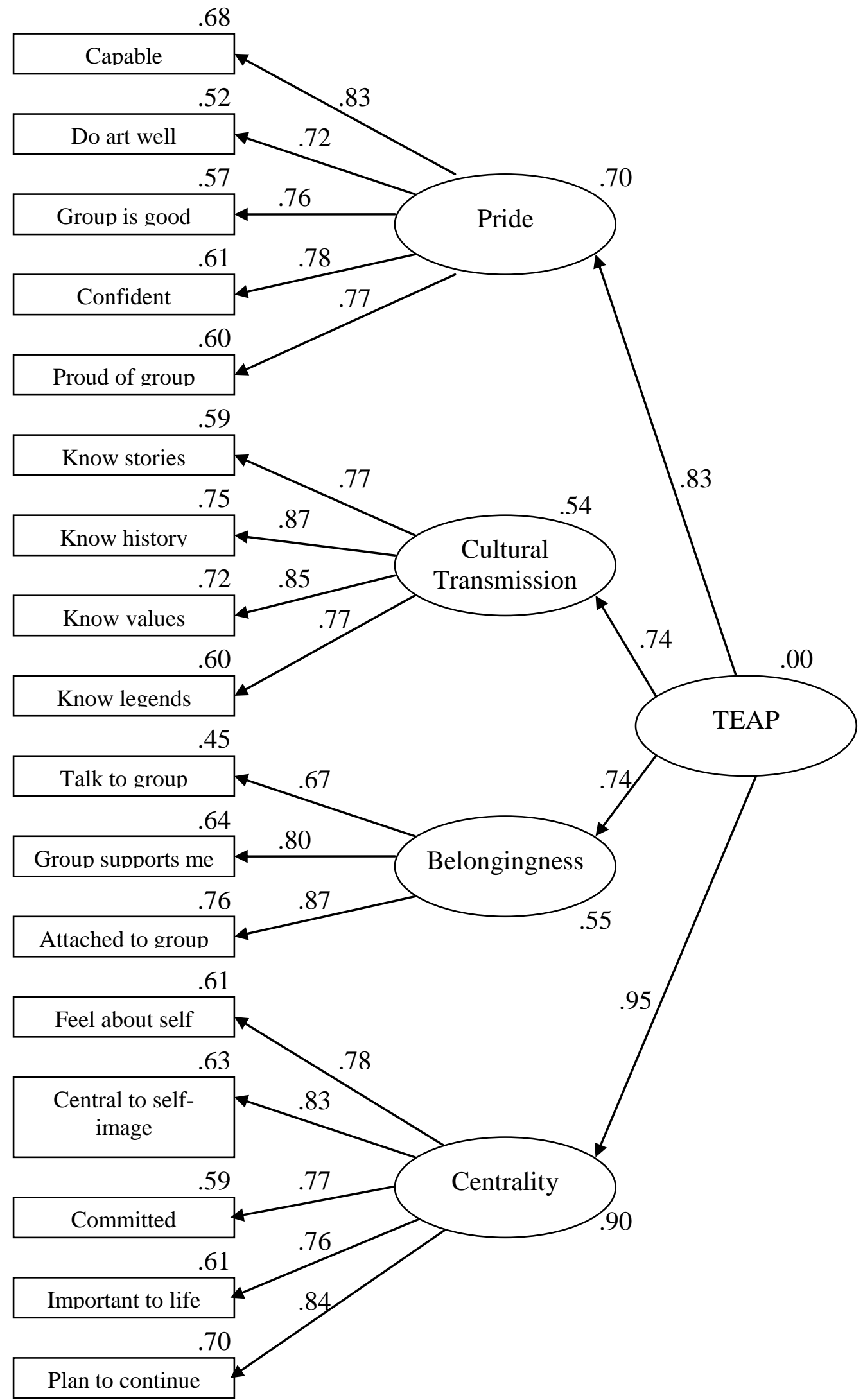

Figure 4.3. Confirmatory Factor Analysis of the TEAPS scale $(\mathrm{N}=118)$ 
Table 4.3

Correlations of TEAP subscales $(N=357)$

Cultural

\begin{tabular}{|c|c|c|c|}
\hline & Pride & Transmission & Belongingness \\
\hline $\begin{array}{l}\text { Cultural } \\
\text { Transmission }\end{array}$ & $.55^{* *}$ & - & \\
\hline Belongingness & $.52 * *$ & $.45^{* *}$ & - \\
\hline Centrality & $.71 * *$ & $.61 * *$ & $.57 * *$ \\
\hline
\end{tabular}

$* * p<.01$

\section{Construct validity.}

In the absence of a similar measure with which to compare the TEAPS instrument, two strategies were employed to assess construct validity of the scale: correlations between objective participation responses and the TEAPS mean score, and $t$-test between the groups comprising the highest and lowest levels of qualification in the participants' art-forms, drawn from the total sample of 357. The correlations between the mean scores of the final TEAPS measure and objective items were significantly and positively correlated at $p<.01, r=.52$ for years of practice, $r=.33$ for days per week of practice, and $r=.39$ for level of advancement (Table 4.4). Level of advancement was bifurcated into two groups with "complete beginner" and "some experience" forming the lower level of achievement and "advanced" or "expert" forming the higher level. Since testing concerned only differences between high and low levels of achievement, the intermediate level of achievement was removed from the analysis. There were 117 participants in the lower level $(\mathrm{M}=3.42, \mathrm{SD}=.78)$ and 143 in the higher level $(\mathrm{M}=4.04, \mathrm{SD}=.66)$. An independent samples $t$-test was performed, revealing a significant difference between the two groups on the mean score for TEAPS $t(25)=6.74, p<.01$, and for each factor (Table 4.5), confirming that more advanced participants scored significantly higher on the TEAPS measure as expected. 
Table 4.4

Correlations of TEAPS to objective participation responses $(N=357)$

\begin{tabular}{lccc}
\hline & Years of practice & $\begin{array}{c}\text { Level of } \\
\text { advancement }\end{array}$ & Days per week \\
\hline Level of advancement & $.52^{* *}$ & & \\
Days per week & $.28^{* *}$ & $.40^{* *}$ & \\
TEAPS & $.30^{* *}$ & $.39^{* *}$ & $.33^{* *}$ \\
\hline
\end{tabular}

$* * p<.01$

Table 4.5

T-test of differences by skill-level of TEAPS score

\begin{tabular}{lccccc}
\hline & Skill level & $\mathbf{N}$ & Mean & S.D. & S.E. \\
\hline Pride & Low & 116 & 3.57 & 0.72 & 0.07 \\
Cultural Transmission & High & 137 & 4.32 & 0.74 & 0.06 \\
& Low & 116 & 3.66 & 0.99 & 0.09 \\
Belongingness & High & 137 & 4.10 & 0.88 & 0.08 \\
& Low & 116 & 3.13 & 0.95 & 0.09 \\
Centrality & High & 137 & 3.57 & 1.01 & 0.09 \\
\multirow{4}{*}{ TEAPS overall } & Low & 116 & 3.34 & 0.97 & 0.09 \\
& High & 137 & 4.18 & 0.83 & 0.07 \\
& Low & 116 & 3.43 & 0.78 & 0.07 \\
& High & 137 & 4.04 & 0.67 & 0.06 \\
\hline
\end{tabular}

\section{Structural Equation Modelling of TEA participation.}

In the present case, a structural equation model based generally on Study 2 results was estimated using the new multidimensional and continuous measure of TEAPS. Four latent variables were constructed, reflecting the four observed variables in Study 2. The four indicators for the latent Traditional/Ethno-cultural Arts Participation (TEAP) variable were the four sub-factors of Centrality, Belongingness, Pride, and Cultural Transmission. The indicators for the latent EID variable are Phinney's (1990) subscale of Identity Search and two parcels of randomly selected items from the Affirmation and Commitment subscale. The 
latent Connectedness variable was composed of subscales for Family, Own Community, Other Community, and Peer connectedness. The Well-Being indicators were the WEMWBS, Resilience, Life Satisfaction, and Self-esteem scales.

Maximum likelihood structural equation modelling was employed to test the paths of influence between these components. Paths which were non-significant in Study 2 were included in this model in the event that the more sensitive measure of TEA participation used in this study might yield somewhat different results. Due to the conflicting results obtained from the concurrent year and longitudinal models for the EID to Connectedness path, two models were tested to determine which better fit these data: the original proposed model (Fig. 3.1) and a competing model with directionality reversed (see Fig 4.1). A bi-directional path could be another possibility for relations between these components, but that would violate the requirement of recursivity for model specification and testing in the AMOS software (Arbuckle, 2008). Directionality was otherwise retained from the Study 2 proposed model (see Figures 3.1, 4.1, and 4.4). Means and standard deviations of all scales and subscales appear in Table 4.6. Correlations of latent variables are found in Table 4.7, and correlations of all observed variables are found in Appendix F. 


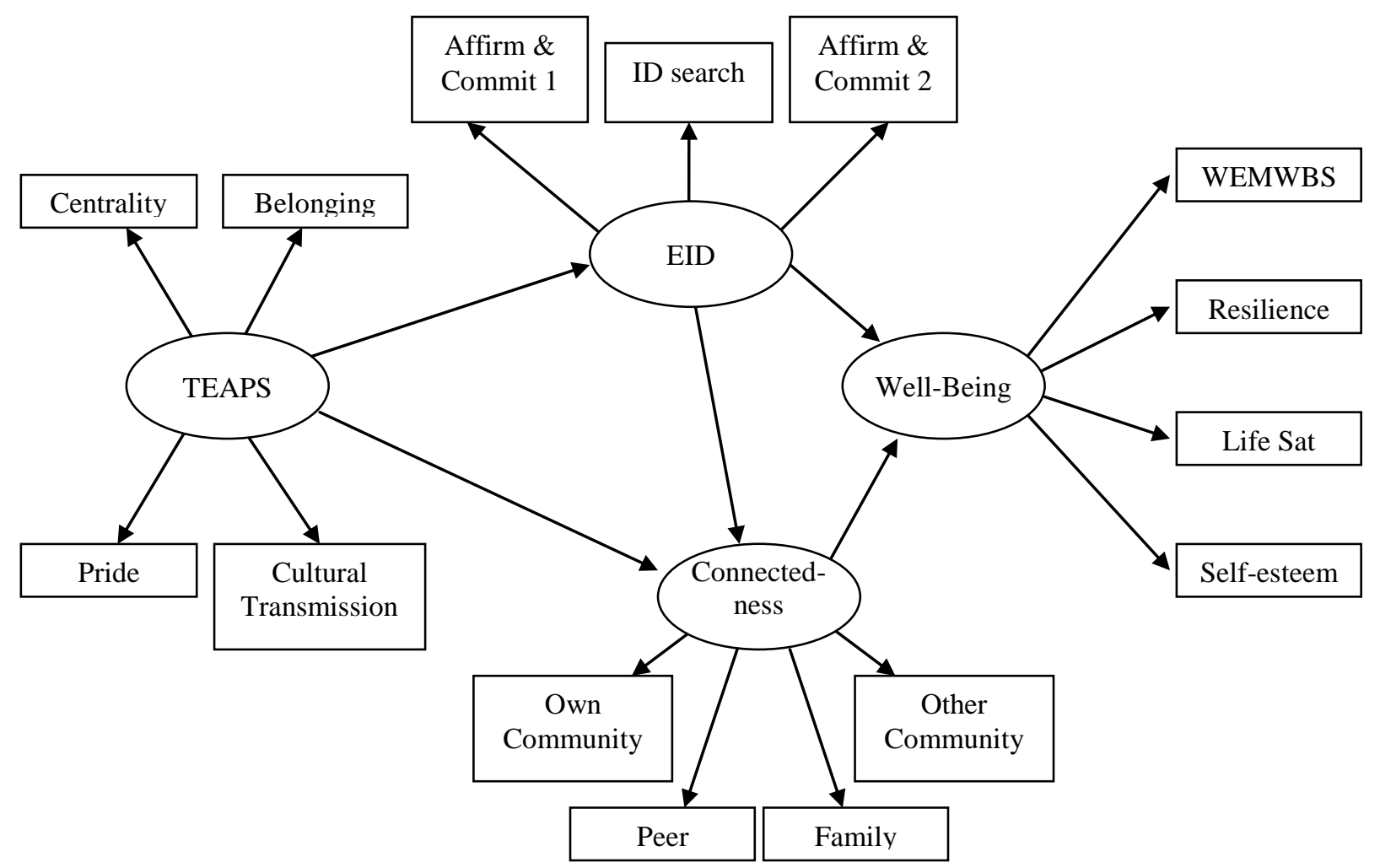

Figure 4.4a. Proposed structural equation Model A of TEAP 


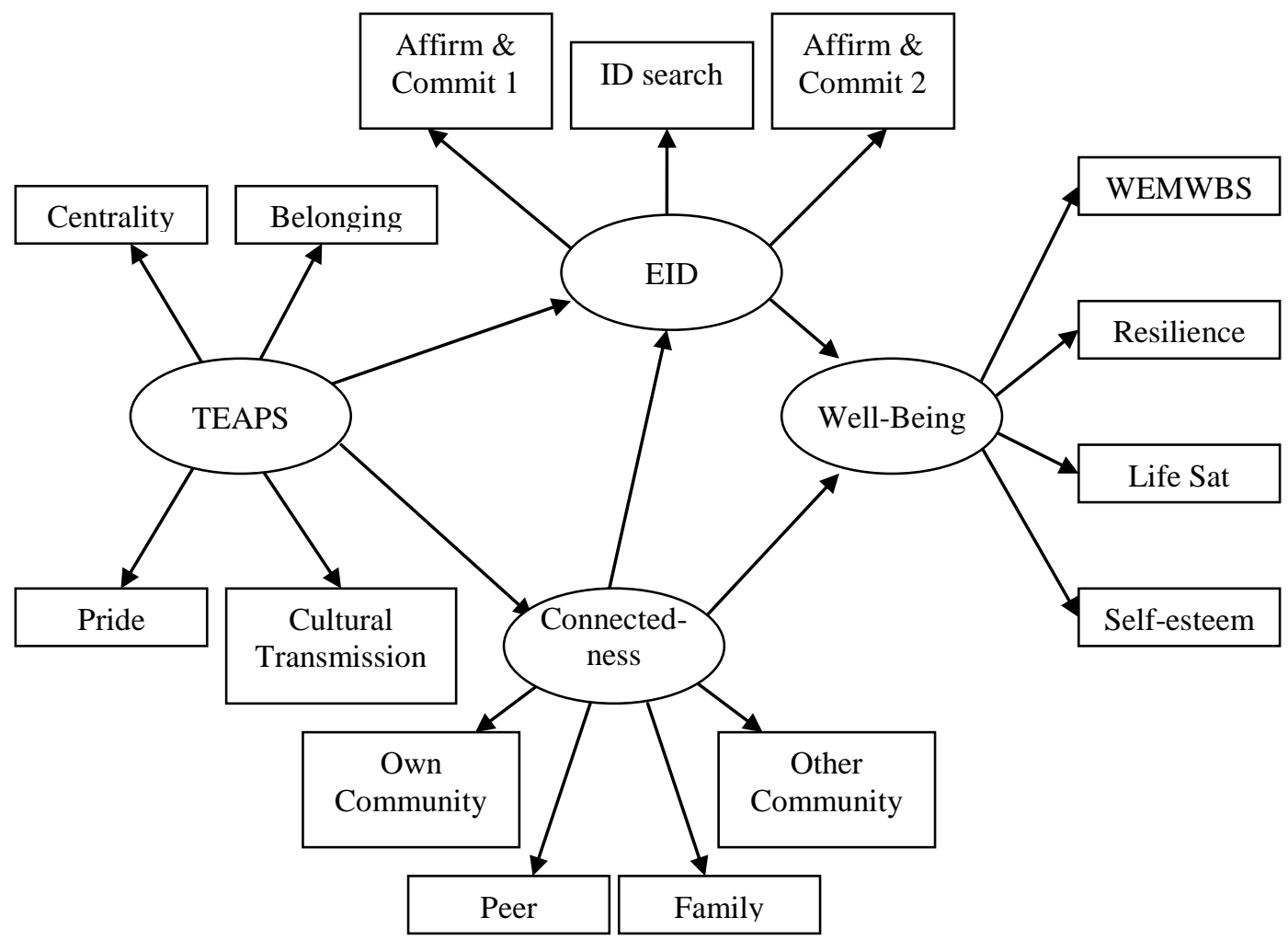

Figure 4.4b. Competing structural equation Model B of TEAP 
Table 4.6

Descriptive statistics and reliability of study instruments $(N=336)$

\begin{tabular}{lcccc}
\hline & \# items & Mean & SD & Cronbach's $\alpha$ \\
\hline Well-Being overall & 35 & 3.77 & 0.45 & .95 \\
WB Warwick-Edinburgh- total & 14 & 3.90 & 0.59 & .92 \\
WB Self Esteem & 8 & 3.37 & 0.31 & .82 \\
WB Resilience & 8 & 4.13 & 0.58 & .91 \\
WB Life Satisfaction total & 5 & 3.70 & 0.77 & .85 \\
Connectedness overall & 21 & 3.90 & 0.54 & .90 \\
Connectedness own community & 5 & 3.56 & 0.66 & .77 \\
Connectedness other communities & 5 & 3.94 & 0.73 & .86 \\
Connectedness family & 8 & 4.07 & 0.73 & .93 \\
Connectedness peer & 3 & 4.05 & 0.70 & .70 \\
TEAPS overall & 17 & 3.74 & 0.74 & .94 \\
TEAPS Pride & 5 & 3.95 & 0.76 & .88 \\
TEAPS Cultural Transmission & 4 & 3.85 & 0.95 & .89 \\
TEAPS Belongingness & 3 & 3.36 & 0.96 & .83 \\
TEAPS Central & 5 & 3.79 & 0.94 & .90 \\
EID total & 12 & 3.83 & 0.71 & .92 \\
EID ID search & 5 & 3.68 & 0.74 & .79 \\
EID Affirmation \& Commitment & 7 & 3.94 & .80 & .91 \\
\hline
\end{tabular}

Two models were specified (Figures 4.4a and 4.4b) and tested using AMOS version 17 (Arbuckle, 2008) as structural equations. The models were evaluated by the five indices discussed above: GFI, CMIN/DF, RMR, RMSEA, and CFI. Also, path coefficients were examined for significance level, with additional analyses for significance of indirect effects in LISREL version 8.80 (Joreskog, 2006).

The original proposed (Model A) and competing (Model B) models did not differ significantly in terms of fit indices (such as change in chi-square value). The chi-square value for both models was $284.23(86, N=336), p<.01$. Surprisingly, the direct influence of EID on Well-Being is strongly negative in both models $(\beta=-.33, p<.01)$, which is which is opposite in sign to the raw positive correlation of EID and Well-Being (Table 4.7 and Appendix G). The positive influences of EID on Well-Being work indirectly via Connectedness in Model A (Fig. 4.4a and Fig. 
4.5), mediated by Connectedness. The competing Model B, however, includes no resulting paths for positive direct or indirect effects of EID on Well-Being. Evaluating the two models logically, a model which accounts for the positive correlations between EID and Well-Being variables should be a more accurate representation of the process, meaning that Model A (Fig. 4.4a and Fig. 4.5) more accurately represents the correlation table (Table 4.8). Fit indices for Model A were as follows: GFI .90, CFI .92, Chi square/DF = 3.31, RMR .04, and RMSEA .08. The Chi square/DF and RMSEA are not optimal, but fall within the maximum values of five for Chi square/DF (Kline, 2005) and .1 for RMSEA (MacCallum et al., 1996). Other indices are within range for acceptable goodness of fit. The negative weighting of the EID to Well-Being path may indicate that stronger EID without the mediating influence of Connectedness has a negative effect on participants.

Further examining Model A, TEA participation had a positive direct influence on Connectedness $(\beta=.72, p<.01)$, and on $\operatorname{EID~}(\beta=.52, p<.01)$. EID positively predicted Connectedness $(\beta=.38, p<.01)$, serving in the model also as a mediator between TEAPS and Connectedness, and evidenced an unexpected significant negative direct effect on Well-Being $(\beta=-.33, p<.01)$. Connectedness predicted Well-Being $(\beta=.63, p<.01)$, serving in the model as a mediator of the influences of TEAPS and the positive influences of EID on Well-Being. Indirect effects are found in Table 4.7. These results confirm significance of all paths of the original hypothesized model in Chapter 3, though the negative direct influence of EID on Well-Being is contrary to predictions. 


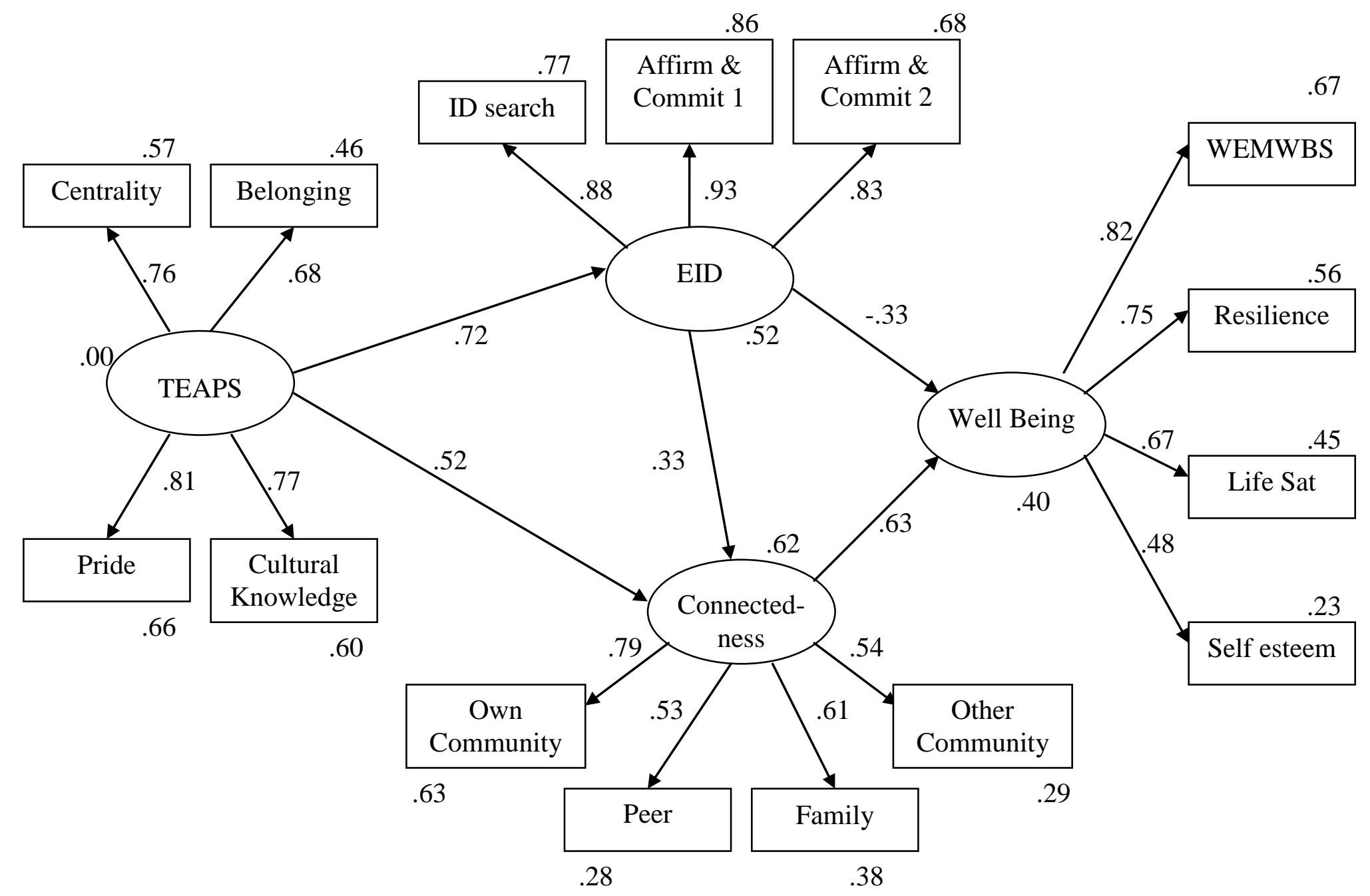

Figure 4.5. Best resulting structural equation model of TEAP $(\mathrm{N}=336)$ 
Table 4.7

Correlations of latent variables of TEAP model $(N=336)$

\begin{tabular}{llll}
\hline $\begin{array}{l}\text { Combined means for } \\
\text { latent variables }\end{array}$ & TEAP & EID & Connectedness \\
\hline EID & $.64^{* *}$ & - & \\
Connectedness & $.59^{* *}$ & $.55^{* *}$ & - \\
Well-Being & $.33^{* *}$ & $.27 * *$ & $.51^{* *}$ \\
\hline
\end{tabular}

Table 4.8

Standardized indirect effects of latent variables $(N=336)$

\begin{tabular}{lccc}
\hline & TEAPS & EID & Connect \\
\hline Connectedness & $.27^{* *}$ & & \\
Well-Being & $.46^{* *}$ & $.35^{* *}$ & \\
EID- ID search & $.63^{* *}$ & & \\
EID-Affirmation \& Commitment 1 & $.67^{* *}$ & & \\
EID-Affirmation \& Commitment 2 & $.59^{* *}$ & & \\
Connectedness own_community & $.59^{* *}$ & $.30^{* *}$ & \\
Connectedness other community & $.41^{* *}$ & $.20^{* *}$ & \\
Connectedness family & $.47^{* *}$ & $.24^{* *}$ & \\
Connectedness peer & $.39^{* *}$ & $.20^{* *}$ & \\
WB- Life Satisfaction & $.31^{* *}$ & $.01^{*}$ & $.42^{* *}$ \\
WB- Resilience & $.34^{* *}$ & $.01^{*}$ & $.47^{* *}$ \\
WB- Warwick-Edinburgh & $.38^{* *}$ & $.02^{*}$ & $.52^{* *}$ \\
WB- Personal Self Esteem & $.22^{* *}$ & $.01^{*}$ & $.30^{* *}$ \\
\hline
\end{tabular}

$* p<.05, * * p<.01$ 


\section{Discussion}

This particular study was designed to examine the model of TEA participation with more sensitive and psychometrically appropriate measures. In particular, a new scale was constructed to measure and evaluate the important components of TEA participation. Factors were identified from a larger set of potential items, and items were selected to form a 17-item measure. Those components were then used to retest the model of influences of TEA participation in a more sophisticated form.

In the exploratory and confirmatory analyses, it was anticipated that there would be seven potential subscales that could subsequently form factors: theoretical subscales for arts-related commitment, arts-efficacy, artistic identity, centrality and salience, arts group esteem, belongingness, and cultural information. The results supported only four factors: Pride, Centrality, Cultural Transmission, and Belongingness. Pride included elements of arts-efficacy and arts group esteem. Belonging retained items from the proposed belonging subscale. Cultural Transmission also retained items from the proposed subscale, in this case "cultural information," renamed Cultural Transmission during analyses. Centrality combined items from both the identity and the centrality and salience proposed subscales.

The resulting factor structure is clear and comprehensible when considered in light of the Study 1 results. The Cultural Transmission and Belongingness factors are both presaged in those results, and Centrality is implied in the importance TEA-practicing participants expressed regarding their practices for themselves and their communities. An interesting aspect of the results is the combination of individual level arts-efficacy and group level arts- 
related esteem in the Pride factor. It is probable, given the cultures represented in the sample, that a majority of the participants hold collectivist beliefs about their lives within their cultures (Hofstede, 1980; 2001), and that they may place entitativity (the individual to collective continuum at which one defines self and makes decisions) at the group level (Kashima et al., 2005; Yamaguchi, 1994). The combining of these individual and group level items may reflect this collectivism, intertwining individual and collective pride.

Self-reported measures of participation (level of advancement, years of practice, and days per week of practice) correlated significantly with the TEAPS measure, with level of advancement correlating most strongly with TEAPS. Results of the $t$-tests similarly reflect the association between higher achievement and higher TEAPS measure scores, including those of each factor. These results suggest the TEA-related processes posited in Study 1 and supported by the differences between groups as tested and modelled in Study 2 are accurately reflected in the TEAPS measure.

As illustrated by the component factors and their items, TEAP operates on a number of levels. Components include cognitive information about the culture as well as increased connection with the group members. A sense of confidence and pride in both the self and the group is enhanced, and the arts practice becomes a central part of the person's life and self-image, Study 1 participants suggested. Those data suggested that these processes would occur simultaneously and thus be interwoven, with the components working together in mutually supportive ways. Particularly interesting is the Cultural Transmission component. It has been suggested in fields of semiotics and memetics that arts function as a source of cultural and symbolic cues (Atran, 
2001; Elicker, 1997; Nattiez, 1991; Sebeok, 1991), and similarly movement has begun toward investigation of dynamic psychological and informational processes in culture (Kashima, 2000; 2008), especially regarding "processes of cultural transmission in situated social activities" (Kashima, 2008, p. 107). TEAP, from the results obtained here, is arguably one such social activity in which this transmission occurs. The process of transmission-reception (Cultural Transmission) is supported by other group members (Belongingness) and internalized as central to self-image (Centrality), while also being reinforced by resulting positive evaluation of self and group (Pride). TEAP is most certainly a dynamic cultural process.

The model demonstrated good fit, and provides a detailed view of the ways in which these variables predict each other. As expected, TEAPS had a very strong influence on EID, as has been described in other literatures (e.g., Coppens, Page, \& Thou, 2006; Hugget, 1992). As has been discussed earlier, TEA practices provide an environment particularly suited to identity construction and reinforcement. This study provides some evidence of how this process operates, particularly regarding the cognitive components of Cultural Transmission retained in factor analyses. The stories, history, values, and legends are transmitted, explained, and made relevant in the context of the arts practice. These processes are happening simultaneously in concert with increasing sense of membership and pride in the arts group and growing arts proficiency, altogether providing a set of interwoven positive reinforcements. These influences forms a set of cultural learning and identity reinforcement mechanisms in enculturation, which has not been addressed in acculturation 
research, but which is part and parcel of the own-group identification aspect of the integrated acculturation strategy (e.g., Berry, 1990; 2007; Ward, 2001).

In regards to the Connectedness construct, the influences of TEA participation were stronger than those of EID. While this does not contradict the literature finding positive relations between EID and connectedness (e.g., Aguilar, 2007; Dole \& Csordas, 2003; Navarro et al., 1997), it would indicate that TEA participation factors have stronger influence on Connectedness than EID for this sample and for these data. The strong, positive influence on the participants' sense of connectedness quantitatively supports the literatures of other disciplines in which social cohesion has been observed to be enhanced by arts practices (O’Hagin Harnish, 2006; Turner, 1982a; 1985; 1986).

Turner's (1982a) concept of communitas describes the process whereby artistic practices increase a sense of social cohesion (including Western theatre, for example). These results corroborate that these anthropological observations point to a measurable psychological process as suggested in the general introduction. These particular, concrete forms of ethno-specific activity may form a potent support for connectedness in acculturation, which is worthy of further investigation, given the importance of connectedness for well-being observed in previous acculturation research (e.g., Chavis et al., 1986; Chipuer \& Pretty, 1999). Overall, the strong support for Connectedness, both from TEA practices directly and through their support of EID, shows that TEA participation may be a powerful tool in overcoming the anomie often experienced in migration (Jablensky et al. 1994). Loss of social connectedness has also been observed to be a serious threat to the well-being of indigenous people (Dole \& Csordas, 2003), especially in wholesale shifts from traditional to urban life such 
as the Maori have experienced in recent generations (Durie, 1994; Walker, 2005). This is particularly true on a familial level as subsequent generations acculturate away from traditional ways, creating ever widening rifts within families and across generations (Liebkind, 1996; Miller \& Rasco, 2004; Nguyen et al., 1999). TEA participation may provide means to reduce these rifts for families and ethnic communities, with the added benefit of supporting feeling of connection to other communities.

Generally, the strong explanation of Well-Being variance in the model suggests that TEA participation can form a supportable, positive influence in the lives of acculturating individuals. A substantial amount of variance in WellBeing was explained by the model, largely due to direct effects of the Connectedness variable. The strong direct path from Connectedness to WellBeing is consistent with previous research connecting those concepts, particularly with literature addressing the import of connectedness with one's community (e.g., Chavis et al., 1986; Chipuer \& Pretty, 1999).

The negative direct path of EID to Well-Being, however, is incongruent with that literature (e.g., Chipuer \& Pretty, 1999; Jones \& Galliher, 2007). This result could indicate that there are different ways in which one may identify culturally, and that the connectedness aspect must be part of the process for the outcome of identification to be favourable. The model would then illustrate that in the absence of connectedness, stronger ethnic identity becomes a liability for well-being outcomes. Such a finding, if clarified and replicated, would greatly contribute to a more refined understanding of EID and processes by which it influences well-being. 
This study has achieved its goals of establishing a continuous scale of traditional and ethno-cultural arts participation and more sensitively modelling the processes involved. The measure exhibited strong evidence of validity. Analyses of mediating and outcome measures in relation to the TEAPS construct additionally support the beneficial influences of such participation, which were predicted based on evidence from the two preceding studies. Altogether, the study supports the view that TEA participation is a meaningful paradigm, and the cross-cultural nature of the sample involved suggests that the measure may be transportable across cultures, representing a generalizable human process.

\section{Limitations and future directions.}

The largest limitation of the study is the lack of further validation and reliability studies. These must certainly be done prior to publication of the TEAPS measure, but were not possible in the financial and temporal constraints of research for this thesis. Researchers have noted difficulties in study participation by ethnic minority groups to whom research processes may seem alien or unpleasant (Carlson \& Rosser-Hagan, 1993). In this case, the time required to achieve sufficient sample size for EFA and CFA prevented a subsequent validation study. Sample size in general is another limitation of this study: a more robust sample may have yielded clearer results. The intent of this study was to generalize both measures and models across groups, but until tested with sufficient samples from a number of different ethno-cultural groups, generalizability is not clearly demonstrated and the sample is insufficient to allow comparison of different ethnic groups. 
This research does, however, provide a measure of TEA participation which may be used to evaluate arts programs and to further study TEA processes. Expansion of this research requires that larger studies be conducted both within and across cultures and in differing contexts. It could be, for instance, that the process is more powerful in Polynesian cultures which maintain a continuous body of oral history and genealogy transmitted specifically by TEA practices, whereas an art such as Scottish Highlands dance which may not contain such specific content could possibly have certain benefits but be less powerful in the transmission of identity information. The processes should also be investigated in differing contexts of acculturation, perhaps yielding different results for the TEAPS measure depending upon the inter-group relations being experienced by the participants. The model must also be longitudinally tested in conditions which control for stationarity as much as possible to verify directionality of predictive paths. It is also true that this study included no measures of dominant culture identification. In Berry's (2006; 2007) integrated strategy of acculturation, identification with both the heritage and dominant cultures are key to observed positive outcomes. Inclusion of this information may clarify the negative path loading of EID to Well-Being, should stronger heritage culture identification without corresponding dominant culture identification lead to less favourable outcomes.

It may also be possible to work from examination of the components of this particular method of enculturation to develop more refined measures of ethnic identity. The components of these arts practices may form a set of social and behavioural influences that could be more important or specific than items used in current identity measures. For instance, some measures include items 
such as eating foods, reading newspapers, or shopping in stores related to the ethno-cultural group involved (Fox, 2004, regarding Vietnamese in Hawai'i). These sorts of behaviours, in and of themselves, may have no specific implications, but rather the sequelae, such as increased connection or cultural information may. In this case, the TEAPS measure illustrates specific ways and means by which EID may be effectively enhanced, and the factors of TEAPS illustrate a set of components important to the process. It may be that inclusion of specific activities such as traditional arts in EID measures would provide more meaningful identification information.

It is also a limitation that this study addressed only identification with the heritage culture. Identification with the host or dominant culture is debated as being an important part of healthy adaptation (e.g. Berry, et al., 2006; Rudmin, 2006). The primary concerns of this research regarded psychological benefits of enculturation and cultural maintenance. In the interest of keeping the research focussed and the survey no longer than necessary, this important aspect of acculturation was omitted. Future research should certainly model both enculturation and acculturation for a complete view of outcomes and influences. 


\section{Chapter 5: General Discussion}

This research investigates the processes and influences of traditional arts participation in situations of acculturation. A series of studies were undertaken to identify components of arts relevant to acculturation, to differentiate between traditional and other arts, to test whether these differences are measurable, and to explicate processes by which traditional arts might influence well-being outcomes during acculturation. The literature upon which this research was based is interdisciplinary, drawing arts-related concepts primarily from anthropology, sociology, ethnomusicology, and cultural studies, while the psychological components are drawn primarily from the literature and theoretical frameworks of acculturation research. The subject is interdisciplinary in nature, crossing borders of ethnography, art, and semiotics, among others, and addressing an area not previously investigated from a psychological perspective.

In those other social sciences, traditional arts have long been observed to contain a wealth of information about the beliefs and understandings by which cultures construct their lives, containing the stories and symbols of those understandings enacted within the behavioural and interpersonal modes of the culture. These arts have been seen to form core components of community cohesion, cultural transmission and maintenance, and identity development. In studying indigenous and migrant groups in acculturative settings, traditional arts have been observed to provide resources in their traditional functions, and at times in new ways such as connecting different communities (e.g., O'Hagin \& Harnish, 2006).

The research began and ended in the examination of the major facets or aspects of traditional arts participation and how they might be psychologically 
relevant in acculturation. The questions arising in that inquiry related to whether there were differences between participation in the specific traditional arts of one's own heritage and in arts of other cultures, non-traditional arts usually comprising the now-widespread arts of Europe and North America. Western and European origin artforms have become ubiquitous as global media products, current practitioners coming from all over the world. Artistic genres and products have widely been stripped of context and internationalized in the process (e.g. Berns-McGown 2007; Boer, 2009). Do different arts have varied psychological functions for different ethnic groups, perhaps depending upon their relevance to one's heritage, and do traditional arts retain their historic functions in acculturation?

To illuminate these questions, a study was undertaken involving participants who were experts or professionals in a variety of traditional and non-traditional arts, all of whom were acculturating as indigenes or immigrant group members in New Zealand. They shared many aspects of life, in terms of experiencing prejudice and of political and intergenerational issues. More specific to their arts practices, there were a number of ways in which arts favourably affected acculturation processes for participants. Both traditional and non-traditional artists in the first study expressed that their arts practices provided resources for coping with difficulties and stresses in their acculturation experiences. For non-traditional artists, arts provided a way to reframe their experiences, through reinterpretation or humour, for instance. All arts also provided opportunities to connect with other ethnic groups through public exposure, particularly the dominant group. Whereas the non-European ethnic groups of New Zealand were ghettoized into near invisibility prior to World War 
II (e.g., Ip, 2003; Liu et al. 2005), visual artists, writers, actors, musicians, and dancers have played roles in generating greater tolerance in subsequent years, putting a non-threatening face on the ethnic "other" in the safety of theatre, gallery, or print. As discussed earlier, this is reminiscent of Allport's Contact Theory (cf. Pettigrew \& Tropp, 2006), though the contact is less direct and personal than the processes Allport and those doing subsequent research have observed (e.g. Crisp \& Turner, 2009; Wright, Aron, McLaughlin-Volpe, \& Ropp, 1997). The effects of the less direct contact may not be as strong or as immediate, but as observed by artists in the qualitative data of Study 1, arts may have been an influence toward change in inter-group relations in New Zealand, and contact through arts may form a worthy avenue of inquiry in other contexts.

Traditional arts were viewed in the Study 1 data as providing particular resources distinct from those of non-traditional arts. On a more cognitive level, these included connecting (or reconnecting) the participant with the heritage culture, transmission of cultural knowledge, construction of cultural identity, and learning culturally preferred ways of being. Experientially, the building of artsbased efficacy brought immediacy and salience to the cultural knowledge, as well as a sense of resilience that carries beyond the arts practice into life in general. Interpersonally, discussion included bonding with the arts group and ethnic community and increased familial cohesion. For traditional artists, the advantages in coping came more from additional social resources or from an increased sense of identity and confidence rather than solely from reframing or reinterpreting experiences, as was the case with non-traditional artists. Through strong social connections and identity, the effects of prejudice, anomie, or misfortune were seen to be lessened. 
The first study clarified components of arts practices and their perceived roles in acculturation, and it revealed differences between the components and processes discussed by traditional and non-traditional artists. It was lacking, however, in empirical evidence that these views psychologically play out in measurable ways. This inspired Study 2, in which longitudinal data were examined for measurable differences between groups of youths who did either traditional arts, Western/other arts, or no arts. Benefits arising from arts participation were statistically demonstrated between these groups. All arts practices led to better Connectedness and Well-Being. In all measures (EID, Connectedness, and Well-Being), the TEA group reported significantly higher scores than the No Arts group, and were also consistently significantly higher in EID than the Other Arts group. These results demonstrate that there are measurable psychological differences between those who do or do not practice some art. The differences between traditional and non-traditional arts in EID responses indicate potential for important underlying differences between the practices in processes and outcomes.

A model of the process was postulated based on Study 1 data, the arts and acculturation related literatures of other social sciences, and the literature of psychological acculturation, proposing particular relations between variables. The model was tested in Study 2, yielding a linear path from TEAP, to EID to Connectedness, to Well-Being in Years $1 \& 2$, and also including a weak but significant influence of EID on Well-Being in Year 3. Clarity of the results was clouded in longitudinal testing, which revealed reversed influences from Connectedness to EID over time. The categorical measurement of arts participation may have been a factor confounding results, suggesting the need 
for a more refined measure accounting for aspects and factors of traditional arts participation.

To better explicate the relevant aspects and factors of TEA participation active in the model, a large set of items potentially related to aspects of TEA participation was generated, included in a study of participants in diverse arts specific to their ethno-cultural heritage, and reduced through factor analyses to form a measure of components of TEA participation. The factors resulting from analyses were Pride, Centrality, Cultural Transmission, and Belongingness. The Cultural Transmission factor represents the semiotic processes at work in transmission, reception, and reinforcement of cultural information. Belongingness is the connection to group members, providing social support in the cultural learning process, as well as providing a specific set of people to whom one can feel connected. Pride constitutes the boost to self-esteem, efficacy, confidence, and CSE from having learned an art and been supported in the process. Centrality is the importance the art and those with whom the art is shared hold for the participant, becoming an essential part of who one perceives one's self to be. These resulting factors are in accord with Study 1 qualitative results, herein derived statistically, and, potentially, happening continuously and simultaneously in an interwoven web wherein each component reinforces and supports all other components.

In the final study, the re-testing of the TEAP model with more sophisticated measures revealed significant influence in all predicted paths, though the direct influence of EID on Well-Being was negative. This model more strongly demonstrated beneficial influences of TEAP on Well-Being, mediated by EID and Connectedness, the positive effects being indirect in the 
case of EID. The negative loading of the EID to Well-Being direct path is a very interesting result, certainly pointing out the complexity of EID issues and perhaps explaining the weak performance of the path in Study 2. Though further study is required to understand this result, it may point to differing implications of EID, depending upon interaction with aspects of connectedness. This result may indicate that EID requires a mediating or moderating influence of connectedness to be beneficial; EID without a corresponding sense of connectedness may actually form a negative influence. It may, however, be that omitted factors such as other-group identity affect results, or that the relations between EID and Connectedness are bi-directional and must be modelled with a statistical program that permits such relations. Further investigation is required to clarify this finding.

The TEAP process as investigated and modelled represents TEAP in situations of acculturation. The model may also potentially describe TEA practices in contexts including the place of cultural origin, though this is not discernable from available data. In either case, TEAP may be particularly important in acculturation, as is suggested in research from other social sciences regarding importance of traditional arts for individuals and groups in acculturative situations (e.g., Dole \& Csordas, 2003; O’Hagin \& Harnish, 2006). In the stress and coping theoretical framework of psychological acculturation research, a primary concern is the availability of social support, which has been seen to alleviate distress and facilitate adjustment (Dunkel-Schetter, Folkman, \& Lazarus, 1987). The collective aspects of many TEAP activities provide a resource of social support to fulfil this need. The anthropologist Victor Turner $(1982 \mathrm{a} ; 1982 \mathrm{~b} ; 1985 ; 1986)$ described, in his theory of communitas, that ritual 
functions in traditional societies are a means by which such social cohesion is nurtured and maintained. The distinction between ritual and art is not so clearly defined outside of European cultures, arts such as hula and kapa haka, for example, having inseparable artistic and ritual function. By being involved in traditional arts, not only do participants have a number of peers and leaders available as part of their social support network, they may also bond more intimately with these others through the communitas components of their practice, potentially providing an exceptionally strong support mechanism.

The social identity framework of acculturation focuses on identification with and participation in both the culture of origin and the dominant culture, including sense of belonging, importance of membership, and evaluation of the group (Ward, Bochner, et al., 2001). The Belonging, Centrality, and Pride factors of TEAP are similar to aspects of membership and evaluation described in social identity literature, though in this case they apply to the arts practice and group. It is, however, a group situated within the heritage culture, thereby having potential positive impact on social identification with that broader culture in addition to specific arts group identification. The Cultural Transmission factor forms an aspect of the process not widely investigated in this framework, that being the cognitive components informing identification within a particular culture. This aspect is discussed further below. Primary features of Berry's (1990) acculturation strategies are the degree to which the individual maintains the heritage culture and, orthogonally, participates in the dominant culture (Ward, Bochner, et al., 2001). The literature of this framework primarily deals with identification and participation within the host or dominant culture and resulting adaptive outcomes. It is widely held that the integrated strategy, in 
which one identifies with and participates in both cultures, constitutes the most adaptive strategy, though research addressing heritage culture aspects is rare. This thesis fits well with the less investigated heritage cultural maintenance and active participation aspects. TEAP provides a situated activity in which the culture is maintained and transmitted, with provision of informational components and of social support for this participation.

TEAP also provides a corollary to the cultural learning framework, in which the individual acquires skills in and understanding of the host culture (Ward, 2001). The heritage culture also potentially requires understanding of language, communication style, rules, conventions, and norms for effective interaction in that cultural milieu. The Cultural Transmission factor, along with the natural interactions within TEA context, provides the opportunity for this learning, inculcating the skills and knowledge necessary to navigate the heritage culture. This may be particularly important for youth, who tend to learn about the host culture more quickly than their elders, resulting in cultural distance within families (Miller \& Rasco, 2004; Nguyen et al., 1999). TEAP provides a counterbalance of learning about the heritage culture.

Acculturation research has become increasingly attentive to contextual factors in the process, including family, peer, community, and national levels (Ward, Fox, et al., 2009). The family is largely regarded as providing the primary source of in-group identity. The ethnic composition of peer groups and communities has implications for how the ethnic group is viewed and treated, and for the personal evaluations of membership. The national level varies in effect on acculturation outcomes depending upon ideologies, attitudes, and regulations affecting the groups, and historical differences in how and why 
groups came to be present. A unique aspect of TEAP practices is that they provide an additional, highly specialized context, which may include particular mechanisms, processes, and supports that may remain effective across a variety of surrounding contextual conditions. The specific dynamics of the cultural practice may be changing due to influences of these super-ordinate contexts, but the present research indicates that some of the power of the TEAP context may remain active regardless of these changes. It is a context in which coping support is available, social identity is nurtured, and cultural learning occurs, regardless of the surrounding conditions, aiding in achievement of more adaptive outcomes in acculturation.

A primary consideration in acculturation research is that acculturating individuals are at risk in a number of ways, including isolation and anomie, potentially incoherent, non-inclusive, or toxic community contexts, and negative prejudice experiences. Stresses result from these factors as well as from challenges of socio-politico-economic status (e.g., Jablensky et al., 1994; Marsella \& Ring, 2003). These risks are growing in the context of increasing globalization and migration (Marsella, 2009). There is continuing need for greater understanding of acculturation processes and aids toward positive adaptation outcomes. TEAP potentially provides a strong source of such beneficial influences.

\section{Processes of TEAP}

Several processes may be simultaneously active in the beneficial influences of TEAP. Most clearly identified in this research are cultural transmission, identity development, and connectedness enhancement, which together influence well-being outcomes including self-efficacy/resilience 
enhancement, life satisfaction, and self-esteem. These are discussed in the following section, including the interconnection and interaction of these processes.

\section{Cultural knowledge, transmission, and enculturation.}

(Taonga tuku iho explained) 'Taonga' embraces the notion that there are things in the world, either naturally occurring, people, entities, or things made that are very precious-- because what they do, they have very strong symbolic value as a carrier of identity. A carving can be taonga, but the art of carving is also taonga. 'Tuku iho' is that which is passed down, or that which is passed on. So taonga tuku iho are those treasures or precious things that are passed on. 'Taonga tuku iho,' as a concept, is that we value the notion that we will pass on our treasures, and one of our greatest treasures is knowledge itself, knowledge about the culture, about the world. (Ross Hemera, 23 October, 2009, personal communication)

It is in the process of bringing arts into the physical world, in that moment of creation or perception, that the important work happens (Hodes, 1994; McKercher, 2006). In that moment, the mind, beliefs, origins, and spirit of the artist are made manifest, potentially to be perceived and received by others (Bresler, 2006). Even with static visual arts or recorded media, there is necessarily an act of creation followed by a subsequent context and experience of reception. It is in that moment of reception, in the traditional world, that the taonga could be passed on and the culture's way of living and thinking could continue, and it was historically the primary way, through the symbols, stories, and actions artistically conveyed, as discussed in the introduction to this thesis.

Taonga tuku iho is an indigenous description of semiotes and semiotic processes. The taonga include the semiotes or memes of a culture, including the symbols and stories that form the content of arts. Tuku iho describes the processes of transmission and reception of that content. Going back to the 
linguistic origins of semiotic theories, the world-view encapsulated by language is also taonga. The taonga of culture have been effectively transmitted in song and oral recitation for millennia: while learning the repertoire of a kapa haka group, for instance, the Maori youth is also learning the language, symbols, concepts, and world view represented in the cultural system that produced the repertoire.

The content and processes by which information is transmitted form key components of the TEAP paradigm. Identity must be developed and informed to become cohesive (Erikson, 1964; 1968). To fit into the cultural milieu, norms and protocols of behaviour must be learned and internalized, as in the cultural learning framework of acculturation, but in this case, the process is one of enculturation into the heritage culture. The integrated strategy in the Berry (1997; 2006) model of acculturation requires the individual to develop identity, competencies, and knowledge to participate in the mainstream culture and maintain the heritage culture, but the bulk of acculturation literature focuses only on host culture aspects. This theoretical gap falls in an area of vulnerability to adverse effects such as inter-generational drift; if the young are acculturating more easily and rapidly to the host culture while simultaneously receiving little heritage culture information and reinforcement, the cultural distance between generations becomes quickly wider. TEA participation provides a direct source of information, skill development, reinforcement, and support to counter this drift, and more generally, to form cohesive identity in the culture of origin.

There may be elements of culture which can only be transmitted in specific contexts and settings of activity. Kapa haka, for instance, traditionally takes place in the Marae environment, with its unique historical and familial 
significance to participants, surrounded by the carved and painted symbols and tiki (depicting ancestral or mythological figures) representing that specific $i w i$ (tribe) and hapu (clan) lineage (Bell \& Mathewman, 2004). The information contained in the stories and songs may be most salient, and therefore more effectively transferred, when incorporated into a highly situated and informational context of activity. For the modern urban Maori, assimilated into mainstream society, that context and practice within the symbol-laden environment may provide a dense network of information, experience, and reinforcement to reconnect with the culture. Indian performance arts in New Zealand may not take place in contexts as filled with visual references, but they may include subtle instructions in the ways of interacting, in the content of the art, and in the particular modes of expression that bring the culture to life for those present. It may be through both explicit and implicit levels that traditional arts provide resources of understanding and connection.

\section{Connectedness and communitas.}

As Turner (1985; 1986) observed, traditional arts historically served as mechanisms of communitas, providing sense of cohesion and supporting changes of status within the community such as transition into adulthood. The long history of these communitas functions within a culture, perhaps extending many generations into the past, may add to the power of these mechanisms in acculturation. Over and above the communitas Turner (1982b) observed later in life in more culture-general arts such as modern theatre, TEAP includes knowledge that one is connecting not only with those immediately present, but also with those who went before, in an unbroken line of history and genealogy to 
places and times preceding the acculturative experience. This may explain aspects of the strong influences of TEAP on connectedness observed in these studies, and the power of connectedness to drive the well-being outcome measures in the models presented. In addition to the more overt taonga transmitted, such as understanding of symbols and stories of a culture, are more subtle learnings, perhaps not overtly expressed, of how to relate properly to others within the culture. The structures and relational dynamics encountered in TEAP are parallel to structures of interpersonal interaction in daily life within a culture, including collective and hierarchic dimensions (M. Mead, 1961; Turner, 1985; 1986), and would have similar psychological implications. Learning of the cultural system, including how to interact comfortably within that culture, takes place in concert with increased and positive social support, and within the larger historical scope of continuity for the artistic practice in the culture. The practitioner gains understanding of the culture and her/his interconnected place within the culture, adding greater cohesion to the sense of self as a member of the ethnic group.

\section{Ethnic Identity.}

In the results of these studies, a principle difference between traditional and non-traditional arts regards identity, and potential answers were posited regarding how traditional arts influence identity and what the important components of that influence would be. It has been recently suggested that processes and components of identity construction and maintenance are crucial to the study of identity (Cokley, 2007; Kashima, 2008). Informational and processual components of cultural identity (Kashima, 2008; Ngo, 2008) are 
clearly represented in transmission and reinforcement aspects of TEAP practices, combining explication of informational elements within a set of processes by which they are transmitted, internalized, and reinforced. In addition to the specific skills of an art, TEA practitioners learn informational components including the stories, history, values, and legends of their culture, as well as subtle behavioural guidelines.

If cultures are systems of behaviours and beliefs which differentiate one group from another (e.g., Keefe, 1992; Phinney, 1990), TEA practices provide instruction in beliefs in the form of the informational components, and of behaviours in the practices and interactions within the ethno-cultural art context. This may lead to more cohesive identity formulation, accompanied by social support and reinforcement for the resulting cultural identity. The negative direct path of influence between EID and Well-Being in the final model, contrasting with the strong and significant positive indirect effect, suggests that enhancement of EID alone is not a simple route to greater well-being, but one which should coincide with enhancement of connectedness to yield adaptive outcomes. TEAP provides both of these, working together. In this light, investigation of TEA practices provides a unique avenue of insight into the components and processes of cultural and ethnic identification.

\section{Interweaving of processes, theoretical structures, and contexts in}

TEAP.

In the TEAP paradigm, as differentiated and illustrated by these studies, the whole of the process may be greater than the sum of the parts. It is not only that EID is informed, supported, and made salient. It is not only that arts 
participation provides enhanced social networks or cultural belonging. TEA participation represents a dynamic construct including all of these components. TEAP provides simultaneous cultural transmission, inculcation, and maintenance within settings of support and reinforcement, increasing connectedness across levels from peer to family to community, with concurrent benefits to selfconcept, efficacy, and resilience, all of which help to construct a positive state of well-being.

The various practices of TEAP across diverse cultures in acculturation share commonality in that they are situated at a nexus of levels of context and analysis. TEAP happens where the individual interfaces with culture and community, where community can beneficially engage the larger society, and where the fate of cultural continuity within globalization is negotiated. As discussed earlier, TEAP processes can be understood within multiple theoretical frameworks of acculturation. From this perspective, the nexus is the same for any ethno-cultural group involved in acculturative processes, regardless of other differences between the cultures. There are definite risks in attempting to generalize across ethnic groups and situations, each ethnic group having a unique set of historical, political and social experiences and challenges with which to be dealt in a huge variety of geographic and societal settings (Ngo, 2008). TEAP processes in abstraction, however, form a cultural dynamic (Kashima, 2008) operating with a limited set of components and implications, as is reflected in the theoretical model. There must be a self-identified ethnocultural group in intercultural contact and there must be a set of pre-existing or evolving aesthetic practices. The practices will have implications for identity, connectedness, and well-being of participants, though contextual and cultural 
differences may affect the exact function and strength of components and the degree to which they affect outcomes. The model provides a starting point for further investigation and explication of TEAP processes and how they might differ by context and culture. It is a framework for study of processes which are potentially beneficial for a range of groups currently at risk in acculturation.

\section{Evaluation and Contributions}

The approach and methodology of this research was broad and interdisciplinary. Use of interdisciplinary approaches has been increasingly suggested as the best way toward understanding of complex and multi-level issues (e.g., Marsella, 1998; Bhatia \& Ram, 2009). In actuality, it is a difficult avenue requiring multiple competencies and understanding of multiple disciplines in which theoretical constructs and methodologies may conflict (Perkins, 2009; Reich \& Reich, 2006). The process of this research was not without difficulty, but the topic required such an approach, informed in multiple disciplines, and drawing together disparate literatures to form a basis and interpret results.

The primary contribution of this thesis is the introduction of arts as an avenue to understanding psychological aspects of culture, both in terms of process and content. This is an area previously omitted in psychological research. As such, there was little supporting literature and no resources such as existing measures upon which to draw. Further, this research specifically addressed processes and influences of traditional arts participation in acculturation, which is also a novel approach and perspective on a subject of great importance within globalization and global migration. This research began with the premise that arts are the observable manifestations of culture and 
concludes with empirical evidence of psychological implications of arts practices in acculturation.

As the research progressed, the processes and components of traditional arts practices were defined and described. By the final study, the components of TEAP had been reduced to a specific set of factors, and the process had been described and tested. The resulting measure, though requiring further psychometric testing, forms a particular contribution to studies of arts, cultural processes, and acculturation as a basic tool of research. The component factors and the processual model provide a new theoretical framework for study not only of traditional arts, but of acculturation and EID. Particularly in the area of EID, the results suggest a crucial link between EID and connectedness in the quest for well-being outcomes in acculturation.

This research advances new psychological theories regarding artistic practices, which previously addressed primarily therapeutic processes, cognition, and skill development. This research expands theory into the realm of psychological processes which are part of the cultural practices themselves, identifying salient components within those processes. The research also advances theories of acculturation, identifying a set of practices with implications for adaptive outcomes in the process, and modelling the process by which these practices positively influence these outcomes. Particularly, this research provides a unique theoretical framework in which processes of arts and acculturation are shown to be linked, and in which new aspects of each are illuminated.

In the broader study of cultural or cross-cultural psychology, TEAP forms a case study in cultural dynamics. Cultural components conveyed by 
these practices are identified and the processes by which they are transmitted and maintained are described. These are analogous to semiotes and semiotic processes or to memes and memetics, concepts which are relatively new to psychology, but which are shared across disciplines as diverse as history and biology. In this intersection of shared concepts, it is possible to find an analytic framework which would facilitate a wide range of interdisciplinary collaborations.

\section{Applications.}

Primarily, this research provides evidence of the value of arts programs in general and ethno-cultural arts programs in specific. There are resulting implications for public support and funding of such programs. This has long been an area of contention, as mentioned previously, with strong sentiments both for and against such support and a dearth of specific evidence to inform the debate (Stickley, 2007). Recent financial crises have increased calls to cut funding of arts as an unnecessary waste of taxpayer money and impassioned the responses of arts proponents (Schama, 2009). This research provides a piece of evidence in that regard as well as a template for future research in the area.

The measure and methodology provide a tool and template for evaluation of arts programs, which has increasingly become a requirement when public funding is involved (Clawson \& Coolbaugh, 2001). Systematized empirical evaluation was not well represented in the literature reviewed for this research, and qualitative evidence may be more easily dismissed, especially when the debate is more ideological than factual (Stickley, 2007). There were no standardized measures or processes for such evaluation. This research provides 
both a model of process and a measure of cultural components in arts participation.

\section{Future Directions}

This research provides initial evidence of the psychological value of arts in acculturation, a theoretical model of the processes involved, and preliminary tools and procedures forming a platform for further investigation. As an initial reconnaissance of the cultural arts domain, however, there are numerous areas in need of illumination and many avenues for further research. These range from investigations of specific traditional arts practices within cultures to broader aspects of cultural dynamics in general.

On a most immediate level, the TEAPS instrument requires further psychometric testing, especially in terms of reliability. It must also be tested across and within cultures with more robust samples to determine if it is indeed a valid and reliable instrument for cross-cultural use. The processual model must also be tested with larger multi-cultural samples and with samples drawn from specific cultures to determine whether the concepts and processes are actually generalizable or not, and whether there are subtle or gross variations between cultures. Such variations may illuminate important aspects of the cultures involved. In inquiries of this sort, TEAP may prove to be a valuable paradigm for the understanding of specific cultures and the study of culture in general.

In terms of cultural specifics, differences in the history, origin, and context of cultural contact and resulting acculturation experience may lead to very different reasons for and outcomes of doing an art. This may suggest that the model requires an additional component comprising the social, economic, and political status of the ethno-cultural community, also potentially including 
the ethnic composition of the cultural milieu. Testing of different groups in a variety of contexts could explicate this component. It may directly or indirectly influence all of the current components of the model as presented in this thesis, or may stand outside the model as a factor for which analyses must control.

The model could also have potential application in study of the processes of Western arts and participation in arts not of one's heritage culture. In such cases, the collective to which the EID component refers may shift to identification with the arts group, and the degree to which connectedness and well-being aspects are affected would probably change. Still in all, development of theoretical frameworks by which to evaluate arts programs is essential to their justification as a public expenditure and analysis for effectiveness. Shared components in studies of more general participation would likely include the connectedness and well-being benefits, given the performance of the Other Arts category Study 2. While more detailed analyses may reveal differences in the exact processes and contributions, further research using a shared model and paradigm could potentially elucidate cultural processes of arts as they exist in contemporary global context, including aspects retained from the longer human experience which may remain, as well as differences of TEA processes for specific groups in current acculturation contexts.

\section{Conclusions}

The world is engaged in a sometimes tense negotiation of globalization versus localization, with an overarching global culture filled with diverse local cultures, and increasing mobility of ethno-specific cultures in migration (Hermans \& DiMaggio, 2007; Marsella, 2009; Marsella \& Ring, 2003). In the 
changing world of globalization and massive migration, who and what we are culturally is becoming more and more multi-layered, with forces working toward uniformity and contravening tenacious retention of diversity. If diversity is to continue, the important elements of cultures must be understood and nurtured. These cultural systems form a collection of ways of knowing and interacting in life, any of which may have clues for creating a better, more harmonious human environment. Each culture is as valuable in these tumultuous socio-politicoethno-psychological times as the fragile flora and fauna of the global ecosystem, and each is at risk of extinction (Marsella, 2009).

As established in the introduction, arts are among the oldest activities of humanity. We have arguably been involved in the practicing of arts for our entire existence, the earliest archaeological evidence of aesthetic production dating back at least 120,000 years to the preceding Neanderthal cultures (e.g., Cross, 2001; d'Errico et al., 2003). Homo sapiens sapiens have been demonstrably involved in arts for three times as long as we have grown domesticated grains (cf. Gilroy, 2009; Kuijt \& Finlayson, 2009). Excepting within the particular technologically advanced civilizations arising from more recent European culture, arts have long formed the principle avenues by which culture has been transmitted, maintained, and enhanced (Turner, 1985; 1986). In humanity's headlong rush into a future which is not so certain, we may do well not to forget these ancient artistic practices and, rather than crush them beneath the wheels of progress and change, to remember that they are taonga, treasures in which we can find sustenance, connection, and resolution. 


\title{
Appendix A: Study 1 information sheet, question schedule, consent form, and debriefing statement
}

\author{
VICTORIA UNIVERSITY OF WELLINGTON \\ Te Whare Wananga o te Upoko o te Ika a Maui
}

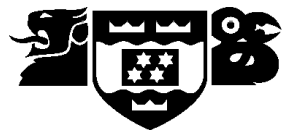

Information Sheet

Stephen Fox
PhD Student
Email: stephen.fox @.vuw.ac.nz
04-463-6976

What is the purpose of this research?

\author{
Marc Wilson, $\mathrm{PhD}$ \\ Senior Lecturer \\ MarcWilson@vuw.ac.nz \\ 04-463-5225
}

- This research will allow us to examine cultural features ethnic artists see as most important to their ethnic identities, and the connections between ethnic arts participation, ethnic identity, and adaptive outcomes in new cultural settings.

\section{Who is conducting the research?}

- We are a team of researchers in the School of Psychology. Stephen Fox is a $\mathrm{PhD}$ student, carrying out this project as part of his thesis research. Drs. Ward and Wilson are supervising this project. This research has been approved by the University ethics committee.

\section{What is involved if you agree to participate?}

- You will be asked a series of questions about what you feel is your ethnic identity, how you express that identity in your art, and how your identity is shaped by life in New Zealand at this time. Sample questions can be found on the attached page. You may choose not to answer any question(s), and you may add other relevant comments if you wish.

- We anticipate that your total involvement will take approximately an hour.

- Your interview may be recorded in audio and video formats for research purposes, and, if you agree, for use in presentation of results.

- During the research you are free to withdraw at any point before the end of the interview, or to request that any particular comment is to be kept confidential. If you do so, all recordings will be automatically wiped and none of the information collected will be used.

\section{Privacy and Confidentiality}

- We will keep your consent forms, data, and recorded material for at least five years after publication of research at the School of Psychology Cross-cultural Laboratory. 
- In accordance with the requirements of some scientific journals and organisations, your data may be shared with other competent researchers.

- If you request that certain statements be confidential or anonymous, nothing linking you to the statements will be included in publication of the research or in shared data.

- Your data may be used in other related studies.

\section{What happens to the information that you provide?}

- The data you provide may be used for one or more of the following purposes:

- The overall findings may be submitted for publication in a thesis or scientific journal, presentation at scientific conferences.

- If you wish, you will receive a copy of the recording of your interview, which you may then use or archive in any manner you choose.

If you would like to know the results of this study, they will be available at approximately the end of 2007, and will be sent to you by postal service or email if you so request. Final results shall also be posted at www.vuw.ac.nz/cacr. If you wish, you may also receive a copy of your recorded interview.

If you have any questions or concerns, please feel free to contact Stephen Fox, Dr. Ward, Dr. Wilson, or the School of Psychology. If you wish to participate, please complete the attached consent form and return it to Mr. Fox in the envelope provided. You will then be contacted to schedule an interview. 


\section{Sample questions you may be asked:}

What do you perceive to be your ethnic identity?

What do you understand the term "ethnic identity" to mean?

How did you learn your art?

Why is it important to you to practice your art?

What about your art do you consider to be unique to your ethnic group?

What do you feel is important in communicating your ethnic identity to others?

Are your children or young people of your community learning or practicing your art?

What is most important for you to express in your art?

How do you feel your artistic practice affects relations with other parts of New Zealand society?

Has life in contemporary New Zealand affected or changed your artistic expression, and, if so, how has it changed? 
VICTORIA UNIVERSITY OF WELLINGTON

Te Whare Wananga o te Upoko o te Ika a Maui

\section{Statement of consent}

I have read the information about this research and any questions I wanted to ask have been answered to my satisfaction.

I agree to participate in this research. I understand that I can withdraw my consent at any time prior to the end of my interview. If I choose to do so, then all recordings will be wiped and any information I have given will not be used.

I understand that the interview will be recorded, and that the transcriptions of my interview will be made anonymous.

I also understand that my video interview may be used in academic conference presentations. I agree/do not agree (please circle one) to usage of my interview at academic conference.

I have had a chance to ask questions about the research, and those questions have been answered to my satisfaction.

Name:

Signature:

Date:

Address to receive a copy of the interview (please tick) and/or summary of results (please tick) via email or postal address provided below:

Copy to:

[a] participant,

[b] researcher (initial both copies below) 


\title{
Debriefing statement
}

\author{
VICTORIA UNIVERSITY OF WELLINGTON \\ Te Whare Wananga o te Upoko o te Ika a Maui
}

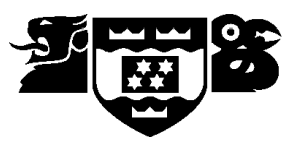

Thank you for participating in this research. This study is investigating ethnic identity and adaptation as experienced by artists in New Zealand.

Previous research has shown that arts serve many functions in how people learn, communicate, and socialize. Ethnic groups frequently use artistic expression to maintain their sense of identity, to share their sense of identity with others, and to help them adapt to new situations.

By interviewing ethnic artists, this research takes a unique approach to investigate the experiences of indigenous peoples, migrants, and ethnic communities as they adapt and negotiate their identities in a multicultural society. The results from this research project and other research projects in the area of cultural adaptation may aid in understanding ways people deal with new or different cultural settings.

The results of the study will be posted at www.vuw.ac.nz/cacr by December of 2007. You shall also receive a copy of your interview and the results if you expressed those wishes on your consent form.

Thank you again for your participation in this research.

Stephen Fox 


\title{
Appendix B: Study 2 Youth Connectedness Project questions
}

\author{
General Background \\ We would like to start by asking you some questions about yourself \\ Are you... Male/Female \\ How old are you (Y1)? 91011121314151617 \\ Well-being \\ Ryff $W B$ \\ These questions ask you how you feel about yourself and your life. \\ Please tell us how much you agree with these: \\ I often think about my future (what I want to do with my \\ life) \\ I find it easy to get on well with other people \\ I feel confident and positive about myself \\ I work hard now to create a good future for myself \\ Most people think I am a nice person \\ I am proud of who I am \\ I'm the sort of person who sets goals and works hard to \\ achieve them \\ I'm good at keeping my relationships positive with others \\ I feel that I have a number of good qualities \\ I feel that I am able to do things as well as most people \\ I am serious about working hard now so that I have a good \\ future \\ Positive \\ affect \\ I was happy \\ I enjoyed life \\ I felt hopeful about the future \\ Life Satisfaction \\ Please tell us how much you agree with these \\ I am happy with my life \\ So far I have the important things I want in life \\ Resilience \\ There is very little that I would change in my life \\ These next statements ask you to think about what you do when you \\ have problems. Please tell us how often you do these things when \\ you have a problem that upsets you... \\ I keep busy and interested in things \\ I try not to take things too seriously (I find something to \\ laugh about) \\ My belief in myself gets me through hard times \\ Self evaluation \\ I can find a way to solve my problems \\ How well do you think you are doing in school/kura in these areas? \\ Your classwork \\ The clubs you belong to in school/kura \\ School sports
}




\section{Connectedness}

General social support

Please tell us how much you agree with these...

There are people I can depend on to help me if I really need it

There is someone I can talk to about important decisions in my life

There is someone in my life who tells me I am special There are people in my life who make me feel safe There are people in my life who accept and understand me There are people in my life who I am comfortable talking with about my problems

There is someone who I trust who I can turn to for advice about problems

There are people in my life who I am close to

There is someone in my life who tells me I am good at things

There are people who I can count on if I get into trouble

There is someone in my life who tells me I am a good person

If something went wrong, someone would help me

\section{Family social support}

Thinking of your Family/Whanau, please tell us how often these statements apply: (If you do not have any Family/Whanau but are cared for by people who are like family, please answer thinking of those people)

For my Family/Whanau, spending time together is very important

We can easily think of things to do together as a Family/Whanau

My Family/Whanau likes to spend free time together

My Family/Whanau ask each other for help

We like to do things just as a Family/Whanau

It means a lot to me to be a member of my Family/Whanau

We are proud to be members of our Family/Whanau

Do you and your Family/Whanau have meals together?

Do you and your Family/Whanau spend time going out together

Do you and your Family/Whanau have holidays together?

\section{School connectedness}

I feel that my teacher(s) respect me

My teacher(s) understand me

I always get an opportunity to talk with my teacher(s)

I feel I am treated with as much respect as other

Adults in my school/kura trust me with responsibility

Adults in my school/kura give me opportunities to make

decisions for myself

I like going to school/kura

I feel proud about my school/kura 
How well do you get on with your classmates?

How well do you get on with the other students in your school/kura?

\section{Peer connectedness}

My friends and I help each other out

I can trust my friends with personal problems

My friends understand and accept me for who I am

EID All of the questions on this page are about the Maori/Pasifika ethnic
group. Please tell us how much you agree with these:
I have spent time finding out more about this ethnic group,
like its history and customs
I am happy that I am a member of this ethnic group
I take part in social groups that include mostly members of
this ethnic group
I have a lot of pride in this ethnic group and its
achievements
I think about how my life will be affected by being part of
this ethnic group
I feel good about this ethnic group

\section{Group involvement}

Thinking about groups in your school/kura, which of the following do you belong to (tick as many as apply)

Student Council

Drama Club

Sports Clubs

Cultural Groups

Music Groups

Interest Groups (i.e. computing, chess, etc)

Library Assistant

Peer Mediation

Patrols

Other:

What groups do you belong to outside of school/kura ? (tick as many as apply)

Church Youth Group

Sports Group/Club

Kapa Haka or Polynesian Club

A group like Scouts or Guides

Music Band

Marching

Drama Group

Dance Group

Other: 


\section{Appendix C: Comparison Models for Study 2 Other Arts and No Arts}

\section{Groups}

Y1-dichotomous Other Arts/No Arts model

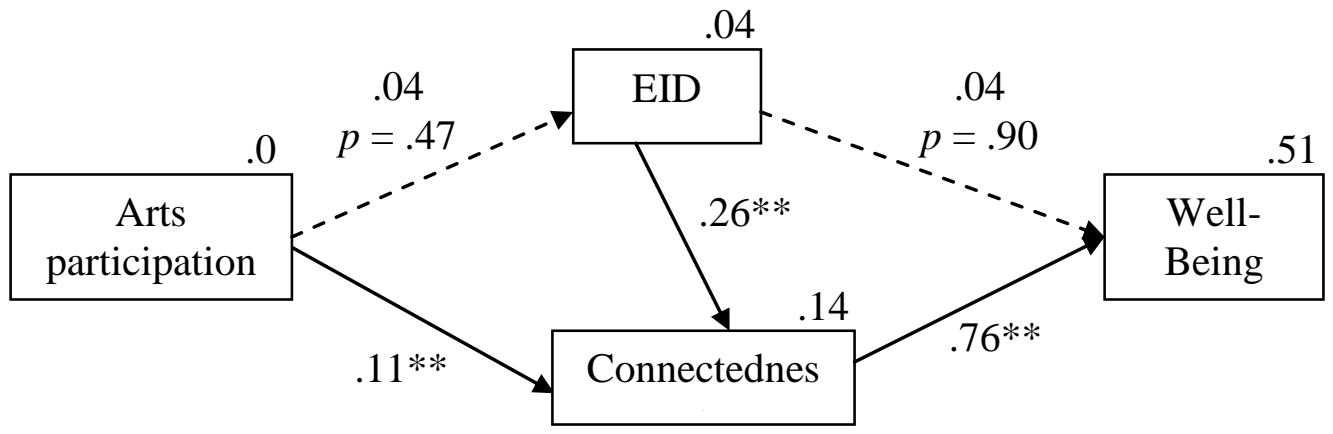

$* * p<.01$

Y2-dichotomous Other Arts/No Arts model

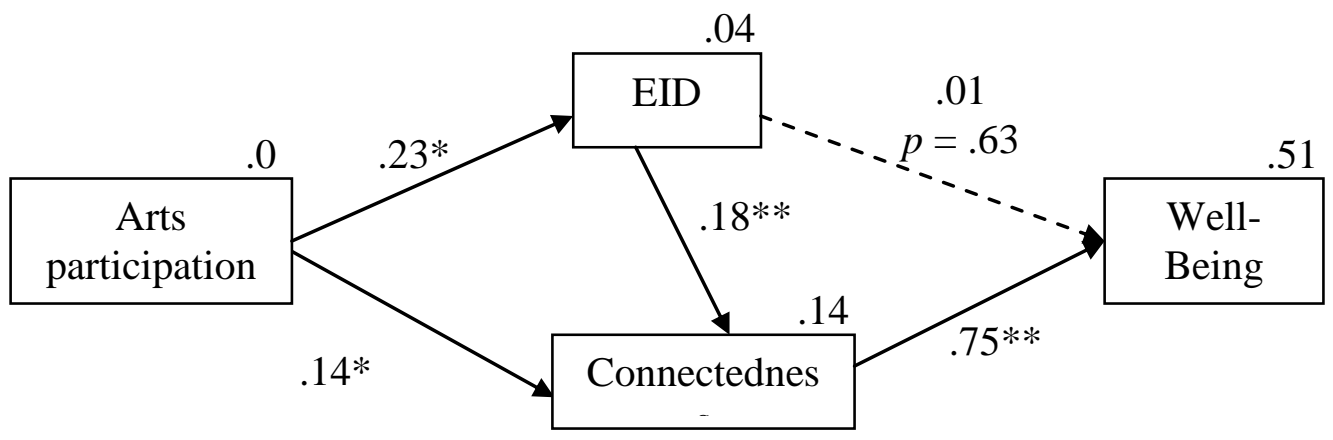

$* p<.05, * * p<.01$

Y3-dichotomous Other Arts/No Arts model

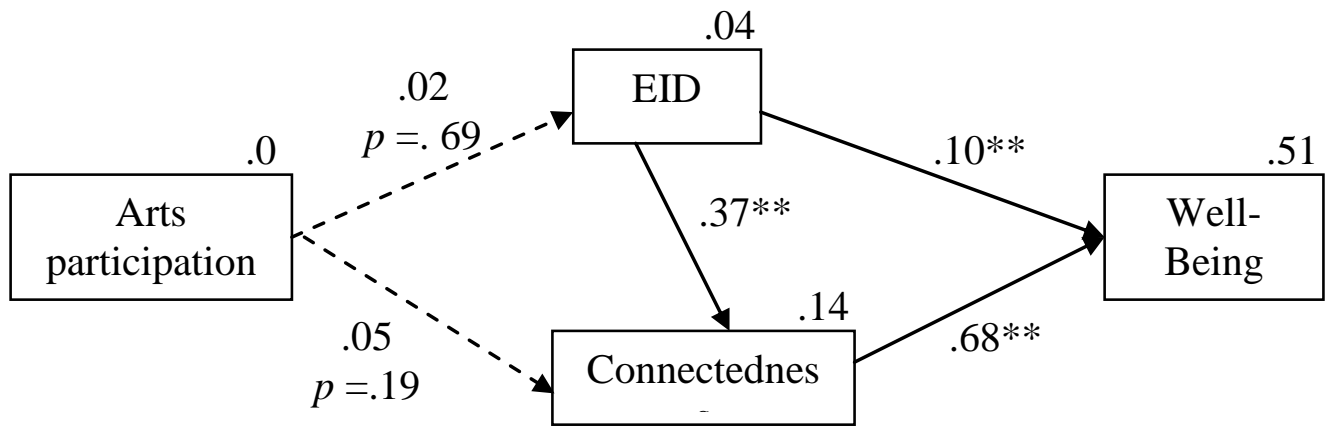

$* * p<.01$ 
Appendix D: Traditional and Ethnic Arts Participation Survey measures

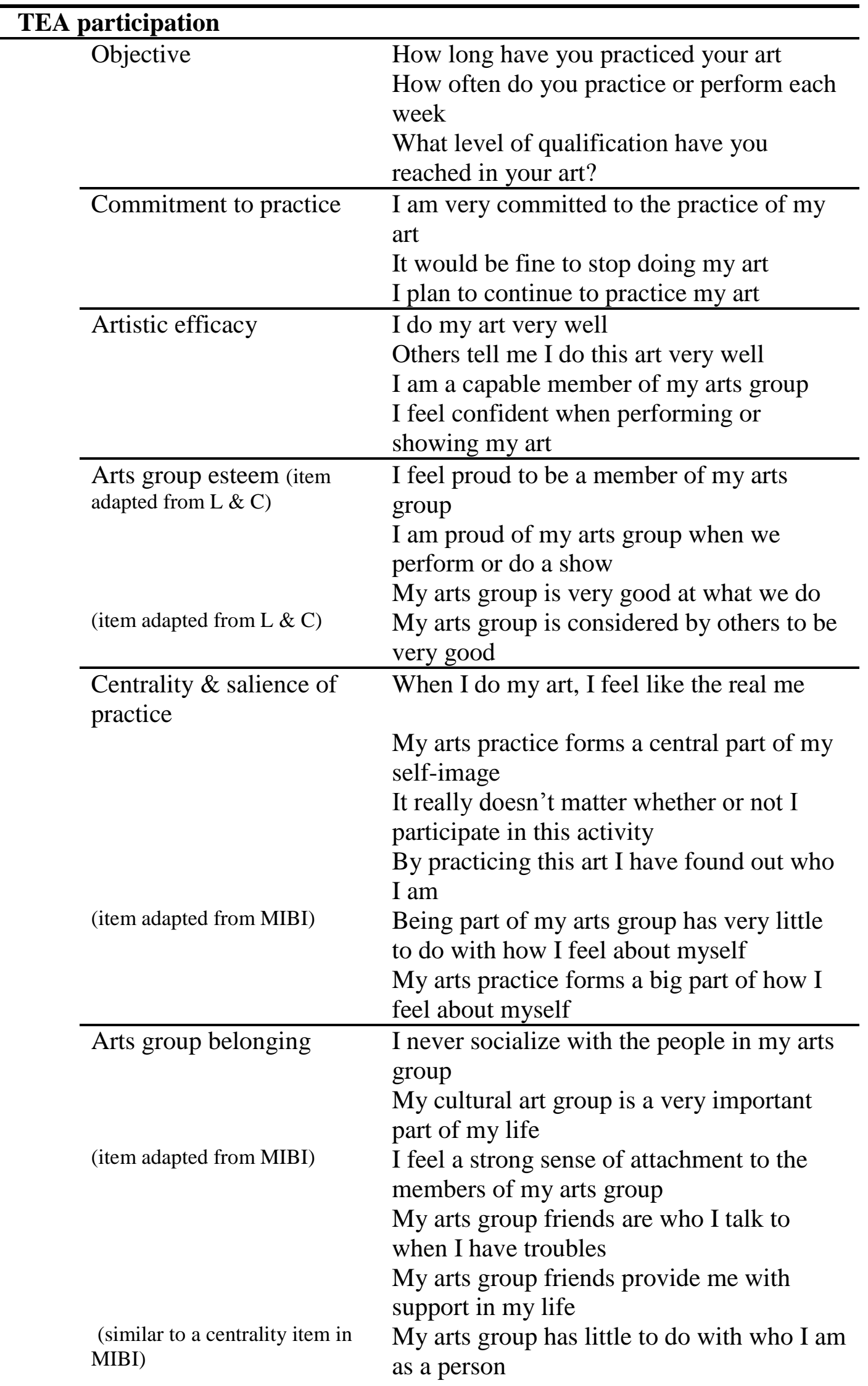


( similar to a centrality item in MIBI)

Attitudes \& motivations for participation
Cultural information
Membership in my arts group is an important reflection of who I am People of my ethnic group are better off if they do this art

Doing their ethnic art helps people to feel more confident in general Doing their ethnic art helps people to feel able to be more effective at everything they do

Doing their ethnic art helps people to feel good about their ethnic group as a whole Ethnic arts help people to see what the important things are about their ethnic group

Doing ethnic arts connects people to others in their ethnic community Doing this art helps people feel closer to their families

Do you feel people of other ethnicities understand your culture better after they see you perform

People of other ethnicities like my ethnic group more after they see us perform

Practicing this art helps me learn the stories of my people

I have learned to speak my language better by doing this art

I understand the meanings of what we do in our art

My arts practice helps me to know the right ways to relate to other people

By learning this art, I learn the values of my people

My arts practice helps me to know the right way to live

By learning this art, I understand the meanings of our myths and legends Practicing this art helps me learn the genealogy of my people

I know the songs, stories or symbols of my arts group from memory

I often think of pieces we perform when doing other things

Doing this art connects me to the history of my ethnic group

I have spent time trying to find out more about my ethnic group, such as its history, traditions, and customs

I am active in organizations or social 
groups that include mostly members of my own ethnic group

I have a clear sense of my ethnic background and what it means for me I think a lot about how my life will be affected by my ethnic group membership. I am happy that I am a member of the group I belong to.

I have a strong sense of belonging to my own ethnic group.

I understand pretty well what my ethnic group membership means to me.

In order to learn more about my ethnic background, I have often talked to other people about my ethnic group.

I have a lot of pride in my ethnic group.

I participate in cultural practices of my own group, such as special food, music, or customs.

I feel a strong attachment towards my own ethnic group.

I feel good about my cultural or ethnic background.

CSE -Membership (adapted from Luhtanen \& Crocker)

Private

Public
I am a worthy member of my ethnic group

I feel I don't have much to offer to the ethnic group I belong to

I am a cooperative member of my ethnic group

I often feel I am a useless member of my ethnic group

I often regret that I belong to my ethnic group

In general, I'm glad to be a member of my ethnic group

Overall, I often feel that my ethnic group is not worthwhile

I feel good about the ethnic group I belong to

Overall, my ethnic group is considered good by others

Most people consider my ethnic group, on the average, to be more ineffective than other groups

In general, others respect the ethnic group I am a member of

In general, others think that my ethnic group is unworthy 


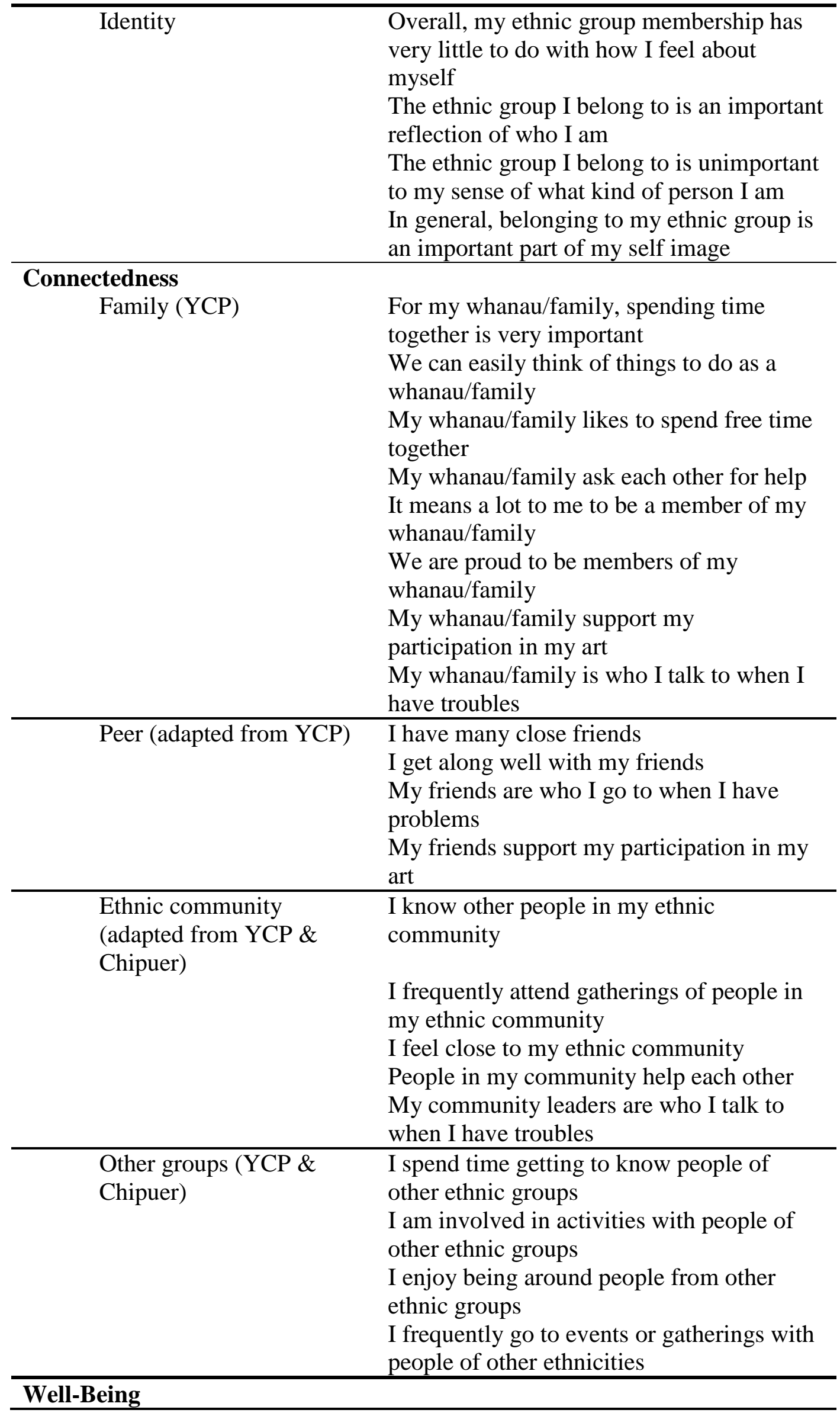




\begin{tabular}{|c|c|}
\hline $\begin{array}{l}\text { Mental well-being } \\
\text { (Warwick-Edinburgh) }\end{array}$ & $\begin{array}{l}\text { I've been feeling optimistic about the future } \\
\text { I've been feeling useful } \\
\text { I've been feeling relaxed } \\
\text { I've been feeling interested in other people } \\
\text { I've had energy to spare } \\
\text { I've been dealing with problems well } \\
\text { I've been thinking clearly } \\
\text { I've been feeling good about myself } \\
\text { I've been feeling close to other people } \\
\text { I've been feeling confident } \\
\text { I've been able to make up my own mind } \\
\text { about things } \\
\text { I've been feeling loved } \\
\text { I've been interested in new things } \\
\text { I've been feeling cheerful }\end{array}$ \\
\hline $\begin{array}{l}\text { Personal Self Esteem } \\
\text { (Rosenberg) }\end{array}$ & $\begin{array}{l}\text { I feel that I am a person of worth, at least } \\
\text { on an equal basis with others. } \\
\text { I feel that I have a number of good } \\
\text { qualities. } \\
\text { All in all, I am inclined to feel that I am a } \\
\text { failure. } \\
\text { I am able to do things as well as most other } \\
\text { people. } \\
\text { I feel I do not have much to be proud of. } \\
\text { I take a positive attitude toward myself. } \\
\text { On the whole, I am satisfied with myself. } \\
\text { I wish I could have more respect for myself. }\end{array}$ \\
\hline $\begin{array}{l}\text { Resilience (from Wagnild } \\
\text { \& Young) }\end{array}$ & $\begin{array}{l}\text { When I make plans, I follow through with } \\
\text { them } \\
\text { I usually manage one way or another. } \\
\text { I am able to depend on myself more than } \\
\text { anyone else. } \\
\text { Keeping interested in things is important to } \\
\text { me. } \\
\text { I feel proud that I have accomplished things } \\
\text { in life. } \\
\text { I usually take things in stride. } \\
\text { I am friends with myself. } \\
\text { I feel that I can handle many things at a } \\
\text { time. } \\
\text { I am determined. } \\
\text { I have self-discipline. } \\
\text { I keep interested in things. } \\
\text { I can usually find something to laugh about. } \\
\text { My belief in myself gets me through hard } \\
\text { times. } \\
\text { I can usually look at a situation in a number } \\
\text { of ways. } \\
\text { My life has meaning. }\end{array}$ \\
\hline
\end{tabular}


I do not dwell on things that I can't do anything about.

Life satisfaction (Diener) In most ways my life is close to my ideal. The conditions of my life are excellent. I am satisfied with life.

So far I have gotten the important things I want in life.

If I could live my life over, I would change almost nothing. 
Appendix E: Study 3 Information and Consent Form and Debriefing

Statement 


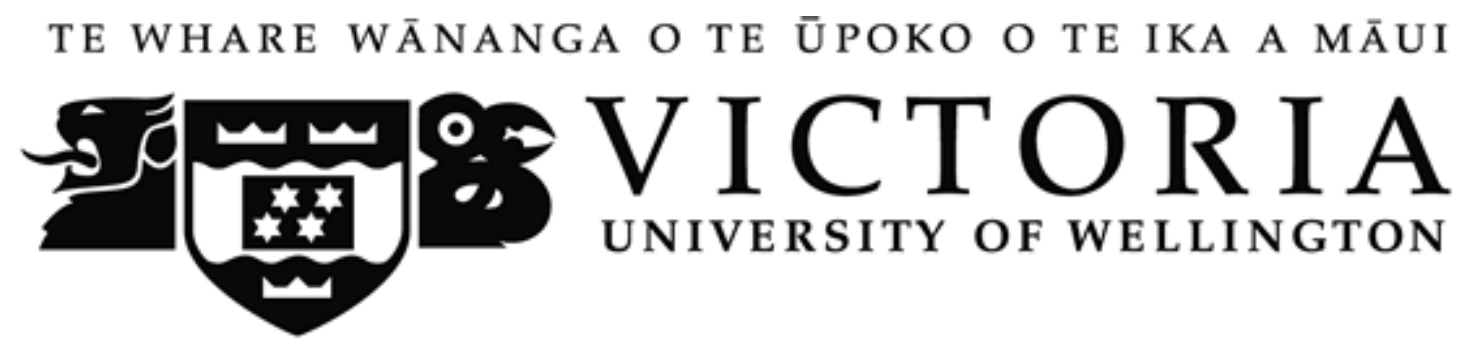

Invitation: Influences of participation in traditional/ethnic arts on identity and well-being

Stephen Fox

PhD Candidate

Email:

Stephen.Fox@vuw.ac.nz

(04) 4636976
Dr. Colleen Ward

Advisor

Colleen.Ward@vuw.ac.nz

(04) 4636037
Dr. Marc Wilson

Advisor

Marc.Wilson@

vuw.ac.nz

(04) 4635225

Hello,

You are invited to participate in a study about the influences participation in ethnic or traditional arts may have on people's well-being. The research is being conducted by Stephen Fox as part of his PhD thesis in the School of Psychology at Victoria University of Wellington. This research is being supervised by Drs. Ward and Wilson and has been approved by the University ethics committee.

What is involved if you agree to participate?

If you agree to participate in this study you will complete a short survey. We anticipate that the survey will take you no more than a half hour to complete.

During the research you are free to withdraw at any time up until you return the questionnaire.

If you complete and return the questionnaire it will be understood that you have consented to participate in the research and you consent to publication of the results as described below.

You may enter a lucky draw for an iPod. Details for entry are on the debriefing statement you will receive when you complete the survey.

Privacy and Confidentiality

This survey is completely anonymous. Please do not put your name on it anywhere. Please note that the data collected for this study will remain with the investigator, and will be stored securely for at least five years.

In accordance with the requirements of some scientific journals and organisations, your coded survey may be shared with other competent researchers on a case by case basis. Your coded data may be used in other, related studies.

What happens to the information that you provide?

The data you provide may be used for one or more of the following purposes:

The overall findings may be submitted for publication in a scientific journal, or presented at scientific conferences.

The overall findings may form part of a $\mathrm{PhD}$ thesis that will be submitted for assessment.

If you have any queries about the project, you may contact Stephen Fox at the School of Psychology, Victoria University of Wellington, P.O. Box 600, Wellington. Email: 
Stephen.Fox@vuw.ac.nz. When the results of the study are available (approximately spring 2009), these will be posted at www.vuw.ac.nz/cacr.

Thank you for considering participation in this research.

Stephen Fox

TE WHARE WĀNANGA O TE ŪPOKO O TE IKA A MĀUI

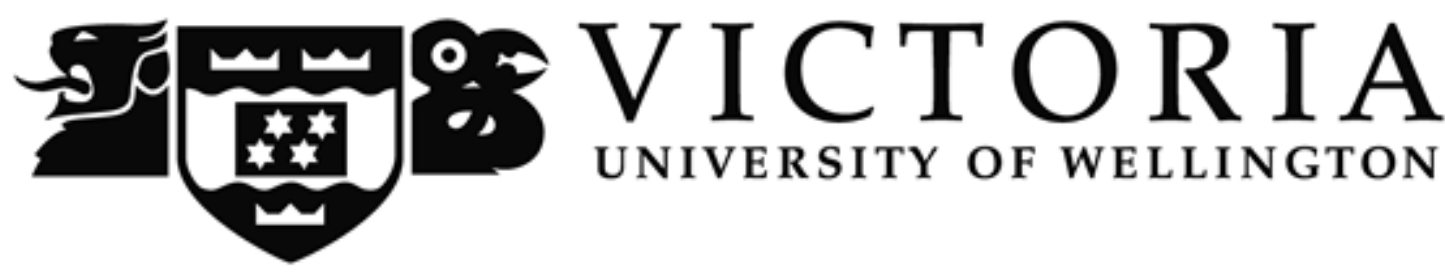

\section{Debriefing statement}

Thank you for participating in this study.

This study examined how participation in ethnic arts activities affects the wellbeing of people involved. Previous research in anthropology and cultural studies has seen important benefits of participation in ethnic arts, both in indigenous cultures and among immigrants. This study seeks to clarify the psychological benefits of this sort of activity, especially among immigrants and ethnic minorities.

In a previous study, the researcher found that professionals in ethnic and traditional arts are very aware of benefits of their arts practice to themselves, their families, their fellow artists, and their communities. This study has further investigated the influence of arts participation on identity and well-being in the lives of those who participate in them.

This kind of research is very important because of the increase in immigration and inter-cultural contact around the world. The process is not always easy for immigrants, indigenous people, or even dominant cultures. It is important to find ways to aid in achieving healthier, less stressful experiences for all involved. The research may also add to better understanding of the specifics of cultural differences and of cultural activities as they work in daily life.

The results of the study will be posted when available (approximately spring 2009) on the web at www.vuw.ac.nz/cacr.

Thank you again for participating in this research.

Stephen Fox, PhD Candidate

Victoria University of Wellington 
Appendix F: Correlations of TEAPS Items and Factors from EFA 
Correlations of TEAPS factors from EFA

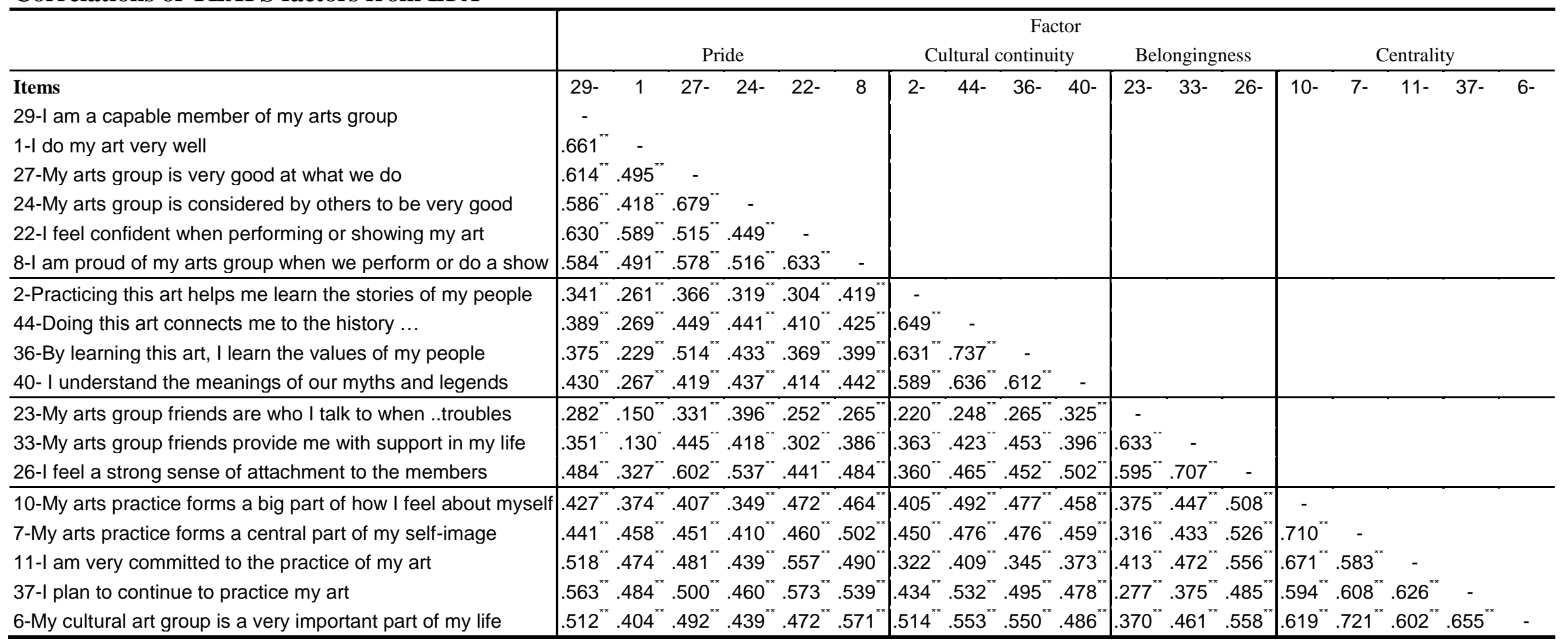


Appendix G: Correlations of all Study 3 Instruments and Subscales 
Correlations of all Study 3 instruments and subscales

\begin{tabular}{|c|c|c|c|c|c|c|c|c|c|c|c|c|c|c|c|c|c|}
\hline & $\begin{array}{c}\text { TEAP } \\
\text { all }\end{array}$ & $\begin{array}{l}\text { TEAP } \\
\text { pride }\end{array}$ & $\begin{array}{c}\text { TEAP Cltr } \\
\text { cont }\end{array}$ & $\begin{array}{c}\text { TEAP } \\
\text { support }\end{array}$ & $\begin{array}{l}\text { TEAP } \\
\text { central }\end{array}$ & $\begin{array}{l}\text { EID } \\
\text { all }\end{array}$ & $\begin{array}{l}\text { EID ID } \\
\text { search }\end{array}$ & $\begin{array}{l}\text { EID Bel \& } \\
\text { Com }\end{array}$ & $\begin{array}{c}\text { Conn } \\
\text { overall }\end{array}$ & $\begin{array}{c}\text { Conn own } \\
\text { com }\end{array}$ & $\begin{array}{l}\text { Conn } \\
\text { other }\end{array}$ & $\begin{array}{c}\text { Conn } \\
\text { family }\end{array}$ & $\begin{array}{l}\text { Conn } \\
\text { peer }\end{array}$ & $\begin{array}{l}\text { WB } \\
\text { all }\end{array}$ & $\begin{array}{l}\text { WB } \\
\text { W-E }\end{array}$ & $\begin{array}{l}\text { WB } \\
\text { LSat }\end{array}$ & $\begin{array}{l}\text { WB } \\
\text { PSE }\end{array}$ \\
\hline TEAP pride & $.82^{\pi x}$ & - & & & & & & & & & & & & & & & \\
\hline $\begin{array}{l}\text { TEAP Cltr } \\
\text { continuity }\end{array}$ & $.82^{n}$ & $.56^{\prime \prime}$ & - & & & & & & & & & & & & & & \\
\hline $\begin{array}{l}\text { TEAP } \\
\text { support }\end{array}$ & $.80^{\prime \prime}$ & $.52^{\prime \prime}$ & $.49^{\prime \prime}$ & - & & & & & & & & & & & & & \\
\hline TEAP cent & $.88^{\times \pi}$ & $.70^{* *}$ & $.63^{\pi x}$ & $.59^{* *}$ & - & & & & & & & & & & & & \\
\hline EID all & $.64^{\pi \pi}$ & $.47^{x *}$ & $.66^{\pi x}$ & $.47^{\times \pi}$ & $.51^{\times x}$ & - & & & & & & & & & & & \\
\hline EID search & $.62^{\prime \prime}$ & $.42^{\prime \prime}$ & $.62^{n}$ & $.48^{\prime \prime}$ & $.52^{\prime \prime}$ & $.95^{\wedge \prime}$ & - & & & & & & & & & & \\
\hline EID B \& C & $.60^{\mathrm{x}}$ & $.47^{x \pi}$ & $.63^{\pi x}$ & $.42^{\pi x}$ & $.46^{\pi x}$ & $.95^{\star \pi}$ & $.81^{\pi \pi}$ & - & & & & & & & & & \\
\hline Conn all & $.59^{\prime \prime}$ & $.49^{\prime \prime}$ & $.52^{n}$ & $.48^{n}$ & $.48^{n}$ & $.55^{n}$ & $.51^{\prime \prime}$ & $.54^{n-}$ & - & & & & & & & & \\
\hline Con own & $.58^{\pi x}$ & $.42^{\pi x}$ & $.51^{\pi \pi}$ & $.50^{\pi x}$ & $.47^{\pi x}$ & $.58^{\star \pi}$ & $.56^{\pi x}$ & $.54^{\pi \pi}$ & $.77^{\pi x}$ & - & & & & & & & \\
\hline Con other & $.39^{x \pi}$ & $.33^{x *}$ & $.34^{\pi \times}$ & $.30^{\pi \times}$ & $.34^{\pi \times}$ & $.34^{\star \pi}$ & $.33^{\times \pi}$ & $.32^{x \times}$ & $.69^{n \pi}$ & $.42^{\pi \times}$ & - & & & & & & \\
\hline Con family & $.40^{n}$ & $.34 "$ & $.41^{\prime \prime}$ & $.29^{\prime \prime}$ & $.30^{n}$ & $.44^{n \prime}$ & $.39 "$ & $.45^{n}$ & $.71^{n}$ & $.46^{n}$ & $.25^{n}$ & - & & & & & \\
\hline Con peer & $.36^{\pi x}$ & $.33^{* x}$ & $.26^{\pi x}$ & $.33^{\pi x}$ & $.29^{\pi x}$ & $.26^{\star \pi}$ & $.24^{\pi \times}$ & $.26^{\pi x}$ & $.73^{\pi x}$ & $.41^{\pi \pi}$ & $.32^{\pi x}$ & $.37^{\mathrm{nx}}$ & - & & & & \\
\hline WB all & $.33^{\pi x}$ & $.36^{\pi x}$ & $.26^{\pi x}$ & $.24^{\pi x}$ & $.26^{\mathrm{xx}}$ & $.27^{x \pi}$ & $.24^{\mathrm{xx}}$ & $.27^{\mathrm{x}}$ & $.51^{\times \pi}$ & $.42^{\pi x}$ & $.33^{\pi x}$ & $.41^{\pi x}$ & $.33^{\pi x}$ & - & & & \\
\hline WB W-E & $.31 "$ & $.32^{\prime \prime}$ & $.22^{n}$ & $.25^{\prime \prime}$ & $.24 "$ & $.26^{n-}$ & $.24 "$ & $.26{ }^{n}$ & $.49^{\prime \prime}$ & $.40^{\prime \prime}$ & .34 & $.39^{-1}$ & $.31^{\prime \prime}$ & $.86^{n}$ & - & & \\
\hline WB LSat & $.25^{\kappa \pi}$ & $.23^{* \pi}$ & $.21^{\pi \pi}$ & $.21^{\pi \pi}$ & $.18^{\pi \pi}$ & $.16^{\pi \pi}$ & $.16^{\pi \times}$ & $.15^{\pi \times}$ & $.41^{\pi x}$ & $.35^{\pi \times}$ & $.21^{\pi \pi}$ & $.37^{\pi *}$ & $.26^{\pi *}$ & $.85^{\pi x}$ & $.59^{\pi *}$ & - & \\
\hline WB PSE & $.27^{\pi *}$ & $.31^{* *}$ & $.28^{\pi x}$ & $.17^{\pi x}$ & $.15^{\pi x}$ & $.23^{* \pi}$ & $.20^{\pi x}$ & $.24^{\pi x}$ & $.32^{\pi x}$ & $.28^{\pi x}$ & $.28^{\pi \pi}$ & $.16^{\pi \pi}$ & $.21^{\pi *}$ & $.40^{\pi x}$ & $.34^{\pi *}$ & $.24^{\pi x}$ & \\
\hline WB Resil & $.29^{\pi \times}$ & $.38^{* \pi}$ & $.23^{\mathrm{nx}}$ & $.15^{\pi \times}$ & $.23^{\pi x}$ & $.28^{\pi *}$ & $.23^{\mathrm{x}}$ & $.31^{\pi \times}$ & $.41^{\pi x}$ & $.33^{\pi x}$ & $.31^{\pi \pi}$ & $.28^{\pi x}$ & $.28^{\pi *}$ & $.80^{\pi x}$ & $.61^{\pi *}$ & $.48^{\pi *}$ & $.46^{\pi \times}$ \\
\hline
\end{tabular}




\section{References}

Adamopoulos, J., \& Lonner, W. J. (2001). Preface. In D. Matsumoto (Ed.), The handbook of culture and psychology (pp. 11-34). New York: Oxford University Press.

Adams, J. S. (1961). Reduction of cognitive dissonance by seeking consonant information. The Journal of Abnormal and Social Psychology, 62(1), 7478.

Aguilar, L. B. (2007). Metaphors, myths and making pots: Chewa clay arts. African Arts, 40(1), 64-70.

Ahmed, S. J. (2006). Tibetan folk opera: Lhamo in contemporary cultural politics. Asian Theatre Journal, 23(1), 149-178.

Aiken, L. S., Stein, J. A., \& Bentler, P. M. (1994). Structural equation analyses of clinical subpopulation differences and comparative treatment outcomes: Characterizing the daily lives of drug addicts. Journal of Consulting and Clinical Psychology, 62(3), 488-499.

Ajrouch, K. J., \& Kusow, A. M. (2007). Racial and religious contexts: Situational identities among Lebanese and Somali Muslim immigrants. Ethnic and Racial Studies, 30(1), 72-94.

Albrecht, T. L., \& Adelman, M. B. (1984). Social support and life stress: New directions for communication research. Human Communication Research, 11(1), 3-32.

al-Deen, H. N. (2005). The Evolution of Rai music. Journal of Black Studies, 35(5), 597-611.

Alexander, B. C. (1991). Correcting misinterpretations of Turner's theory: An African-American pentecostal illustration. Journal for the Scientific Study of Religion, 30(1), 26-44.

Altschul, I., Oyserman, D., \& Bybee, D. (2006). Racial-ethnic identity in midadolescence: Content and change as predictors of academic achievement. Child Development, 77(5), 1155-1169.

Amabile, T. M. (1983). The social psychology of creativity. New York: Springer-Verlag.

Andaya, L. Y. (1996). From American-Filipino to Filipino-American. Social Process in Hawaii, 37, 99-111. 
Anderson, A. J. (1991). The chronology of colonization in New Zealand. Antiquity, 65, 767-795.

Andrews, F. M., \& Withey, S. B. (1976). Social indicators of well-being: Americans' perceptions of life quality. New York: Plenum.

Anggraeni, D. (2001, March 15). Images of injustice in the history of Kalimantan. The Jakarta Post, p. 1.

Anthony, E. J., \& Cohler, B. J. (Eds.). (1987). The invulnerable child. New York: Guilford Press.

APA (1959). Mental health and the American Psychological Association. American Psychological Association, ad hoc planning group on the role of the APA in mental health programs and research. American Psychologist, 14(12), 820-825.

Appalacia Educational Laboratory (1999). Preventing Antisocial Behavior in Disabled and At-Risk. Retrieved 28 Nov. 2009 from http://www.ldonline.org/article/5973

Arbuckle, J. L. (2008). Amos (Version 17.0) [Computer Program]. Chicago: SPSS.

Arbuckle, J. L. \& Wothke, W. (1999) Amos 4.0 User's Guide. Chicago, IL: SPSS Inc. and Small Waters Corporation.

Arpin, J. (2003). Masters of their conditions: At the crossroads of health, culture and Performance. Transcultural Psychiatry, 40, 299-328.

Arroyo, C. G., \& Zigler, E. (1995). Racial identity, academic achievement, and the psychological well-being of economically disadvantaged adolescents. Journal of Personality and Social Psychology. 69(5), 903-914.

Asia New Zealand Foundation (ANZF) (2009). Diwali festival of lights. Retrieved August 9, 2009 from http://www.asianz.org.nz/diwali

Atran, S. (2001). The trouble with memes: Inference versus imitation in cultural creation. Human Nature, 12(4), 351-381.

Attride-Stirling, J. (2001). Thematic networks: An analytical tool for qualitative research. Qualitative Research, 1(3), 385-405.

Avorgbedor, D. (2008). In and out of song. Research in African Literatures, $39(2), 131-137$.

Ayer, F. L., Corman, B. R., Mussen, P. H., Newcomb, T. M., \& Allport, G. W. (1953). Persistence and change of attitudes. In J. M. Seidman (Ed.), The 
adolescent: A book of readings. The Dryden Press publications in interpersonal relations (pp. 360-411). Ft Worth, TX: Dryden Press.

Azman, R. L. (2005). The Development of the Scale of Educational Attitudes. Journal of College Teaching and Learning, 2(4), 51-63.

Bailis, D. S., \& Chipperfield, J. G. (2006). Emotional and self-evaluative effects of social comparison information in later life: How are they moderated by collective self-esteem? Psychology and Aging, 21(2), 291-302.

Ballas, D., Dorling, D., \& Shaw, M. (2007). Societal inequality, health and wellbeing. In J. Haworth \& G. Hart (Eds.), Well-being: Individual, community and social perspectives (pp. 163-18). New York: Palgrave Macmillan.

Bandalos, D. L. (2008). Is parcelling really necessary? A comparison of results from item parcelling and categorical variable methodology. Structural Equation Modeling: A Multidisciplinary Journal, 15(2), 211-240.

Bonini, B. F. (2009). All the pain and joy of the world in a single melody: A Transylvanian case study on musical emotion. Music Perception, 26(3), 257-261.

Barber, B. K., \& Schluterman, J. M. (2008). Connectedness in the lives of children and adolescents: A call for greater conceptual clarity. Journal of Adolescent Health, 43(3), 209-216.

Barclay, B. (2005). Mana tuturu: Maori treasures and intellectual property rights. Auckland, N.Z.: Auckland University Press.

Bartko, W. T., \& Eccles, J. S. (2003). Adolescent participation in structured and unstructured activities: A person oriented analysis. Journal of Youth and Adolescence, 32(4), 233-241.

Bartley, A. (2004). Cotemporary Asian migration to New Zealand. In P. Spoonley, C. Macpherson, \& D. Pearson (Eds.), Tangata, tangata: The changing ethnic contours of New Zealand (pp. 157-74). Southbank, Victoria: Thomson.

Batcho, K. I., DaRin, M. L., Yaworsky, R. R., \& Nave, A. M. (2008). Nostalgia and identity in song lyrics. Psychology of Aesthetics, Creativity, and the Arts, 2(4) 236-244. 
Baum, J. A. C. (2007). Cultural group selection in organization studies. Organization Studies, 28(1), 37-47.

Baumeister, R. F., \& Leary, M. R. (1995). The need to belong: Desire for interpersonal attachments as a fundamental human motivation. Psychological Bulletin, 117(3), 497-529.

Becatti, G. (1939/1968). The art of ancient Greece and Rome: From the rise of Greece to the fall of Rome. Englewood Cliffs, NJ: Prentice-Hall.

Beaglehole, J. C. (1961). The discovery of New Zealand. London: Oxford University Press.

Behne, T., Carpenter, M., Gräfenhain, M., Liebal, K., Liszkowski, U., Moll, H., Rakoczy, H., Tomasello, M., Warneken, F., \& Wyman, E. (2008). Cultural learning and cultural creation. In U. Müller, J. Carpendale, N. Budwig, \& B. Sokol (Eds.), Social life and social knowledge: Toward a process account of development (pp 65-101). New York: Erlbaum.

Becker, A. (2000). The avant-garde, madness and the great war. Journal of Contemporary History, 35(1), 71-75.

Becker, H. S. (1994). Review of sociology of culture -- Inside culture: Art and class in the American home by David Halle. Contemporary Sociology, $23(6), 882$.

Becker, M. J. (2004). The Oneida creation story/Finding the center: The Art of the Zuni storyteller/American Indians: Folk tales and legends/Native American legends of the Great Lakes and the Mississippi Valley. Journal of American Folklore, 117(463), 117-119.

Becker, N. (2008). Primitivism revisited: After the end of an idea. African Arts, 41(1) 86-87.

Bedford, R., Ho, E., \& Lidgard, J. (2000). Policy paper: International migration in New Zealand: Context, components and policy issues. Hamilton, NZ: Population Studies Centre, Waikato University.

Belcourt-Dittloff, A. E. (1996). Resiliency and risk in Native American communities: a culturally informed investigation (Unpublished doctoral dissertation). The University of Montana: Missoula, Montana.

Belgrave, M. (2009). The effect of expressive and instrumental touch on the behavior states of older adults with late-stage dementia of the 
Alzheimer's type and on music therapist's perceived rapport. Journal of Music Therapy, 46(2), 132-146.

Bellingham, R., Cohen, B., Jones, T., \& Spaniol, L. (1989). Connectedness: Some skills for spiritual health. American Journal of Health Promotion, $4(1), 18-24,31$.

Bemak, F., Chung, R., \& Pederson, P. (2003). Counselling refugees: A psychosocial approach to innovative multicultural interventions. Westport, Connecticut: Greenwood Press.

Bentler, P. M. (1980). Multivariate analysis with latent variables: Causal modelling. Annual Review of Psychology, 31, 419-456.

Bernier, R. (1998). Art and architecture of India [videorecording]. India: Alarion Press.

Berns-McGown, R. (2007). Redefining "diaspora": The challenge of connection and inclusion. International Journal, 63(1), 3-21.

Berry, J. W. (1970). Marginality, stress and ethnic identification in an acculturated Aboriginal community. Journal of Cross-Cultural Psychology, 1, 239-252.

Berry, J. W. (1980). Acculturation as varieties of adaptation. In A. Padilla (Ed.), Acculturation: Theory, models, and some new findings (pp. 9-25). Boulder, CO: Westview.

Berry, J. W. (1990). Psychology of acculturation. In J. Berman (Ed.), Nebraska Symposium on Motivation, 1989: Vol. 37. Cross Cultural Perspectives (pp. 201-34). Lincoln: University of Nebraska.

Berry, J. W. (1995). Psychology of acculturation. In N. R. Goldberger \& J. Veroff (Eds.), The culture and psychology reader, (pp. 457-488). New York: New York University Press.

Berry, J. W. (1997). Immigration, acculturation, and adaptation. Applied Psychology: An International Review, 46(1), 5-34.

Berry, J. W. (2006). Acculturation: A conceptual overview. In M. H. Bornstein \& L. R. Cote (Eds.), Acculturation and parent-child relationships: Measurement and development (pp. 13-32). Mahwah, NJ: Lawrence Erlbaum Associates. 
Berry, J. W. (2007). Acculturation. In J. Grusec \& P. Hastings (Eds.), Handbook of socialization: Theory and research (pp. 543-558). New York: Guilford Press.

Berry, J. W., Phinney, J. S., Sam, D. L., \& Vedder, P. (2006). Immigrant youth: Acculturation, identity, and adaptation. Applied Psychology: An International Review, 55(3), 303-332.

Berry, J. W., Poortinga, Y. H., Segall, M. H., \& Dasen, P. R. (1992). Crosscultural psychology: Research and applications. New York: Cambridge University Press.

Berry, J. W. \& Sam, D. L. (1997). Acculturation and adaptation. In J. W. Berry, M. H. Segall \& C. Kagitcibasi (Eds.), Handbook of Cross-cultural Psychology, Vol. 3: Social behaviour and Applications (2nd. Ed., pp. 291-326). Boston: Allyn \& Bacon.

Birman, D. (2006), Measurement of the "acculturation gap" in immigrant families and implications for parent-child relationships. In M. H. Bornstein, \& L. R. Cote (Eds.), Acculturation and parent-child relationships: Measurement and development (pp.113-134). Mahwah, NJ: Lawrence Erlbaum Associates.

Bishop, B., Colquhoun, S., \& Johnson, G. (2006). Psychological sense of community: An Australian Aboriginal experience. Journal of Community Psychology, 34(1), 1-7.

Blacking, J. (1995). Music, culture, and experience: Selected papers of John Blacking. London: University of Chicago Press.

Blagg, H. (2008). Crime, Aboriginality and the decolonisation of justice. Sydney: Hawkins Press.

Blackmore, S. (2007). Those dreaded memes: The advantage of memetics over "symbolic inheritance." Behavioral and Brain Sciences, 30(4), 365-366.

Blackmore, S. (2006). Why we need memetics. Behavioral and Brain Sciences, 29(4), 349-350.

Blackmore, S. (2001). Evolution and memes: The human brain as a selective imitation device. Cybernetics and Systems, 32, 225-255.

Blatt, S. (1984). Continuity and change in art: The development of modes of representation. London: Lawrence Erlbaum Associates. 
Block, J., \& Kremen, A. M. (1996). IQ and ego-resiliency: Conceptual and empirical connections and separateness. Journal of Personality and Social Psychology, 70(2) 349-361.

Blum, R. W., McNeely, C. A., \& Rinehart, P. M. (2002). Improving the odds: The untapped power of schools to improve the health of teens. Minneapolis, MN: Center for Adolescent Health and Development, University of Minnesota.

Boer, D. (2009). Music makes the people come together: Social functions of music listening for young people across cultures (Unpublished doctoral dissertation). Victoria University of Wellington: Wellington, New Zealand.

Bohlman, P. V. (2007). Review: Identity and the arts in diaspora communities. Music \& Letters, 88(1), 186-188.

Bollen, K. (1989). Structural equations with latent variables. New York: John Wiley.

Bornstein, M. H., \& Cote, L. R. (2006). Introduction to acculturation and parentchild relationships. In M. H. Bornstein, \& L. R. Cote (Eds.), Acculturation and parent-child relationships: Measurement and development (pp. 3-12). Mahwah, NJ: Lawrence Erlbaum Associates.

Braun, V., \& Clarke, V. (2006). Using thematic analysis in psychology. Qualitative Research in Psychology, 3, 77-101.

Bresler, L. (2006). Toward connectedness: Aesthetically based research. Studies in Art Education, 48(1), 52-69.

Briggs, S. R., \& Cheek, J. M. (1986). The role of factor analysis in the development and evaluation of personality scales. Journal of Personality, 54, 106-148.

Britan, H. H. (1905). The power of music. Journal of Philosophy, Psychology, and Scientific Methods, 3, 352-357.

Bruno, J. B., \& Lepro, S. (2008). Wall Street ends turbulent week sharply lower. AP Business Writer. Retrieved November 14, 2008 from http://news.yahoo.com/s/ap/20081114/ap_on_bi_st_ma_re/wall_street;_y lt=Ar.ZjEulCXgLpk4u4fa2brOyBhIF

Bruner, J. S. (1990). Acts of meaning. Cambridge, MA: Harvard University Press. 
Bucknavage, L. B., \& Worrell, F. C. (2005). A study of academically talented students' participation in extracurricular activities. The Journal of Secondary Gifted Education, 16(2/3), 74-135.

Buenker, J. D., \& Ratner, L. A. (1992). Multiculturalism in the United States: A comparative guide to acculturation and ethnicity. New York: Greenwood Press.

Buhi, E. R., Goodson, P, \& Neilands, T. B. (2007). Structural equation modelling: A primer for health behavior researchers. American Journal of Health Behavior, 31(1), 74-85.

Buriel, L., \& de Ment, T. (2006). The relation of language brokering to depression and parent-child bonding among Latino adolescents. In M. H. Bornstein, \& L. R. Cote (Eds.), Acculturation and parent-child relationships: Measurement and development (pp. 249-70). Mahwah, NJ: Lawrence Erlbaum Associates.

Burke, K. (1973). The Philosophy of Literary Form. Berkeley, CA: University of California Press.

Burr, V. (2003). Social constructionism (2nd ed.). London: Routledge.

Byrne, B. M. (2006). Structural equation modelling with EQS: Basic concepts, applications, and programming ( $2^{\text {nd }}$ ed.). Mahwah, NJ: Lawrence Erlbaum Associations Publishers.

Cacioppo, J. T., \& Patrick, W. (2008). Loneliness: Human nature and the need for social connection. New York: W. W. Norton \& Co.

Caffaro, L. (2002). What's yours is mine: Issues in private legal disputes regarding title of stolen art and artifacts. Appeal, Review of Current Law and Law Reform, 8, 46-59.

Cameron, M. (2005). Two-spirited Aboriginal people: Continuing cultural appropriation by non-Aboriginal society. Canadian Woman Studies, 24(2/3), 123-127.

Campbell, A. (1976). Subjective measures of well-being. American Psychologist, 31(2), 117-124.

Campbell, J. (1997). The mythic dimension: Selected essays 1959-1987 by Joseph Campbell. San Francisco, CA: Harper. 
Campbell, J. (1986, November). From Ritual to Rapture, from Dionysus to the Grateful Dead. Lecture presented at the Palace of Fine Arts, San Francisco, CA.

Campbell, J. (1949/1973). The hero with a thousand faces. Princeton, NJ: Princeton University Press.

Carlson, E., \& Rosser-Hogan, R. (1993). Mental health status of Cambodian refugees ten years after leaving their homes. American Journal of Orthopsychiatry, 63(2), 223-231.

Carson, A. J., Chappell, N. L., \& Knight, C. J. (2007). Promoting health and innovative health promotion practice through a community centre. Health Promotion Practice, 8(4), 366-374.

Castro, V. S. (2003). Acculturation and psychological adaptation. Westport, CT: Greenwood Press.

Cattell R. B. (1966). The scree test for the number of factors. Multivariate Behavior Research, 1, 245-276.

Catterall, J. S., \& Peppler, K. A. (2007). Learning in the visual arts and the worldviews of young children. Cambridge Journal of Education, 37(4), 543-560.

Chagnon, N. A. (1988). Life histories, blood revenge, and warfare in a tribal population. Science, 239(4843), 985-992.

Chase, P. G., \& Nowell, A. (1998). Source: Taphonomy of a suggested middle paleolithic bone flute from Slovenia. Current Anthropology, 39(4), 549553.

Chavis, D. M., Hogge, J. H., McMillan, D. W., \& Wandersman, A. (1986). Sense of community through Brunswik's lens: A first look. Journal of Community Psychology, 14, 24-40.

Cheng, C., \& Cheung, M. W. L. (2005). Cognitive processes underlying coping flexibility: Differentiation and integration. Journal of Personality, 73, 859-86.

Chipuer, H. M., \& Pretty, G. M. H. (1999). A review of the sense of community index. Journal of Community Psychology, 14(1), 24-40.

Chipuer, H. M., \& Pretty, G. H., Delorey, E., Miller, M., Powers, T., Rumstein, O., Barnes, A., Cordasoc, N., \& Laurent, K. (1999). The neighbourhood 
youth inventory: Development and validation. Journal of Community \& Applied Social Psychology, 9, 355-368.

Choi, Y., \& Lee, K. (2007). Evidence-based nursing: Effects of a structured nursing program for the health promotion of Korean women with HwaByung. Archives of Psychiatric Nursing, 21(1), 12-16.

Christakopoulou, S., Dawson, J., \& Gari, A. (2001). The community well-being questionnaire: Theoretical context and initial assessment of its reliability and validity. Social Indicators Research, 56(3), 321-351.

Chun, C.-A., \& Choi, J. M. (2003). The violence of assimilation and psychological well being. In E. M. Kramer (Ed.), The emerging monoculture (pp. 75-84). Westport, CT: Praeger Publishers.

Cicchetti, D., \& Garmezy, N. (1993). Prospects and promises in the study of resilience [Special issue: Milestones in the development of resilience]. Development and Psychopathology, 5(4), 497-502.

Clarke, S. G., \& Haworth, J. T. (1994). "Flow" experience in the daily lives of sixth-form college students. British Journal of Psychology, 85(4), 511523.

Clawson, H. J., \& Coolbaugh, K. (2001). The YouthARTS development project. Juvenile Justice Bulletin. Retrieved June 25, 2009 from http://permanent.access.gpo.gov/lps12551/www.ncjrs.org/pdffiles1/ojjdp /186668.pdf

Cole, D. (2003). 1000 patterns: Design through the centuries. San Francisco: Chronicle Books.

Collins, T. (1985). Mythic reflections: Thoughts on myth, spirit, and our times, an interview with Joseph Campbell. In Context (4), 52. Retrieved July 16, 2009 from http://www.context.org/ICLIB/IC12/TOC12.htm.

Coppens, N. M., Page, R, \& Thou, C. T. (2005). Reflections on the evaluation of a Cambodian youth dance program. American Journal of Community Psychology, 37(3/4), 321-331.

Coronado, A. A. (1999). The effects of a summer performing arts program on at-risk adolescents (Unpublished Master's thesis). University of Southern California: Los Angeles, CA.

Cordingley, L., \& Webb, C. (1997). Independence and aging. Reviews in Clinical Gerontology, 7, 137-146. 
Costigan, C. L., \& Dokis, D. P. (2006). Similarities and differences in acculturation among mothers, fathers, and children in immigrant Chinese families. Journal of Cross-Cultural Psychology, 37, 723-741.

Cota, A.A., Longman, R.S., Holden, R.R., Fekken, G.C., \& Xinaris, S. (1993). Interpolating 95th percentile eigenvalues from random data: An empirical example. Educational \& Psychological Measurement, 53, 585596.

Communitas. (2009). In Encyclopadia Britannica. Retrieved June 14, 2009, from http://www.britannica.com/EBchecked/topic/129353/communitas

Cranston, M. W. (1991). The noble savage: Jean-Jacques Rousseau, 1754-1762. Chicago: University of Chicago Press.

Creative New Zealand (CNZ) (2007). Asian Aucklanders and the arts: Attitudes, attendance and participation in 2006. Retrieved July 18, 2009 from http://www.creativenz.govt.nz/Portals/0/publications/Asian\%20Auckland ers\%20and\%20the\%20arts.pdf

Creative New Zealand (CNZ) (2008). New Zealanders and the arts: Attitudes, attendance and participation in 2008. Retrieved July 16, 2009 from http://www.creativenz.govt.nz/Resources/Publicationspresentationsandre ports/tabid/2373/language/en-NZ/Default.aspx

Creative New Zealand (CNZ) (2000). A Survey of Māori Arts Participation Tirohanga ki te Iwi Māori Kei Roto i Ngā Toi Māori (Findings from the 1997-1998 survey into the arts participation patterns of New Zealand adults). $\quad$ Retrieved July 18, 2009 from http://www.creativenz.govt.nz/Portals/0/publications/participation.pdf

Crisp, R. J., \& Turner, R. N. (2009). Can Imagined Interactions Produce Positive Perceptions? Reducing Prejudice Through Simulated Social Contact. The American Psychologist. 64(4), 231-240

Crocker, J., \& Luhtanen, R. (1990). Collective self-esteem and ingroup bias. Journal of Personality and Social Psychology, 58(1), 60-67.

Crocker, J., Luhtanen, R., Blaine, B., \& Broadnax, S. (1994). Collective selfesteem and psychological well-being among White, Black, and Asian college students [Special issue]. Personality and Social Psychology Bulletin, 20(5), 503-513. 
Crocker, J., \& Major, B. (2003).The self-protective properties of stigma: Evolution of a modern classic. Psychological Inquiry 14(3/4), 232-237.

Cross, I. (2006). The origins of music: Some stipulations on theory. Music Perception, 24(1), 79-82.

Cross, I. (2001). Music, mind, and evolution. Psychology of Music, 29(1), 95102.

Cross, I. (1999). Is music the most important thing we ever did? Music, development and evolution. In S. W. Yi (Ed.), Music, Mind and Science. Seoul: Seoul National University Press. Retrieved May 26, 2008 from http://www.mus.cam.ac.uk/ ic108/MMS/

Cudeck, R., \& Browne, M. W. (1983). Cross-validation of covariance structures. Multivariate Behavioral Research, 18, 147-167.

Curran, D., \& O’Riordan, C. (2006). Increasing population diversity through cultural learning. Adaptive Behavior, 14(4), 315-338.

Cushner, K., \& Brislin, R. W. (1996). Intercultural interactions: A practical guide. Thousand Oaks, CA: Sage.

Cutrona, C. E., \& Russell, D. W. (1987). The provisions of social relationships and adaptation to stress. In W. H. Jones \& D. Perlman (Eds.), Advances in personal relationships (p. 37-67). Greenwich, CT: AI Press.

Darwin, C. (1861). On the origin of species by means of natural selection, or The preservation of favoured races in the struggle for life. Retrieved July 18, 2009 from http://www.netlibrary.com.helicon.vuw.ac.nz/Reader/

Davidson, J. (1984). The prehistory of New Zealand. Auckland: Longman Paul.

Davidson, W. B., \& Cotter, P. R. (1991). The relationship between sense of community and subjective well-being: A first look. Journal of Community Psychology, 19(3), 246-253.

Davis, B., McGrath, N., Knight, S., Davis, S., Norval, M., Freelander, G., \& Hudson, L. (2004). Aminina Nud Mulumuluna ("You gotta look after yourself"): Evaluation of the use of traditional art in health promotion for Aboriginal people in the Kimberley region of Western Australia. Australian Psychologist, 39(2), 107-113.

Davis, C. V. (2008). Pond-women revelations: The subaltern registers in Maithil women's expressive forms. Journal of American Folklore, 121(481), 286-319. 
Dawson, A. (2005). Bollywood flashback. South Asian Popular Culture, 3(2), 161-176.

De Goede, I. H., Branje, S. J., \& Meeus, W. H. (2009). Developmental changes and gender differences in adolescents' perceptions of friendships. Journal of Adolescence, 32(5), 1105-1123.

Derks, B., van Laar, C., \& Ellemers, N. (2007). Social creativity strikes back: Improving motivated performance of low status group members by valuing ingroup dimensions. European Journal of Social Psychology, 37, 470-493.

de Leon, F. (1990). The roots of people's art in indigenous psychology. In V. G. Enriquez (Ed.), Indigenous psychology: A book of readings (pp. 310-27). Quezon City, Philippines: Akademya Ng Silohiyang Pilipino.

Denbigh, K. G. (1989). Note on entropy, disorder and disorganization. The British Journal for the Philosophy of Science, 40(3), 323-332.

d'Errico, F., Henshilwood, C., Lawson, G., Vanhaeren, M., Tillier, A.-M., Soressi, M., Bresson, F., Maureille, B., Nowell, A., Lakarra, J., Backwell, L., \& Julien, M. (2003). Archaeological evidence for the emergence of language, symbolism, and music -- An alternative multidisciplinary perspective. Journal of World Prehistory, 17(1), 1-70.

de Saussure, F. (1916/1986). (R. Harris, Trans.) A course in general linguistics. Peru, IL: Open Court.

de Silva Jayasuriya, S. (2006). Trading on a thalassic network: African migrations across the Indian Ocean. International Social Science Journal, 58 (2/188), 215-225.

De Vos, G. (2004). Totem: The return of the G'psgolox Pole. Electronic Reviewing Journal of Canadian Materials for Young People, 11(8). $\begin{array}{llll}\text { Retrieved } & \text { May } & \text { 14, } & 2009\end{array}$ http://proquest.umi.com.helicon.vuw.ac.nz/pqdweb?index $=1 \&$ did=77056 8541\&SrchMode $=1 \&$ sid=4\&Fmt=3\&VInst=PROD $\&$ VType $=$ PQD $\&$ RQ $\mathrm{T}=309 \&$ VName$=\mathrm{PQD} \& \mathrm{TS}=1242613320 \&$ clientId=7511

Diener, E. (2000). Subjective well-being: The science of happiness and a proposal for a national index. American Psychologist, 55(1), 34-43.

Diener, E. (1984). Subjective well-being. Psychological Bulletin, 95(3), 542575. 
Diener, E., Emmons, R., Larsen, J., \& Griffin, S. (1985). The satisfaction with life scale. Journal of Personality Assessment, 49(1), 71-75.

DiMaggio, P., \& Ostrower, F. (1990). Participation in the arts by Black and White Americans. Social Forces, 68(3), 753-778.

Dobson, K. S. (2001). Handbook of cognitive-behavioral therapies. New York: Guilford Press.

Dole, C., \& Csordas, T. (2003). Trials of Navajo youth: Identity, healing, and the struggle for maturity. Ethos, 31(3), 357-384.

Donahue, K. (2005). Nomad souls across time and space: West African musicians as ethnographers. Journal of the Society for the Anthropology of Europe, 5(2), 2-12.

Donne, J. (1624/1987). Devotions upon emergent occasions. Montreal, Canada: Oxford University Press.

Douglas, O., Burton, K. S., \& Reese-Durham, N. (2008). The effects of the multiple intelligence teaching strategy on the academic achievement of eighth grade math students. Journal of Instructional Psychology, 35(2), 182-187.

Drury, J., \& Reicher, S. (1999). The Intergroup dynamics of collective empowerment: Substantiating the social identity model of crowd behavior. Group Processes Intergroup Relations, 2, 381-401.

Drury, J., \& Reicher, S. (2000). Collective action and psychological change: The emergence of new social identities. British Journal of Social Psychology $39,579-604$.

Dunkel-Schetter, C., Folkman, S., \& Lazarus, R. S. (1987). Correlates of social support receipt. Journal of Personality and Social Psychology, 53(1), 7180.

Durie, M. (1995). Mental health patterns for the New Zealand Maori. In A. Issa (Ed.), Handbook of culture and mental illness: An international perspective (pp. 331-345). Madison, CT: International Universities Press.

Dyson, L. (2005). Reinventing the nation: British heritage and the bicultural settlement in New Zealand. In J. Littler \& R. Naidoo (Eds.), The politics of heritage: The legacies of "race" (pp. 115-130). London: Routledge. 
Eccles, J. S., \& Barber, B. L. (1999). Student council, volunteering, basketball, or marching band: What kind of extracurricular involvement matters? Journal of Adolescent Research, 14(1), 10-43.

Eco, U. (1984). Semiotics and the philosophy of language. London: Macmillan.

Eliade, M. (1978). A history of religious ideas, translated from the French by Willard R. Trask. Chicago: University of Chicago Press.

Elicker, M. (1997). Semiotics of popular music: The theme of loneliness in mainstream pop and rock songs. Tubingen: Gunter Narr.

Emerson, E., \& Shelton, D. (2001). Using creative arts to build coping skills to reduce domestic violence in the lives of female juvenile offenders. Issues in Mental Health Nursing, 22(2), 181-195,

Enzlin-Dixon, M. (2004). Cultures under threat (Yanomamo, Makuxi). Faces: People, Places, and Cultures, 20(5), 26-29.

Ericsson, K. A., \& Charness, N. (1994). Expert performance: Its structure and acquisition. American Psychologist, 49(8), 725-747.

Erikson, E. H. (1964). Childhood and society (2nd ed.). New York: Norton.

Erikson, E. H. (1968). Identity: Youth and crisis. Oxford, England: Norton \& Co.

Evans, M., \& Ngarimu, R. (2005). The art of Maori weaving: The eternal thread. Wellington, New Zealand: Huia Publishers/Toi Maori Aotearoa/Te Waka Toi.

Farr, M. (1997). The role of dance/movement therapy in treating at-risk African American Adolescents. The Arts in Psychotherapy, 24(2), 183-191.

Farrer, J. (2004). A practical approach to diversity. Industrial and Commercial Training, 36(4), 175-177.

Fauth, R. C., Brooks-Gunn, J., \& Roth, D. L. (2007). Does the neighbourhood context alter the link between youth's after-school time activities and developmental outcomes? A multilevel analysis. Developmental Psychology, 43(3), 760-777.

Festinger, L., \& Carlsmith, J. M. (1959). Cognitive consequences of forced compliance. The Journal of Abnormal and Social Psychology, 58(2), 203-210. 
Fine, G. A., \& Fields, C. F. (2008). Culture and microsociology: The anthill and the Veldt. The Annals of the American Academy of Political and Social Science, 619, 130-148.

Finney, B. (1994). Polynesian voyagers to the new world. Man and Culture in Oceania, 10, 1-13.

Fischman, J. (1995). Painted puzzles line the walls of an ancient cave. Science, 267,614 .

Flick, U. (2002). An introduction to qualitative research. London: Sage Publications.

Flanagan, C. A., Cumsille, P., Gill, S., \& Gallay, L. S. (2007). School and community climates and civic commitments: Patterns for ethnic minority and majority students. Journal of Educational Psychology, 99(2), 421431 .

Fortes, M. (1936). Ritual festivals and social cohesion in the hinterland of the gold coast. New Series, 38(4), 590-604.

Fox, S. (2007). The Well-Being of Vietnamese refugees and immigrants in Hawaii. In J. Liu, C. Ward, A. Bernardo, M. Karasawa, \& R. Fischer (Eds.), Casting the individual in societal and cultural contexts (pp. 225240). Seoul: Kyoyook-Kwahak-Sa Publishing Co.

France, H. (1997). First nations: Helping and learning in the aboriginal community. Guidance \& Counselling, 12(2), 3-9.

Francis, B. A. (1997). Kapa-making in Hawaii: Cultural reconstruction through art. Journal of Multi Cultural and Cross-Cultural Research in Art Education, 15, 51-62.

Feredricks, J. A., \& Eccles, J. S. (2008). Participation in extracurricular activities in the middle school years: Are there developmental benefits for African American and European American youth? Journal of Youth and Adolescence, 37(9), 1029-1043.

Frisbie, W. P., Cho, Y., \& Hummer, R. A. (2001). Immigration and the health of Asian and Pacific Islander adults in the United States. American Journal of Epidemiology, 153, 372-380.

Frith, S. (1996). Music and identity. In S. Hall, \& P. duGay (Eds.), Questions of cultural identity (pp. 108-127). London: Sage. 
Gaunt, K. D. (2006). The games black girls play: Learning the ropes from double-dutch to Hip-Hop. New Brunswick, NJ: New York University Press.

Gardner, H. (1993). Multiple intelligences: The theory in practice. New York: Basic Books.

Gardner, H. (2006). Multiple intelligences: New horizons. New York: Basic Books.

Geertz, C. (1993). The interpretation of cultures: Selected essays. London: Fontana.

Geertz, C. (1988). Works and lives: The anthropologist as author. Stanford, CA: Stanford University Press.

Gerdes, E. V. P. (2008). Contemporary Yangge: The moving history of a Chinese folk dance form. Asian Theatre Journal, 25(1), 138-147.

Gest, S. D., Welsh, J. A., \& Domitrovich, C. E. (2005). Behavioral predictors of changes in social relatedness and liking school in elementary school. Journal of School Psychology, 43(4), 281-301.

Gilroy, W. G. (2009, June 23). Notre Dame study describes evidence of world's oldest known granaries. Notre Dame Newswire. Retrieved from http://newsinfo.nd.edu/news/11901

Glaser, B. G. (1992). Basics of grounded theory analysis. Mill Valley, CA: Sociology Press.

Glass, A. (2004). Return to sender: On the politics of cultural property and the proper address of art. Journal of Material Culture, 9(2), 115-139.

Gomez, M. J., Fassinger, R. E., Prosser, J., Cooke, K., Mejia, B., \& Luna, J. (2001). Voces abriendo caminos (Voices forging paths): A qualitative study of the career development of notable Latinas. Journal of Counseling Psychology, 48(3), 286-300.

Gone, J. P. (2006). Mental health, wellness, and the quest for an authentic American Indian identity. In T. M. Witko (Ed.), Mental health care for urban Indians: Clinical insights from native practitioners (pp. 55-80). Washington, DC: American Psychological Association.

Goodenow, C. (1993). The psychological sense of school membership among adolescents: Scale development and educational correlates. Psychology in the Schools, 30, 70-90. 
Goodman, J. (2005). Berber culture on the world stage: From village to video. Bloomington: Indiana University Press.

Goodstein, R., \& Ponterotto, J. G. (1997). Racial and ethnic identity: Their relationship and their contribution to self-esteem. Journal of Black Psychology, 23, 275-292.

Gorsuch, R. L. (1983). Factor analysis (2nd ed.). Hillsdale, NJ: Erlbaum.

Gouveia, V. V., Milfont, T. L., da Fonseca, P. N., de Miranda Coelho, J. A. P. (2009). Life satisfaction in Brazil: Testing the psychometric properties of the Satisfaction with Life Scale (SWLS) in five Brazilian samples. Social Indicators Research, 90(2), 267-277.

Government of Niue (2006). Statistics Niue. Retrieved May 1, 2008 from http://www.spc.int/prism/country/nu/stats/

Graburn, N. H. H. (2004). Authentic intuit art: Creation and exclusion in the Canadian north. Journal of Material Culture, 9(2), 141-159.

Grahame, M. (1998). Material culture and Roman identity. In R. Laurence \& J. Berry (Eds.), Cultural identity in the Roman Empire (pp. 156-78). New York: Routledge.

Graves, T. D. (1967). Acculturation, access and alcohol in a tri-ethnic community. American Anthropologist, 69, 306-321.

Gray-Little, B., \& Hafdahl, A. R. (2000). Factors influencing racial comparisons of self-esteem: A quantitative review. Psychological Bulletin, 126(1), 2654.

Green, E. G. T. (2009). Who can enter? A multilevel analysis on public support for immigration criteria across 20 European countries. Group Processes \& Intergroup Relations, 12(1), 41-60.

Gregory, A. H. (1997). The role of music in society. In D. J. Hargreaves \& A. C. North (Eds.), The Social Psychology of Music (pp. 123-40). Oxford: Oxford University Press.

Greve, W. (2008). Review of well-being: Individual, community, and social perspectives. European Psychologist, 13(4), 316-317.

Guenther, M. (2003). Contemporary Bushman art, identity politics and the primitivism discourse. Anthropologica, 45(1), 95-110.

Guerin, P., Fatuma, H. E., \& Guerin, B. (2006). Weddings and parties: Cultural healing in one community of Somali women. Australian e-Journal for 
the Advancement of Mental Health (AeJAMH), 5(2). Retrieved March 20, 2008 from http://www.auseinet.com/journal/vol5iss2/guerin.pdf

Hacking, S., Secker, J., Kent, L., Shenton, J., \& Spandler, H. (2008). Mental health and arts participation: The state of the art in England. The Journal of the Royal Society for the Promotion of Health, 126(3), 121-127.

Hahn, J., \& Münzel, S. C. (1995). Knochenflöten aus dem Aurignacien des Geißenklösterle bei Blaubeuren, Alb-Donau-Kreis. Fundb. aus BadenWürttemberg 20, 1-12.

Haley, D. (2007). Art, Health and Well-Being. In J. Haworth \& G. Hart (Eds.), Well-being: Individual, community and social perspectives (pp. 110-19). New York: Palgrave Macmillan.

Hall, S. P., \& Brassard, M. R. (2008). Relational support as a predictor of identity status in an ethnically diverse early adolescent sample. The Journal of Early Adolescence, 28, 92-114.

Hallam, S., Cross, I., \& Thaut, M. (2009). Where now? In S. Hallam, I. Cross, \& M. Thaut (Eds.), The Oxford Handbook of Music Psychology (pp. 561568). Oxford: Oxford University Press.

Hancock, G. R., \& Mueller, R. O. (2006). Structural Equation Modeling: A second course. Greenwich, CT: Information Age Publishing.

Hardaway, C., \& Fulghini, A. J. (2006). Dimensions of family connectedness among adolescents with Mexican, Chinese, and European backgrounds. Developmental Psychology, 42(6), 1246-1258.

Harding, J. (1979). Artistes pompiers: French academic art in the $19^{\text {th }}$ century. London: Academy editions.

Hargreave, D., \& North, A. (1999). The functions of music in everyday life: Redefining the social psychology of music. Psychology of Music, 27, 7183.

Harrington, D. M. (1990). The ecology of human creativity: A psychological perspective. In M. A. Runco \& R. S. Albert (Eds.), Theories of creativity (pp. 143-169). Newbury Park, CA: Sage.

Hatton, T. J., \& Williamson, J. G. (2005). Global migration and the world economy: Two centuries of policy and performance. Cambridge, MA: MIT Press. 
Haworth, J., \& Hart, G. (2007). Introduction. In J. Haworth \& G. Hart (Eds.), Well-being: Individual, community and social perspectives (pp. 1-24). New York: Palgrave Macmillan.

Haworth, J., \& Lewis, S. (2005). Work, leisure and well-being. British Journal of Guidance and Counseling, 33(1), 67-78.

Heath, S. B. (2004). Learning language and strategic thinking through the arts. Reading Research Quarterly, 39(3), 338-342.

Heath, S. B. (2001). Three's not a crowd: Plans, roles, and focus in the arts. Educational Researcher, 30(7), 10-17.

Heath, S. B., \& Roach, A. A. (1998). The arts in the nonschool hours. Menlo Park, CA: Stanford University and the Carnegie Foundation for the Advancement of Teaching.

Hermans, H. J. M., \& Dimaggio, G. (2007). Self, identity, and globalization in times of uncertainty: A dialogical analysis. Review of General Psychology, 11(1), 31-61.

Herzog, T. R., \& Strevey, S. J. (2008). Contact with nature, sense of humor, and psychological well-being. Environment and Behavior, 40(6), 747-776.

Hill, D. L. (2006). Sense of belonging as connectedness, American Indian worldview, and Mental Health. Archives of Psychiatric Nursing, 20(5), 210-216.

Hoerder, D. (2002). Cultures in contact: World migrations in the second millennium. Durham, NC: Duke University Press.

Hofstede, G. (1980). Culture's consequences: International differences in work related values. Beverly Hills, CA: Sage.

Hogg, A. G., Higham, T. F. G., Lowe, D. J., Palmer, J., Reimer, P. J., \& Newnham, R. M. (2003). A wiggle-match date for Polynesian settlement of New Zealand, Antiquity, 77(295), 116-125.

Hoover, E. L. (2007). There is no scientific rationale for race-based research. Journal of the National Medical Association, 99(6), 690-692.

House, J. S., Umberson, D., \& Landis, K. S. (1988). Structures and processes of social support. Annual Review of Sociology, 1(4), 293-318.

Hu, L.-T., \& Bentler, P. M. (1995). Evaluation model fit. In R. H. Hoyle (Ed.), Structural equation modelling: Concepts, issues, and applications (pp. 76-99). Thousand Oaks, CA: Sage Publications, Inc. 
Hu, L.-T., \& Bentler, P. M. (1999). Cutoff criteria for fit indexes in covariance structure analysis: Conventional criteria versus new alternatives. Structural Equation Modeling, 6(1), 1-55.

Huggett, B. (1992). Te Whaea: Mother of change. Auckland: Te Ao Marama Productions.

Hui Tamata (2005). Maori in tertiary education: A picture of the trends. $\begin{array}{lllll}\text { Retrieved } & 8 & \text { May, } & 2008 & \text { from }\end{array}$ http://www.huitaumata.maori.nz/pdf/tertiary.pdf

Hunter, J. E., \& Gerbing, D. W. (1982). Unidimensional measurement, second order factor analysis, and causal models. Research in Organizational Behavior, 4, 267-320.

Hurley-Glowa, S. M. (1977). 'Batuko' and 'Funana': Musical traditions of Santiago, Republic of Cape Verde. (Unpublished doctoral dissertation). Brown University, Rhode Island.

Hurtes, K. P., \& Allen, L. R. (2001). Measuring resiliency in youth: The resiliency attitudes and skills profile. Therapeutic Recreation Journal, 35(4), 333-347.

Huyge, D. (1991). The Venus of Laussel in the light of ethnomusicology. Archeologie in Vlanderen, 1, 11-18.

Hynie, M., Lalonde, R. N., \& Lee, N. (2006). Parent-child value transmission among Chinese immigrants to North America: The case of traditional mate preferences. Cultural Diversity and Ethnic Minority Psychology, 12(2), 230-244.

IMG (2009). Kiri Te Kanawa: Full biography. Retrieved 10 Oct. 2009 from http://www.imgartists.com/?page=artist\&id=369\&c=2

Ip, M. (2003). Unfolding history, evolving identity: The Chinese in New Zealand. Auckland, Auckland University Press.

Irwin, G. (2008, November 18). Pacific migrations. Te Ara - the Encyclopaedia of New Zealand. Retrieved from http://www.TeAra.govt.nz/NewZealanders/MaoriNewZealanders/Pacific MigraPacif/en

Irwin, G., \& Walrdon, C. (2008, November 18). When was New Zealand first settled? Te Ara - the Encyclopaedia of New Zealand. Retrieved from 
http://www.TeAra.govt.nz/NewZealanders/MaoriNewZealanders/When WasNewZealandFirstSettled/en

Issawi, C. (1998). Cross-cultural encounters and conflicts. New York: Oxford University Press.

Jablensky, A., Marsella, A., Ekblad, S., Jannsonn, B., Levi, L., \& Bornemann, T. (1994). Refugee mental health and well-being: Conclusions and recommendations. In A. Marsella, T. Bornemann, S. Ekblad, \& J. Orley (Eds.), Amidst peril and pain (pp. 327-39). Washington, DC: American Psychological Association.

James, D. (1999). "Bagagešu" (Those of my home): Women migrants, ethnicity, and performance in South Africa. American Ethnologist, 26(1), 69-89.

Jeong, Y. J., Hong, S. C., Lee, M., Park, M. C., Kim, Y. K., \& Suh, C. M. (2005). Dance/movement therapy improves emotional responses and modulates neurohormones in adolescents with mild depression, International Journal of Neuroscience 115(12), 1711-1720.

Jilek, W. G. (1995). Emil Kraepelin and comparative sociocultural psychiatry [Special Issue]. European Archives of Psychiatry and Clinical Neuroscience, 245(4-5), 231-238.

John, L., Wright, R., Duku, E. K., \& Willms, J. D. (2008). The use of propensity scores as a matching strategy. Research on Social Work Practice, 18(1), 20-26.

Johnson, V., \& Stanley, J. (2007). Capturing the contribution of community arts programs to health and well-being. International Journal of Mental Health Promotion, 9(2), 28-35.

Jones, R. (1986). Using art to develop self-esteem for troubled youth. Art Education, 39(1), 21- 22.

Jones, H., Cross, W., \& Defour, D. (2007). Race-related stress, racial identity attitudes, and mental health among Black women. Journal of Black Psychology, 33, 208-231.

Jones, M. D., \& Galliher, R. (2007). Ethnic identity and psychosocial functioning in Navajo adolescents. Journal of Research on Adolescence, 17(4), 683-696. 
Jones, M. H., West, S. D., \& Estell, D. B. (2006).The Mozart effect: Arousal, preference, and spatial performance. Psychology of Aesthetics, Creativity, and the Arts, 1, 26-32.

Joreskog, K. G., \& Sornbom, D. (1986). Recent developments in structural equation modelling. Journal of Marketing Research, 19, 404-16.

Joreskog, K. G., \& Sorbom, D. (1996). LISREL 8: User's reference guide. Chicago: Scientific Software International.

Juang, L. P., Nguyen, H. H., \& Lin, Y. (2006). The ethnic identity, other-group attitudes, and psychosocial functioning of Asian American emerging adults from two contexts. Journal of Adolescent Research, 21(5), 542568.

Juslin, P. N. \& Västfjäll, D. (2008). Emotional responses to music: The need to consider underlying mechanisms. Behavioral and Brain Sciences, 31(5), $559-621$.

Kagan, R. (2004) Rebuilding attachments with traumatized children. New York: The Haworth Maltreatment and Trauma Press.

Kagan, C., \& Kilroy, A. (2007). Psychology in the community. In J. Haworth \& G. Hart (Eds.), Well-being: Individual, community and social perspectives (pp. 93-109). New York: Palgrave Macmillan.

Kaiser, H. F. (1974). An index of factorial simplicity. Psychometrika, 39(1), 3136.

Kalish, M., Griffiths, T., \& Lewandowsky, S. (2007). Iterated learning: Intergenerational knowledge transmission reveals inductive biases. Psychonomic Bulletin \& Review, 14(2), 288-294.

Kame'eleihiwa, L. (2009). Hawai'i-nui-akea cousins: Ancestral gods and bodies of knowledge are treasures for the descendants. Te Kaharoa, 2, 42-63.

Kammann, R., \& Flett, R. (1986). Structure and measurement of psychological well-being: A report to the New Zealand Social Sciences Research Fund Committee. Wellington: Social Sciences Research Fund Committee.

Kanuha, V. K. (2005). `Ohana: Native Hawaiian families. In M. McGoldrick, J. Giordano, \& N.G. Preto. (Eds.), Ethnicity and family therapy (3rd ed., pp. 64-74). New York: Guilford Press. 
Kashima, Y. (2008). A social psychology of cultural dynamics: Examining how cultures are formed, maintained, and transformed. Social and Personality Psychology Compass, 2(1), 107-120.

Kashima, Y. (2000). Conceptions of culture and person for psychology. Journal of Cross-Cultural Psychology, 31, 14-32.

Kashima, Y., Kashima, E., Chiu, C.-Y., Farsides, T. Gelfand, M., Hong, Y.-Y., K, U., Strack, F., Werth, L., Yuki, M., \& Yzerbyt, V. (2005). Culture, essentialism, and agency: Are individuals universally believed to be more real entities than groups? European Journal of Social Psychology, 35(2), 147-169.

Katz, J. (1985). The sociopolitical nature of counseling. The Counseling Psychologist, 13, 615-624.

Keefe, S. E. (1992). Ethnic identity: The domain of perceptions of and attachment to ethnic groups and cultures. Human Organization, 51(1), 35 .

Keightley, R. (2005). eNZed. Ancient and modern history. Retrieved June 21, 2009, from http://www.enzed.com/hist.html

Kiang, L., \& Fuligni, A. J. (2009). Ethnic identity in context: Variations in ethnic exploration and belonging within parent, same-ethnic peer, and different-ethnic-peer relationships. Journal of Youth and Adolescence, 38(5), 732-743.

Kiang, L., Yip, T., Gonzales-Backen, M., Witkow, M., \& Fuligni, A. J. (2006). Ethnic identity and the daily psychological well-being of adolescents from Mexican and Chinese backgrounds. Child Development, 77(5), 1338-1350.

Kim, M. , Kim, E. and Kim, J. (2009-05-20) "Examining the Causal Direction Between Subjective Well-Being and Sense of Relatedness"Paper presented at the annual meeting of the International Communication Association, Marriott, Chicago, IL. Retrieved June 18, 2010 from http://www.allacademic.com/meta/p299774_index.html

King, M. (2001). Nga iwi o te motu: 1000 years of Maori history. Auckland: Reed Books.

Kirch, P. (1986). Rethinking East Polynesian prehistory. Journal of the Polynesian Society, 95, 9-40. 
Kirkwood, S., Liu, J. H., \& Weatherall, A. (2005). Challenging the standard story of indigenous rights in Aotearoa/New Zealand. Journal of Community and Applied Social Psychology, 15, 1-13.

Kline, R. B. (2005). Principles and practices of structural equation modeling ( $2^{\text {nd }}$ ed.). New York: Guilford.

Kluckhohn, F. R., \& Strodtbeck, F. L. (1961). Variations in value orientations. Evanston, IL: Row \& Peterson.

Kobin, C., \& Tyson, E. (2006). Thematic analysis of hip hop. The Arts in Psychotherapy, 33, 343-356.

Koch, S. C., Morlinghaus, K., Fuchs, T. (2007). The joy dance: Specific effects of a single dance intervention on psychiatric patients with depression. The Arts in Psychotherapy, 34(4), 340-349.

Kohut, H. (1984). How does analysis cure? Chicago: University of Chicago Press.

Kopano, B. N. (2002). Rap music as an extension of the Black rhetorical tradition: "Keepin' it real." Western Journal of Black Studies, 26(4), 204214.

Koser, K. (2009). Why migration matters. Current History, 108(717), 147-153.

Kramer, J. (2004). Figurative repatriation: First nations 'Artist-Warriors' recover, reclaim, and return cultural property through self-definition. Journal of Material Culture, 9(2), 161-182.

Krippendorff, K. (1980). Content analysis: An introduction to its methodology. Newbury Park, CA: Sage.

Kuijt, I. (2009). Proceedings of the National Academies of Sciences, 106(25). $\begin{array}{llll}\text { Retrieved June } & 24, & 2009 & \text { from }\end{array}$ http://www.pnas.org/content/106/25.toc.pdf

Kulis, S., Napoli, M., \& Marsiglia, F. F. (2002). Ethnic pride, biculturalism, and drug use norms of urban American Indian adolescents. Social Work Research, 26(2), 101-112.

Kyselka, W. (1987). An ocean in mind. Honolulu: University of Hawaii Press.

Langston, P. (1998). Music quotes -- Strauss, Schoenberg, Sellars, Hale, Stravinsky. Retrieved May 13, 2009 from http://www.langston.com/Fun_People/1998/1998AGJ.html 
Laurence, R. (1998). Introduction. In R. Laurence \& J. Berry (Eds.), Cultural identity in the Roman Empire (pp. 1-9). London: Routledge.

Lazarus, R. S., \& Folkman, S. (1984). Stress, appraisal, and coping. New York: Springer.

Le, T. N., Lai, M. H., \& Wallen, J. (2009). Multiculturalism and subjective happiness as mediated by cultural and relational variables. Cultural Diversity and Ethnic Minority Psychology, 15(3), 303-313.

Ledesma, R. D. (2007). Determining the number of factors to retain in EFA: An easy-to-use computer program for carrying out parallel analysis. Practical assessment, research, and evaluation, 12(2), [online]. Retrieved November 16, 2009 from http://pareonline.net/pdf/v12n2.pdf

Lee, S., \& Song, X. (2004). Bayesian model comparison of nonlinear structural equation models with missing continuous and ordinal categorical data. British Journal of Mathematical and Statistical Psychology, 57(1), 131150 .

Lee, S., \& Tang, N. (2006). Bayesian analysis of structural equation models with mixed exponential family and ordered categorical data. British Journal of Mathematical and Statistical Psychology, 59(1), 151-172.

Li., M.-H., \& Yang, Y. (2009). Determinants of problem solving, social support seeking, and avoidance: A path analytic model. International Journal of Stress Management, 16(3), 155-176.

Liebkind, K. (1996). Acculturation and stress. Journal of Cross-Cultural Psychology, 27(2), 161-180.

Little, J. F. (1961). The social architect. American Psychologist, 16(9), 602-603.

Little, T., Cunningham, W., Shahar, G., \& Widaman, K. (2002). To parcel or not to parcel: Exploring the question, weighing the merits. Structural Equation Modeling, 9, 151-173.

Liu, J. H., McCreanor, T., McIntosh, T., \& Teaiwa, T. (2005). Constructing New Zealand identities. In J. H. Liu, T. McCreanor, T. McIntosh \& T. Teaiwa (Eds.), New Zealand Identities: Departures and Destinations (pp. 11-20). Wellington, NZ: Victoria University Press.

Liu, J. H., Wilson, M. S., McClure, J., \& Higgins, T. R. (1999). Social identity and the perception of history: Cultural representations of Aotearoa/ $\mathrm{New}$ Zealand. European Journal of Social Psychology, 29(8), 1021-1047. 
Loomis, T. (1990). Pacific migrant labour, class, and racism in New Zealand: fresh off the boat. Brookfield, VT: Avebury.

Luck, K. E. (2005). It's all about loving your "self": National identity and the Indian diaspora in Bollywood cinema. (Unpublished master's thesis). University of Wyoming, Wyoming.

Luhtanen, R., \& Crocker, J. (1992). A collective self-esteem scale: Selfevaluation of one's social identity. Personality and Social Psychology Bulletin, 18(3), 302-318.

Lundqvist, L.-O., Carlsson, F., Hilmersson, P., \& Juslin, P. (2009). Emotional responses to music: Experience, expression, and physiology. Psychology of Music, 37(1), 61-90.

Maasjo, Dennis (2002). Blackfoot, Hidatsa, and Lakota Sioux students' perceptions regarding preferred learning styles using Gardner's multiple intelligences (Unpublished doctoral dissertation). University of South Dakota, Vermillion, SD.

MacCallum, R. C., Browne, M. W., \& Sugawara, H. M. (1996). Power analysis and determination of sample size for covariance structure modeling. Psychological Methods, 1(2), 130-149.

MacCallum, R. C., Widaman, K. F., Zhang, S., \& Hong, S. (1999). Sample size in factor analysis. Psychological Methods, 4, 84-99.

Machida, M. L. (2002). The poetics of positionality: Art, identity, and communities of imagination in Asian America (Unpublished doctoral dissertation). University of New York at Buffalo: Buffalo, New York.

Macpherson, C. (2004). From Pacific Islanders to Pacific People and beyond. In P. Spoonley, C. Macpherson \& D. Pearson (Eds.), Tangata, tangata: The changing ethnic contours of New Zealand (pp. 135-156). Southbank, Victoria: Thomson.

Maher, T. F. (1976). "Need for resolution" ratings for harmonic musical intervals: A comparison between Indians and Canadians. Journal of Cross-Cultural Psychology, 7(3), 259-276.

Maori.org.nz (2009). Tikanga: Pohiri - what is it? Retrieved May 13, 2009 from http://www.maori.org.nz/tikanga/default.asp?pid=sp40\&parent=39

Marcia, J. E. (1966). Development and validation of ego-identity status. Journal of Personality and Social Psychology, 3(5), 551-558. 
Markovitzky, G., \& Mosek, A. (2005). The role of symbolic resources in coping with immigration. Journal of Ethnic and Cultural Diversity in Social Work, 14(12), 145-158.

Markus, H. R., \& Kitayama, S. (1991). Culture and the self: Implications for cognition, emotion and motivation. Psychological Review, 98(2), 224253.

Marsella, A. J. (1994). Ethnocultural diversity and international refugees. In A. Marsella, T. Bornemann, S. Ekblad, \& J. Orley (Eds.), Amidst peril and pain (pp. 341-64). Washington, DC: American Psychological Association.

Marsella, A. J. (1999). Internationalizing the psychology curriculum: Toward a new psychology. Paper presented at 107th Annual Convention of American Psychological Association, Boston, MA.

Marsella, A. J. (2009). Diversity in a global era: The context and consequences of differences. Counselling Psychology Quarterly, 22(1), 119-135.

Marsella, A. J. \& Pedersen, P. (2004). Internationalizing the counselling psychology curriculum: Toward new values, competencies, and directions. Counselling Psychology Quarterly, 17(4), 413-423.

Marsella, A. J., \& Ring, E. (2003). Human migration and immigration. In L. Adler \& U. Gielen (Eds.), Migration: Immigrants and emigration in international perspective (pp. 3-22). Westport, CT: Greenwood Press.

Marsella, A. J., Bornemann, T., Ekblad, S. \& Orley, J. (1994). Amidst peril and pain. Washington, DC: American Psychological Association.

Marsh, H. W., Balla, J. R., \& McDonald, R. P. (1988). Goodness-of-fit indexes in confirmatory factor analysis: The effect of sample size. Psychological Bulletin, 103(3), 391-410.

Marsh, H. W., \& Roche, L. A. (1996). Structure of artistic self-concepts for performing arts and non-performing arts students in a performing arts high school: "Setting the stage" with multigroup confirmatory factor analysis. Journal of Educational Psychology, 88(3), 461-477.

Marshall, E. (1998). Constructing the self and the other in Cyrenaica. In R. Laurence and J. Berry (Eds.), Cultural identity in the Roman Empire (pp. 49-63). New York: Routledge. 
Martin, R. A. (2001). Humor, laughter, and physical health: Methodological issues and research findings. Psychological Bulletin, 127, 504-519.

Martinez, R., \& Dukes, R. L. (1997). The effects of ethnic identity, ethnicity, and gender on adolescent well-being. Journal of Youth and Adolescence, 26(5), 503-516.

Marton, F. (1994) Phenomenography. In T. Husten \& T. N. Postlewaite (Eds.), International encyclopedia of education, 8 (2nd ed., pp. 4424-4429). London: Pergamon.

Maruyama, G. M. (1998). Basics of structural equation modelling. Thousand Oaks, CA: Sage.

Maslow, A. H. (1943). A theory of human motivation. Psychological Review, 50(4), 370-396.

Mason, M. J., \& Chuang, S. (2001). Culturally-based after-school arts programming for low-income urban children: Adaptive and preventive effects. The Journal of Primary Prevention, 22(1), 45-54.

Matsumoto, D., Weissmann, M. D., Preston, K., Brown, B. R., \& Kuppersbusch, C. (1997). Context specific measurement of individualism-collectivism on the individual level: The individualism-collectivism interpersonal assessment inventory. Journal of Cross-cultural Psychology, 28(6), 743767.

Mayer, F., Frantz, S., \& McPherson C. (2004). The connectedness to nature scale: A measure of individuals' feeling in community with nature. Journal of Environmental Psychology, 24(4), 503-515.

McCoach, D. B., Black, A. C., O'Connell, A. A. (2007). Errors of inference in structural equation modeling [Special Issue]. Psychology in the Schools, 44(5), 461-470.

McFerran, K., Roberts, M., O'Grady, L. (2010). Music Therapy with Bereaved Teenagers: A Mixed Methods Perspective. Death Studies, 34(6), 541565 .

Mcgraw, K., Moore, S., Fuller, A., \& Bates, G. (2007) Family, peer and school connectedness in final year secondary school students. Australian Psychologist, 43(1), 27-37.

McIntosh, T. (2005). Maori identities: Fixed, fluid, forced. In J. Liu, T. McCreanor, T. Mcintosh, \& T. Teaiwa (Eds.), New Zealand identities: 
Departures and destinations (pp. 11-20). Wellington, New Zealand: Victoria University Press.

McKennell, A. C. (1978). Cognition and affect in perceptions of well-being. Social Indicators Research, 5, 389-426.

McKennell, A. C., \& Andrews, F. M. (1980). Models of cognition and affect in perceptions of well-being. Social Indicators Research, 8, 251-298.

McKinnon, M. (1996). Immigrants and citizens: New Zealanders and Asian immigration in historical context. Wellington: Institute of Policy Studies.

Mead, G. H. (1967). Mind, self, \& society from the standpoint of a social behaviorist. Chicago: University of Chicago Press.

Mead, M. (1961). Coming of age in Samoa: A psychological study of primitive youth for Western civilization. New York: Morrow.

Merriam, A. P. (1977). Anthropology and the arts. In S. Tax \& L. Freeman (Eds.), Horizons of Anthropology ( $2^{\text {nd }}$ ed., pp. 332-343). Chicago: P. Aldine Publishing Co.

Meyers, L. S., Gamst, G., Guarino, A. J. (2006). Applied multivariate research: Design and interpretation. Thousand Oaks: Sage Publications.

Michalos, A. C., \& Kahlke, P. M. (2008). Impact of arts-related activities on the perceived quality of life. Social Indicators Research, 89(2), 193-258.

Michalos, A. C. (2005). Arts and the quality of life: An Exploratory study. Social Indicators Research. 71(1), 11-59.

Miller, K., \& Rasco, L. (2004). The mental health of refugees, ecological approaches to healing and adaptation. Mahwah, NJ: Lawrence Erlbaum Associates.

Mimura, C., \& Griffiths, P. (2007). Translation and equivalence assessment for a Japanese version of the modified Parental Nurturance Scale: A comparative study. BioPsychoSocial medicine, 1(4), [online]. Retrieved $\begin{array}{llll}\text { November } & 11, & \text { from }\end{array}$ http://www.ncbi.nlm.nih.gov/pmc/articles/PMC2569029/

Ministry of Social Development (2008). Diverse communities: Exploring the refugee and migrant experience in New Zealand. Wellington, NZ: Ministry of Social Development.

Montagu, J. (2007). Origins and development of musical instruments. Lanham, MD: Scarecrow Press. 
Moorfield, J. C. (2005). Aka Māori-English, English-Māori Dictionary and Index. Auckland, N.Z.: Pearson Longman. Retrieved from http://www.maoridictionary.co.nz/index.cfm?dictionaryKeywords=toi\&n $=1 \&$ idiom $=\&$ phrase $=\&$ proverb $=\&$ loan $=\&$ search $. x=35 \&$ search $. y=10$

Morley, I. (2003). The evolutionary origins and archaeology of music (Unpublished doctoral dissertation). Darwin College Cambridge University, Oxford.

Mrázek, J. (2005). Masks and selves in contemporary Java: The Dances of Didik Nini Thowok. Journal of Southeast Asian Studies, 36(2), 249-279.

Murray, T. (2004). Introduction. In T. Murray (Ed.), The archaeology of contact in settler societies (pp. 1-18). Cambridge, U.K: Cambridge University Press.

Murrock, C. J. (2005). Music and mood. In A. V. Clark (Ed.), Psychology of moods (pp. 141-155). Hauppauge, NY: Nova Science.

Myers, F. (2004). Social agency and the cultural value(s) of the art object. Journal of Material Culture, 9(2), 205-213.

Myers, H. (2007, August 17). Around the galleries -- Picasso, powerful and erotic. Los Angeles Times. Retrieved from http://articles.latimes.com/2007/aug/17/entertainment/et-galleries17

Nacpal, R., \& Sell, H. (1985). SEARS regional health papers: Subjective wellbeing. New Delhi: World Health Organization.

Naidoo, J. C., \& Mahabeer, M. (2006). Acculturation and integration patterns among Indian and African university students in South Africa: Implications for ethno-gender relations in the "Rainbow" Nation. Psychology and Developing Societies, 18(1), 115-132.

National Endowment for the Arts (NEA) (2009). Arts Participation 2008. Retrieved from http://www.nea.gov/research/NEA-SPPA-brochure.pdf

Nattiez, J.-J. (1990). Music and discourse: Toward a semiology of music (C. Abbate, Trans.). Princeton, NJ: Princeton University Press.

Navarro, J., Wilson, S., Berger, L. R., \& Taylor, T. (1997). Substance abuse and spirituality: A program for Native American students. American Journal of Health Behavior, 21(1), 3-11. 
Nayar, S. C. (2009). The everyday occupations of Indian migrant women: A process of navigating cultural spaces (Unpublished doctoral dissertation). Auckland University of Technology, Auckland, New Zealand.

Neto, F., Barros, J., \& Schmitz, P. G. (2005). Acculturation attitudes and adaptation among Portuguese immigrants in Germany: Integration or separation. Psychology \& Developing Societies, 17, 19-32.

New Zealand Legislation (2003). Maori Television Service (Te Aratuku Whakaata Irirangi Maori) Act 2003. Retrieved May 14, 2009 from: http://www.legislation.govt.nz/act/public/2003/0021/latest/DLM193696. html?search=ts_act_television+service_resel\&sr=1

Ng'andu, J., \& Herbst, A. (2004). Lukwesa ne Ciwa - The story of Lukwesa and Iciwa: Musical storytelling of the Bemba of Zambia. British Journal of Music Education, 21(1), 41-61.

Niell, J. T., \& Dias, K. L. (2001). Adventure education and resilience: The double edged sword. Journal of Adventure Education and Outdoor Learning, 1(2), 35-42.

Niesche, C. (2002, September 23). Haka studies stir up real song and dance. The Australian. Retrieved April 13, 2009 from: http://proquest.umi.com.helicon.vuw.ac.nz/pqdweb?index=6\&did=39507 $1801 \&$ SrchMode $=2 \&$ sid $=1 \&$ Fmt $=3 \&$ VInst=PROD $\&$ VType $=$ PQD $\&$ RQ $\mathrm{T}=309 \&$ VName $=\mathrm{PQD} \& \mathrm{TS}=1239605898 \&$ clientId $=7511$

Nguyen, H., Messe, L., \& Stollack, G. (1999). Toward a more complex understanding of adjustment and acculturation. Journal of Cross-Cultural Psychology, 30(1), 5-31.

Noh, S., Beiser, M., Kaspar, V., Hou, F., Rummens, J. (1999). Perceived racial discrimination, depression, and coping: A study of Southeast Asian refugees in Canada. Journal of Health and Social Behavior. 40(3), 193207.

Nolen, J. L. (2003). Multiple intelligences in the classroom. Education, 124(1) 115-120.

Obeng, P. (1998). Re-membering through oath: Installation of African kings and queens. Journal of Black Studies, 28(3), 334-356.

Oberg, K. (1960). Culture shock: Adjustment to new cultural environments. Practical Anthropology. 7, 177-182. 
O'Brian, P. (1976). Picasso: Pablo Ruiz Picasso: a biography. New York: Putnam.

O’Connor, M. (1990). An immigrant nation. Auckland: Heinemann Education.

O’Donnell, C. R., Tharp, R. G., \& Wilson, K. (1993). Activity settings as the unit of analysis: A theoretical basis for community intervention and development. American Journal of Community Psychology, 21(4), 501520.

O'Donnell, S. A. (1999). Ancient healing secrets. Journal of Prevention, 51(10), 126-137.

Oetting, G. R., \& Beauvais, F. (1990). Orthogonal cultural identification theory: The cultural identification of minority adolescents [Special Issue]. International Journal of the Addictions, 25(5-A-6-A), 655-685.

O’Hagin, I. B., \& Harnish, D. (2006). Music as cultural identity. International Journal of Music Education, 24(1), 56-70.

Olson, D. H., Portner, J., \& Bell, R. (1982). Family Adaptability \& Cohesion Evaluation Scales (FACES II) manual. Minneapolis: University of Minnesota, Family Social Science Department.

Oxford English dictionary online (2009). [electronic resource] New York:

Oxford University Press, http://helicon.vuw.ac.nz:2048/login?url=http://dictionary.oed.com/

Pahl, J. (2007). Friendship, trust and mutuality. In J. Haworth \& G. Hart (Eds.), Well-being: Individual, community and social perspectives (pp. 256270). New York: Palgrave Macmillan.

Palacio, J. (2008). Ruins of absence, presence of Caribs -- (Post) Colonial representations of Aboriginality in Trinidad and Tobago. Journal of Eastern Caribbean Studies, 33(3), 82-86.

Pallant, J. (2007). SPSS survival manual: A step by step guide to data analysis using SPSS for windows (3rd ed.). Maidenhead, England; New York: McGraw Hill/Open University Press.

Panagos, D. (2007). The plurality of meanings shouldered by the term "Aboriginality": An analysis of the Delgamuukw case. Canadian Journal of Political Science, 40(3), 591-613.

Pang, C. J. (2005). (Re)cycling culture: Chinese opera in the United States. Comparative Drama. 39(3/4) 361-396. 
Paradies, Y. C. (2006). Beyond black and white: Essentialism, hybridity and indigeneity. Journal of Sociology, 42(4), 355-367.

Park, R. E. (1928). Human migrations and the marginal man. American Journal of Sociology, 33, 881-893.

Pascual i Ruiz, J. (2002). Culture, connectedness, and social cohesion in Spain. Canadian Journal of Communication, 27(2), 167-177

Patton, M. Q. (2002). Qualitative research and evaluation methods. Thousand Oaks, CA: Sage Publications.

Pearson, D. (1990). A deferred dream: The origins of ethnic conflict in New Zealand. Wellington, NZ: Allen \& Unwin.

Peirce, C. S. (1931-1935) Collected papers (Vols. 1-6). Cambridge, MA: Harvard University Press.

Pereira, H. B. (1950). The colour of chivalry. London: Imperial Chemical Industries.

Petrova, P. K., Cialdini, R. B., \& Sills, S. (2007). Consistency-based compliance across cultures. Journal of Experimental Social Psychology, 43(1), 104111.

Pettigrew, T. F. (1998). Intergroup contact theory. Annual Review of Psychology. $49,65-85$.

Pettigrew, T. F. (2008). Future directions for intergroup contact theory and research. International Journal of Intercultural Relations 32, 187-199.

Pettigrew, T. F., \& Tropp, L. R. (2006). A meta-analytic test of intergroup contact theory. Journal of Personality and Social Psychology, 90(5), $751-783$.

Phalet, K., \& Schönpflug, U. (2001). Intergenerational transmission of collectivism and achievement values in two acculturation contexts: The case of Turkish families in Germany and Turkish and Moroccan families in the Netherlands [Special Issue]. Journal of Cross-Cultural Psychology, 32(2), 186-201.

Phillips, C. (2007). Pain(ful) subjects regulated bodies in medicine and social work. Qualitative Social Work, 6(2), 197-212.

Phillips, J. (2008). History of immigration. Te Ara -- the Encyclopedia of New $\begin{array}{lllll}\text { Zealand. } & \text { Retrieved June } & \text { 18, } & & \end{array}$ 
http://www.TeAra.govt.nz/NewZealanders/NewZealandPeoples/History OfImmigration/en

Phinney, J. S. (1990). Ethnic identity in adolescents and adults: Review of research. Psychological Bulletin, 10(3), 499-514.

Phinney, J. (1992). The multigroup ethnic identity measure: A new scale for use with diverse groups. Journal of adolescent research, 7, 156-76.

Phinney, J. S. (1996). Understanding ethnic diversity. The American Behavioral Scientist, 40(2) 143-152.

Ponterotto, J. G., Gretchen, D., Utsey, S., Stracuzzi, T., \& Saya, R. (2003). The Multigroup Ethnic Identity Measure (MEIM): Psychometric review and further validity testing. Educational and Psychological Measurement, 63(3), 502-515.

Pradittatsanee, D. (2000). Spiritual quest, orientalist discourse, and "assimilating power": Emerson's dialogue with Indian religious thought in cultural context (Unpublished doctoral dissertation). University of Oregon, Eugene, OR.

Prelow, H. M., Bowman, M. A., \& Weaver, R. S. (2006). Predictors of psychosocial well-being in urban African American and European American youth: The role of ecological factors. Journal of Youth and Adolescence, 36(4), 543-553.

Prilleltensky, I., \& Prilleltensky, O. (2007). Organizational and communal wellbeing. In J. Haworth \& G. Hart (Eds.), Well-being: Individual, community and social perspectives (pp. 57-74). New York: Palgrave Macmillan.

Provine R. C. (1992). The Korean Courtyard Ensemble for ritual music (Aak). Yearbook for Traditional Music, 24, 91-117.

Provine, R. C., Tokumaru, Y., \& Witzleben, J. L. (2006) Garland Encyclopedia of World Music. Retrieved May 28, 2009 from http://glnd.alexanderstreet.com/

Puig, A., Lee, S. M., Goodwin, L., \& Sherrard, P. A. D. (2006). The efficacy of creative arts therapies to enhance emotional expression, spirituality, and psychological well-being of newly diagnosed Stage I and Stage II breast cancer patients: A preliminary study. The Arts in Psychotherapy 33, 218228. 
Pukui, M., \& Ebert, S. H. (1986). Hawaiian dictionary: Hawaiian-English, English-Hawaiian. Honolulu: University of Hawaii Press.

Punathambekar, A. (2005). Bollywood in the Indian-American diaspora: Mediating a transitive logic of cultural citizenship. International Journal of Cultural Studies, 8(2), 151-173.

QSR NVivo version 7.0.247.0. [Computer software]. Australia: QSR International.

Raby, P. (1982). Fair Ophelia: A life of Harriet Smithson Berlioz.: Cambridge University Press.

Radloff, L. S. (1977). The CES-D Scale: A self report depression scale for use in the general population. Applied Psychological Measurement, 1, 385-401.

Raids set Maori-Pakeha relations back 100 years --Sharples. (2007, October 18). New Zealand Herald. Retrieved October 11, 2009 from http://www.nzherald.co.nz/maori/news/article.cfm?c_id=252\&objectid=1 0470629

Rapp-Paglicci, L. A., Rowe, W., \& Ersing. R. L. (2006). The effects of cultural arts programs on at-risk youth: Are there more than anecdotes and promises? Journal of Social Service Research, 33(2), 51-56.

Reck, D. (1977). Music of the whole earth. New York: Scribner.

Redfield, R., Linton, R., \& Herskovits, M. J. (1936). Memorandum for the study of acculturation. American Anthropologist, New Series, 38(1) 149-152.

Reicher, S., \& Sani, F. (1998). Introducing SAGA: Structural Analysis of Group Arguments. Group Dynamics: Theory, Research, and Practice, (2)4, 267-284.

Reynolds, F., Prior, S., \& Lim, K. H. (2008) Narratives of therapeutic artmaking in the context of marital breakdown: Older women reflect on a significant midlife experience. Counselling Psychology Quarterly, 21(3), $1-12$.

Richardson, J. L., Radziszewska, B., Dent, C. W., \& Flay, B. R. (1993). Relationship between after-school care of adolescents and substance use, risk taking, depressed mood, and academic achievement. Pediatrics, 92, $32-38$.

Rivas-Drake, D., Hughes, D., \& Way, N. (2009). A preliminary analysis of associations among ethnic racial socialization, ethnic discrimination, and 
ethnic identity among urban sixth graders. Journal of Research on Adolescence, 19(3), 558-584.

Rosenberg, M. (1965). Society and the adolescent self image. Princeton, NJ: Princeton University Press.

Rowe, I., \& Marcia, J. E. (1980). Ego identity status, formal operations, and moral development. Journal of Youth and Adolescence, 9(2), 87-99.

Rowley, S. J., Sellers, R. M., Chavous, T. M., \& Smith, M. A. (1998). The relationship between racial identity and self-esteem in African American college and high school students. Journal of Personality and Social Psychology, 74(3), 715-724.

Royal, T. A. C. (2008). Hawaiki. Te Ara -- the Encyclopedia of New Zealand. $\begin{array}{llll}\text { Retrieved } & 26 & \text { May, } & 2009\end{array}$ http://www.TeAra.govt.nz/NewZealanders/MaoriNewZealanders/Hawaik i/en

Rude, S. S., \& Burnham, B. L. (1993). Do interpersonal and achievement vulnerabilities interact with congruent events to predict depression? Comparison of DEQ, SAS, DAS, and combined scales. Cognitive Therapy and Research, 17(6), 531-548.

Rudmin, F. W. (2006). Debate in science: The case of acculturation. AnthroGlobe Journal. Retrieved April 30, 2008 from http://www.anthroglobe.ca/docs/rudminf_acculturation_061204.pdf

Rush, A. J., Khatami, M., \& Beck, A. T. (1975). Cognitive and behavior therapy in chronic depression. Behavior Therapy, 6(3), 398-404.

Ryan, G.W., \& Bernard, H. R. (2000). Data management and analysis methods. In N. K. Denzin \& Y. S. Lincoln (Eds.), Handbook of qualitative research $\left(2^{\text {nd }}\right.$ ed., pp. 769-802). Thousand Oaks, CA: Sage.

Ryan, R. M., \& Deci, E. L. (2001). On happiness and human potentials: A review of research on hedonic and eudaimonic well-being. Annual Review of Psychology, 52, 141-166.

Ryff, C. D., \& Keyes, C. L. M. (1995). The structure of psychological wellbeing revisited. Journal of Personality and Social Psychology, 69(4), 719-727. 
Sabatier, C. (2008). Ethnic and national identity among second-generation immigrant adolescents in France: The role of social context and family. Journal of Adolescence, 31(2), 185-205.

Sachs, J. (2004). Validation of the Satisfaction with Life Scale in a sample of Hong Kong University students. Psychologia, 46, 225-234.

Sacks, O. (2008). Musicophilia: Tales of music and the brain: Revised \& expanded. New York: Alfred A. Knopf.

Sadie, S. (1980). The New Grove dictionary of music and musicians. London: Macmillan Publishers.

Salant, T., \& Lauderdale, D. S. (2003). Measuring culture: A critical review of acculturation and health in Asian immigrant populations. Social Science \& Medicine, 57, 71-90.

Sam, D. (2006) Acculturation: Conceptual background and core components. In D. L. Sam \& J. W. Berry (Eds.), The Cambridge handbook of acculturation psychology (pp. 11- 26). Cambridge: Cambridge University Press.

Sarason, S. B. (1974). The psychological sense of community: Prospects for a community psychology. San Francisco: Jossey Bass.

Saylor, E. S., \& Aries, E. (1999). Ethnic identity and change in social context. The Journal of Social Psychology, 139(5), 549-566.

Schumacker, R. E. \& Lomax, R. G. (1996). A beginner's guide to structural equation modeling. Mahwah, NJ: Lawrence Erlbaum Associates.

Sebeok, T. A. (1991). A sign is just a sign. Bloomington: Indiana University Press.

Sevik, G. (2001). What Price, Fame? Popular Music and Society, 25(3/4), 85-90.

Seligman, M., \& Csikszentmihalyi, M. (2000). Positive psychology: An introduction. American Psychologist, 55(1), 5-14.

Sellers, R. M., Rowley, S. A. J., Chavous, T. M., Shelton, J. N., \& Smith, M. A. (1997). Multidimensional inventory of Black identity: A preliminary investigation of reliability and construct validity. Journal of Personality and Social Psychology, 73(4), 805-815.

Sgarbi, V. (2007). Caravaggio. Milano: Thames \& Hudson.

Sharma, A. (2009). The world's religions after September 11 (vol. 4) Spirituality. Westport, CT: Praeger Publishers/Greenwood Publishing Group. 
Shin, K. R. (1992). Correlates of depressive symptomatology in KoreanAmerican women in New York City (Unpublished doctoral dissertation). Teachers College, Columbia University, New York.

Sieber, R., \& Walker, R. A. (1987). African art in the cycle of life. Washington, DC: Smithsonian Press.

Silverman, M. J. (2010) Applying levels of evidence to the psychiatric music therapy literature base. The Arts in Psychotherapy, 37(1), 1-7.

Simonton, D. K. (1975). Sociocultural context of individual creativity: A transhistorical time-series analysis. Journal of Personality and Social Psychology, 32, 1119-1133.

Sloboda, J. (2008). Leonard Meyer: Embracing uncertainty. Music Perception, 25(5), 489-491.

Slot, B. J. (1992). Abel Tasman and the discovery of New Zealand. Amsterdam: Otto Cramwinckel.

Snyder, C. R., \& López, S. J. (2007). Positive psychology: the scientific and practical explorations of human strengths. Thousand Oaks, CA: Sage Publications.

Sokal, R. R. (1958). Thurstone's analytical method for simple structure and a mass modification thereof. Psychometrika, 23, 237-257.

Social Science Research Council (1954). Acculturation: An exploratory formulation. The Social Science Research Council Summer Seminar on Acculturation. American Anthropologist, New Series, 56(6), 973-1000.

Son, G., \& Kim, H. (2006). Culturally familiar environment among Korean elders. Research and Theory for Nursing Practice, 20 (2), 159-172.

Sousa, M. D. R., Neto, F., \& Mullet, F. N. E. (2005). Can music change ethnic attitudes among children? Psychology of Music, 33(3), 304-316.

Spencer, M. B., Noll, E., Stoltzfus, J., \& Harpalani, V. (2001). Identity and school adjustment: Revisiting the "acting White" assumption [Special Issue]. Educational Psychologist, 36(1), 21-30.

Sperber, D., \& Wilson, D. (1995). Relevance: Communication and cognition (2nd ed.). Oxford, UK: Blackwell.

Spike, J. T. (2001). Caravaggio. New York: Abbeville Press.

Stage Challenge (2009). Stage Challenge New Zealand. Retrieved November 28, 2009 from http://www.stagechallenge.co.nz/ 
Statistics New Zealand (2008). QuickStats National highlights. Retrieved May 9 , 2008 from

http://www.northshorecity.govt.nz/PDFs/Population/Census-2006national-highlights.pdf

Statistics New Zealand (2006). Census. Retrieved May 9, 2008 from http://www.stats.govt.nz/NR/rdonlyres/62F419D4-5946-407A-9553-

DA9E7A847622/0/09ethnicgroup.xls

Statistics New Zealand (2002). Employment and income of Pacific peoples in New Zealand. Retrieved May 9, 2008 from http://www.stats.govt.nz/products-and-services/Articles/Pac-ppl-empincome-Dec02.htm

Stern, F. (2004). Bridging two cultures. The World \& I, 19(3), 96-102.

Stewart, D.W., \& Shamdasani, P.N. (1990). Focus groups: Theory and practice. London: Sage.

Stickley, T. (2007). Guest editorial. Journal of Psychiatric and Mental Health Nursing, 14, 335-337.

Su, T. F., \& Costigan, C. L. (2009). The development of children's ethnic identity in immigrant Chinese families in Canada: The role of parenting practices and children's perceptions of parental family obligation expectations. The Journal of Early Adolescence, 29(5), 638-663.

Sussman, N. (in press). Return migration: A global phenomenon, a Hong Kong case. Hong Kong: Hong Kong University Press.

Sutton, D. G. (1987). A paradigmatic shift in Polynesian prehistory: Implications for New Zealand. New Zealand Journal of Archaeology, 9, 135-55.

Tadmor, C. T., Tetlock, P. E., \& Peng, K. (2009). Acculturation strategies and integrative complexity: The cognitive implications of biculturalism. Journal of Cross-Cultural Psychology, 40(1), 105-139.

Taonui, R. (2008). Canoe navigation. Te Ara -- the Encyclopedia of New Zealand. Retrieved May 28, 2009 from http://www.TeAra.govt.nz/NewZealanders/MaoriNewZealanders/Canoe Navigation/en

Tajfel, H. (1981). Human groups and social categories. Cambridge: Cambridge University Press. 
Tajfel, H., \& Turner, J. C. (1979). An integrative theory of intergroup conflict. In W. G. Austin \& S. Worchel (Eds.), The social psychology of intergroup relations (pp. 33-47). Monterey, CA: Brooks/Cole.

Taub, D. J. (1995). Relationship of selected factors to traditional-age undergraduate women's development of autonomy. Journal of College Student Development, 36, 141-151.

Taum, R. (2009). Ho 'oponopono. Paper presented at the 2009 Conference of the International Academy of Intercultural Research, Honolulu, HI.

Tauroa, H., \& Tauroa, P. (1990). Te marae: A guide to customs \& protocol. Auckland: Heinemann Reed.

Tennant, R., Hiller, L., Fishwick, R., Platt, S., Joseph, S., Weich, S., Parkinson, J., Secker, J., \& Stewart-Brown S. (2007). The Warwick-Edinburgh Mental Well-being Scale (WEMWBS): development and UK validation. Health and Quality of Life Outcomes 2007, 5:63. Retrieved March 18, 2008 from http://wrap.warwick.ac.uk/543/

Thomas, W., \& Bellefeuille, G. (2006). An evidence-based formative evaluation of a cross cultural Aboriginal mental health program in Canada. Australian e-Journal for the Advancement of Mental Health (AeJAMH), 5(3). $\quad$ Retrieved $\quad$ March 10, 2008 from www.auseinet.com/journal/vol5iss3/thomas.pdf

Thurstone, L. L. (1954). An analytical method for simple structure. Psychometrika, 19, 173-194.

Todd, J. (Ed.). (1984). Worlds of music: An introduction to the music of the world's peoples. New York: Collier Macmillan.

Townsend, K. C., \& McWhirter, B. T. (2005). Connectedness: A review of the literature with implications for counseling, assessment, and research. Journal of Counseling \& Development, 83(2), 191-201.

Triandis, H. C., McCusker, C., \& Hui, C. H. (1990). Multimethod probes of individualism and collectivism. Journal of Personality and Social Psychology, 59, 1006-1020.

Traindis, H. C., \& Triandis, L. M. (1960). Race, social class, religion, and nationality as determinants of social distance. The Journal of Abnormal and Social Psychology, 61(1), 110-118. 
Trlin, A., \& Watts, N. (2004). Immigration policy and immigrant settlement: A flawed relationship at the turn of the millennium. In P. Spoonley, C. Macpherson, \& D. Pearson (Eds.), Tangata, tangata: The changing ethnic contours of New Zealand (pp. 111-134). Southbank, Victoria: Thomson.

Tsai, J. L., Ying, Y.-W., \& Lee, P. A. (2001). Cultural predictors of self-esteem: A study of Chinese American female and male young adults [Special Issue]. Cultural Diversity and Ethnic Minority Psychology, 7(3), 284297.

Turino, T. (1999). Signs of imagination, identity and experience: A Peircian semiotic theory for music. Ethnomusicology, 43(2), 221-255.

Turk, I., Dirjec, J., \& Kavur, B. (1995). The oldest musical instrument in Europe discovered in Slovenia. Retrieved from http://www.zrcsazu.si/www/iza/piscal.html

Turnbull, C. M. (1992). Mbuti Pygmies of the Ituri Rainforest [CD]. Washington, DC: Smithsonian Folkways.

Turner, J. (1999). Some current issues in research on social identity and selfcategorization theories. In N. Ellemers, R. Spears, \& B. Doosje (Eds.), Social identity: Context, commitment, content (pp. 6-34). Oxford, England: Blackwell Science.

Turner, R. J., \& Marino, F. (1994). Social support and social structure: A descriptive epidemiology. Journal of Health and Social Behavior, 35(3), 193-212.

Turner, V. (1982a). Celebration, studies in festivity and ritual. Washington, DC: Smithsonian Institution Press.

Turner, V. (1982b). From ritual to theatre: The human seriousness of play. New York: Performing Arts Journal Publications.

Turner, V. (1986). The anthropology of performance. New York: PAJ Publications.

Turner, V., \& Turner, E. L. B. (Eds.). (1985). On the edge of the bush: Anthropology as experience. Tucson, AZ: University of Arizona Press.

Twenge, J. M., Baumeister, R. F., Tice, D. M., \& Stucke, T. S. (2001). If you can't join them, beat them: Effects of social exclusion on aggressive 
behavior. Journal of Personality and Social Psychology, 81(6), 10581069.

Twenge, J. M., Catanese, K. R., \& Baumeister, R. F. (2003). Social exclusion and the deconstructed state: Time perception, meaninglessness, lethargy, lack of emotion, and self-awareness. Journal of Personality and Social Psychology, 85(3), 409-423.

Twenge, J. M., Zhang, L., Catanese, K. R., Dolan-Pascoe, B., Lyche, L. R., \& Baumeister, R. F. (2007). Replenishing connectedness: Reminders of social activity reduce aggression after social exclusion. British Journal of Social Psychology, 46(1), 205-224.

Umaña-Taylor, A. J. (2004). Ethnic identity and self-esteem: Examining the role of social context. Journal of Adolescence, 27, 139-146.

Umaña-Taylor, A. J., Diversi, M., \& Fine, M. A. (2002). Ethnic identity and self-esteem of Latino adolescents: Distinctions among the Latino populations. Journal of Adolescent Research, 17(3), 303-327.

UN (1948). The Universal Declaration of Human Rights. Retrieved November 4, 2008 from http://www.un.org/Overview/rights.html

Utsey, S. O., Chae, M. H., Brown, C. F., \& Kelly, D. (2002). Effect of ethnic group membership on ethnic identity, race-related stress and quality of life. Cultural Diversity and Ethnic Minority Psychology, 8(4), 366-377.

Vaillant, G. E. (2000). Adaptive mental mechanisms: Their role in a positive e psychology. American Psychologist, 55(1), 89-98.

Valladas, H., Clottes, J., Geneste, J.-M., Garcia, M. A., Arnold, M., Cachier, H., \& Tisnérat-Laborde, N. (2001). Evolution of prehistoric cave art nature, 413(4), 479.

Valdez, A., \& Halley, J. A. (1996). Gender in the culture of Mexican American Conjunto Music. Gender and Society, 10(2), 148-167.

Valsiner, J. (2009). Cultural psychology today: Innovations and oversights. Culture \& Psychology, 15(1), 5-39.

Van Oudenhoven, J. P., Ward, C., \& Masgoret, A.-M. (2006). Patterns of relations between immigrants and host societies. International Journal of Intercultural Relations, 30(6), 637-651.

Van Tubergen, F. (2006). Immigrant integration: A cross-national study. New York: LFB Scholarly Pub., LLC. 
Vassar, M. (2008). A note on the score reliability for the Satisfaction With Life Scale: An RG study. Social Indicators Research. 86(1), 47-57.

Viladrich, A. (2005). Tango immigrants in New York City: The value of social reciprocities. Journal of Contemporary Ethnography, 34(5), 533-559.

Wagner, J. A. (1995). Studies of individualism-collectivism: Effects on cooperation in groups. Academy of Management Journal, 38, 152-172.

Wagnild, G. M., \& Young, H. M. (1993). Development and psychometric evaluation of the resilience scale. Journal of Nursing Measurement, 1, 165178.

Walker, R. (2004). Ka whawhai tonu matou: Struggle without end. Auckland, New Zealand: Penguin.

Walrond, C. (2009). Cook Islanders. Te Ara -- the Encyclopedia of New Zealand. Retrieved March 4, 2009 from http://www.TeAra.govt.nz/en/cook-islanders

Walters, M. D. (2007). Histories of colonialism, legality, and Aboriginality. University of Toronto Law Journal, 57(4), 819-832.

Wanzer, M. B., Sparls, L., \& Frymier, A. B. (2009). Humorous communication within the lives of older adults: The relationships among humor, coping efficacy, age, and life satisfaction. Health Communication, 24(2), 128136.

Ward, C. (2001). The ABC's of acculturation. In D. Matsumoto (Ed.), The handbook of culture and psychology (pp. 411-416). New York: Oxford University Press.

Ward, C., Bochner, S., \& Furnham, A. (2001). The psychology of culture shock (2nd ed.). New York: Routledge.

Ward, C., \& Chang, W. C. (1997). "Cultural fit": A new perspective on personality and sojourner adjustment. International Journal of Intercultural Relations, 21(4), 525-533.

Ward, C., Fox, S., Wilson, J., Stuart, J., \& Kus, L. (2009). National contextual influences on acculturation processes: The roles of family, community and society. Psychological Studies, 54, in press.

Ward, C., \& Kennedy, A. (1994). Acculturation strategies, psychological adjustment, and sociocultural competence during cross-cultural 
transitions. International Journal of Intercultural Relations, 18(3), 329343.

Ward, C., \& Masgoret, A.-M. (2006). An integrative model of attitudes toward immigrants. International Journal of Intercultural Relations, 30(6), 671682.

Ward, C., \& Masgoret, A.-M. (2007). Immigrant entry into the workforce: A research note from New Zealand. International Journal of Intercultural Relations, 31(4), 525-530.

Ward, C., Okura, Y., Kennedy, A., \& Kojima, T. (1998). The U-curve on trial: A longitudinal study of psychosocial and sociocultural adjustment during cross-cultural transition. International Journal of Intercultural Relations, 22(3), 277-291.

Ward, C., \& Rana-Deuba, A. (1999). Acculturation and adaptation revisited. Journal of Cross-Cultural Psychology, 30(4), 422-442.

Waseda, M. (2005). Extraordinary circumstances, exceptional practices: Music in Japanese American concentration camps. Journal of Asian American Studies, 8(2), 171-209.

Westin, C. (2006). Acculturation in Nordic countries. In D. L. Sam \& J. W. Berry (Eds.), The Cambridge handbook of acculturation psychology (pp. 368-384). New York: Cambridge University Press.

White, J. (2001). The ancient history of the Maori (Vols. 1-13). Retrieved from http://www.nzetc.org/tm/scholarly/tei-corpus-WhiAnci.html

Whitinui, P. (2008). Kapa Haka counts: Improving participation levels of Māori students in mainstream secondary schools. MAI Review, 3. Retrieved from http://ojs.review.mai.ac.nz/index.php/MR/article/viewFile/187/194.

Wilkinson, R. B. (2004). The role of parental and peer attachment in the psychological health and self-esteem of adolescents. Journal of Youth and Adolescence, 33(6), 479-493.

Wilson, M., \& Parker, P. (2007). The gap between immigration and employment. New Zealand Journal of Employment Relations, 32(1), 2843.

Wilton, J. (2005). Identity, racism, and multiculturalism : Chinese-Australian responses. In R. Benmayor \& A. Skotnes (Eds.), Migration \& identity (pp. 85-100). New Brunswick, NJ: Transaction Publishers. 
Witzke, J., Rhona, R. A., Backhaus, D., \& Shaver, N. A. (2008). How sweet the sound: Research evidence for the use of music in Alzheimer's dementia. Journal of Gerontological Nursing, 34(10), 45-51.

World Health Organization (1946, 2006). Constitution of the World Health Organization (Basic Documents, $45^{\text {th }}$ ed.). Retrieved from http://www.who.int/governance/eb/who_constitution_en.pdf

Wright, S. C., Aron, A., McLaughlin-Volpe, T., \& Ropp, S. A. (1997). The extended contact effect: Knowledge of cross-group friendships and prejudice. Journal of Personality and Social Psychology, 73(1), 73-90.

Yamaguchi, S. (1994). Collectivism among the Japanese: A perspective from the self. In U. Kim, H. C. Triandis, C. Kagitcibasi, S. C. Choi, \& G. Yoon, (Eds.), Individualism and collectivism: Theory, method, and applications (pp. 175-188). Thousand Oaks, CA: Sage.

Yip, T. (2009). Simultaneously salient Chinese and American identities: An experience sampling study of self-complexity, context, and positive mood among Chinese young adults. Cultural Diversity and Ethnic Minority Psychology, 15(3), 285-294.

Zentner, M., Grandjean, D., \& Scherer, K. (2008). Emotions evoked by the sound of music: Characterization, classification, and measurement. Emotion, 8(4), 494-521.

Zhang, X. W., Fan, Y., Manyande, A.,Tian, Y. K., \& Yin, P. (2005). Effects of music on target-controlled infusion of propofol requirements during combined spinal-epidural anaesthesia. Anaesthesia, 60(10), 990-994.

Zhang, J., Xiao, X., Lee, Y. K. (2004). The early development of music. Analysis of the Jiahu bone flutes. Antiquity, 78(302), 769-778.

Zimmerman, E. (1997). Excellence and equity issues in art education: Can we be excellent and equal too? Arts Education Policy Review, 98(4) 20-26.

Zodgekar, A. (2005). The changing face of New Zealand's population and national identity. In J. Liu, T. McCreanor, T. Mcintosh, \& T. Teaiwa (Eds.), New Zealand identities: Departures and destinations (pp. 11-20). Wellington, New Zealand: Victoria University Press. 